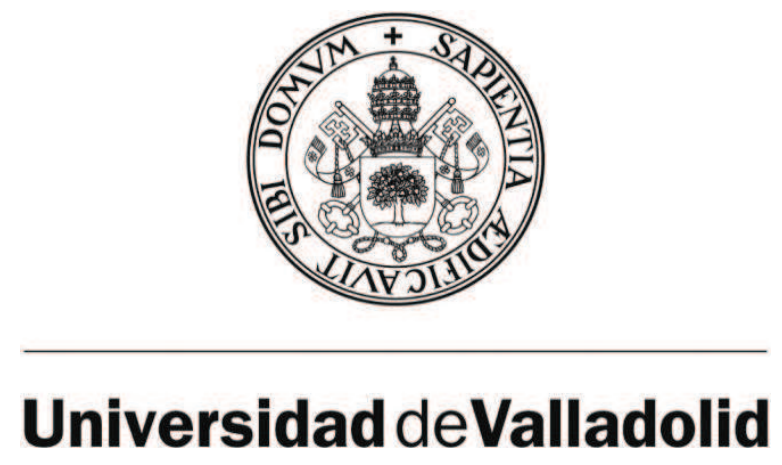

\author{
FACULTAD DE EDUCACIÓN \\ DEPARTAMENTO DE PSICOLOGÍA
}

TESIS DOCTORAL

\title{
Aplicación del "Aprendizaje Basado en Problemas" en los estudios de Grado en Enfermería
}

Presentada por Carolina González Hernando para optar al grado de Doctor por la Universidad de Valladolid

Dirigida por el Dr. Miguel Ángel Carbonero Martín

Valladolid, 2012 
Universidad deValladolid

Impreso 2T

AUTORIZACIÓN DEL DIRECTOR DE TESIS

(Art. 21 del R.D. 1393/2007 de 29 de octubre y Art. 4 c) de la Normativa para la defensa de la Tesis Doctoral)

D. Miguel Ángel Carbonero Martín, con D.N.I. n 12233952-E profesor del Departamento de Psicología de la Facultad de Educación y Trabajo Social de la Universidad de Valladolid, como Director de la Tesis Doctoral titulada "Aplicación del "Aprendizaje Basado en Problemas" en los estudios de Grado en Enfermería", presentada por Dña. Carolina González Hernando (con D.N.I.: 09322868W ) alumna del programa "PSICOLOGÍA" impartido por el departamento de "PSICOLOGÍA"

Autoriza la presentación de la misma, puesto que constituye un trabajo de investigación original, riguroso e inédito, cumpliendo todos los requisitos para optar al grado de Doctor por parte de su autor Dña. Carolina González Hernando.

Para que conste a los efectos oportunos lo firmamos en Valladolid, 22 de Noviembre de 2012

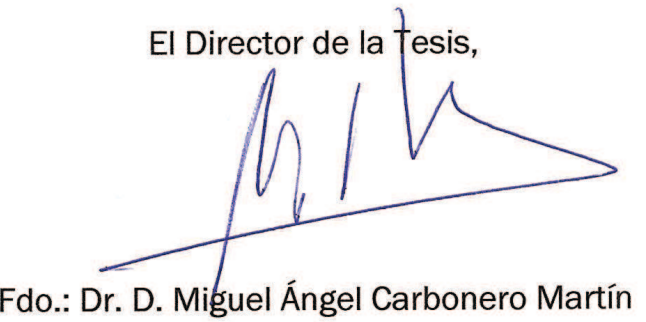

ILMO. SR. PRESIDENTE DE LA COMISIÓN DE DOCTORADO 
A José Ramón, Claudia y Andy A mis padres $y$ hermanos 
"Con mis maestros he aprendido mucho,

Con mis alumnos todavía más".

(Proverbio hindú)

“La observación indica cómo está el paciente; la reflexión indica qué hay que hacer; la destreza práctica indica cómo hay que hacerlo. La formación y la experiencia son necesarias para saber cómo observar y qué observar; cómo pensar y qué pensar" (Florence Nightingale, 1882). 


\section{Agradecimientos}

En primer lugar quisiera agradecer al profesor Dr. Miguel Ángel Carbonero Martín, por su generosidad al dirigir esta tesis doctoral, por su ayuda y su optimismo en todos los momentos que he necesitado.

A la Escuela Universitaria de Enfermería de Valladolid, en la que estudié y de la que soy profesora, por facilitarme la realización de esta investigación, la Escuela ha sido la inspiración para realizar este trabajo.

Al profesor Dr. Pedro Martín Villamor, por su apoyo y confianza para realizar este proyecto; su paciencia y su labor docente son un ejemplo a seguir.

Al profesor Dr. Fernando Lara Ortega por su ayuda y su tiempo a pesar de sus muchas ocupaciones, los desplazamientos a Burgos merecieron la pena.

A mis compañeros y amigos del Máster de Investigación aplicada a la Educación, y a los profesores, con ellos he seguido parte del camino.

A mis alumnas y alumnos, estudiantes de enfermería, por su entusiasmo y sus aportaciones, sin ellos no habría sido posible realizar esta tesis doctoral.

Muchas gracias a todos 


\section{Índice general:}

Resumen 19

Introducción 21

\section{I-MARCO TEÓRICO}

CAPÍTULO 1. Nuevas formas de enseñar y aprender en las aulas del S.XXI

1.1. Marco legislativo 39

1.2. Nuevo contexto de EEES 53

1.3. Formación basada en competencias 57

1.4. Competencia "aprender a aprender" 70

1.4.1. Definición de términos $\quad 71$

1.4.2. Elementos de autorregulación del aprendizaje $\quad 73$

1.5. Innovación docente $\quad 82$

$\begin{array}{ll}\text { 1.5.1. Resistencia al cambio } & 87\end{array}$

\section{CAPÍTULO 2.Enseñanza Superior en Enfermería}

2.1. Estudios de Enfermería 93

2.1.1. Evolución $\quad 94$

2.1.2. Formación universitaria en Enfermería 102

2.1.2.1. Diplomado Universitario en Enfermería 102 
2.2. Competencias de Grado en Enfermería 111

2.2.1 Competencias transversales $\quad 115$

2.2.2. Competencias específicas 118

2.3. Programa de Grado en Enfermería por la Universidad de

$\begin{array}{ll}\text { Valladolid } & 123\end{array}$

2.3.1Asignatura Salud Sexual y Reproductiva 124

\section{CAPÍTULO 3.Aprendizaje Basado en Problemas (ABP)}

3.1. Teorías constructivistas del aprendizaje

3.2. Aprendizaje Basado en Problemas (ABP)

3.2.1. Antecedentes

3.2.2. Concepto

3.2.3. Características del ABP

3.2.4. Fases del proceso

3.2.5. Roles en ABP

3.2.5.1. Rol del docente

\section{II-MARCO METODOLÓGICO}

\section{CAPÍTULO 4.Diseño de la Investigación}


4.4. Material y método 184

$\begin{array}{ll}\text { 4.5. Sujetos o participantes } & 187\end{array}$

4.6. Instrumentos

4.6.1. Cuestionario de Indagación del Perfil Auto dirigido CIPA

4.6.2. Cuestionario sobre el grado de satisfacción del Alumnado

4.6.3. Observación de tutorías y presentaciones orales

4.6.4. Análisis de contenido (A.C)

4.6.5. Autoevaluación y evaluación a compañeros

4.6.6. Evaluación a la tutora

\section{CAPÍTULO 5.Resultados}

5.1. Efecto de la estrategia didáctica ABP en la autodirección del aprendizaje

5.2. Evaluación por competencias con $\mathrm{ABP}$

5.2.1. Autoevaluación y evaluación a pares de estudiantes

5.2.2. Evaluación a la tutora 228

5.2.3. Observación de las prácticas de aula o tutorías 233

5.2.4. Observación de las presentaciones orales 235 
5.3. Satisfacción de los estudiantes de Grado en Enfermería que han aprendido con ABP

5.4. Ventajas e inconvenientes percibidos por los estudiantes al utilizar ABP

\section{CAPÍTULO 6.Discusión y Conclusiones}

6.1. Competencia "aprender a aprender" 253

6.2 .Grado de satisfacción 263

6.3. Aprendizaje de calidad 267

6.4. Desarrollo de competencias 269

6.5. Evaluación de competencias 272

6.6. Innovación educativa 278

$\begin{array}{ll}\text { Conclusiones } & 279\end{array}$

$\begin{array}{ll}\text { Limitaciones } & 280\end{array}$

$\begin{array}{ll}\text { Recomendaciones } & 281\end{array}$

Referencias bibliográficas $\quad 285$ 


\section{Anexos}

Anexo 1- Cuestionario CIPA de perfil auto dirigido

Anexo 2- Cuestionario sobre el grado de satisfacción al utilizar metodología $\mathrm{ABP}$

Anexo 3- Rúbricas para la Observación de los trabajos de presentación oral

Anexo 4- Cuestionario para la evaluación de pares y auto-

Evaluación

Anexo 5- Cuestionario para la evaluación a la tutora

Anexo 6-Casos clínicos para el trabajo con metodología ABP

Anexo 7-Roles de grupo ABP

Anexo 8- Guía del estudiante para el trabajo con ABP

Anexo 9-Análisis de contenido de las ventajas percibidas por estudiantes que aprendieron con ABP.

Anexo 10- Análisis de contenido de las desventajas del ABP percibidas por los alumnos.

Anexo 11- Resultados de la prueba de Kolmogov aplicada a los resultados pre-test y pos-test del cuestionario CIPA 


\section{Índice de tablas}

Tabla 1. Horas de dedicación del alumnado al ABP 125

Tabla 2. Criterios de evaluación de la asignatura SSR 127

Tabla 3. Roles en ABP 166

Tabla 4.Estructura formal de una guía tutorial 167

Tabla 5. Estadísticos de fiabilidad del cuestionario de satisfacción de la Universidad de la Colima 186

Tabla 6. Distribución de las puntuaciones globales del CIPA 191

Tabla 7.Componentes e ítems del cuestionario CIPA 192

Tabla 8.Procesamiento de los casos $\quad 212$

Tabla 9.Puntuaciones globales en cuestionario 214

Tabla 10.Correlaciones entre CIPA total pre-test y pos-test 214

Tabla 11.Diferencias relacionadas entre puntuaciones globales 214

Tabla 12. Puntuaciones del componente 1 en pre y pos-test 216

Tabla 13.Correlaciones entre pre y pos-test en componente 1216

Tabla 14. Diferencias relacionadas en componente $1 \quad 216$

Tabla 15. Puntuaciones del componente 2 en pre y pos-test 217

Tabla 16. Correlaciones entre pre y pos-test en componente $2 \quad 217$

Tabla 17. Diferencias relacionadas en componente 2

Tabla 18. Puntuaciones del componente 3 en pre y pos-test 218

Tabla 19. Correlaciones entre pre y pos-test en componente $3 \quad 218$

Tabla 20. Diferencias relacionadas en componente $3 \quad 218$

Tabla 21. Puntuaciones del componente 4 en pre y pos-test 219 
Tabla 22. Correlaciones entre pre y pos-test en componente $4 \quad 219$

Tabla 23. Diferencias relacionadas en componente 4

Tabla 24.Componente 4 y tipo de acceso 220

Tabla 25.Correlaciones del componente 4 y tipo de acceso 220

Tabla 26.Diferencias en componente 4 según acceso 220

Tabla 27. Puntuaciones del componente 5 en pre y pos-test 221

Tabla 28. Correlaciones entre pre y pos-test en componente $5 \quad 221$

Tabla 29. Diferencias relacionadas en componente 5

Tabla 30. Procesamiento de los casos (cuestionario satisfacción) 238

Tabla 31. Variable sexo (cuestionario de satisfacción) 238

Tabla 32. Nota media actual 238

Tabla 33. Metodología preferida 239

Tabla 34. ¿Te gusta ABP? 239

Tabla 35. ¿Cómo te consideras como estudiante? 239 


\section{Índice de figuras}

Figura 1.Proceso de adquisición de competencias de Acción $\quad 64$

Figura 2. Elementos del aprendizaje autorregulado(AAR) 74

Figura 3. Inicio del cambio desde la dirección o desde niveles más bajos $\quad 87$

Figura 4.Ciclo del ABP 146

Figura 5. Desarrollo del ABP 149

Figura 6. Fases del proceso ABP 160

$\begin{array}{ll}\text { Figura 7. Muestra variable sexo } & 187\end{array}$

Figura 8. Muestra variable tipo de acceso 188

Figura 9. Respuestas a pregunta 1 de la autoevaluación 222

Figura 10. Respuestas a pregunta 2 de la autoevaluación 222

Figura 11. Respuestas a pregunta 3 de la autoevaluación 223

Figura 12. Respuestas a pregunta 4 de la autoevaluación 223

Figura 13. Respuestas a pregunta 5 de la autoevaluación 224

Figura 14. Respuestas a pregunta 6 de la autoevaluación 224

Figura 15. Respuestas a pregunta 7 de la autoevaluación 225

Figura 16. Respuestas a pregunta 8 de la autoevaluación 225

Figura 17. Respuestas a pregunta 9 de la autoevaluación 226

Figura 18. Respuestas a pregunta 10 de la autoevaluación 226

Figura 19.Puntuación media de las respuestas del cuestionario de evaluación a compañeros. 227

Figura 20. Respuestas a pregunta 1 de la evaluación a la tutora 228 
Figura 21. Respuestas a pregunta 2 de la evaluación a la tutora 228

Figura 22. Respuestas a pregunta 3 de la evaluación a la tutora 229

Figura 23. Respuestas a pregunta 4 de la evaluación a la tutora 229

Figura 24. Respuestas a pregunta 5 de la evaluación a la tutora 230

Figura 25. Respuestas a pregunta 6 de la evaluación a la tutora 230

Figura 26. Respuestas a pregunta 7 de la evaluación a la tutora 231

Figura 27. Respuestas a pregunta 8 de la evaluación a la tutora 231

Figura 28. Respuestas a pregunta 9 de la evaluación a la tutora 232

Figura 29. Respuestas a pregunta 10 de la evaluación a la tutora 232

Figura 30.Observación de las prácticas de aula con ABP 234

Figura 31.Presentaciones que se insertaron en Moodle 237

Figura 32.Grado de satisfacción con contenidos ABP 240

Figura 33.Respuestas justificadas sobre los contenidos ABP 240

Figura 34.Grado de satisfacción con el rol del tutor en ABP 241

Figura 35.Respuestas justificadas respecto al rol del tutor ABP 241

Figura 36.Grado de satisfacción de estudiantes en ABP 242

Figura 37.Respuestas justificadas respecto al rol del estudiante 242

Figura38.Grado de satisfacción con el proceso tutorial en ABP 243

Figura 39.Respuestas justificadas respecto al proceso tutorial 243

Figura 40.Grado de satisfacción con la evaluación ABP 244

Figura 41.Grado de satisfacción con recursos utilizados 245

Figura 42.Satisfacción respecto a los casos clínicos 245

Figura 43.Satisfacción con el tiempo asignado al caso 246 
Figura 44. Satisfacción con las características de las aulas

Figura 45.Satisfacción general ABP

Figura 46.Ventajas del ABP percibidas por estudiantes

Figura 47.Desventajas del ABP percibidas por los estudiantes 


\section{Abreviaturas}

AAR: Aprendizaje autorregulado

ABP: Aprendizaje basado en problemas

ANECA: Agencia Nacional de Evaluación de Calidad y de la Acreditación

APA (normas $6^{\text {a }}$ edición): Estilo de cita de la Asociación Psicológica Americana

APP: Apprentissage par problèmes o aprendizaje basado en problemas ATS: Ayudante Técnico Sanitario

BOE: Boletín Oficial del Estado

DUE: Diplomado Universitario en Enfermería

ECTS: Sistema Europeo de Transferencia de Créditos

ENQA: Asociación Europea de Garantía de Calidad en Enseñanza Superior

EEES: Espacio Europeo de Educación Superior

EIR: Enfermera/o Interna/o Residente

EU2015: Estrategia Universidad 2015

INE: Instituto Nacional de Estadística 
ISTEM: Instituto Tecnológico de Monterrey

LOMLOU: Ley Orgánica 4/2007

LOU: Ley Orgánica 6/2001

MECES: Marco Español de Cualificaciones para la Enseñanza

Superior

OCDE: Organización para la Cooperación y el Desarrollo Económico

PBL: Problem- Based of Learning o aprendizaje basado en problemas

SPSS: instrumento de análisis de datos estadísticos y gestión de la información

SRL: Self-Regulated Learning o aprendizaje autorregulado

SSR: Salud sexual y reproductiva

UNAM: Universidad Nacional Autónoma de Méjico

UVA: Universidad de Valladolid 


\section{Resumen}

Con el fin de mejorar la calidad docente universitaria, en esta investigación, se propuso utilizar metodologías activas como el Aprendizaje Basado en Problemas (ABP) en la formación de los estudiantes de Grado en Enfermería, para que participen, sean protagonistas de su propio aprendizaje y desarrollen las competencias necesarias para su futuro ejercicio profesional.

Este trabajo constituye un nuevo paso, mi planteamiento abordó una innovación educativa desde un ángulo nuevo, realizando las prácticas de aula de los estudiantes a través de la metodología ABP, para agregar conocimiento nuevo sobre su utilidad en el proceso de enseñanza y aprendizaje en Enfermería.

Se utilizó una metodología mixta. Los instrumentos de recogida de datos fueron cuestionarios, evaluaciones, documentos escritos y observaciones, permitiendo una triangulación de métodos múltiples, para una mejor comprensión de la realidad en el contexto de la Educación Superior en Enfermería.

ABP es una metodología docente que permite una formación basada en competencias, los estudiantes presentan una alta satisfacción, y mejoran el aprendizaje auto dirigido fundamental para "aprender a aprender" a lo largo de la vida. 


\section{Palabras clave:}

Proceso de Bolonia, estilos de aprendizaje, formación basada en competencias, aprendizaje basado en problemas (ABP). 


\section{Introducción}

El trabajo que a continuación se expone, surge a partir de una inquietud por la calidad del proceso enseñanza-aprendizaje en un momento de grandes cambios.

Coincidiendo con Zabala (2011), son tiempos difíciles para la universidad, escasean los recursos y se exige una mayor eficiencia. Las causas no solo se pueden atribuir a acontecimientos externos que no podemos controlar. La universidad y el profesorado forman parte del problema, por lo que deberán formar parte también de la solución. Hay que planificar modalidades positivas de afrontamiento de los problemas y crear contextos de aprendizaje enriquecedores como el que se propone en esta investigación. "Es mejor prepararse para afrontarlo que quedarse quieto y esperar que las situaciones y sus efectos vayan impactándonos" (Zabala, 2011, pág10).

Las nuevas necesidades de salud de la población, requieren profesionales que busquen la creatividad y resolución de problemas que son cambiantes. El papel de los profesionales de enfermería necesita evolucionar de forma acorde a las nuevas demandas de cuidados de salud, ya que tienen a su cargo mayores responsabilidades para las que deben ejercer la autonomía profesional y demostrar buenas habilidades de cooperación dentro del equipo interdisciplinario 
de salud. Las instituciones encargadas de la formación de los estudiantes de enfermería y de los especialistas en Ciencias de la Salud, deben adaptarse para formar a futuros profesionales capaces de afrontar estos nuevos desafíos.

En la actualidad, los estudios de Grado en Enfermería, amplían la formación y se adaptan al proceso de la Enseñanza Europea de Educación Superior (EEES). Si los "nuevos estudiantes" desarrollan las competencias necesarias para el futuro ejercicio profesional, estarán preparados para los cambios que demanda la sociedad actual, la necesidad de una formación continua, y la importancia del aprendizaje para toda la vida. Además, los enfermeros y enfermeras generales que opten por continuar sus estudios con una formación especializada y/o Máster y Doctorado, habrán desarrollado competencias que serán imprescindibles para los estudios de posgrado.

Como el contexto al que ha de responder el Espacio Europeo de Educación Superior ha cambiado, es necesario que se modifique también el modelo de formación, si se quiere dar respuesta a las necesidades de la sociedad actual (Mora, 2004). La globalización y sus necesidades formativas afectan de manera muy directa al funcionamiento de las instituciones universitarias, debiendo dar respuesta a unas necesidades de formación, que ya no son las 
específicas de un entorno inmediato. La velocidad con la que se mueve el conocimiento, hace que ya no se piense en una estabilidad de las profesiones ligada a unos conocimientos constantes. Además, el éxodo de enfermeras y médicos en España, debido a la crisis económica y los recortes sanitarios, se ha duplicado en el año 2012 (Sahuquillo \& Sevillano, 2012) acrecentando la necesidad de formarse como profesionales para un mundo globalizado.

De entre todos los cambios que conlleva adaptar la filosofía del Espacio Europeo de Educación Superior (EEES) hay uno sustancial, profundo y de carácter renovador. Se trata de la modificación de los procesos de enseñanza y aprendizaje, es decir, de la filosofía que acompaña a la docencia y lo que implica aprender en la universidad. El cambio necesita el impulso de nuevas metodologías docentes centradas en el proceso de aprendizaje del estudiante, en un contexto que se extiende ahora a lo largo de toda la vida (Esteban \& Branda, 2011).

El Aprendizaje Basado en Problemas es una metodología que se ajusta perfectamente a las evoluciones de los sistemas de enseñanza superior y de formación sanitaria, porque facilita no sólo la adquisición de conocimientos, sino de otras habilidades tales como trabajo en equipo, habilidades de comunicación, pensamiento reflexivo, responsabilidad en el aprendizaje autónomo, cooperación en la búsqueda de 
información, evaluación crítica de la información, escucha activa y respeto de otros puntos de vista (Albanese \& Mitchell, 1993;Baker, 2000;Blumberg, 2000;Cooke \& Moyle, 2002;Hmelo \& Evensen, 2000; Lieberman, Stroup-Benham, Peel, \& Camp, 1997;MacKinnon, 1999;Morales-Mann \& Kaitell, 2001;Norman \& Schmidt, 1992;Schmidt \& van der Molen, 2001 ;White, Amos, \& Kouzekanani, 1999).

Las necesidades del nuevo contexto de educación superior exigen, además de los conocimientos, formar a los individuos en un amplio conjunto de competencias que incluyan conocimientos, pero también las habilidades y actitudes que son requeridas para el puesto de trabajo (Mora, 2004).

Si la finalidad de la educación en Enfermería es mejorar la atención de la salud, y un buen profesional constituye un compromiso con la excelencia en la atención de los pacientes mediante la innovación, así como con la participación en la comunidad profesional, ¿cómo debería diseñarse y llevarse a cabo el proceso educativo? Se propone la necesidad de cambios en el currículo, la pedagogía y la evaluación, teniendo en cuenta las tres premisas siguientes (Cooke, Irby, \& O'Brien, 2010):

1. Aprender es un desarrollo progresivo

2. El aprendizaje debe ser contextualizado 
3. Aprender es un proceso participativo

El objeto de estudio de esta investigación son las potencialidades, el valor y la finalidad de la metodología Aprendizaje Basado en Problemas, en adelante ABP, en la adquisición de las competencias del alumnado de Grado en Enfermería. Se pretende mejorar la calidad docente introduciendo un cambio en la metodología de enseñanzaaprendizaje, comprobar si los alumnos mejoran en aprendizaje auto dirigido y en su grado de satisfacción al utilizar ABP.

“Aprender a aprender" ha sido clave en la trayectoria profesional de la autora, tanto como enfermera especialista (matrona), como docente, puesto que los conocimientos son cambiantes y mucha información queda obsoleta en un período de diez años. En las diferentes disciplinas de Ciencias de la Salud, es fundamental el aprendizaje para toda la vida, permite una actualización continua que exigen profesiones como la enfermería o la medicina. Desde el punto de vista disciplinar, el cuidado es el objeto del conocimiento de la Enfermería y es el criterio fundamental para distinguirlo de otras disciplinas del campo de la salud.

El interés por implementar la metodología $\mathrm{ABP}$ en la Escuela de Enfermería de Valladolid, surge después de aplicarla en la formación teórica de posgrado de las enfermeras internas residentes (EIR) de la 
especialidad "Enfermería Obstétrico-Ginecológica". Como profesora en la Unidad Docente de Matronas de Valladolid, la autora ha comprobado que $\mathrm{ABP}$ es eficaz para trabajar con grupos de estudiantes, no sólo la adquisición de conocimientos, sino de otras competencias profesionales, porque los estudiantes han de resolver y enfrentarse a problemas clínicos reales. Se hizo una investigación previa, demostrando que la metodología $\mathrm{ABP}$ encaja perfectamente con la formación de profesionales de enfermería obstétrica que cuentan con un cuerpo de conocimientos multidisciplinar; y que incrementa el desarrollo y la mejora continua de las competencias del tutor, para ser un guía o acompañante de los estudiantes (González, Carbonero, \& Sánchez-Crespo, 2011). Es importante empezar a hacer, y no simplemente mantenerse en un discurso muy bueno que nunca llega a la implementación.

La universidad debe dar una formación epistemológica más que teórica es decir, una capacitación en el ejercicio de problematizar el conocimiento teórico, adentrarse en los tipos de razonamiento que produjeron dichas teorías y de romper con los propios límites de la razón teórica a través de potenciar el pensamiento crítico y creativo. La cuestión es convertir el qué pensar en cómo pensar...Una formación que atienda a las características de las prácticas profesionales y que reaccione a los contenidos de las demandas del mercado laboral desde el 
marco de autonomía y de vanguardia intelectual y social que ha solido caracterizar a las instituciones universitarias (Benedito, 1995, págs. 59-60).

El estudiante de enfermería, como todo estudiante de nivel universitario, requiere ser formado con alta calidad científica, tecnológica, humanística y con compromiso social; necesita adquirir conocimientos mediante la información verbal, conceptos, principios, resolución de problemas... Necesita también, adquirir habilidades procedimentales y actitudes. El alumnado, al interactuar con los usuarios a los que atenderá en el futuro profesional, no sólo debe cumplir funciones y tareas, sino también desarrollar actitudes que le permitan brindar un cuidado ético y humanizado.

"El profesional de enfermería, con su visión global del paciente y su adaptabilidad a diversos escenarios, se convierte en un puntal de la medicina del siglo XXI en igualdad de condiciones que otros profesionales con dominios y expertos diferentes" (Guillanet, González, Heierle, y Celma, 2008, pág. 64).

Para este estudio, ha sido necesario revisar y profundizar en varias disciplinas. Se trata de un estudio transdisciplinar siguiendo la filosofía de Edgar Morin (1999) que nos coloca en perspectiva, la importancia de las disciplinas en el aporte científico. 
Las disciplinas en las que se ha profundizado incluyen la didáctica, con las metodologías activas y el proceso de enseñanza y aprendizaje; la enfermería, en la que se aplica la metodología ABP siendo el punto central de esta investigación; la psicología, indagando en la Psicología Cognitiva y el Constructivismo; y la sociología, puesto que en la metodología $\mathrm{ABP}$, se seleccionan problemas de un contexto real y el aprendizaje es inseparable del contexto social de los estudiantes.

La tesis doctoral se estructura en dos partes, el Marco Teórico y el Marco Metodológico. En la primera parte se describe el Marco Teórico que consta de 3 capítulos:

En el primer capítulo se justifica la innovación educativa propuesta basándose en el marco legislativo y la mejor calidad de la enseñanza en el Espacio Europeo de Educación Superior (EEES); en las demandas de un mundo globalizado; y en la necesidad de un proceso de enseñanza-aprendizaje basado en competencias. El nuevo contexto en el que se desarrolla la educación superior, implica utilizar nuevas metodologías docentes puesto que el mundo ha cambiado, se ha globalizado, y hay un constante avance tecnológico y sobreabundancia de información. Como el fin de la educación es formar a profesionales competentes, la formación en competencias por tanto, incluye conocimientos, habilidades y actitudes necesarias para el futuro ejercicio profesional. En el capítulo se exponen varias definiciones de 
diferentes autores sobre las competencias, cómo éstas se demuestran en la acción, y se concluye que la formación en competencias no puede centrarse solo en el aprendizaje teórico, es necesario utilizar metodologías activas y una renovación de objetivos y de contenidos para cambiar la enseñanza universitaria centrándola en "el que aprende". Se resalta la importancia del aprendizaje autorregulado para una formación continua y actualizada, la necesidad de aprender a seleccionar información pertinente y de conseguir una autonomía en el aprendizaje. La propuesta de esta investigación pretende el desarrollo de competencias, entre ellas una fundamental, la competencia "aprender a aprender". Esta innovación educativa, se propone partir de otras experiencias exitosas con metodología ABP, teniendo en cuenta que innovar en educación es costoso y a veces se presenta un rechazo inicial, pero el esfuerzo que supone, aportará una mejor calidad docente en nuestra institución educativa, una vez superados los obstáculos. En síntesis, es preciso formar a ciudadanos para un mundo globalizado; profesionales competentes con pensamiento creativo, reflexivo y crítico; con una actitud abierta ante una sociedad cambiante como la actual y con actitudes para un aprendizaje para toda la vida.

En el segundo capítulo, al igual que en el capítulo anterior, en el que se resaltó la necesidad de una adaptación de la enseñanza a un contexto de un mundo globalizado y cambiante, la práctica de la 
enfermería, también debe adaptarse a los cambios. Es necesario desarrollar las habilidades de pensamiento crítico y razonamiento clínico, trabajo en equipo, el uso de las tecnologías y una actualización continua para asumir las responsabilidades de su disciplina de forma competente. En el capítulo se hace un repaso histórico de la formación en Enfermería desde la profesionalización con Florence Nigthingale en el año 1860, hasta la actualidad. Se expone el paralelismo en la evolución de la enfermería internacional y española. Es de suma importancia una correcta comprensión de la evolución histórica de la formación enfermera puesto que en la actualidad, existen diferentes profesionales que han recibido distinta formación, y esto se traduce en una variabilidad de actitudes y asunción de responsabilidades dentro de un mismo colectivo. Como se expone en el capítulo, el Ayudante Técnico Sanitario (ATS) recibió una formación enfocada a ayudar al médico, más técnica. El Diplomado Universitario en Enfermería (DUE) sin embargo, recibió una formación universitaria teórico-práctica, que le ha permitido mayor autonomía profesional y mayor responsabilidad en los cuidados de enfermería. Actualmente con la formación de Grado en Enfermería, el proceso de enseñanza y aprendizaje se centra en las competencias. Los nuevos graduados pueden optar por continuar su formación con estudios de Máster, de Doctorado o con estudios de una especialidad de enfermería. Al final del capítulo se explica de forma breve el 
contexto educativo y el currículo en el que se implementó el Aprendizaje Basado en Problemas en que se basa esta investigación.

El tercer capítulo se centra en explicar el paradigma constructivista de aprendizaje. ABP se fundamenta en el constructivismo en el que la motivación del alumnado, sus experiencias previas, el esfuerzo, y la comprensión, son esenciales para construir nuevos aprendizajes. Se reseña que el aprendizaje se construye de forma activa y se detallan los distintos estilos de aprendizaje que nos sugieren que es arriesgado utilizar exclusivamente metodología ABP. Se describen las diferencias entre la enseñanza tradicional y el enfoque constructivista, aportando referencias de varios autores que enfatizan las ventajas de $\mathrm{ABP}$ en la adquisición de un aprendizaje más profundo, complejo y transformador. Se examinan los antecedentes en las universidades del mundo y de España en las que se está utilizando ABP, siendo en el área de Ciencias de la Salud donde más se ha extendido su uso. En ABP el aprendizaje es circular, supone un estímulo para los estudiantes porque son los protagonistas de su propio aprendizaje y además, la interacción social a través del trabajo en grupo lo favorece.

En la segunda parte de la tesis, se desarrolla el Marco Metodológico que se describe en los tres últimos capítulos:

En el cuarto capítulo se explica la metodología utilizada en el estudio, la población, la muestra y los criterios de inclusión y 
exclusión. Se detallan los instrumentos utilizados que al tratarse de una metodología mixta, se necesitó una recogida de los datos a través de cuestionarios, observaciones y análisis de contenido escrito. Se utilizó el paquete estadístico SPSS para el tratamiento de los datos cuantitativos, y se analizaron las observaciones, las notas de campo y otros documentos recogidos para esta investigación a través de análisis de contenido. La triangulación de métodos múltiples fue necesaria para la obtención e interpretación de los resultados.

En el quinto capítulo se exponen los resultados obtenidos tras el análisis de los datos. Los resultados se agruparon en cuatro categorías partiendo de los objetivos de la investigación:

a. Efecto de la estrategia didáctica ABP en la autodirección del aprendizaje

b. Evaluación por competencias

c. Satisfacción de los estudiantes de Grado en Enfermería que han aprendido con ABP

d. Ventajas e inconvenientes del ABP percibidas por los estudiantes

El sexto capítulo engloba la discusión y las conclusiones de los resultados. Para seguir una secuencia ordenada, se hizo la discusión en base a los objetivos y se contrastaron las hipótesis planteadas con los resultados obtenidos. Las conclusiones más importantes al 
implementar metodología ABP en la Escuela de Enfermería de Valladolid son el progreso en el perfil auto dirigido de los estudiantes, la elevada satisfacción de los alumnos y de la profesora, un aprendizaje de mayor calidad, y el desarrollo de competencias necesarias para el ejercicio profesional de enfermería como el trabajo en equipo, la búsqueda de información, la capacidad de análisis y síntesis, la mejora en habilidades sociales y comunicación escrita y oral, el uso de tecnologías y una fundamental, "aprender a aprender". 


\section{I-MARCO TEÓRICO}


CAPÍTULO 1 


\section{Nuevas formas de enseñar $y$ aprender en las aulas del siglo XXI}

\subsection{Marco legislativo y calidad de enseñanza en el Espacio Europeo de Educación Superior (EEES)}

A nivel mundial se ha ido reconociendo la importancia de la educación general, y de la educación superior en particular, para el fututo de los habitantes. Nadie pone en duda, la existencia de una estrecha relación entre el nivel de educación y la capacidad tecnológica e innovadora de cada país y el papel que aquél es capaz de desempeñar en un mundo cada vez más globalizado y competitivo. En otras palabras, el futuro de cada país en Europa, y el futuro de Europa en el mundo, dependen de la capacidad innovadora y competitiva de su sistema de educación (Salaburu, Haug, \& Mora, 2011).

La construcción del Espacio Europeo de Educación Superior (EEES) se sitúa en el marco de las reformas educativas impulsadas por el proceso económico de globalización pilotado políticamente por diversas instancias internacionales como el Banco Mundial, la Organización Mundial del Comercio, la OCDE (Organización para la Cooperación y el Desarrollo Económico) y la UNESCO (1998 a). 
El Espacio Europeo de Educación Superior es un proyecto conjunto de 47 países, dentro y fuera de la Unión Europea, en el cual participan los Ministerios de Educación de todos ellos, además de contar con la cooperación de Universidades y estudiantes, que se marcaron como meta el establecimiento de un Espacio Europeo de Educación Superior (EEES) en el año 2010. Su objetivo principal es cambiar la filosofía y la metodología de los estudios universitarios armonizando los diferentes sistemas educativos de la Unión Europea, facilitando la movilidad de estudiantes y docentes, tanto como la compatibilidad y la equiparación entre estudios. EEES afecta directamente a más de 8.000 instituciones de educación superior y a más de 25 millones de estudiantes y a sus familias.

El movimiento hacia EEES comenzó con el "Proceso de Bolonia" en el año 1999, en el que veintinueve ministros de Educación de países europeos, entre ellos España, firmaron en Bolonia un acuerdo para avanzar hacia un sistema universitario común que facilite la movilidad de los estudiantes y de los titulados europeos. El objetivo de los primeros países, hasta llegar a los cuarenta y siete países que se han ido adhiriendo después, fue el compromiso de organizar la educación de acuerdo a unos principios comunes a nivel europeo (Salaburu, Haug, \& Mora, 2011). 
En el verano del año 2000, un grupo de universidades aceptaron colectivamente el desafío de Bolonia y diseñaron un proyecto piloto llamado European Tuning Project. El Proyecto Tuning aborda varias de las líneas de acción señaladas en Bolonia, y en particular, la adopción de un sistema de titulaciones fácilmente reconocibles y comparables, la estructuración en dos ciclos y el establecimiento de un sistema de créditos. Este proyecto, en el que colaboran más de cien instituciones, tiene como objetivo determinar puntos de referencia para las competencias genéricas y las específicas de cada disciplina de primer y segundo ciclo en una serie de áreas. Se trata de llegar a un acuerdo para los puntos de referencia de la convergencia y la comprensión común, teniendo en cuenta la protección de la rica diversidad de la educación europea (González \& Wagenaar, 2003). A partir de ahora, se tendrá que formar a los profesionales de enfermería en competencias (habilidades, actitudes y conocimientos) en vez de solamente en conocimientos.

EEES tiene tres características principales: un conjunto de títulos universitarios homogéneos; enseñanza basada en ciclos (Grado, Máster y Doctorado); y medición del aprendizaje (no sólo de contenidos) mediante un sistema común de créditos (Sistema Europeo de Transferencia de Créditos o ECTS) que tiene en cuenta el tiempo total dedicado por el estudiante a cada materia. 
La Declaración pretende alcanzar estas tres metas:

1. Mejorar la competitividad y el atractivo internacional de la educación superior europea

2. Mejorar la tasa de empleo de los graduados europeos

3. Desarrollar la movilidad interna y externa de estudiantes y de graduados

A estas metas, se añadieron en las reuniones de Praga (2001) y Berlín (2003) las siguientes:

4. Integrar el aprendizaje para toda la vida (life-long learning) en la estrategia educativa,

5. Implicar a los alumnos en el proceso de aprendizaje y

6. Promover la creación de un área europea en investigación.

El Grupo de Seguimiento de Bolonia es un equipo en el que han confiado los ministros de Educación europeos para gestionar el proceso de Bolonia; intervienen los 47 países; se reúne dos veces al año; y está presidido por el país que tiene la Presidencia en el turno de la Unión Europea (Ministerio de Educación, 2012). El Grupo de Seguimiento mantiene reuniones bianuales como la de Bergen (2005), Londres (2007), Lovaina (2009), Budapest-Viena (2010) y la última reunión, en Bucarest en abril de 2012.

La Comisión Europea forma parte de un Grupo de Seguimiento de Bolonia y de sus grupos de trabajo; apoya la Secretaría de Bolonia y 
la red de expertos sobre el Proceso de Bolonia; contribuye a la financiación de reuniones ministeriales y de numerosos informes, conferencias y seminarios. Muchas herramientas de Bolonia (por ejemplo el ECTS) tuvieron su origen en el programa de intercambio de estudiantes Erasmus, de la Comisión.

La agenda de modernización de la Comisión en relación con la educación superior, señala cinco ámbitos clave de reforma: en primer lugar, aumentar el número de titulados con el fin de que, a más tardar en 2020, se cumpla el objetivo establecido en Europa 2020 de que haya un $40 \%$ de jóvenes con cualificaciones de educación superior; en segundo lugar, aumentar la calidad y hacer que la educación superior sea más acorde a las necesidades de los puestos de trabajo y a las demandas sociales; en tercer lugar, mejorar la calidad de la movilidad para el estudio; en cuarto lugar, integrar la educación superior en el triángulo del conocimiento de la educación, la investigación y el desarrollo; y finalmente, mejorar la gobernanza y la financiación. El Proceso de Bolonia y la agenda de modernización de la Comisión se refuerzan mutuamente.

En el último informe de aplicación de Bolonia presentado a los ministros de Educación en Bucarest (Comisión Europea, 2012), se concluye que todos los países han realizado cambios importantes que han permitido que se desarrolle el Espacio Europeo de Educación 
Superior. Sin embargo, los avances son desiguales, en el actual contexto de austeridad del gasto público en educación superior, y sigue habiendo problemas prácticos. Muchos estudiantes abandonan los estudios de educación superior o se gradúan y no obtienen empleo, algunos se enfrentan a obstáculos para el reconocimiento de su cualificación académica en otro país. A las instituciones les cuesta ofrecer un aprendizaje centrado en el estudiante, con programas educativos adaptados a sus necesidades, exponiéndoles con claridad lo que deben aprender y ser capaces de hacer al terminar sus estudios, resultados de aprendizaje. En general, la educación superior aún no está aprovechando todo su potencial para estimular el crecimiento.

Para aclarar los términos, en el Real Decreto 1027/2011 se definen:

“a) Cualificación académica: Cualquier título, diploma o certificado emitido por una institución educativa que acredita haber adquirido un conjunto de resultados del aprendizaje, después de haber superado satisfactoriamente un programa de formación en una institución legalmente reconocida en el ámbito de la educación superior.

b) Resultado del aprendizaje: Aquello que se espera que un estudiante conozca, comprenda o sea capaz de hacer" (Real Decreto 1027/2011, pág.87914). 
La estructura de titulación de Bolonia se está adoptando de forma generalizada; en tres cuartas partes de los países del EEES, entre el 70 y el $90 \%$ del alumnado estudian en programas que se corresponden con el sistema de grado y máster de Bolonia.

Varios instrumentos desarrollados en el marco del Proceso de Bolonia están ayudando a dar un impulso para conseguir unos sistemas más centrados en los estudiantes. El Sistema Europeo de Transferencia y Acumulación de Créditos (ECTS) asigna créditos a cada parte de un programa de estudios, basándose en la carga de trabajo del estudiante para lograr unos resultados de aprendizaje especificados. Esta unidad de medida, a diferencia del crédito académico antiguo, que sólo contabilizaba como carga de trabajo las horas presenciales es decir, el tiempo de ocupación del profesor, se modifica para incorporar las horas de trabajo del alumno, con y sin la presencia de un docente (Prat, Palés, Nolla, Oriol, \& Gual, 2010). Así, para los estudiantes es más sencillo acumular los créditos obtenidos en el marco de distintos programas, y simplifica el reconocimiento de los estudios realizados en otro país por parte de su centro de enseñanza de origen (Gijón \& Crisol, 2012).

Un crédito ECTS equivale a 25 horas de trabajo del estudiante; incluye: actividades académicas dirigidas (tutorías), búsquedas bibliográficas o de investigación; seminarios; talleres; prácticas de 
aula; análisis y tratamiento de la información como búsquedas en bibliotecas, en internet...; horas dedicadas al estudio y horas dedicadas a la evaluación.

El "Suplemento europeo al Diploma", es un anexo que se adjunta al título, presenta una descripción normalizada de los estudios concluidos con las calificaciones del estudiante, las competencias adquiridas, así como la Universidad que expide el título y el sistema universitario en el que se integra. El objetivo es que facilite la comprensión y transparencia del contenido de cualquier titulación, sea cual sea el país en que se haya obtenido (Ministerio de Educación, 2010). En realidad, Bolonia es un esfuerzo por adaptarse a la sociedad del conocimiento y acomodarse al mundo globalizado en el que vivimos y el proceso se dirige hacia la educación centrada en el que aprende.

De los países grandes que firmaron la Declaración de Bolonia ya en el 1999, España es quizá el que ha acumulado más retrasos y sufrido más dificultades, como bien lo señala el informe de la OCDE de 2009 sobre el estado de la educación superior española (Ministerio de Educación, 2009). Las estructuras universitarias previas, las del punto de partida, estaban más alejadas en España que en otros países de la propuesta que hacía el nuevo modelo del EEES. Al inicio del Proceso de Bolonia, la universidad española en general, se encuentra en una 
situación un poco complicada, puesto que crea poco conocimiento en comparación a los países con una renta similar, y transfiere poco conocimiento a las empresas. Esto se comprueba con el número de publicaciones de alto impacto y en el número del patentes. Sin embargo, transmite con eficacia conocimiento a los estudiantes en las aulas ya que no parecen tener excesivos problemas para competir en el exterior con sus colegas de otros países (Salaburu, Haug, \& Mora, 2011). La enfermería española destaca por un alto nivel respecto a otros países de su entorno y cada vez, adquiere más importancia la investigación y la innovación (Europa.press, 2012).

En España, desde el punto de vista legislativo, se inicia la reforma educativa a través de la Ley Orgánica 4/2007,del 12 de Abril (LOMLOU) dando cobertura legal y formal al proceso de Bolonia. La nueva estructura de enseñanzas universitarias oficiales, está organizada en tres ciclos, según el Real Decreto 1393/2007, de 29 de octubre, por el que se establece la ordenación de las enseñanzas universitarias oficiales:

1. Grado. Los planes de estudio que conducen a la obtención del título de grado tienen 240 créditos ECTS.

2. Máster Universitario. Se puede realizar un máster de entre 60 y 120 créditos ECTS para aumentar el nivel de especialización. Con el título de grado y un máster se 
accede directamente al doctorado (Comisión Europea, 2012).

3. Doctorado. Tiene como finalidad la formación avanzada del estudiante, en las técnicas de investigación e incluye la elaboración y presentación de la tesis doctoral, consistente en un trabajo original de investigación.

Los estudios de Grado en Enfermería por ejemplo, quedan estructurados con un total de 240 créditos ECTS en cuatro años. La formación se puede completar en la universidad con un el Máster (60 créditos ECTS) y el Doctorado (con 300 créditos cursados); o pueden optar a la formación posgrado en una especialidad enfermera.

El sistema de especialización en Ciencias de la Salud, según el Real Decreto 450/2005, de 22 de abril, sobre especialidades de Enfermería, legisla que la formación de especialistas ha de producirse dentro del modelo del EEES, y el catálogo de especialidades ha de responder al objetivo de proporcionar una mejor atención sanitaria a los ciudadanos, sin que ello suponga obviar las aspiraciones de desarrollo profesional y de libre movilidad en el Sistema Nacional de Salud, tanto de los enfermeros especialistas como de los enfermeros responsables de la prestación de cuidados generales. 
La Estrategia Universidad 2015 (EU2015) está dirigida a obtener cambios estructurales y culturales en las universidades españolas para adecuarlas a las nuevas necesidades y demandas de las sociedades modernas. No obstante, esta voluntad para mejorar la educación, y la financiación del Sistema Universitario Español, se enfrenta a la realidad de la recesión económica internacional, especialmente intensa en España (Ministerio de Educación, 2010).

La sociedad del conocimiento necesita ciudadanos con un alto nivel formativo y con una visión crítica y creativa del mundo, que se adquieren fundamentalmente en la educación universitaria. Pero la universidad no sólo debe centrar la atención en los aspectos formativos; también debe acometer tareas de investigación y de transferencia de conocimiento y de tecnología con criterios de excelencia (EU2015, pág16).

También hay que mencionar el Real Decreto 1027/2011 por el que se establece el Marco Español de Cualificaciones para la Educación Superior (MECES), éste es un instrumento que implica cambios estructurales y de gestión. Permite romper con compartimentos estanco en la formación puesto que contempla la existencia de distintos niveles en un marco de cualificaciones sin un título oficial. MECES es un instrumento, reconocido internacionalmente, permite la 
nivelación coherente de las cualificaciones de la educación superior, facilita la movilidad en el EEES y en el mercado laboral internacional. El Marco Español de Cualificaciones para la Educación Superior se estructura en cuatro niveles:

- Nivel 1: Técnico Superior.

- Nivel 2:Grado

- Nivel 3:Máster

- Nivel 4: Doctor

En el Nivel de Grado, de mayor interés para este estudio de investigación, se incluyen aquellas cualificaciones que tienen como finalidad la obtención por parte del estudiante de una formación general, en una o varias disciplinas, orientada a la preparación para el ejercicio de actividades de carácter profesional. Las características de las cualificaciones ubicadas en este nivel vienen definidas por los siguientes descriptores presentados en términos de resultados del aprendizaje:

a) Haber adquirido conocimientos avanzados y haber demostrado una comprensión de los aspectos teóricos y prácticos y de la metodología de trabajo en su campo de estudio con una profundidad que llegue hasta la vanguardia del conocimiento;

b) Poder, mediante argumentos o procedimientos elaborados y sustentados por ellos mismos, aplicar sus conocimientos, la comprensión de estos y sus capacidades de resolución de problemas 
en ámbitos laborales complejos o profesionales y especializados que requieren el uso de ideas creativas e innovadoras;

c) Tener la capacidad de recopilar e interpretar datos e informaciones sobre las que fundamentar sus conclusiones incluyendo, cuando sea preciso y pertinente, la reflexión sobre asuntos de índole social, científica o ética en el ámbito de su campo de estudio;

d) Ser capaces de desenvolverse en situaciones complejas o que requieran el desarrollo de nuevas soluciones tanto en el ámbito académico como laboral o profesional dentro de su campo de estudio;

e) Saber comunicar a todo tipo de audiencias (especializadas o no) de manera clara y precisa, conocimientos, metodologías, ideas, problemas y soluciones en el ámbito de su campo de estudio;

f) Ser capaces de identificar sus propias necesidades formativas en su campo de estudio y entorno laboral o profesional y de organizar su propio aprendizaje con un alto grado de autonomía en todo tipo de contextos (estructurados o no).

La Agencia Nacional de Evaluación de la Calidad y de la Acreditación (ANECA) es un organismo de carácter autónomo que ha realizado y desarrollado diferentes programas, ayudando a incrementar la calidad del sistema universitario español. ANECA fue creada el 19 de julio de 2002, en cumplimiento de lo establecido en la (Ley Orgánica 6/2001, de 21 de diciembre ) de Universidades (LOU), en sus artículos 31 y 
32. Las actividades que realiza, abarcan diferentes líneas como la evaluación de la enseñanza y las instituciones, la evaluación del profesorado y la evaluación de servicios; estudios y prospectiva; y relaciones con Europa, Iberoamérica y el Mediterráneo (van Grieken, 2012).

En el último Comunicado de Bucarest de 2012, la Garantía de la Calidad de la enseñanza universitaria aparece como un elemento destacado. ANECA es la encargada de validar y archivar las interpretaciones de los niveles del MECES. ANECA ha sido evaluada de forma externa por la Asociación Europea de Garantía de Calidad en la Enseñanza Superior (ENQA) y forma parte de del Registro Europeo de Agencias de Garantía de Calidad.

En resumen, el camino recorrido en el EEES ha permitido reflexionar sobre nuestro sistema de educación superior, adaptándolo a una nueva realidad europea e integradora; se han seguido criterios y estándares europeos de calidad como la Asociación Europea de Garantía de Calidad en la Enseñanza Superior (ENQA) que han permitido mejoras significativas del proceso de evaluación y eficacia de las agencias de calidad siendo, la preocupación por la calidad de la enseñanza y por la cultura de la evaluación, una constante en el ámbito educativo (van Grieken, 2012). 


\subsection{Nuevo contexto EEES}

En un mundo cambiante y complejo, en el que la información crece de forma exponencial, es impensable que los alumnos aprendan todos los conocimientos necesarios para el futuro. Un profesional competente, necesitará seguir aprendiendo para estar actualizado ante la inmensa producción científica del mundo globalizado y los cambios tecnológicos. Aprender con autonomía y con buen resultado es la meta de todo estudiante, y el deseo de todo docente (Cázares, 2009).

El proceso de convergencia europea, supone un profundo cambio en el planteamiento de la enseñanza en la Universidad. Se hablará de una "nueva Universidad" en el aprendizaje para toda la vida. Se tratará de un sistema universitario más moderno, centrado en el estudiante, donde el profesor universitario además de dar clase, fomentará el aprendizaje creativo y autónomo haciendo que el estudiante piense por sí mismo. A partir de este momento, la enseñanza dejará de ser una prioridad y el alumno será el protagonista de su aprendizaje (Gijón \& Crisol, 2012).

La organización de la docencia pasará de un modelo constituido por clases teóricas y prácticas, a un abanico más amplio en el que las clases se complementan con seminarios y talleres específicos, con tutorías individuales y grupales, con estudio y trabajo autónomo y con trabajos de grupo (Marcelo, 2011). También se contemplan 
actividades no formales como el voluntariado, asistencia a cursos, conferencias...que proporcionan créditos ECTS a los estudiantes.

En la sociedad del conocimiento adquiere gran relevancia la educación superior y las universidades, por ser una de las fuentes más importantes en generar conocimiento y de transmisión del mismo, de la ciencia y de la tecnología.

Se ha producido una expansión geográfica de las universidades y además existen universidades virtuales permitiendo el acceso a la formación desde cualquier punto del mundo. Actualmente se ofrecen estudios a lo largo de toda la vida, por lo que la universidad no es exclusiva de "jóvenes". Hay que tener en cuenta los cambios en el perfil de los estudiantes (más heterogéneos, compatibilizan estudios y trabajo, tienen responsabilidades familiares, hijos a su cargo...) y los cambios producidos por los avances científicos, que requieren una actitud crítica y abierta. Los cambios propiciados por la incorporación de las Tecnologías de la información y comunicación (TIC) a la vida cotidiana de los estudiantes y usuarios de las universidades. Una sociedad más compleja, más diversa, más libre, que necesita ciudadanos formados e informados que sepan enfrentarse a situaciones cambiantes y complejas. La universidad del futuro debería ser una institución que suministrase formación a la gran mayoría de la población a lo largo de toda la vida, accesible en cualquier lugar, y 
por tanto, su funcionamiento no puede ser igual que el de la universidad tradicional.

La crisis económica por la que atravesamos, hace que haya un mayor acceso de personas en la universidad. Según las cifras oficiales de la población española de enero de 2011 (INE, 2012), y a pesar de que las cohortes de acceso a la universidad seguirán descendiendo por motivos demográficos, los jóvenes acuden o tienden a quedarse en la universidad debido a la crisis económica y a la tasa de paro actuales en España, estudiando, en muchas ocasiones, una segunda carrera universitaria. Otra de las razones del aumento de universitarios se debe a que la enseñanza obligatoria se ha extendido hasta los 16 años y es natural que accedan más jóvenes a la universidad; además, las estadísticas demuestran que los titulados universitarios se colocan mejor, siendo otro de los motivos de mayor acceso a la universidad (Salaburu, Haug, \& Mora, 2011).

Uno de los principales desafíos del Proceso de Convergencia Europea en la Universidad, será la transformación del modelo de enseñanza tradicional, transmisivo, donde el docente es la figura principal, por un modelo de enseñanza centrado en el aprendizaje autónomo del alumno. Aunque probablemente tengan algo de razón quienes hablan de un menor nivel de conocimientos, no es menos cierto que muchos contenidos carecen de utilidad y aplicación posterior para los 
estudiantes. El nuevo modelo docente, permite desarrollar competencias generales, al promover situaciones de comunicación, búsqueda de información, análisis y presentación de la información y relaciones interpersonales que confieren mayor complejidad de la habitual. Respecto a la planificación, exige al profesor una buena distribución de actividades presenciales y no presenciales. Los cambios se articularán entorno a la planificación de la materia, del trabajo del alumno, y de la comunidad de aprendizaje que incluye a los alumnos, profesores y el contexto institucional (Fernández Enguita, 2009). La base educativa ha de ser flexible y los titulados universitarios deben poseer las destrezas necesarias para adaptarse a un mercado laboral que cambia con rapidez. La cuestión de fondo es que las habilidades profesionales y técnicas se pueden adquirir $\mathrm{y}$ actualizar en una fase posterior de la carrera profesional, mientras que las teóricas para la resolución de problemas y para aprender a aprender se deben conseguir a través del proceso de formación académica en las universidades o especialización (Aráujo y Sastre, 2008).

El Aprendizaje Basado en Problemas, es una metodología que se ajusta perfectamente a las evoluciones de los sistemas de enseñanza superior y sanitario, porque facilita no sólo la adquisición de conocimientos, sino de otras habilidades tales como trabajo en equipo, habilidades de comunicación, responsabilidad en el 
aprendizaje independiente, cooperación en la búsqueda de información, evaluación crítica de la información, escucha activa y respeto de los puntos de vista del otro.

\subsection{Formación basada en Competencias}

El término competencia proviene del latín competentia y es definido por la Real Academia Española (RAE, 2012) como "pericia, aptitud, idoneidad, para hacer algo o intervenir en un asunto determinado".

El informe sobre la Educación para el siglo XXI publicado por la UNESCO (1998 a) destaca la relevancia que tiene la educación en los múltiples desafíos que tendrá que afrontar la humanidad del presente siglo y sugiere la necesidad de pasar de la calificación a la competencia, con el fin de ampliar las relaciones entre educación y el mundo laboral. La formación por competencias tiene impacto en el mundo de la educación desde hace décadas en el que se propone un cambio del paradigma de la enseñanza, al paradigma del aprendizaje (Langevin \& Bruneau, 2000; Tardif, 1998).

Para Langevin y Bruneau (2000), el paradigma de la enseñanza se centra en el contenido, en el que el profesor experto transmite a los estudiantes pasivos, que aprenden los contenidos de forma memorística. Por otra parte, el paradigma del aprendizaje se centra en la transferencia, en el que el estudiante es un socio activo del proceso 
de aprendizaje y es guiado por el tutor. El fin de este paradigma es el desarrollo de competencias relacionadas con la profesión y requiere desarrollar habilidades cognitivas y metacognitivas para la integración y transferencia de aprendizajes (Legault, 2012).

Las necesidades del nuevo contexto de educación superior exigen además de los conocimientos, formar a los individuos en un amplio conjunto de competencias que incluyan conocimientos, pero también las habilidades y actitudes que son requeridas para el puesto de trabajo (Mora, 2004). El conjunto de cualificaciones que necesita un trabajador para ocupar un puesto laboral se denomina competencias.

Una persona tiene competencia profesional si posee los conocimientos, las destrezas y las aptitudes que necesita para desenvolverse en una profesión, si es capaz de resolver tareas independientemente y flexiblemente, y si tiene la voluntad y la capacidad de desarrollar su esfera de trabajo dentro de la estructura organizativa en la que está inmerso (Bunk, 1994, pág. 9).

En el ámbito de la educación, las definiciones de competencia exigen iniciativa de los estudiantes, transferencia de conocimiento e innovación (Cano, 2008). El aprendizaje es un acto complejo que demanda participación, actitud crítica, reflexión y búsqueda activa de 
información. Requiere la movilización de factores internos como los conocimientos, procedimientos y actitudes que se reflejan en el saber, saber hacer y saber ser del estudiante. Los factores externos se refieren a los materiales, recursos tecnológicos y profesores que son fuente de conocimiento indispensable para formar al nuevo profesional y también, se refieren al contexto profesional, por esto interesa que la educación se aproxime a lo que será el futuro ejercicio de la profesión (Gimeno, 2008).

La relación entre el desarrollo de competencias y el aprendizaje se logra movilizando recursos cognitivos o actividades por parte del alumno, para recuperar lo aprendido al enfrentarse a situaciones que demandan su intervención y proponer soluciones. Nos aproxima a un concepto de competencia como un conocer para saber hacer con base en la experiencia y el conocimiento previo y, aprender del saber hacer a través de un proceso reflexivo y de interacciones sociales (Carrera \& Marín, 2011).

Según De Ketele (1996), la competencia es un conjunto ordenado de capacidades que se ejercen sobre los contenidos de aprendizaje y cuya integración permite resolver los problemas que se plantean dentro de una categoría de situaciones. Se trata de ejecutar una tarea compleja, o un conjunto de tareas más o menos del mismo tipo, dentro de una familia de situaciones. Una familia de situaciones son el conjunto de 
necesidades que se presentan alrededor de una general, todas ellas tienen que ver con tareas específicas pero interrelacionadas.

Para Roegiers (2000), la competencia es la posibilidad que tiene un individuo de movilizar de manera interiorizada, un conjunto integrado de recursos con el fin de resolver situaciones o problemas.

Le Boterf (2001), define la competencia como un saber entrar en acción, lo cual implica saber integrar, movilizar y transferir un conjunto de recursos (conocimientos, saberes, aptitudes y razonamientos) en un determinado contexto, con el fin de realizar una tarea o de hacer frente a diversos problemas que se presentan.

Toda competencia involucra un conjunto de conocimientos, procedimientos y actitudes, los cuales se combinan, se coordinan e integran en función de lo que el individuo ha de saber hacer y saber estar para el ejercicio profesional. Por otra parte, las competencias solo son definibles en la acción, no reside en los recursos (capacidades) sino en la movilización, articulación e integración de los mismos en función de una determinada situación y un determinado contexto. Saber, no es poseer, es utilizar (Tejada \& Navío, 2005).

Para Tardif (2006), una competencia tiene como característica ser integradora, combinatoria, en el desarrollo, contextual y evolutiva. 
Según este autor, una competencia integra diversos recursos, de ahí su carácter integrador que hace referencia a la complejidad del saber actuar es decir, implica movilización y combinación de recursos complementarios y sinérgicos. Además se desarrolla a lo largo de la vida de manera compleja y exige tiempo. Por eso es importante en los objetivos previstos en la formación de los estudiantes, reflexionar sobre el nivel de desarrollo que se debe alcanzar en cada una de las competencias. El carácter contextual de la competencia da sentido al aprendizaje que se vuelve reflexivo y consciente. El carácter evolutivo se refiere a que a lo largo del tiempo, de forma gradual la persona acumula recursos y es eficaz en situaciones cada vez más complejas.

"La competencia es un saber actuar complejo que se apoya en la movilización y la combinación eficaz de una variedad de recursos internos y externos dentro de una familia de situaciones" (Tardif, 2006 pág. 22)

Para Perrenoud $(1998,2008)$ las competencias son capacidades que utilizan varios recursos cognitivos para enfrentar ciertas situaciones; no son conocimientos, habilidades o actitudes, sino acciones que integran y movilizan esos recursos. Las competencias profesionales se adquieren en el proceso de formación, pero se fortalecen en la práctica laboral. La competencia permite identificar las necesidades para resolver problemas a los que se enfrentará en su vida por lo tanto, la 
competencia consistirá en la intervención eficaz en los diferentes ámbitos de la vida, mediante acciones en las que se movilizan al mismo tiempo y de manera interrelacionada, actitudes, procedimientos y conceptos. La movilización de recursos se hace de manera integrada (Zabala, 2008;Roegiers, 2000).

En los estudios de Le Boterf (2001), Gimeno (2008), De Ketele (1996), Roegiers (2007), Tardif (2006), y Zabala (2008) se llegó a la conclusión de que existe una relación muy estrecha entre el desarrollo de las competencias de los alumnos y la movilización de recursos cognitivos como los conocimientos previos, las habilidades para integrar el conocimiento y su utilización, el análisis y la síntesis; todos ellos encaminados a la solución de problemas reales y cercanos al alumno.

En las anteriores definiciones sobre competencia, los autores coinciden en que es preciso la movilización o el uso de recursos cognitivos ante situaciones problema. Se entiende por situación el entorno en el que se desarrolla una actividad articulándose el contexto y la tarea. Metodologías activas como el ABP permiten el desarrollo de competencias en los estudiantes.

Contrastando los diferentes estudios sobre competencias hay varias vertientes. En la primera se aboga por los beneficios y logros de una 
educación basada en competencias que facilitará la inserción al mundo laboral (Álvarez \& Ayuste, 2003; Alles, 2002; Cajide \& Abeal, 2002; González, 2010; Martínez \& Echeverría, 2009; Legault, 2012; López, 2011; Silva, 2008; Westera, 2001). En la segunda se incluyen los detractores preocupados por perder una educación basada en conocimientos que se aleje de una educación integral (Barrón, 2000; Boutin \& Julien, 2010; Díaz, 2006; Perrenoud, 2004, 2008;). En la tercera se da un enfoque conductista (Barnet, 2001; Pérez, 2007) con el cambio al enfoque constructivista paulatinamente (Moreno, 2009). En la cuarta se encuentran los estudios sobre los cambios que han ocurrido en el proceso de enseñanza-aprendizaje generados por las tecnologías de información y comunicación. Sin embargo, existe poca bibliografía sobre la relación del desarrollo de las competencias en las diferentes modalidades educativas, como es el caso de las modalidades presencial y online y la comparación entre ellas (Andrade \& Campo-Redondo, 2008; Argudín, 2009; Cabero, 1994).

Uno de los objetivos fundamentales de la formación basada en competencias es "aprender a aprender" siendo fundamental potenciar un aprendizaje autónomo y significativo. Las estrategias didácticas se deben orientar más al desarrollo de destrezas y actitudes que el dominio de conocimientos. 
La adquisición de las competencias (véase figura 1) suele seguir un proceso de retroalimentación (Martínez \& Echeverría, 2009).

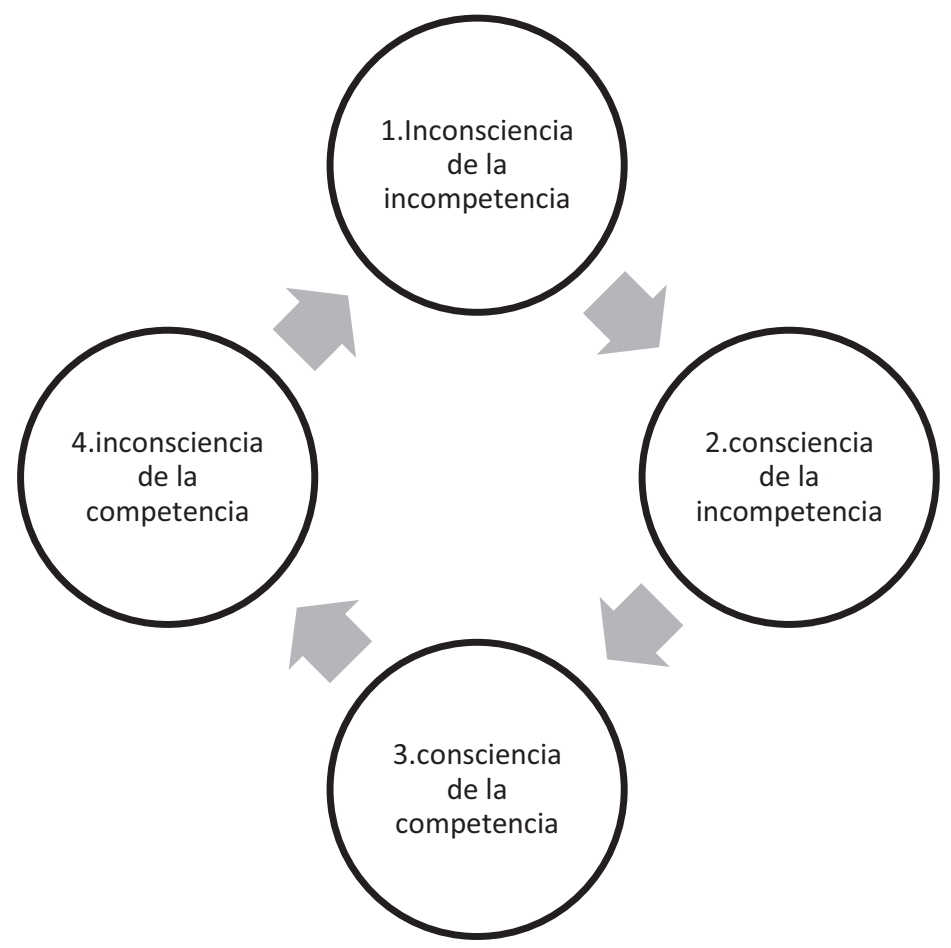

Figura 1.Proceso de adquisición de la Competencia de Acción (Martínez \& Echeverría, 2009).

Las competencias se manifiestan y demuestran en la acción, lo que implica que la educación superior debe centrarse en proporcionar conocimientos relevantes, destrezas y habilidades clave y un sistema de valores y actitudes que doten al estudiante para desarrollar tareas complejas y resolver problemas académicos o profesionales de forma 
autónoma o en equipo (López, 2011). Este proceso dinámico, se fundamenta en teorías del aprendizaje como el constructivismo-Piaget, Vygotsky, Bruner, etc-, el cognitivismo-Gagné, Lemaire, Ausbel, etc.y el socioconstructivismo-Borght, Brown y Campione-. La primera teoría enfatiza el papel activo de los aprendices. La segunda se centra en la forma de la adquisición y utilización de los conocimientos. La última resalta la dimensión relacional del aprendizaje. Para desarrollar estos principios hay que acudir a metodologías activas de enseñanzaaprendizaje. Las diferentes metodologías requieren una diversificación de las formas sociales de agrupamiento, ya que el trabajo grupal adquiere gran relevancia para potenciar la adquisición de algunas competencias como la comunicación, trabajo en equipo, habilidades interpersonales, etc.

Adquiere interés para esta investigación, la propuesta didáctica hecha por (Gijón \& Crisol, 2012):

1. Es necesario diversificar las actividades de enseñanza y dar utilidad a los contenidos de la materia, para la adquisición de competencias generales y específicas.

2. Debemos conocer los conocimientos previos de los estudiantes y a partir de ahí construir aprendizajes significativos. El profesor además, debe esforzarse por presentar los contenidos en la forma más motivadora que conozca. 
3. Se debe partir desde lo particular a lo general, desde los datos cercanos y reconocibles por los alumnos, a las generalizaciones, permitiendo elaborar hipótesis, proponer alternativas y analizar conclusiones.

4. Hemos de favorecer el control del aprendizaje por el propio estudiante, el profesor debe ser el que le guíe. Por su parte, el alumno deberá desprenderse de la comodidad de tomar apuntes o estudiar fotocopias, y cambiar por procesos de lectura reflexiva, de búsqueda de información y de participación en los trabajos colaborativos.

5. Es esencial incorporar en la enseñanza y el aprendizaje el uso de la Tecnología de la Información y Comunicación (TIC) por su potencia didáctica.

6. Debemos darle la oportunidad a los alumnos de ejercitar y mejorar las competencias interpersonales. Los proyectos colaborativos, encuestas, entrevistas, grupos de discusión... pueden ser importantes en su formación. El esfuerzo compartido debe ser entonces, una autoexigencia para el estudiante.

7. Las actividades de evaluación deben servir para un seguimiento adecuado de la adquisición de competencias previstas. Sin que el nuevo modelo de evaluación implique el olvido de las pruebas más tradicionales, se debe ser coherente adecuándose al modelo de evaluación por competencias. 
La formación por competencias comprende conocimientos declarativos (saber), los conocimientos procedimentales (saber hacer) y los conocimientos condicionales (saber cuándo utilizar los otros dos saberes) (Lasnier, 2000). Cuando llegue el momento de saber hasta qué punto debemos profundizar en la teoría, lo que nos puede guiar será el nivel de desarrollo esperado de una competencia que debe utilizar los conocimientos teóricos para su desarrollo. Además, como el alumnado debe adquirir competencias procedimentales "saber actuar" complejos en diferentes situaciones, hay que encontrar un equilibrio entre conocimientos declarativos (teóricos), los procedimentales y las actitudes. Por lo tanto, la formación en competencias no puede centrarse en aprendizaje teórico (Legault, 2012).

El enfoque pedagógico por competencias permite una formación integral de los estudiantes.Por un lado, las competencias transversales van encaminadas a lograr en la educación superior una adecuada formación en valores democráticos y desarrollo humano. Por otro, las competencias específicas permiten adquirir conocimientos específicos y destrezas profesionales. Adquirir competencias a partir de una única materia es casi imposible, lo ideal es un desarrollo de competencias transdisciplinar. Este es el motivo por el que un buen plan de estudios se debería estructurar en varios módulos integrados, en vez de en asignaturas compartimentadas (López, 2011). 
El enfoque por competencias requiere una renovación en objetivos, contenidos del programa y metodologías docentes con la adopción de un papel activo, participativo y reflexivo del alumnado, y un rol de tutor o guía del docente que facilita y supervisa la adquisición de competencias de los estudiantes. Se trata de utilizar las metodologías que aseguren una participación lo más activa posible por parte de los alumnos (Palés \& Gual, 2004). En síntesis, es necesario un cambio en la enseñanza universitaria centrado en el aprendizaje y en los estudiantes (UNESCO, 1998 a; Declaración de Bolonia, 1999; Yániz, 2006).

Villa \& Poblete (2011) afirman que evaluar las competencias es quizás el más importante de los pasos del proceso de formación en competencias. La enseñanza centrada en el estudiante permite analizar de forma activa su propio aprendizaje a través de la auto-reflexión y un proceso de retroalimentación para corregir los aprendizajes erróneos. La competencia se debe evaluar de forma integral (conocimientos, actitudes y habilidades), para ello se pueden utilizar distintos instrumentos diferentes al examen de conocimientos teóricos tradicional. Los instrumentos que permiten recoger información para evaluar competencias son los portafolios, mapas conceptuales, los protocolos de observación, las entrevistas, autoevaluaciones, evaluación a pares, etc. La evaluación por competencias mide un 
grado de dominio del estudiante en esa competencia y orienta cómo va a aprender el alumno, si enfocará su esfuerzo a un aprendizaje superficial (memorístico) o de mayor profundidad (Marton \& Säljö, 1976, a y b). Los estudiantes siempre muestran interés por conocer los criterios de evaluación que se van a seguir, por eso es importante planificar la evaluación en función de las competencias que se quieran alcanzar.

De acuerdo con Barbeau, Montini, \& Roy (1997), el éxito académico es una responsabilidad compartida entre el estudiante y el profesor ya que éste último pone sus recursos y energía al servicio del estudiante, pero es el alumno el que decide hacer el esfuerzo necesario para su aprendizaje. Aprender es una tarea compleja y mantener la motivación de los estudiantes requiere profesores comprometidos en un proceso consciente y estructurado. Es necesario un cambio de actitud, así como una nueva forma de abordar el papel del profesor y de concebir la relación entre la enseñanza y el aprendizaje. El cambio de paradigma y de la práctica pedagógica no es fácil. Pone en tela de juicio algunas formas de actuar de la enseñanza tradicional en la universidad. La lección magistral ya no ocupa el lugar principal y la evaluación no se centra sólo en el saber adquirido (Legault, 2012). 


\subsection{Competencia "aprender a aprender"}

Los nuevos tiempos requieren nuevos aprendices y en la sociedad de la información, que queremos sea del conocimiento, hace falta desarrollar la competencia de "aprender a aprender". El estudiante debe aprender a desarrollar su autonomía y responsabilidad ante la sobreabundancia de la información (Gallardo, 2012). Para ello, tiene que ser un aprendiz estratégico en el que el aprendizaje autorregulado, es un proceso clave. El aprendizaje autorregulado supone un avance en la autodirección personal del estudiante y le permite transformar sus aptitudes mentales en competencias académicas (Zimmerman, 2001).

Exige a los estudiantes universitarios que reflexionen sobre su propia actividad de aprendizaje. La adquisición de esta competencia es importante en sí misma para los que defienden que el objetivo último de la formación universitaria es preparar a los estudiantes a aprender por ellos mismos (Pintrich, 2004; Ramsdem, Prosser, Trigwell, \& Martin, 2007).

Las habilidades de autodirección en las que se centra esta investigación son:

- Aprendizaje por iniciativa propia. 
- Aprendizaje de metas y seguimiento a los procesos de construcción de conocimiento.

- Capacidad de identificar las actividades que le resulten de mayor o menor interés.

- Capacidad de reconocer y controlar sus propias reacciones frente a retos y obstáculos que se les presentan.

- Capacidad de articular sus conocimientos, relacionarlos entre sí y con su vida diaria.

\subsection{1- Definición de términos}

El concepto de trabajo y aprendizaje autónomo ha sido objeto de un intenso análisis de la literatura de la enseñanza. Se le ha denominado con diferentes términos: aprendizaje autónomo, aprendizaje auto dirigido, aprendizaje autorregulado, aprendizaje estratégico y auto aprendizaje. Y se le ha relacionado con el desarrollo personal, la dirección hacia el interior de uno mismo, la autorrealización y la autonomía (De Miguel, 2006, pág. 77).

Por lo tanto, la autonomía implica una actitud activa por parte del estudiante hacia la adquisición de conocimientos, además de una serie de habilidades que le permitan dicha adquisición. La noción de autonomía se puede entender en el contexto del aprendizaje como un proceso de autorregulación. 
Autodirección o Auto aprendizaje, en su sentido más amplio, describe un proceso en el que los individuos toman la iniciativa, con o sin la ayuda de otros, en el diagnóstico de sus necesidades de aprendizaje, la formulación de objetivos de aprendizaje así como la identificación de recursos para el aprendizaje (Ramnarayan \& Hande, 2005).

El término Aprendizaje Autorregulado (AAR) o Self-Regulated Learning (SRL) en inglés, se refiere a la aplicación de modelos generales de regulación y autorregulación a áreas del aprendizaje que se realiza en las aulas (Pintrich, 2000).

Otra definición de autorregulación según (Claxton, 2001) parte de que en la sociedad del conocimiento el que aprende debe decidir cada vez más, cuándo y cómo debe evaluarse a sí mismo sobre lo que sabe y sobre lo que necesita conocer. Debe saber controlar su progreso, cuándo ha hecho un buen trabajo, conocer sus puntos fuertes y débiles para detectar sus necesidades de aprendizaje.

El aprendizaje autorregulado es proceso activo y constructivo mediante el cual, el alumno fija sus propias metas de aprendizaje, supervisa y controla su motivación, comportamiento y conocimientos al realizar una actividad o tarea en un contexto de aprendizaje (Pintrich 2004; Zimerman \& Schunk, 2008). 
El concepto de autorregulación tiene un papel importante en la vida contemporánea, puesto que se convierte en un patrón de habilidades de uso habitual en la universidad. La autorregulación en el contexto académico es un concepto complejo que Zimmerman \& Martínez (1990) lo definen como el grado en que el alumno tiene un papel activo en el proceso de su propio aprendizaje, e incluye varios elementos. El constructo de aprendizaje autorregulado es de naturaleza mixta e integradora, puesto que se interrelacionan variables cognitivas, motivacionales y contextuales (Boekaerts, 1996; Monereo, 2007; Pintrich, 2003).

\subsection{2-Elementos de la autorregulación del aprendizaje}

Entre los elementos que forman parte de la autorregulación se encuentran la cognición, la metacognición, la motivación, la conducta y el contexto (Dembo, Junge, \& Lynch, 2004; Pintrich, 2000; Zimmerman, 2000 ).

Como vemos en la figura 2 los elementos que integran el AAR son :

\section{- La cognición}

Los procesos cognitivos que hacen posible el aprendizaje incluyen la memoria, el razonamiento, la construcción del significado y la solución de problemas. Se relacionan con estrategias de aprendizaje: estrategias de ensayo como recitar o repetir la información, 
estrategias de elaboración como resumir o hacer esquemas, y estrategias organizativas creando estructuras como diagramas, matrices, jerarquías o secuencias.

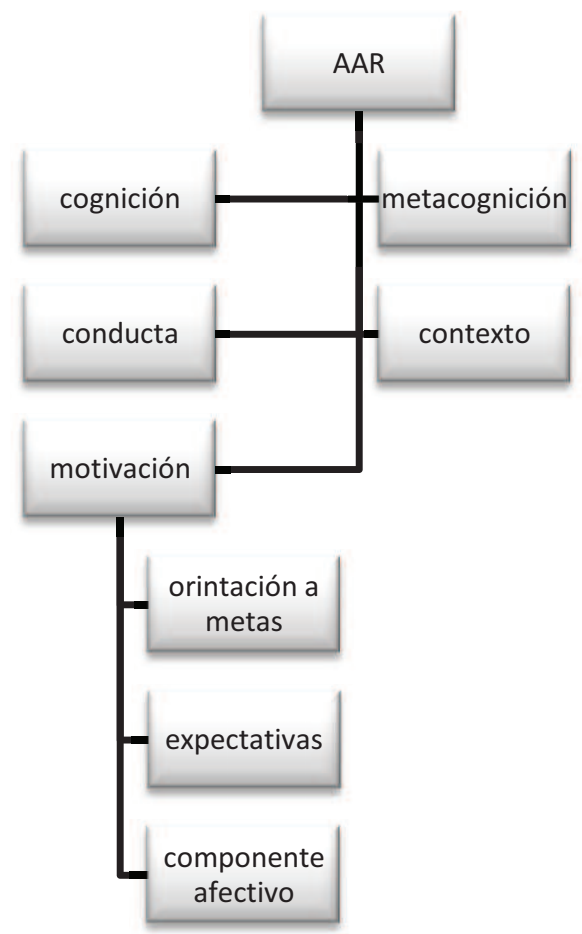

Fig 2.Elementos del Aprendizaje autorregulado.(Peñalosa,Landa\& Vega,2006)

\section{- La metacognición}

Es un término acuñado por John Flavell (1979), la metacognición consiste en ser consciente del proceso mental que se emplea para desarrollar una tarea y controlar lo que se hace, incluye actividades de planificación y evaluación propias. Es un pensamiento sobre el 
pensamiento y una reflexión sobre las acciones propias. Por medio de la metacognición, la persona se reconoce a sí misma como agente de su propio pensamiento, siendo consciente de las propias acciones de aprendizaje. Por ejemplo, después de leer un texto, el estudiante se pregunta sobre su comprensión preguntándose a sí mismo, y si no lo ha entendido bien, puede decidir volver a leerlo hasta contestar las preguntas autogeneradas. En este caso, ha empleado la estrategia metacognitiva de auto cuestionamiento. La metacognición incluye variables de persona (por ejemplo, ser consciente de que estudio mejor en la biblioteca), de tarea (por ejemplo, ser consciente de que me cuesta más leer un artículo científico que un periódico) y de estrategias metacognitivas como la planificación, monitorización y evaluación propias. Hay que diferenciar las estrategias cognitivas de las metacognitivas, las primeras ayudan al alumno a lograr una meta, como entender un texto y las estrategias metacognitivas aseguran que dicha meta ha sido cumplida, auto cuestionándose para evaluar la comprensión del texto. Ambas estrategias están interrrelacionadas y pueden solaparse.

\section{- La motivación}

En la literatura científica se hace referencia a los procesos de autorregulación como una de las principales contribuciones para aumentar la motivación y el aprendizaje académico (Rosário, Mourao, Trigo, Núñez, \& González-Pineda, 2005; Suárez, Fernández , \& Anaya, 2005; Torrano \& González Torres, 2004; Zimmerman \& 
Martínez-Pons, 1990; Zimmerman, 2000). La motivación es un factor esencial para el logro y el aprendizaje de los estudiantes (Pintrich \& Schunk, 2006). Existe evidencia de que los estudiantes con alto rendimiento académico, emplean más a menudo metas, que los estudiantes con bajo rendimiento. Las metas dirigen la atención, movilizan el esfuerzo, aumentan la persistencia y motivan el desarrollo de estrategias. Sin embargo las metas académicas requieren de tiempo para lograrse puediendo existir fluctuaciones en la motivación debido a los distintos estados emocionales y las actitudes. Por ello, la habilidad para utilizar estrategias y dirigir la motivación hacia la acción en dirección a la meta propuesta, es un aspecto central del aprendizaje autorregulado.

Las distintas estrategias para el manejo de la motivación como señalan Peñalosa, Landa, \& Vega, (2006):

1. La orientación a metas

En la medida que el estudiante selecciona y persigue metas, será capaz de progresar, obtener retroalimentación y autocontrolar su progreso en el aprendizaje (Dembo, Junge, \& Lynch, 2004). Para incrementar la motivación, las metas deben ser específicas, susceptibles a cumplirse a corto plazo, implicar cierto reto y ser autoimpuestas.

\section{Las expectativas}

En la medida de que el estudiante esté convencido que puede realizar una tarea, tendrá una mayor motivación para llevarla a cabo. Las 
expectativas incluyen las creencias sobre la habilidad propia para realizar las tareas (Pintrich \& De Groot, 1990).

3. El componente afectivo

El componente afectivo incluye las emociones ante la tarea. Efklides (2009) destaca la importancia de los sentimientos, estimaciones o juicios relativos a uno mismo, a las tareas de aprendizaje, a cómo tiene lugar el proceso cognitivo, así como a los resultados y todo esto tiene que ver con la motivación. Por ejemplo, un estudiante que revisa sus materiales para un examen, cuando tiene reacciones de ansiedad a las evaluaciones, tendrá menor motivación (Pintrich \& De Groot, 1990).

\section{- La conducta}

Es la actuación del estudiante al realizar la tarea por ejemplo, escribir metas, revisarlas, realizar los pasos para conseguir sus metas, supervisar si los pasos se realizaron adecuadamente, rectificar las metas si fuese necesario y ejecutar pasos consecuentes (Zimmerman, 2000). Los aprendices que autorregulan su proceso, actúan de manera proactiva en su esfuerzo por aprender; son conscientes de sus puntos fuertes y débiles y se guían por objetivos de aprendizaje y estrategias relacionadas con la tarea. Estos estudiantes monitorizan (supervisan y regulan) su aprendizaje en términos de logro y autodirección con el fin de aumentar su efectividad, así aumenta su satisfacción y motivación para mejorar el método de aprendizaje (Escribano \& del Valle, 2008). 


\section{- El contexto}

Es el ambiente en el que el estudiante aprende (Martínez, 2002) y señala la importancia del clima y las relaciones. Una comunicación fluida en el contexto académico, posibilita el diálogo positivo en la construcción del conocimiento y ayuda al alumnos a interiorizarlo y hacerlo suyo. De ahí, la importancia de que la actividad pedagógica se lleve a cabo en un ambiente acogedor, de cooperación y diálogo.

Zimmerman \& Martínez-Pons (1986), afirman que los estudiantes con mejor desempeño son proactivos al elegir el sitio en el que estudiarán y los pasos que realizarán para asegurarse de tener las mejores condiciones. También Dembo, Junge \& Lynch (2004), destacan la importancia de estructurar y reestructurar el ambiente de estudio para obtener mejores resultados académicos.

Siguiendo a Cázares (2009), el AAR puede ser observado a través del desarrollo de ciertos componentes como lo son:

- Planificación y ejecución de estrategias de aprendizaje. El individuo muestra un alto grado de razonamiento buscando las mejores alternativas y medios para alcanzar una meta determinada. Tiene claramente establecidos sus objetivos.

- Uso de la experiencia y conciencia crítica. Las personas que han desarrollado este componente toman en cuenta las experiencias vividas y cómo solucionaron los problemas 
anteriormente, sin embargo, también se apoya en las experiencias de los demás. Socialmente se desarrolla en armonía con sus semejantes y presenta un alto grado de justicia social.

- Potencial interno. Este componente es el más importante para el desarrollo de la autodirección, pues está basado en la personalidad del individuo, quien se muestra entusiasta por aprender habilidades, conocimientos de lo que le rodea. Le gusta sobresalir y por ello se esfuerza constantemente. Tiene la voluntad para aprender con el profesor, sin el profesor y a pesar del profesor. Busca y analiza información relevante para lograr su objetivo.

- Interdependencia social y tecnológica. Quienes desarrollan este componente saben participar en "procesos de interacción social" y se relaciona adecuadamente con sus semejantes, ya sea de forma virtual o presencial.

Los componentes descritos son de máximo interés para la presente investigación, porque el instrumento seleccionado, el cuestionario de perfil autodirigido CIPA de Cázares y Aceves (2007), incluye estos componentes y se medirán en los estudiantes de Grado en Enfermería.

Una persona auto dirigida, por lo general muestra una alta autoestima y como consecuencia el logro de sus objetivos. Este tipo de individuo 
sabe perfectamente qué es lo pretende conseguir, como hacerlo, analiza con cuidado lo irrelevante, lo bueno de lo malo, tiene presente los valores éticos, y sabe relacionarse adecuadamente con la gente que le rodea (Cázares, 2009).

Aunque el Aprendizaje Basado en Problemas (ABP) se describe como una estrategia educativa en la que los estudiantes son animados a tomar responsabilidades para su propio aprendizaje, se trata de un descubrimiento personal con diversas formas de ayuda social. Los objetivos del aprendizaje autorregulado en al ABP son de suma importancia, porque ABP facilita el desarrollo de las estrategias necesarias para comprometerse con un aprendizaje que dure toda la vida, es decir, para estar constantemente actualizados en los avances tecnológicos y científicos que suceden de forma rápida en el siglo XXI. El aprendizaje autorregulado se aprende y se desarrolla, por esto se habla de la competencia "aprender a aprender" y se puede enseñar por medio de la instrucción y la práctica repetida de experiencias diversas en diferentes contextos (Gallardo, 2012; García, 2012). La experiencia académica es la principal fuente de formación para conseguir una autorregulación en el aprendizaje (González Fernández,2001; Pozo, Monereo \& Castelló, 2005; Tesouro, 2005; Zimmerman, 2000; Zimmerman, Bonner \& Kovach, 1996).

En la medida en que todo el potencial regulador descanse en el polo docente, la situación de aprendizaje no desarrollará realmente la 
autonomía del alumno (Rué, 2008). Un deseo y una queja expresados habitualmente por los docentes es que desean alumnos más autónomos; la queja, es que no lo son. La intervención del profesorado interviniendo sobre las condiciones contextuales y apoyando actitudes favorables en los alumnos, puede favorecer la autonomía de los mismos.

Existe consenso entre diferentes autores en que se desarrolla mayor autonomía en el pensar y en el hacer cuando se piensa y se hace en el propio contexto o en el proceso formativo y no después o al margen de éste. Hay que tener en cuenta que no todos los contextos de aprendizaje favorecen la autonomía de los alumnos, no todas las personas pueden tener interés en ser autónomas y que, cualquier estrategia o actividad que favorece la autonomía no ejerce el mismo efecto en diferentes personas y en distintos contextos y situaciones de aprendizaje. Sin embargo, hay evidencias como el estudio de Kirk, Bélise, \& McAlphine (2003), en la Universidad McGuill de Canadá, que demuestran que ciertas situaciones prácticas como trabajar mediante proyectos o problemas, trabajar en equipos y leer por cuenta propia desarrollan la autonomía de los estudiantes. Para Kirk y su equipo, las condiciones favorecedoras de un aprendizaje autónomo son:

- Una fuerte actitud de compromiso o implicación en el esfuerzo de estudiar 
- Trabajo y reflexión personal como leer, informarse, sintetizar mediante escritura...

- Interacción social y socialización del conocimiento, así como evaluación interna y externa de sus elaboraciones: presentaciones, intercambio con los compañeros, etc.

En síntesis, la autonomía y el AAR, no son propiedad del alumno, sino que es un efecto generado a partir de las condiciones específicas de un contexto y unos objetivos de logro de un aprendizaje. Una de las condiciones específicas más importantes es el nivel de profundización del aprendizaje. La autonomía requiere actividades de mayor complejidad y proporciona un aprendizaje más profundo (Rué, 2008). El aprendizaje activo empleando ABP debería promover, como señalan Bereiter \& Scardamalia (1989), estrategias de AAR así como actitudes necesarias para el aprendizaje a lo largo de la vida(long life learning). Los objetivos de Aprendizaje Autorregulado son particularmente importantes porque el ABP facilita el desarrollo de estrategias para un aprendizaje que dure toda la vida.

\subsection{La innovación docente}

Para de la Torre (1994, pág 50) "la innovación curricular es un proceso de gestión de cambios específicos (en ideas, materiales o 
prácticas del currículo) hasta su consolidación con miras al crecimiento personal e institucional”.

La innovación aparece asociada a intentos concretos de cambio, de mejora de la práctica, siempre relacionada con contextos dados y centrada en los agentes directos de la enseñanza. Tiene que ver con cambios en los procesos educativos y sus contextos más inmediatos de funcionamiento, cambios más internos y cualitativos, cambios específicos en los elementos curriculares, orientado a la mejora y crecimiento personal. Se considera, por lo tanto necesario visualizar las relaciones entre los componentes propios de la innovación y los del contexto donde se va aplicar, en nuestro caso, en el contexto educativo: en el currículum.

Desde el marco conceptual de la Organización para la Cooperación y Desarrollo Económico (OCDE, 2000):

Por innovación o mejoramiento se entiende un plan deliberado para mejorar la escuela que tenga un claro inicio y un conjunto identificable de cambios que muevan la escuela hacia una organización de aprendizaje. Las innovaciones deberán conducir o tener el potencial para inducir mejorías significativas en la calidad de la educación, en sus costos o en la equidad de acceso. 
Esta definición de innovación implica en sí misma una mejora en la calidad y requiere una transformación o reforma. Los otros elementos importantes son el cambio deliberado y el plan como estrategia con inicio y fin explícitos, ambos elementos representan los criterios mínimos de casi todo proyecto curricular.

En términos generales, los diversos significados que se atribuyen a las innovaciones están directamente relacionados con la idea de cambio, ya sea de conducta, actitudes, aproximaciones, estrategias o incluso formas de pensamiento. El término del cambio, se asocia de manera directa con la implementación y requiere la ubicación del sentido o finalidad de para qué es el cambio, qué es y cómo funciona.

Los procesos de innovación educativa han de contemplar no sólo aquellos aspectos de investigación sobre nuevos procedimientos, metodologías o tecnologías, sino también, y especialmente, la asimilación de aquellos aspectos ya desarrollados, dominados y aplicados con éxito en otros campos de actividad, pero que constituyen una novedad en su aplicación en el contexto de los procesos de enseñanza-aprendizaje. Ejemplos de éxito en la puesta en práctica de un modelo educativo nuevo, fue la experiencia de más de diez años en la Universidad de Aalborg de Dinamarca (Moesby, 2008), una revisión de 30 años de experiencia ABP de la Universidad 
McMaster de Canadá (Branda, 2001), y de 15 años en la Universidad de Linkoning de Suecia, entre otros.

Cuando una institución, un departamento o una unidad docente, se enfrentan a la tarea de realizar un cambio hacia un estilo de aprendizaje orientado hacia $\mathrm{ABP}$ afrontan una serie de retos. La mayoría de las personas adoptan por naturaleza una actitud defensiva y escéptica ante el cambio. Para la puesta en práctica de un nuevo modelo educativo Trice y Beyer (1993) han estudiado el proceso de la implementación en las organizaciones y su conclusión es que "todas las fases de cualquier proceso de cambio conllevan al riesgo de la omisión, el abandono o el retroceso de una fase anterior". En esta afirmación se señala que es fácil que los procesos de cambio no funcionen y que, para crear un cambio que perdure es necesario adoptar nuevas ideas y ajustar la conducta a las mismas. La aceptación y el entusiasmo inicial son insuficientes para llevar adelante el cambio. Estos autores proponen un modelo de tres pasos:

1. Adopción

2. Implementación

3. Institucionalización

La adopción se relaciona con el proceso de decisión de realizar un cambio, la implementación abarca las actividades necesarias para introducir los cambios deseados y la institucionalización se produce 
cuando el proceso de cambio se encuentra en una fase estable y duradera. Anterior a estos tres pasos, la fase de investigación o de pre acción demuestra que el cambio puede partir de arriba-abajo o a la inversa (véase la figura 3), pero lo realmente importante es que exista una alianza entre los miembros de la dirección y los entusiastas de los niveles más bajos, para que ambas partes cuenten con apoyo mutuo y pueda producirse el cambio de forma dinámica. Hay que implicar a los directores académicos en el proceso desde el principio, para que se conviertan en agentes activos a favor del cambio.

Las palabras pueden decir muchas cosas de valor, pero ver que algo realmente puede funcionar es muy positivo, pues crea la confianza en que también puede funcionar en nuestra institución, y en que de hecho lo hará (Moesby, 2008). 


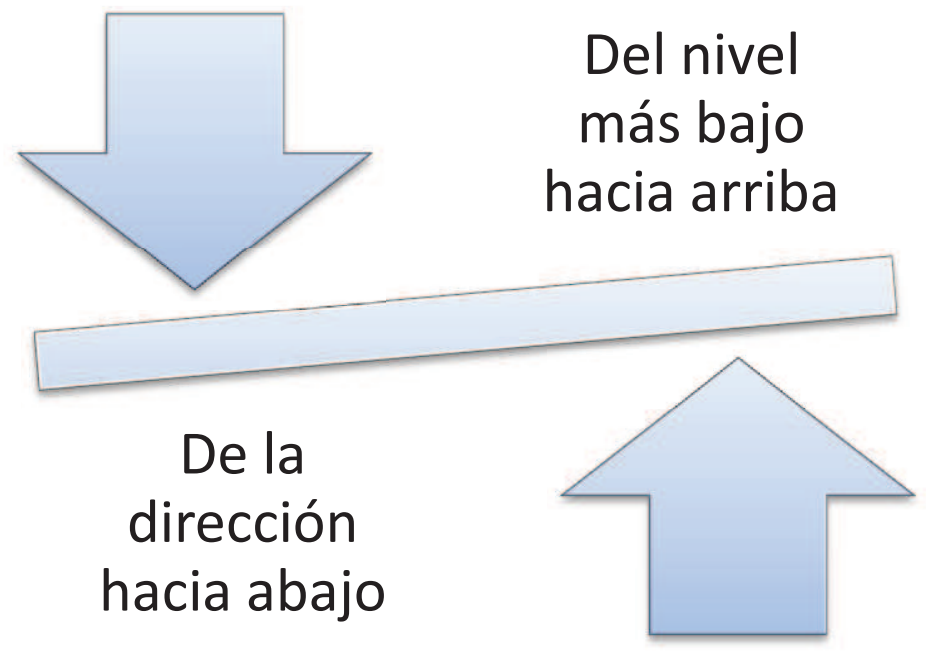

Figura 3. Inicio del cambio por parte de la dirección/desde niveles más bajos (Moesby, 2006)

\subsubsection{Resistencia al cambio}

El cambio educativo, por su propia naturaleza presenta una serie de problemas y dificultades que se utilizan bien para contrarrestarlo, descalificarlo u oponerse a él. Para Tejada (1998), las resistencias a la innovación educativa son las dificultades inherentes e ineludibles al mismo proceso de cambio y como tal hemos de asumirlo. Incluso, podríamos afirmar que la propia resistencia es una necesidad para el propio cambio, de forma que si no fuera así, este sería automático.

No puede existir un cambio exitoso en la organización si no existe un cambio en la conducta de sus miembros. Que el proceso de cambio siempre va acompañado de resistencia al mismo, es una realidad que 
se debe asumir. Todo cambio representa un estrés o un esfuerzo de adaptación y por esto las personas tienden a reaccionar con conductas defensivas ante situaciones que perciben como amenazantes.

El manejo de la resistencia al cambio incluye la eliminación del miedo a lo desconocido, que es lo que principalmente ocasiona la resistencia. Se tendrá que producir el cambio de manera que provoque el menor número de problemas y temores que sea posible. La transición resulta ser siempre difícil. ¿A qué se debe ese fenómeno general de resistencia al cambio? ¿Cómo superarlo? Estas preguntas adquieren relevancia en una época caracterizada por una aceleración del cambio en todos los dominios y sectores sociales.

Nuestra vida diaria se rige por una serie de costumbres, hábitos y modelos que afectan tanto a la forma de alimentarse y vestirse, como a la de trabajar y establecer relaciones con los demás. Un fenómeno de inercia y rigidez tiende a frenar el esfuerzo necesario para realizar una nueva adaptación. La conducta es el resultado de un aprendizaje y de una adaptación al medio físico o social. Todo lo que cambie lo habitual parece difícil o amenazador.

Las resistencias al cambio se pueden dar en el profesorado pero también en los alumnos. Todo cambio en la cultura del trabajo requiere tiempo, reflexión y autocrítica (Sola, 2006). Estar preparado para neutralizar la resistencia, es una de las tareas más importantes 
para propiciar que surja la creatividad y la innovación por tanto, es necesario que el cambio sea de forma voluntaria.

Como afirma Gairin (2006), pocas veces, el cambio cala realmente en los individuos a nivel de actitudes y conductas, $\mathrm{y}$ en las organizaciones a nivel de la cultura.

Las resistencias pueden manifestarse de forma inmediata: con quejas, amenazas, posición frontal... de forma implícita: pérdida de motivación, aumento en los errores, absentismo injustificado... o de forma diferida incluso semanas, meses y años después del proceso de cambio.

En este capítulo se justificó la innovación educativa que se propone usando $\mathrm{ABP}$ en la formación de estudiantes de enfermería, basándose en el marco legislativo y en la necesidad de una mejor calidad de la enseñanza. Se concluye que la formación en competencias no puede centrarse solo en el aprendizaje teórico, es necesario utilizar metodologías activas y una renovación de objetivos y de contenidos para cambiar la enseñanza universitaria centrándola en "el que aprende". 
CAPÍTULO 2 


\section{Enseñanza Superior en Enfermería}

Con el fin de mejorar la fluidez del texto y reflejar la preponderancia femenina en la profesión enfermera, se utilizará el término enfermera que engloba también el género masculino. De la misma forma, cuando se hace referencia a los términos profesor y alumno se integra el género femenino.

\subsection{Estudios de Enfermería}

En el capítulo anterior se remarcó la necesidad de una adaptación de la enseñanza a un contexto de un mundo globalizado y cambiante, también la enseñanza de Enfermería debe adaptarse a los cambios y a las nuevas responsabilidades profesionales que requieren mayor autonomía. El rol actual, exige de las enfermeras, utilizar estrategias para estimular las habilidades de pensamiento crítico y razonamiento clínico siendo el reto prioritario de la Educación Superior en Enfermería para el siglo XXI (Baker 2000; Bowles, 2000; Cossette, Mc Clish, \& Ostiguy, 2004; Williams, 2001).

La explosión de conocimientos en las Ciencias de la Salud, los nuevos campos de competencias como las tecnologías de la información y la bioética, hacen que los estudiantes deban asimilar un volumen cada vez mayor de conocimientos y esto favorece un aprendizaje superficial (Sefton, Gordon, \& Field, 2000). El momento actual de formación centrada en competencias, con una integración 
multidisciplinar de conocimientos, es una oportunidad para emplear metodologías activas que permitan proporcionan un aprendizaje más profundo, y el aprendizaje centrado en el discente.

El profesional sanitario del siglo XXI debe ser un profesional competente en aspectos conceptuales y personales necesarios para alcanzar un desempeño superior ante los desafíos que se plantean. Por esto, el perfil del profesional sanitario, formado en la universidad y posteriormente en los centros de trabajo de forma contínua, debe ser integral y constar de las competencias específicas y transversales (Martínez, 2008).

\subsubsection{Evolución}

Se describe la evolución de la Enfermería desde que se considera su profesionalización. Anteriormente, en la Edad Moderna tuvo lugar la incorporación de las mujeres laicas a los hospitales, con salario y horario y no se requería preparación. En la sociedad industrial hubo un fuerte desarrollo de la atención sanitaria; a las enfermeras se les comenzó a exigir algo más que buena voluntad (Matesanz, 2009). En Alemania, Theodor Friedner y su esposa, mostraron el interés de ofrecer una formación sistemática a enfermeras y fundaron la primera escuela en Kaiserswert en 1836, pero no puede hablarse de auténticas Escuelas de Enfermería, hasta que Florence Nightingale fundara en 1860 la Escuela de Enfermeras en el hospital Saint Thomas en 
Londres, donde se formaron enfermeras con un nuevo enfoque científico, transformando la enfermería inglesa e internacional (Ladios, 2005).

Florence Nightingale representa el fin de la actividad empírica y exclusivamente vocacional, se puede considerar que es la fundadora de la Enfermería moderna. Es ella la verdadera pionera de la profesionalización (Matesanz, 2009), iniciando las artes literarias de la disciplina, la organización de la profesión y la educación formal de las enfermeras. La Escuela Nightingale fue una escuela modelo, se trataba de hacer comprender a la sociedad que las profesionales de enfermería eran personas de ética, moralidad y preparación dignas. Sus aportaciones pueden considerarse a dos niveles (Young, Hortis, Chambi, \& Finn, 2011):

I. En el ámbito general de la disciplina enfermera:

- Inició la búsqueda de un cuerpo de conocimientos propio de la Enfermería

- Organizó las enseñanzas y la educación de la profesión.

- Inició la investigación enfermera y fue la primera en escribir sobre la disciplina.

II. Aportaciones asociadas:

- Inició la organización de la enfermería militar. 
- Fue la primera en utilizar la estadística, la epidemiología y los conceptos de higiene y saneamiento dentro de la enfermería.

Nightingale ha sido objeto de estudio como reformadora, como estadística, como administradora y como investigadora. Escribió más de 200 libros, informes y artículos, entre ellos "Notas sobre enfermería: qué es y qué no es" en 1859, el cual ha sido publicado en once idiomas y continúa utilizándose en la actualidad (Bishop \& Goldie, 1962; Museo Florence Nightingale, 2012; Nightingale, 1990). En él se mostraban los principios básicos de la Enfermería, la observación cuidadosa y sensibilidad hacia las necesidades de los pacientes que continúa resultando útil para demostrar las raíces de la profesión enfermera (Siles, 1999).Marcó un hito para la Enfermería e inscribió para todas las generaciones de enfermeras el concepto de "cuidar de uno mismo, del entorno y del paciente" a través de toda su obra (Young, Hortis, Chambi, \& Finn, 2011).

Las primeras emigraciones de "enfermeras Nightingale" a Australia, Canadá, India, Finlandia, Alemania, Suecia y Estados Unidos permitieron la creación de una red internacional de escuelas que aplicaban el sistema Nightingale (UNESCO, 1998 b).

En España en 1857, con la ley de Instrucción Pública conocida como Ley Moyano, se regularon los estudios para obtener la titulación de 
enfermeras, practicantes y matronas. Desde entonces, se les proporcionó el reconocimiento legal dando lugar a la institucionalización de los cuidados. Se sucedieron profundas transformaciones en los estudios, funciones y titulaciones de los profesionales de enfermería de forma paralela a los cambios sociales y culturales del momento. No obstante, tuvieron que transcurrir varios años para que se creara en Madrid en 1896, la primera escuela de enfermeras, "Santa Isabel de Hungría”, fundada por el médico Rubio y Gali. En el primer cuarto del siglo XX, aparecen nuevas y prestigiosas escuelas como las de la Cruz Roja Española, en Madrid y Barcelona, la Casa de la Salud Marqués de Valdecilla, en Santander, y Santa Madrona, en Barcelona. Las condiciones de ingreso en las Escuelas de Enfermería siguieron los mismos criterios que establecieron los precursores de la moderna enfermería en Europa: Nightingale y Kaiserswerth.

Las matronas, por su parte, tenían sus propias escuelas, vinculadas a hospitales maternales. El primer centro del que se tiene referencia en la formación de este personal es la Escuela de Matronas de la Casa de Salud Santa Cristina de Madrid. El ejercicio de las matronas empezó a regularse alrededor de 1888, quienes al igual que los practicantes, quedaron bajo jurisdicción médica y limitaron sus actividades a la atención de partos normales (Gómez, Hernández, \& Moral de Calatrava, 1999). Esta profesión era exclusivamente femenina, tenían 
asignadas funciones concretas, tanto en el ámbito hospitalario como extra hospitalario, que consistían en atender y asistir partos naturales, cuidar a la embarazada y al recién nacido y ayudar al ginecólogo en la asistencia a los embarazos y los partos (Fernández, Garrido, Tomás, \& Serrano, 2000; Hernández, 1996).

La ley de Instrucción General de 1904 habilitó a los practicantes, como profesión auxiliar de la medicina y para pequeñas intervenciones de cirugía menor, bajo la tutela de un médico. Fundamentalmente su labor se centraba en ayudar a los médicos en intervenciones quirúrgicas, aplicación de tratamientos prescritos por médicos, ponían inyecciones... (Domínguez, 1986; Hernández , 1996).

En 1915 se reconoció la actividad profesional de enfermeras. La creación de la titulación de Enfermera supuso tensiones y conflictos para el colectivo de practicantes, que lo vieron como un menoscabo a sus intereses. Los practicantes consideraban que las enfermeras incurrían en intrusismo y suponían un detrimento de las posibilidades laborales de los practicantes (Domínguez, 1986). Aunque los practicantes y enfermeras tenían funciones similares, su formación era diferente. Las enfermeras cursaban sus estudios en escuelas dependientes de hospitales, mientras que los practicantes en escuelas dependientes de las Facultades de Medicina. Hasta 1940, los estudios 
previos requeridos para estudiar Enfermería eran los de la escolaridad primaria, tanto para los practicantes como para las enfermeras (Fernández, Garrido, Tomás, \& Serrano, 2000 ;Hernández, 1996). El temario teórico-práctico era prácticamente el mismo: 70 temas para las enfermeras y 78 para los practicantes. Posiblemente, la diferencia de enfoque de los estudios de practicante y enfermera influía en la posterior elección de las áreas donde ejercían unos y otras. La actividad de las enfermeras se centraba en la atención hospitalaria y, aunque los practicantes también desarrollaban su actividad en los hospitales, su mayor actividad profesional se centraba en trabajo extra hospitalario y rural donde eran reconocidos.

El desarrollo de la profesión de enfermería en España fue lento, en 1931 después de 15 años desde la creación del Título Oficial de Enfermera, se exige nuevamente la unificación de los títulos de enfermera en todas las Facultades de Medicina en una orden ministerial de la República.

En 1936, durante la Guerra Civil Española, se interrumpe la formación de las enfermeras (Domínguez, 1986;Fernández, Garrido, Tomás, \& Serrano, 2000;Gómez, Hernández, \& Moral de Calatrava, 1999). La Guerra Civil Española aumentó la demanda de enfermeras, con la consecuente incorporación de cientos de mujeres a la práctica de la Enfermería. Fue la Cruz Roja y después la Falange Española, la 
encargada de realizar cursillos de enfermeras, creando el título Dama Enfermera Española (Domínguez, 1986). Tras la guerra civil, hay una vuelta a los valores tradicionales. La división sexual del trabajo y la profesión enfermera que se ocupa del cuidado siendo eminentemente femenina, comporta el carácter discriminatorio en base al género, por los imperativos ideológicos y sociales dominantes.

En la década de los 50, con el crecimiento económico y los avances de la ciencia, se inició en España un progresivo desarrollo hospitalario, por lo que se edificaron grandes hospitales con dotaciones tecnológicas avanzadas. Este hecho generó, la demanda de mayor número de profesionales, tanto médicos como enfermeras. En el caso de las enfermeras, debían ser profesionales capacitadas para realizar técnicas cada vez más complejas, capaces de enfrentarse a los retos de las nuevas tecnologías y permanecer en la fiel tradición de sumisión y obediencia al médico (Dominguez, Rodríguez, \& de Miguel, 1983;Fernández, Garrido, Tomás, \& Serrano, 2000; Hernández, 1996).

En 1952, se diseñó una reforma del plan de estudios, y con el Decreto del 4 de diciembre de 1953, se unificaron los estudios de las tres profesiones en una sola, denominada Ayudante Técnico Sanitario (ATS). La exigencia previa de estudios cursados se fijó en cuatro años de bachillerato (Bachillerato Elemental) y la duración de los estudios 
de ATS en tres. Se estableció un plan de estudios de obligado cumplimiento, con enseñanzas teóricas y prácticas, que debía ser seguido por todas las escuelas de ayudantes técnicos sanitarios. Esta reforma elevó el nivel formativo, aunque el profesional que se formaba era claramente un ayudante médico, como respuesta a las necesidades del momento y al tipo de atención sanitaria imperante.

Las escuelas de Ayudantes Técnicos Sanitarios surgieron como centros vinculados a las Facultades de Medicina, al amparo de la Ley de Ordenación Universitaria de 1943, vigente en aquel momento. La máxima autoridad académica en el centro docente era el catedrático inspector, designado por el decano de la Facultad de Medicina a la que estaba vinculada la escuela. La dirección correspondía a un médico y a una enfermera, asesorados ambos por una junta rectora. Durante algunos años (1952 - 1972) fue obligatorio para las alumnas de ATS estudiar en régimen de internado según la Orden del 2 de julio de 1955. Existió un estricto control de prácticas planificadas convenientemente por la escuela. A pesar del cambio, en cierto modo espectacular, de la disposición de los estudios en las escuelas de ATS femeninas, el planteamiento organizativo de las enseñanzas tuvo como marco de referencia los principios generados en Europa en el siglo XIX. En ellos se reflejan los requisitos de ingreso en las escuelas, la normativa para las internas $\mathrm{y}$, sobre todo, la importancia de la vocación de servicio en un sentido de entrega, abnegación y 
obediencia al superior. Entre 1972 y 1976 fue cuando se suprimió la obligatoriedad de internado, y se autorizó la enseñanza mixta (Dominguez, Rodríguez, \& de Miguel, 1983).

\subsubsection{Formación Universitaria en Enfermería}

\subsubsection{Diplomado Universitario en Enfermería}

La Enfermería ha estado en continua transformación pasando de ser una profesión subordinada al médico, con los anteriores Ayudantes Técnicos Sanitarios o ATS, a la incorporación en la enseñanza universitaria de los Diplomados en Enfermería, que permitió una mayor autonomía profesional, sin olvidar el fundamental trabajo en equipo multidisciplinar de las enfermeras.

Un momento crucial para el desarrollo de la Enfermería fue la incorporación de los estudios a la universidad en 1977. Este hecho permitió orientar la formación de forma radicalmente distinta dando lugar a que las enfermeras empezaran a construir un perfil profesional específico (Alberdi \& Cuxart, 2005).

Con el Real Decreto 2128/1977, se transformaron las escuelas de ATS en Escuelas Universitarias de Enfermería. Se denominan ahora, Diplomados Universitarios en Enfermería (DUE), esto supuso recuperar la denominación de enfermería (Garcia \& Calvo, 1992). 
La Enfermería, que debía implementar el diseño de los nuevos planes de estudio, fue una de las primeras disciplinas en España en incluir las recomendaciones de Alma-Ata en los contenidos formativos de los diplomados en Enfermería (Caja, 2011). La Conferencia Internacional sobre Atención Primaria de Salud de Alma-Ata, realizada en Kazajistán, del 6 al 12 de septiembre de 1978, fue el evento de política de salud internacional más importante de la década de los 70. La conferencia, fue organizada por la OMS y UNICEF. La síntesis de sus intenciones se expresa en la Declaración de Alma-Ata, subrayando la importancia de la atención primaria de salud como estrategia para alcanzar un mejor nivel de salud de los pueblos. Su lema fue "Salud para Todos en el año 2000" (Tejada, 2003). En ella, se declara e identifica la atención primaria de salud como (Declaración Alma-Ata, 2002):

La asistencia sanitaria esencial basada en métodos y tecnologías prácticos, científicamente fundados y socialmente aceptables, puesta al alcance de todos los individuos y familias de la comunidad mediante su plena participación y a un costo que la comunidad y el país puedan soportar, en todas y cada una de las etapas de su desarrollo con un espíritu de autorresponsabilidad y autodeterminación. La atención primaria forma parte integrante tanto del sistema nacional de salud, del que constituye la función central y el núcleo 
principal, como del desarrollo social y económico global de la comunidad. Representa el primer nivel de contacto de los individuos, la familia y la comunidad con el sistema nacional de salud, llevando lo más cerca posible la atención de salud al lugar donde residen y trabajan las personas, y constituye el primer elemento de un proceso permanente de asistencia sanitaria.

En la década de los 80 la Enfermería empieza a consolidarse como disciplina, desarrollando un cuerpo de conocimientos propio. La formación que había sido mayoritariamente práctica, da un giro en diseño del currículo, planteando un peso equitativo entre la formación teórica y práctica. Los diplomados en Enfermería, tienen que capacitarse para prestar cuidados integrales a las personas, realizar actividades de gestión, docencia e investigación propias de la disciplina enfermera. En estos momentos hay un reconocimiento claro, de la importancia de la prestación de cuidados a la hora de proporcionar atención sanitaria de calidad y a la vez, hay profundos obstáculos (conceptuales, estructurales y organizativos), respecto al reparto de poder y responsabilidad, que han dificultado y en ocasiones anulado dentro del sistema sanitario, la posibilidad de desarrollar la práctica enfermera en su totalidad prestando cuidados integrales (Alberdi \& Cuxart, 2005). 
Otra de las dificultades de las enfermeras ha sido, la imposibilidad del acceso a un tercer ciclo universitario (programas de doctorado). Quienes han continuado con estudios de tercer ciclo, los han realizado en disciplinas diferentes a la Enfermería, teniendo que obtener previamente un título de licenciado estudiando otra carrera de licenciatura.

Para las enfermeras, la reforma de la atención primaria supuso una gran oportunidad que permitió el desarrollo de nuevas perspectivas profesionales y la puesta en práctica de las nuevas directrices de los planes de estudio de Diplomados en Enfermería del año 1990 (Caja, 2011; Real Decreto 1466/1990).

Como novedades, se introdujo en el nuevo plan de estudios la materia Enfermería Comunitaria, así como materias básicas como Bioestadística, Epidemiología, Demografía y Ecología Humana, instrumentos imprescindibles para un desarrollo científico de la profesión. La Enfermería Comunitaria, se complementa con la realización de prácticas en la comunidad y en los nuevos Centros de Atención Primaria. También, se incluyó la materia de Enfermería Geriátrica, para dar respuesta las necesidades de una población cada vez más envejecida y con mayor esperanza de vida. 
La trayectoria profesional de la autora, iniciada en 1.986, se ha desarrollado siempre en Atención Primaria permitiendo vivir en primera persona los cambios y las resistencias mencionados anteriormente. Los profesionales de enfermería ahora, empiezan a trabajar en consultas de enfermería, abandonan las consultas médicas y realizan funciones propias y otras derivadas por los médicos. Su trabajo se integra en el Equipo de Atención Primaria siendo éste, un nuevo enfoque multidisciplinar de la atención en salud. Las enfermeras realizan actividades asistenciales, docentes, administrativas e investigadoras; además de la aplicación de técnicas de enfermería (inyectables, curas, extracciones de sangre, citologías...), desarrollan multitud de actividades preventivas, de control y seguimiento de enfermos crónicos, los programas de salud (programa de la mujer, del niño sano, del adulto, del anciano...) en los que priman las actividades de promoción y prevención de la salud a través de la educación para la salud, el trabajo comunitario, los protocolos consensuados...que le aportaron una mayor autonomía y eficiencia al trabajo enfermero. Este momento de transformación del rol enfermero, supuso un gran esfuerzo y una oportunidad para demostrar la necesidad del trabajo autónomo de los profesionales de enfermería, puesto que nuestra disciplina se centra en los cuidados y es una disciplina distinta y complementaria a la medicina. Supuso también, un cambio de mentalidad, primero en las enfermeras y después, en el resto de profesionales que trabajaban en el equipo de 
salud con nosotras. Se necesitó un reciclaje formativo de todos los profesionales de los equipos de Atención Primaria. En esta sociedad cambiante, aún más en la era digital del siglo XXI, son necesarios profesionales que sepan dirigir su propio aprendizaje a lo largo de toda la vida porque, los conocimientos han de actualizarse y no es posible obtener todo el aprendizaje necesario para el ejercicio profesional exclusivamente en la universidad. Se debería formar a estudiantes que sean reflexivos y críticos, trabajen en un equipo multidisciplinar sin perder la autonomía enfermera ,y que puedan asumir en un futuro profesional, las responsabilidades propias que requiere una disciplina científica como es la enfermería.

\subsubsection{Grado en Enfermería}

Como hemos visto anteriormente, si en estas tres décadas se produjeron importantes cambios en la formación y el perfil profesional de las enfermeras, la creación del Espacio Europeo de Educación Superior supone una oportunidad única para la mejora de la calidad de la enseñanza superior en toda Europa, abriendo otra nueva etapa para la formación en Enfermería. Es deseable que en los próximos años, la reforma de la enseñanza superior sirva para dar respuesta a la complejidad actual de los servicios de salud, que cada vez más, requieren profesionales de enfermería competentes para manejar informaciones complejas, utilizar las nuevas tecnologías, 
evaluar las intervenciones de cuidado y ayudar a los pacientes en las diferentes situaciones de salud (Martínez, 2007).

La construcción del Espacio Europeo de Educación Superior (EEES) se sitúa en el marco de las reformas educativas impulsadas por el proceso económico de globalización pilotado políticamente por diversas instancias internacionales como el Banco Mundial, la Organización Mundial del Comercio, la Organización para la Cooperación y el Desarrollo Económicos y la UNESCO.

En el Real Decreto 1393/2007, se establece la ordenación de las enseñanzas universitarias oficiales, los estudios quedan estructurados con el Grado (con un total de 240 créditos ECTS en cuatro años), el Máster (60 créditos ECTS) y el Doctorado (con 300 créditos cursados). El objetivo general del título de Grado en Enfermería pretende (ANECA, 2005, pág. 111):

Una formación de enfermeras generalistas con preparación científica y humana y capacitación suficientes para valorar, identificar, actuar y evaluar las necesidades de salud y de cuidados de las personas sanas o enfermas de las familias y la comunidad. Los fenómenos que conciernen particularmente a las enfermeras son las respuestas a problemas de salud reales o potenciales de las personas, familias o grupos. Estas respuestas 
humanas abarcan de forma genérica, desde las necesidades de salud, hasta la recuperación de la enfermedad. Así pues, la función de la enfermera al cuidar de las personas sanas o enfermas, es la de evaluar sus respuestas a su estado de salud y de ayudarlas a la realización de aquellas actividades que contribuyan a su salud o a su restablecimiento o a una muerte digna, ayudándoles si es posible, a recuperar lo más pronto posible su independencia. Dentro del entorno del sistema de salud, la enfermera comparte con otros profesionales sanitarios las funciones de planificación, organización, dirección y evaluación para garantizar un sistema de salud adecuado para el desarrollo de las potencialidades de las personas en distintas situaciones de su vida cotidiana, la promoción de la salud, la prevención de enfermedades y los cuidados de las personas enfermas o incapacitadas.

Actualmente la Enfermería se halla inmersa en un complejo proceso de re conceptualización de su propia disciplina, y se abre un abanico de posibilidades que deberán ir acompañadas inevitablemente de la asunción de desafíos. Es necesario fundamentar nuestras actuaciones en la Enfermería Basada en la Evidencia (Alonso, y otros, 2004), incrementar la investigación enfermera y el número de enfermeros y enfermeras doctores, aumentar el número de profesionales enfermeros en la gestión sanitaria, que contribuirá en un crecimiento científico de 
la Enfermería... para lo cual será necesario estar correctamente formados (Sancho \& Prieto, 2012).

Siguiendo la propuesta del Libro Blanco (ANECA, 2005) la formación de las enfermeras debe orientarse para que:

1. Adquieran conocimientos amplios de la ciencia enfermera, las ciencias de la salud, humanas y sociales y para dar respuesta a las necesidades y expectativas de las salud de las personas, familias, grupos y comunidad

2. Desarrollen habilidades para la aplicación de procedimientos de los cuidados enfermeros y guías clínicas

3. Desarrollen la capacidad de establecer relaciones positivas con las personas asignadas a su cuidado

4. Utilicen la metodología científica en sus intervenciones

5. Adquieran los instrumentos necesarios para desarrollar una actitud crítica y reflexiva

Las estrategias formativas propuestas para conseguir estos objetivos requieren:

- Un enfoque transdiciplinar con unos contenidos educativos que den respuesta a las necesidades de la formación universitaria en relación a cuestiones sociales, humanísticas, científicas y sanitarias, abarcando la complejidad de los problemas de salud. 
- Un currículum académico que incluya los métodos, procesos y contenidos propios de la disciplina enfermera.

- Atender las necesidades específicas de la disciplina respecto a habilidades para resolver las necesidades de salud de la población; adquisición de habilidades, actitudes y conocimientos durante las prácticas clínicas en hospitales y centros de Atención Primaria; y desarrollar habilidades de comunicación y educación para la salud.

- Reconocer la necesidad de adoptar un cambio de paradigma en el proceso enseñanza-aprendizaje centrado en el estudiante que requiere, métodos didácticos más activos y un mejor aprovechamiento de las tecnologías de la información y comunicación (TIC).

\subsection{Competencias de Grado en Enfermería}

Con el acuerdo del Proyecto Tunnig del proceso de Bolonia, se tiene que formar a los profesionales de enfermería en competencias (habilidades, actitudes y conocimientos) en vez de solamente en conocimientos. Se han definido tres tipos de competencias: las genéricas o transversales, las específicas y las curriculares. Las competencias genéricas o transversales que se exponen en la tabla 2 , engloban las competencias instrumentales (habilidades cognitivas, capacidades metodológicas, destrezas en lenguaje, manejo de recursos, tecnologías...), las interpersonales (habilidades individuales 
en expresión, crítica, destreza social, relación interpersonal, trabajo en equipo...) y las sistémicas (combinación de destrezas y habilidades en entendimiento, sensibilidad y conocimiento).

Las competencias específicas vienen descritas según la disciplina, es decir, las enfermeras tendrán que estar capacitadas para informar y educar al paciente y a la familia, planificar actuaciones, desarrollar el pensamiento crítico, establecer relaciones eficaces e identificar necesidades del paciente, manejar y adecuar la utilización de recursos, tomar decisiones, gestionar el tiempo y priorizar acciones, desarrollar la comunicación, trabajar en equipo y actuar para elevar el nivel de calidad. Las competencias curriculares se relacionan con las materias de la carrera para permitirle al alumno ser un profesional con capacidad ético/legal, para prestar y gestionar los cuidados y desarrollar la profesión.

Las competencias transversales o genéricas rebasan los límites de una disciplina para desarrollarse potencialmente en todas ellas. Son habilidades necesarias para ejercer eficazmente cualquier profesión pero no es frecuente que se consideren de forma explícita en una asignatura determinada, al menos en Ciencias de la Salud (Baños y Pérez, 2005). 
En la Orden CIN/2134/2008, de 3 de julio, las competencias que los estudiantes de Enfermería deben adquirir:

1. Ser capaz, en el ámbito de la enfermería, de prestar una atención sanitaria técnica y profesional adecuada a las necesidades de salud de las personas que atienden, de acuerdo con el estado de desarrollo de los conocimientos científicos de cada momento y con los niveles de calidad y seguridad que se establecen en las normas legales y deontológicas aplicables.

2. Planificar y prestar cuidados de enfermería dirigidos a las personas, familia o grupos, orientados a los resultados en salud evaluando su impacto, a través de guías de práctica clínica y asistencial, que describen los procesos por los cuales se diagnostica, trata o cuida un problema de salud.

3. Conocer y aplicar los fundamentos y principios teóricos y metodológicos de la enfermería.

4. Comprender el comportamiento interactivo de la persona en función del género, grupo o comunidad, dentro de su contexto social y multicultural.

5. Diseñar sistemas de cuidados dirigidos a las personas, familia o grupos, evaluando su impacto y estableciendo las modificaciones oportunas.

6. Basar las intervenciones de la enfermería en la evidencia científica y en los medios disponibles. 
7. Comprender sin prejuicios a las personas, considerando sus aspectos físicos, psicológicos y sociales, como individuos autónomos e independientes, asegurando el respeto a sus opiniones, creencias y valores, garantizando el derecho a la intimidad, a través de la confidencialidad y el secreto profesional.

8. Promover y respetar el derecho de participación, información, autonomía y el consentimiento informado en la toma de decisiones de las personas atendidas, acorde con la forma en que viven su proceso de salud -enfermedad.

9. Fomentar estilos de vida saludables, el auto cuidado, apoyando el mantenimiento de conductas preventivas y terapéuticas.

10. Proteger la salud y el bienestar de las personas, familia o grupos atendidos, garantizando su seguridad.

11. Establecer una comunicación eficaz con pacientes, familia, grupos sociales y compañeros y fomentar la educación para la salud.

12. Conocer el código ético y deontológico de la enfermería española, comprendiendo las implicaciones éticas de la salud en un contexto mundial en transformación.

13. Conocer los principios de financiación sanitaria y sociosanitaria y utilizar adecuadamente los recursos disponibles.

14. Establecer mecanismos de evaluación, considerando los aspectos científico-técnicos y los de calidad. 
15. Trabajar con el equipo de profesionales como unidad básica en la que se estructuran de forma uni o multidisciplinar e interdisciplinar los profesionales y demás personal de las organizaciones asistenciales.

16. Conocer los sistemas de información sanitaria.

17. Realizar los cuidados de enfermería basándose en la atención integral de salud, que supone la cooperación multiprofesional, la integración de los procesos y la continuidad asistencial.

18. Conocer las estrategias para adoptar medidas de confortabilidad y atención de síntomas, dirigidas al paciente y familia, en la aplicación de cuidados paliativos que contribuyan a aliviar la situación de enfermos avanzados y terminales.

\subsubsection{Competencias transversales propuestas en el Proyecto} Tunning sobre la convergencia EEES

\section{Instrumentales}

Capacidad de análisis y síntesis

Capacidad de organización y planificación

Conocimientos generales básicos

Conocimientos básicos de la profesión

Comunicación oral y escrita

Conocimiento de idiomas

Habilidades de gestión de la información

Resolución de problemas

Toma de decisiones 


\section{Interpersonales}

Capacidad crítica y autocrítica

Trabajo en equipo

Habilidades interpersonales

Trabajo en equipo interdisciplinario

Capacidad para comunicarse con expertos de otras áreas

Reconocimiento de la diversidad y multiculturalidad

Habilidad para trabajar en un contexto internacional

Compromiso ético

\section{Sistémicas}

Capacidad de aplicar los conocimientos en la práctica

Habilidades de investigación

Aprendizaje

Adaptación a nuevas situaciones

Capacidad para generar nuevas ideas (creatividad)

Liderazgo

Conocimiento de culturas y costumbres de otros países

Habilidad para trabajar de forma autónoma

Diseño y gestión de proyectos

Iniciativa y espíritu emprendedor

Motivación por la calidad

Motivación por la consecución de objetivos 
El Aprendizaje Basado en Problemas (ABP) es un método excelente para desarrollar estas competencias ( Cossette, Mc Clish, \& Ostiguy, 2004; Walton \& Matthews, 1989): instrumentales-cognitivas y metodológicas (capacidad de análisis y síntesis, resolución de problemas, toma de decisiones, capacidad de organización y planificación, gestión del tiempo, razonamiento crítico), instrumentales-tecnológicas y lingüísticas (búsqueda y análisis crítico de la información, comunicación oral y escrita), interpersonales (trabajo en equipo, habilidades interpersonales, liderazgo, compromiso ético) y sistémicas (capacidad para el aprendizaje autónomo, la adaptación a nuevas situaciones).

Partiendo del Proyecto Tuning, la Agencia Nacional de Evaluación de Calidad y Acreditación ha realizado el Libro Blanco de la titulación de Grado en Enfermería (ANECA, 2005), en el que sobre 2105 encuestas a profesionales asistenciales, directivos y profesores, se reflejan las competencias más importantes para formar a futuros profesionales de enfermería. 


\subsubsection{Competencias específicas del Libro Blanco Proyecto de la titulación de Enfermería (ANECA, 2005)}

\section{Competencias asociadas con valores profesionales y papel de la enfermera:}

- Capacidad para trabajar en un contexto profesional, ético y de códigos reguladores y legales, reconociendo y respondiendo a dilemas y temas éticos o morales en la práctica diaria.

- Capacidad para trabajar de una manera holística, tolerante, sin enjuiciamientos, cuidadosa y sensible, asegurando que los derechos, creencias y deseos de los diferentes individuos o grupos no se vean comprometidos.

- Capacidad para educar, facilitar, apoyar y animar la salud, el bienestar y el confort de las poblaciones, comunidades, grupos e individuos cuyas vidas están afectadas por la mala salud, sufrimiento, enfermedad, incapacidad o la muerte.

- Capacidad para reconocer los diversos roles, responsabilidades $\mathrm{y}$ funciones de una enfermera.

- Capacidad para ajustar su papel con el objeto de responder efectivamente a las necesidades de la población o los pacientes. Cuando sea necesario y apropiado, ser capaz de desafiar los sistemas vigentes para cubrir las necesidades de la población y los pacientes.

- Capacidad para aceptar la responsabilidad de su propio aprendizaje y desarrollo profesional, utilizando la evaluación 
como el medio para reflejar y mejorar su actuación y aumentar la calidad de los servicios prestados.

\section{Competencias asociadas con la práctica enfermera y la toma de decisiones clínicas}

- Capacidad para emprender valoraciones exhaustivas y sistemáticas utilizando las herramientas y marcos adecuados para el paciente, teniendo en cuenta los factores físicos, sociales, culturales, psicológicos, espirituales y ambientales relevantes.

- Capacidad para reconocer e interpretar signos normales o cambiantes de salud-mala salud, sufrimiento, incapacidad de la persona (valoración y diagnóstico).

- Capacidad para responder a las necesidades del paciente planificando, prestando servicios y evaluando los programas individualizados más apropiados de atención junto al paciente, sus cuidadores y familias y otros trabajadores sanitarios o sociales.

- Capacidad para cuestionar, evaluar, interpretar y sintetizar críticamente un abanico de información y fuentes de datos que faciliten la elección del paciente.

- Capacidad de hacer valer los juicios clínicos para asegurar que se alcanzan los estándares de calidad y que la práctica está basada en la evidencia 
Competencias en habilidades, intervenciones y actividades para proporcionar cuidados óptimos

- Capacidad para mantener la dignidad, privacidad y confidencialidad del paciente.

- Capacidad para poner en práctica principios de salud y seguridad, incluidos la movilización y manejo del paciente, control de infecciones, primeros auxilios básicos y procedimientos de emergencia.

- Capacidad para administrar con seguridad fármacos y otras terapias.

- Capacidad para considerar los cuidados emocionales, físicos y personales, incluyendo satisfacer las necesidades de confort, nutrición e higiene personal y permitir el mantenimiento de las actividades cotidianas.

\section{Competencias cognitivas}

- Conocimiento y capacidad para aplicar teorías de enfermería y práctica enfermera.

- Conocimiento y capacidad para aplicar ciencias básicas de la vida.

- Conocimiento y capacidad para aplicar ciencias sociales, del comportamiento y de la salud.

- Conocimiento y capacidad para aplicar, ética legislación y humanidades. 
- Conocimiento y capacidad para aplicar tecnología e informática a los cuidados de salud.

- Conocimiento y capacidad para aplicar política nacional e internacional.

- Conocimiento y capacidad para aplicar resolución de problemas y toma de decisiones.

- Conocimiento y capacidad para aplicar principios de investigación e información.

Competencias interpersonales y de comunicación (incluidas las tecnologías para la comunicación)

- Capacidad para una comunicación efectiva (incluyendo el uso de las tecnologías): con pacientes, familias y grupos sociales, incluidos aquellos con dificultades de comunicación.

- Capacidad para permitir que los pacientes y cuidadores expresen sus preocupaciones e intereses, y que puedan responder adecuadamente.

- Capacidad para representar adecuadamente la perspectiva del paciente y actuar para evitar abusos.

- Capacidad para usar adecuadamente las habilidades de consejo.

- Capacidad para identificar y tratar comportamientos desafiantes.

- Capacidad para reconocer la ansiedad, el estrés y la depresión. 
- Capacidad para dar apoyo emocional e identificar cuándo es necesario el consejo de un especialista.

- Capacidad para informar, registrar, documentar y derivar cuidados utilizando tecnologías adecuadas

\section{Competencias de liderazgo, gestión y trabajo en equipo}

- Capacidad para darse cuenta que el bienestar del paciente se alcanza a través de la combinación de recursos y acciones de los miembros del equipo socio-sanitario de cuidados.

- Capacidad para dirigir y coordinar un equipo, delegando cuidados adecuadamente.

- Capacidad para trabajar y comunicarse en colaboración y de forma efectiva con todo el personal de apoyo para priorizar y gestionar el tiempo eficientemente mientras se alcanzan los estándares de calidad.

- Capacidad para valorar el riesgo y promocionar activamente el bienestar y seguridad de toda la gente del entorno de trabajo (incluida/os ella/os misma/os).

- Utiliza críticamente las herramientas de evaluación y auditoria del cuidado según los estándares de calidad relevantes.

- Dentro del contexto clínico, capacidad para educar, facilitar, supervisar y apoyar a los estudiantes de cuidados de salud y trabajadores socio-sanitarios. 
- Es consciente de los principios de financiación de cuidados socio-sanitarios y usa los recursos eficientemente.

Para una mejor comprensión de la investigación realizada, se expone de forma breve el contexto educativo y el currículo en la que se implementó el Aprendizaje Basado en Problemas, siendo la autora la responsable de la asignatura.

\subsection{Programa de Grado en Enfermería por la} Universidad de Valladolid

El programa de Grado en Enfermería por la Universidad de Valladolid, con una carga lectiva de 240 créditos ECTS y una duración de cuatro años, está diseñado para que a lo largo de los cinco primeros semestres, los estudiantes adquieran las competencias que les permitan, de forma progresiva, ir fundamentando la disciplina enfermera $\mathrm{e}$ ir adquiriendo competencias que faciliten la toma de decisiones, la capacidad de utilizar el juicio crítico, la empatía y la responsabilidad. A lo largo de los tres semestres restantes, que completan los cuatro años de formación, los estudiantes deberán adquirir las competencias que permitan demostrar la adquisición de conocimientos (saber) y las habilidades para aplicarlos en el campo de la práctica (saber hacer), adquiriendo no solo habilidades sino también el compromiso ético y profesional (saber ser), que se demanda a una enfermera y que es imprescindible para incorporarse al 
mundo laboral dentro del área de la salud; la demostración definitiva de la consecución de todas las competencias, así como de la integración los conocimientos, deberá ser evaluada en la elaboración y defensa del proyecto fin de grado, que bajo la dirección y tutela del profesor o profesora que le haya sido asignado, deberá demostrar la capacitación del estudiante para recibir su título de Grado en Enfermería por la Universidad de Valladolid (UVA, 2012).

\subsubsection{Asignatura Salud Sexual y Reproductiva (SSR)}

En la asignatura Salud Sexual y Reproductiva se utilizó la estrategia metodológica ABP durante el curso 2011-2012, siendo el objeto de estudio de esta investigación. Forma parte de las asignaturas obligatorias de Grado en Enfermería, con una carga de 6 ECTS, se imparte en $2^{\circ}$ de Grado y pretende proporcionar el desarrollo de competencias para prestar los cuidados de enfermería necesarios para el mantenimiento de la salud sexual y reproductiva humana.

La metodología elegida para las prácticas de aula es el ABP, con un total de 10 horas presenciales de trabajo en grupos tutorizados. Las horas no presenciales de trabajo autónomo y grupal del estudiante corresponden a 90 horas conjuntamente para el ABP y el estudio de la asignatura. Además de ABP, se utilizan otras metodologías docentes dando prioridad al aprendizaje activo del estudiante; entre otras: sesiones expositivas, lectura de artículos, videos, talleres 
teórico-prácticos, discusión en aula y en los foros virtuales, búsqueda bibliográfica, trabajo colaborativo grupal y diferentes actividades en la plataforma digital de la Universidad de Valladolid (plataforma Moodle).

Tabla 1. Horas de dedicación del alumno.

Fuente: Guía docente de la asignatura Salud Sexual y Reproductiva de $2^{\circ}$ de Grado en Enfermería.UVA, 2011.

\begin{tabular}{|l|l|l|l|}
\hline $\begin{array}{l}\text { Actividades } \\
\text { presenciales }\end{array}$ & horas & $\begin{array}{c}\text { Actividades no } \\
\text { presenciales }\end{array}$ & h \\
\hline $\begin{array}{l}\text { Clases } \\
\text { práctica- } \\
\text { (T/M) }\end{array}$ & 45 & $\begin{array}{l}\text { Estudio y trabajo } \\
\text { autónomo individual }\end{array}$ & 50 \\
\hline $\begin{array}{l}\text { Clases } \\
\text { prácticas de } \\
\text { aula (A) }\end{array}$ & 10 & Estudio y trabajo grupal & 40 \\
\hline $\begin{array}{l}\text { Laboratorios } \\
\text { (L) }\end{array}$ & 4 & Total no presencial & \\
\hline Total \\
presencial
\end{tabular}

Se programó esta asignatura para utilizar una de las metodologías que propicia la formación basada en competencias como es el ABP, utilizada en los últimos años en la educación en Ciencias de la Salud, 
tanto en pregrado como en posgrado. En la tabla 2 se puede ver cómo el 50\% de la calificación final proviene de la evaluación del proceso ABP. La metodología ABP conlleva múltiples evaluaciones que se insertan dentro del propio proceso de aprendizaje, así los estudiantes son más conscientes de sus fortalezas y sus debilidades. Entre otros, se utiliza evaluación a pares, autoevaluación, evaluación a la tutora, evaluación de la comunicación oral, evaluación del trabajo de investigación $\mathrm{ABP}$ por escrito, manejo de la tecnología a través de presentaciones en formato PowerPoint y el uso de foros virtuales, seguimiento de la participación y del trabajo grupal a través de la observación, las tutorías y las intervenciones en los foros virtuales. Se trata de que los estudiantes integren conocimientos, habilidades, actitudes y valores, y que con ello logre ser competente en su futuro ejercicio profesional (Martínez, 2008).

En resumen, para conseguir los objetivos del currículum en esta asignatura, se utiliza una modalidad hibrida, con clases expositivas siguiendo una metodología tradicional y con prácticas de aula utilizando una metodología ABP. 
Tabla 2. Criterios de evaluación de la asignatura SSR

\begin{tabular}{|c|c|c|}
\hline Instrumento & NOTA & Observaciones \\
\hline $\begin{array}{l}\text { Entrega de un trabajo } \\
\text { escrito sobre un caso } \\
\text { clínico con } \\
\text { metodología ABP }\end{array}$ & $20 \%$ & $\begin{array}{l}\text { Se trata de un trabajo de indagación } \\
\text { sobre un caso clínico, el progreso } \\
\text { del trabajo de grupo, y la resolución } \\
\text { de problema planteado. Se tendrá en } \\
\text { cuenta la presentación, expresión } \\
\text { escrita y la bibliografía revisada. }\end{array}$ \\
\hline $\begin{array}{l}\text { Presentación oral del } \\
\text { trabajo realizado con } \\
\text { ABP }\end{array}$ & $20 \%$ & $\begin{array}{l}\text { A través observación y de rúbricas } \\
\text { se evalúa la expresión oral, la } \\
\text { comprensión, profundidad y la } \\
\text { creatividad en la exposición. }\end{array}$ \\
\hline $\begin{array}{l}\text { Participación y trabajo } \\
\text { grupal del estudiante } \\
\text { (tutorías y reuniones } \\
\text { grupales ): evaluación } \\
\text { ABP }\end{array}$ & $10 \%$ & $\begin{array}{l}\text { A través de la observación por la } \\
\text { tutora y la evaluación de los } \\
\text { compañeros del equipo, se evalúa la } \\
\text { participación y aportaciones de } \\
\text { cada alumno en el grupo, Desarrollo } \\
\text { de competencias de trabajo en } \\
\text { grupos colaborativos }\end{array}$ \\
\hline $\begin{array}{l}\text { Evaluación a través de } \\
\text { un test de } \\
\text { conocimientos }\end{array}$ & $50 \%$ & Examen escrito \\
\hline
\end{tabular}

Fuente: Elaboración propia. ${ }^{*}$ La valoración en la nota final proviene en un $50 \%$ del ABP y en el otro $50 \%$ del examen 


\section{CAPÍTULO 3}




\section{Aprendizaje Basado en Problemas}

\subsection{Teorías constructivistas del aprendizaje y ABP}

El sujeto entiende e interpreta el mundo con base en su experiencia y en el contexto en el que se desarrolla. La persona aprende durante toda la vida, algunas veces lo hace de manera consciente y otras de manera tácita. El aprendizaje es significativo cuando tiene alguna relevancia en la vida del sujeto y cuando éste puede relacionar los nuevos conocimientos con sus experiencias o conocimientos previos. El aprendizaje no sólo consiste en memorizar, sino también en entender, adaptar, asimilar y cómo, empleando ciertas técnicas y estrategias, éste se hace efectivo (Crispin, Esquivel, Loyola, \& Fregoso, 2011, pág. 10).

Los avances de las últimas décadas en las ciencias cognitivas han permitido elaborar el paradigma 'constructivista' del aprendizaje en el que la motivación personal para aprender desempeña un papel esencial. Según este paradigma constructivista, el aprendizaje es un fenómeno singular e individual, que puede verse facilitado por la interacción en grupo, pero no se aprende desde tabula rasa, es decir, desde el no saber nada, sino que se aprende a partir de lo que ya se sabe, se construye sobre las experiencias educativas previas. 
El paradigma constructivista del aprendizaje, requiere saber qué es lo que llamamos 'conocimiento' y su utilidad, cómo se organiza y reorganiza permanentemente el archivo mental que denominamos 'memoria', cómo se movilizan sus contenidos, cómo se construyen las 'rutinas' con sus ventajas y limitaciones, y finalmente, cómo se identifican $\mathrm{y}$ definen los problemas y las estrategias para solucionarlos (Prat, Palés, Nolla, Oriol, \& Gual, 2010).

Tipos de aprendizaje constructivista:

- Aprendizaje Cognoscitivo: es un conjunto de fenómenos dependientes del contexto y debe ser descrito en términos de las relaciones internas entre el individuo, la cultura y la situación en la que el individuo esté inmerso.

- Aprendizaje por Descubrimiento: el alumno es el constructor principal del aprendizaje. Aprender es contraponer hechos a conceptos y conceptos a hechos.

- Aprendizaje Contextualizado: promueve un aprendizaje basado en experiencias concretas (casos, problemas...) dentro de un contexto lo más realista posible.

- Aprendizaje de Solución de problemas: facilita el desarrollo de habilidades para la resolución de problemas, mediante el pensamiento crítico. 
Aprender es por tanto, un desarrollo de las capacidades personales y se produce de forma progresiva. Puede ser guiado y favorecido, o no, por los recursos y organización docente pero lo fundamental es que los estudiantes se guíen por la motivación, por su esfuerzo y perseverancia. Lo que el sujeto sabe y sabe hacer, depende del conocimiento y la comprensión, de las experiencias previas y si las situaciones son favorables, permiten acceder a un nuevo conocimiento. El conocimiento no es una copia de la realidad, sino un proceso de construcción activa del ser humano que implica necesariamente elaboración y reconstrucción personal de la realidad (Aznar, 1992; Carretero, 1993).

De las teorías constructivistas podemos extraer una serie de características fundamentales:

- El papel activo del sujeto en el proceso de aprendizaje: en el Constructivismo, el alumno no es un mero receptor pasivo de información, sino que el aprendizaje tiene lugar por medio de un proceso de construcción personal en el que él es el principal responsable.

- El aprendizaje se produce a través de un proceso en el cual se relacionan de manera significativa los conocimientos nuevos que el estudiante debe aprender con los que ya posee en su estructura cognitiva. 
- El aprendizaje no tiene lugar aisladamente, sino en un contexto socio-cultural determinado y a través de la interacción con los demás. De las aportaciones e influencias de ambos se nutrirá, posibilitando, facilitando y enriqueciendo el mismo.

Se parte de que el aprendizaje se dirige a todos los aspectos del ser humano. No sólo se aprenden conocimientos sino que se consideran fundamentales otros aspectos como las creencias, las intenciones o propósitos personales, las actitudes, las motivaciones y las expectativas del alumno.

La teoría de los estilos de aprendizaje establece que las personas poseen diferentes enfoques de aprendizaje y estudio, relacionados con el modo en que las personas prefieren usar sus capacidades y optan por unas determinadas estrategias, permitiendo explicar diferencias individuales en los logros que no pueden ser explicadas en función de otras variables. El uso exclusivo de ABP es una opción arriesgada puesto que los estudiantes tienen distintos enfoques de aprendizaje, lo más adecuado es utilizar distintos métodos para dar respuesta a las necesidades de todos (Milligan, 1999).

Los Estilos de Aprendizaje se pueden implementar desde los dos enfoques de enseñanza que actualmente coexisten en las aulas de las universidades: tradicional y el constructivista. 
Desde el enfoque tradicional, con clases magistrales, el proceso de enseñanza-aprendizaje se reduce a transmitir los conocimientos que forman parte de nuestra cultura (Bernando, 1991). La actividad en el aula se concreta básicamente en explicar los contenidos de una determinada y aislada disciplina, insistiendo en los contenidos conceptuales, definiendo correctamente su significado con el argumento lógico que justifica su inclusión en el currículum (Orlan, 1993). Esta perspectiva, que ha venido dominando y domina nuestros centros educativos, se realiza en un proceso unidireccional profesoralumno, cuyo objetivo final es la acumulación de contenidos curriculares en la mente de los alumnado. Los conocimientos, que se encuentran en el docente o en los libros de texto $\mathrm{y}$, a los que se les supone los valores de "verdad y fin en sí mismos", deben pasar al discente sin tener en cuenta otras consideraciones. El proceso se estructura en torno a una serie de lecciones o temas ordenados lógicamente desde el ámbito disciplinar y que el alumno debe asimilar con idéntica estructura. Por tanto, la acción principal desde este enfoque consiste en la explicación y/o exposición de los contenidos parcelados por núcleos temáticos. A continuación se dedican amplios espacios de tiempo a ejercicios de aplicación y de repetición de lo expuesto por el profesor para, posteriormente, mediante exámenes o controles, medir el nivel de adquisición y memorización. 
Siguiendo a Pozo (1999), en la enseñanza tradicional se considera al alumnado pasivo y receptor, se exponen los contenidos de forma verbal, clara, ordenada y lógicamente los contenidos curriculares se consideran un reflejo exacto de la realidad y se desarrollan por acumulación. La intencionalidad del docente se hace evidente en el esfuerzo en transmitir los conocimientos para que los comprendan. Requiere una competencia profesional en la que el profesor debe tener un conocimiento en profundidad de la disciplina que imparte. No existe compromiso mutuo entre docente y discente, no ya sobre los conocimientos que son relevantes para el segundo, sino sobre la misma acción de enseñar. Las únicas exigencias que se le hace al estudiante son que procure orden y acate la disciplina.

En contraposición, desde el enfoque constructivista, aprender es una actividad extremadamente compleja donde se ponen en juego un gran número de factores que dependen a la vez de las características personales del alumnado y del contexto del aprendizaje (Valle y Barca, 1993). Aprender es una actividad individual, nadie puede aprender por otro, y esencialmente personal, donde están implicadas todas las dimensiones de la personalidad desde las afectivas a las cognitivas pasando por las sensoriales, motrices, etc. El discente es el agente principal y central del aprendizaje. Utilizará las conductas y seleccionará las estrategias adecuadas para construir su conocimiento. Existe una gran variabilidad en la manera en que el alumnado se 
enfrenta a una tarea de aprendizaje ya que sus representaciones tienen un papel predominante en el grado de implicación y en las diversas maneras de poner en acción sus recursos. El proceso de enseñanzaaprendizaje contribuye a que cambie sus estructuras de conocimiento. Es por tanto, un enfoque que se desarrolla dentro de la fundamentación cognitiva del aprender (Pozo, 1999). Lo que los estudiantes piensan, sus ideas previas son el punto de partida de la enseñanza que hay que desarrollar para que, confrontándolas con el conocimiento deseable, se puedan modificar o cambiar para que puedan ser utilizadas en otros contextos. El docente se reconvierte en un investigador en el aula que formula hipótesis sobre los problemas pedagógicos que aparecen al hilo del proceso y toma decisiones preventivas para aminorarlos o solucionarlos. Las interacciones del profesor y alumno; y de los alumnos entre ellos, son igualmente valiosas. El trabajo cooperativo es conveniente para su desarrollo. Los debates, el diálogo, el clima de compromiso por ambas partes, así como la continua elaboración de materiales y la facilidad de acceso a recursos variados son algunos elementos esenciales de la enseñanza bajo este enfoque. Considerar las preguntas más que las respuestas es una manera de favorecer la autorreflexión y por tanto de autonomía de los alumnos. La intencionalidad de enseñar debe manifestarse en provocar conflictos cognitivos (Zabala, 1995), dinámicas creadoras que conduzcan a la superación de los desequilibrios y en construir estructuras mentales cada vez más ricas y complejas. 
Cuando la metodología se enmarca en una enseñanza expositiva, tener en cuenta los Estilos se convierte en una tarea añadida a la práctica habitual. Sin embargo, si la enseñanza se desarrolla de acuerdo con el enfoque constructivista, el desarrollo de los Estilos de Aprendizaje es un trabajo integrado en el quehacer docente (Martínez, 2008).

Hay estudios que consideran que los alumnos que siguen metodologías ABP tienen un estilo de aprendizaje más profundo, reflexivo, auto dirigido y versátil, en comparación con los que utilizan métodos tradicionales. El aprendizaje en profundidad corresponde a un tratamiento activo de la información utilizando estrategias de elaboración y organización en vez de las estrategias de memorización. Los estudiantes elaboran y organizan sus conocimientos para darle sentido a la información y tienen una fuerte implicación afectiva. En contraposición, el aprendizaje superficial se basa en la memorización y reproducción de los conocimientos, con pocas estrategias meta cognitivas (Larue \& Hrimech, 2009).

ABP favorece un aprendizaje profundo y transformador en los estudiantes, en los cuales el nivel de autonomía debe ser alto. En psicología del aprendizaje, se entiende como "enfoque profundo" aquella orientación adoptada por el estudiante que le llevará a tener un dominio de contenidos y procedimientos propuestos en los objetivos. Por el contrario, un "enfoque superficial" es la orientación en la que el estudiante es capaz de repetir, reconocer o aplicar la 
información recibida sin demostrar un dominio integrado y contextual de los conceptos (Rué, Font, \& Cebrián, 2011). Por tanto, un aprendizaje de calidad es un tipo de aprendizaje más profundo y complejo en el que no se pueden separar los contextos, los entornos de aprendizaje y las funciones gestionadas. Los estudiantes necesitan saber qué están haciendo, para qué y cómo y, dan importancia al hecho de autorregularse en el trabajo y los aprendizajes.

Diferentes estudios comparten las ventajas del ABP respecto al estilo de enseñanza tradicional (Aspegren, Blomqvist, \& Borgstrom, 1998; Cossette, Mc Clish, \& Ostiguy, 2004; Dochy, Segers, Van den Bossche, \& Gijbels, 2003; Duek, 2000; Hmelo, 1998; Morales-Mann \& Kaitell, 2001; Myers \& Horst, 2000 ; Savin-Baden, 2000; White, Amos, \& Kouzekanani, 1999). Según estas investigaciones, los estudiantes que aprenden a través de $\mathrm{ABP}$ tienen un mejor razonamiento clínico, son más hábiles para utilizar los conocimientos en tiempo real (integran), mantienen la motivación, utilizan estrategias para un aprendizaje en profundidad y estrategias meta cognitivas, en mayor proporción que los estudiantes que reciben enseñanza expositiva de forma tradicional.

Si bien puede existir una predisposición del estudiante hacia un determinado enfoque de aprendizaje, también es cierto que las percepciones del estudiante respecto al entorno de aprendizaje pueden 
modificarlo. Se consideran como factores claves para el aprendizaje: la calidad del profesorado, la claridad de los objetivos y qué se espera del alumnado, el tipo de evaluación, la carga de trabajo y el grado de libertad de los estudiantes en su aprendizaje (Gijbels, Van de Watering y Dochy, 2005; Lizzio, Wilson, y Simons, 2002; Nijhuis, Segers, y Gijselaers, 2008).

El docente es considerado punto clave en el proceso de aprendizaje, porque la función del docente no es solo transmitir conocimientos como tradicionalmente se decía, sino suscitar el aprendizaje para que el estudiante sea capaz de construir su propio conocimiento. El docente requiere poseer ciertas características que le permiten lograr resultados hacia la excelencia académica, es decir un desempeño docente de calidad.

\subsection{Aprendizaje Basado en Problemas}

Es una estrategia de enseñanza-aprendizaje en la que se da importancia tanto la adquisición de conocimientos como el desarrollo de habilidades y actitudes. En el ABP un grupo pequeño de alumnos se reúne, con la facilitación de un tutor o una tutora para analizar y resolver un problema seleccionado o diseñado especialmente para el logro de ciertos objetivos de aprendizaje (Porres, y otros, 2006).El objetivo prioritario del ABP no es la adquisición de conocimientos de la especialidad, sino un desarrollo integral del profesional en 
formación. El alumno es quién identifica objetivos, se compromete, descubre, desea conocer más y, así se retroalimenta el proceso y se estimula la capacidad de liderazgo, de comunicación y toma de decisiones, la creatividad, el pensamiento crítico y el trabajo en equipo.

Es un error concebir el Aprendizaje Basado en Problemas como una mera técnica docente, olvidando que se trata de un enfoque educativo en el que hay que adaptar el currículum haciendo los cambios necesarios (Bouhuijs, 2011). La propuesta educativa por tanto, exige cambios profundos de comprensión, organización e implementación.

En la investigación de López, González, \& Agudo (2007), se concluye que $\mathrm{ABP}$ es una herramienta que permite aprender además de los conocimientos teóricos, el desarrollo de competencias transversales muy importantes para los estudiantes en su vida académica y especialmente, en su futuro ejercicio profesional. El aula se convierte en un laboratorio de ensayo, puesto que los estudiantes deben resolver problemas clínicos reales. 


\subsubsection{Antecedentes}

Para una mejor comprensión sobre el ABP se describen los antecedentes. A finales de la década de los 60 y comienzos de los 70, un grupo de educadores médicos de la Universidad de McMaster (Canadá) detectaron que era necesario un replanteamiento de las formas de enseñanza de la Medicina para mejorar la preparación de los estudiantes y satisfacer las demandas de profesionales competentes. La primera promoción se graduó en 1972. En la década de los 70, las universidades de Maastricht (Holanda), Aalborg (Dinamarca) y Newcastle (Australia) aplicaron ABP en sus Facultades de Medicina. A la Universidad de Maastricht se la conoce en todo el mundo por su planteamiento educativo $\mathrm{ABP}$, del que es una institución pionera con treinta años de experiencia en este sistema. E1 planteamiento de implementar ABP suscitaba oposición y escepticismo al principio. Estudios comparativos de todas las universidades holandesas señalan que los estudiantes aprecian en alto grado la calidad de la enseñanza y de las instalaciones de la Universidad de Maastricht (Steenkamps, De Looper, \& Bliekendaal, 2006).

Posteriormente, en los años 80, en la Universidad de Nuevo México (Estados Unidos), Hawai, Harvard y Sherbrooke (Canadá) se extendió el uso de ABP, siendo en los últimos 30 años, utilizado en Facultades de Medicina del todo el mundo (Morales y Landa, 2004). 
En Latinoamérica varias facultades llevan aplicando ABP, Universidad de la Colima año 2005 (México), Instituto Tecnológico y de Estudios Superiores de Monterrey (ITESM) y en la Universidad Nacional Autónoma de México (UNAM), Universidad de Buenos Aires (2002), Universidad Católica de Lima (2003), Universidad San Simón de Cochabamba (Bolivia), Universidad del Valle (Cali) desde 2001, Universidad de la Frontera (Chile) desde 1999, Facultad de Medicina de Brasilia, entre otros (Escribano \& del Valle, 2008).

Debido a la convergencia del EEES, ABP se ha convertido en una estrategia activa de enseñanza-aprendizaje ampliamente utilizada en España (Esteban, 2008; Esteban \& Branda, 2008; Esteban, 2009; Molina, García, Pedraz, \& Antón, 2003; Planella, Escoda, \& Suñol, 2009). De entre las experiencias llevadas a cabo, se señalan las de la Facultad de Medicina de la Universidad de Castilla-La Mancha (Alonso, Sáez, \& Serrano, 2004), de la Escuela de Enfermería del Hospital Vall d'Hebron de la Universitat Autónoma de Barcelona (Quintanilla, Bernaus, Guillamet, \& Fernández, 2004), la Universidad Autónoma de Madrid, y la Escuela de Enfermería de la Universidad Europea de Madrid (López, González, \& Agudo, 2007).

Aunque ha sido en el área de la salud donde más se ha extendido el método, también se está aplicando con éxito en ciencias económicoadministrativas, ciencias sociales, entre otras. En la Enseñanza 
superior de Ottawa se ha establecido en veintitrés programas de casi todas las disciplinas, en la Delaware en las especialidades de Biología, Bioquímica, Nutrición, Ciencias de la Información; en Stamford en cinco áreas: Enfermería, Farmacia, Educación, Arte y Ciencias (Escribano \& del Valle, 2008).

\subsubsection{Concepto}

El Aprendizaje Basado en Problemas (ABP), Problem Based Learning (PBL) o Apprentissage par problèmes (APP) es un método de aprendizaje basado en el principio de usar problemas como punto de partida para la adquisición e integración de los nuevos conocimientos (Barrows, 1996; Larue \& Hrimech, 2009 ; Rué, Font, Cebrián, \& G, 2011). El ABP es una fórmula pedagógica para conseguir una participación activa del alumno. El aprendizaje está centrado en el estudiante, éste trabaja en grupos pequeños y adquiere conocimientos, habilidades y actitudes a través de situaciones o problemas de la vida real y donde los profesores son facilitadores o guías (Barrows, 1996). La finalidad es formar estudiantes capaces de analizar y enfrentarse a los problemas de la misma forma en que lo hará durante su actividad profesional, es decir, valorando e integrando el saber que los conducirá a la adquisición de competencias profesionales.

La característica más innovadora del $\mathrm{ABP}$ es el uso de problemas como punto de partida para la adquisición de conocimientos nuevos y 
la concepción del estudiante como protagonista de la gestión de su aprendizaje. Con ABP, se pretende que el estudiante construya su conocimiento sobre la base de problemas o situaciones de la vida real y que, además, lo haga con el mismo proceso de razonamiento que utilizará cuando sea profesional. Mientras que tradicionalmente primero se expone la información y posteriormente se intenta aplicarla en la resolución de un problema, en el ABP, primero se presenta el problema, después se identifican las necesidades de aprendizaje, se busca la información necesaria y finalmente se regresa al problema.

En el proceso de enseñar-aprender intervienen una amplia gama de funciones, entre otras: cerebrales, motoras, cognitivas, memorísticas, lingüísticas y prácticas, la asociación e interacción de estas es lo que permite llegar al nivel conceptual, nivel que posibilita la abstracción, los razonamientos y los juicios. Es a través de construcciones individuales como cada uno va realizando su propio edificio intelectual. 


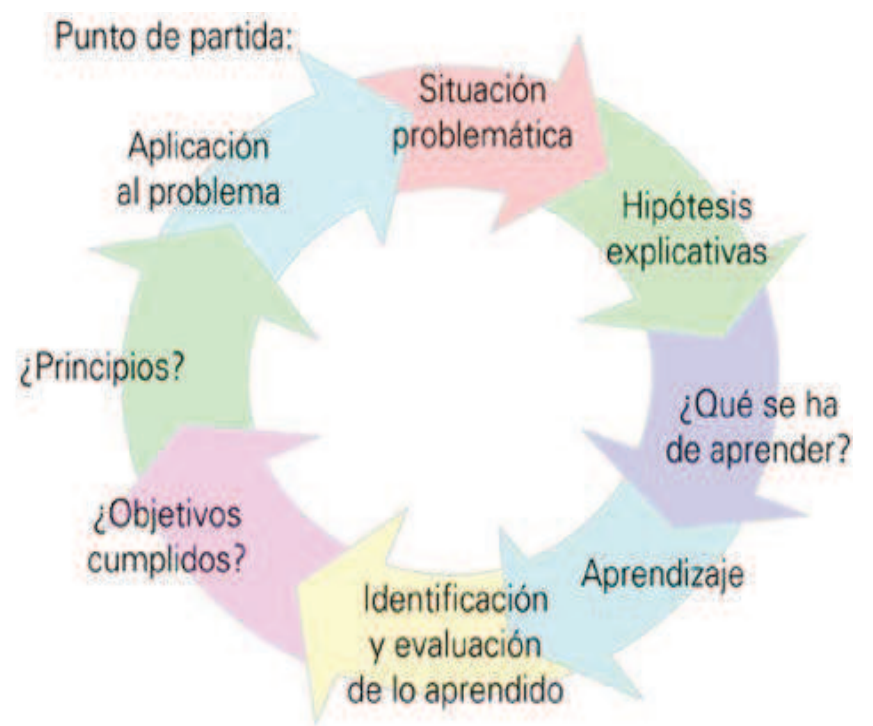

Figura 4.Ciclo de exploración de una situación problemática en el ABP. Fuente Branda (2001).

El ABP se fundamenta en el paradigma constructivista en el que conocer, y por analogía aprender, implica ante todo una experiencia de construcción interior, opuesta a una actividad intelectual receptiva y pasiva. De la descripción que hace Carretero (1993) del constructivismo, resaltamos los principios que nos hacen concebir el ABP dentro del mismo:

$\checkmark$ En el aprendizaje constructivo interno no basta con la presentación de la información a la persona para que aprenda, sino que es necesario que la construya o la aprenda mediante una experiencia externa. 
$\checkmark \quad$ El aprendizaje consiste en un proceso de reorganización interna. Desde que se recibe una información hasta que se asimila completamente, la persona pasa por fases en las que modifica sus sucesivos esquemas hasta que comprende plenamente dicha información.

$\checkmark$ La creación de contradicciones o conflictos cognitivos, mediante el planteamiento de problemas e hipótesis para su adecuado tratamiento en el proceso de enseñanza-aprendizaje, es una estrategia eficaz para lograr el aprendizaje.

$\checkmark$ El aprendizaje se favorece enormemente con la interacción social. La investigación de problemas concretos crea un terreno propicio para dicha interacción. Barrows ( 1996) señala que la meta primaria de la enseñanza basada en problemas es favorecer el razonamiento y las habilidades para la solución de problemas, con lo cual, seguramente, el resultado será una ampliación en la adquisición, retención y uso de los conocimientos.

Son muchas las definiciones que distintos autores han elaborado sobre el ABP, pero siguiendo a McGrath (2002) podemos definirlo como: "método de aprendizaje en grupo que usa problemas reales como estímulo para desarrollar habilidades de solución de problemas y adquirir conocimientos específicos". 
El ABP surge así, como un enfoque innovador que hunde sus raíces en el constructivismo (Harland, 2003) y en el que, a partir de un problema inicial, se desarrolla un trabajo creativo de búsqueda de soluciones o interpretación de la situación objeto de estudio. Esto se realiza, mayoritariamente, a través del trabajo en grupos tutorizados y del trabajo individual auto dirigido, con la finalidad de combinar la adquisición de conocimientos con el desarrollo de habilidades generales y actitudes útiles para el ámbito profesional.

En la figura 5 se presenta un mapa conceptual del desarrollo de ABP: el alumno es responsable de su aprendizaje; el tutor es un guía; se desarrollan competencias necesarias para su futuro profesional; los problemas son poco estructurados, generales, de solución abierta y se basan en el mundo real; y se trata de una metodología activa en la que los estudiantes planifican y gestionan los recursos necesarios para aprender, buscan la información necesaria para resolver el problema y necesitan hacer una síntesis de lo aprendido. 


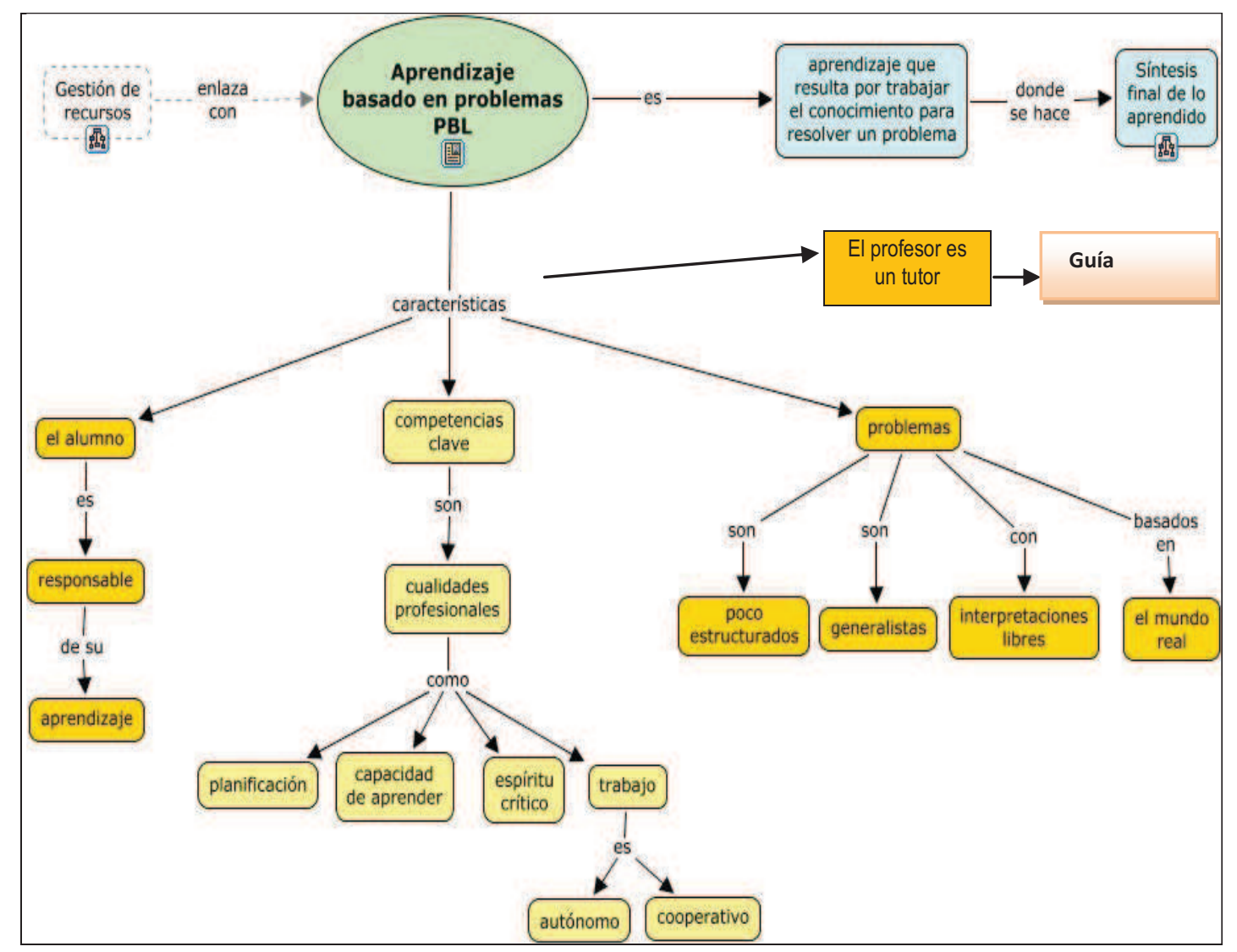

Figura 5.Desarrollo del Aprendizaje Basado en Problemas

Fuente: http://sinergiacreativa.wordpress.com/2008/04/27 


\subsubsection{Características del ABP}

En este enfoque, se plantea un problema inicial sin lecturas, conferencias o lecciones previas que sirve de estímulo, ya que muestra la necesidad de adquirir nuevos conocimientos.

El problema o caso clínico debe ser un problema complejo. Pero ¿qué es un problema complejo? en los problemas complejos las informaciones son incompletas, imprecisas y contradictorias. Un problema complejo obliga a tener en cuenta múltiples aspectos como son los biológicos, psicológicos, sociales, económicos, éticos, culturales, científicos, entre otros. Se puede enfocar desde diferentes puntos de vista teniendo en cuenta las opiniones o hipótesis generadas para lograr abordar el problema. Por tanto, no hay una solución única, siendo posibles diferentes soluciones según los criterios definidos, en base a la pertinencia de la información y los conocimientos actuales sobre la cuestión (Larue \& Hrimech, 2009).

A partir de aquí, el alumnado empieza a trabajar en grupos tutorizados, formados generalmente de modo aleatorio. La duración del trabajo en grupo y el número de reuniones varían según el programa, aunque habitualmente se suele seguir el siguiente esquema: en las primeras sesiones, se establecen las normas básicas sobre el funcionamiento del grupo, las expectativas de cada uno y del tutor, se puede entregar una guía de orientación para los estudiantes, y una vez 
realizada esta toma de contacto inicial, se trata de que los estudiantes comiencen a identificar y definir el problema, elaborar hipótesis y explorar los conocimientos previos que ya poseen sobre el tema para poder determinar cuáles deben ser adquiridos. Una vez seleccionados los temas objeto de aprendizaje, es preferible que los aspectos básicos sean estudiados por todos, y no divididos entre los miembros del grupo, se establece un tiempo de trabajo individual. Posteriormente, los miembros del grupo debaten, discuten, comparan y contrastan sus aprendizajes con los del resto. De este modo, aprenden unos de otros y se aplica la nueva información al problema, cambiando o reevaluando las hipótesis iniciales. Si fuese necesario, se plantean nuevos temas que pueden ser objeto de aprendizaje y si no, se sintetiza lo que se ha aprendido y se reflexiona sobre el progreso realizado tanto por el grupo, como por cada individuo (Mennin, Gordan, Majoor, y Osman, 2003).

El ABP es un método didáctico, que utiliza pedagogías activas como el aprendizaje por descubrimiento que se contrapone a la enseñanza expositiva magistral. Si en la estrategia expositiva el docente es el protagonista del proceso de enseñanza aprendizaje, en el aprendizaje basado en problemas es el estudiante quien dirige el proceso buscando información, seleccionando y organizándola para conseguir la resolución del problema planteado. El docente se transforma en un tutor, que guía al alumno en el aprendizaje, le 
sugiere fuentes de información y colabora con las necesidades del aprendiz (Restrepo, 2005). Los objetivos son el desarrollo de las habilidades de pensamiento, la activación de los procesos cognitivos y la transferencia de metodologías para "aprender a aprender".

$\mathrm{El} \mathrm{ABP}$ asume por tanto, que el aprendizaje es un proceso activo, integrado y constructivo, influido tanto por factores sociales como contextuales (Barrows, 1996).

Prieto (2006), defiende el enfoque de aprendizaje activo y señala que “el aprendizaje basado en problemas representa una estrategia eficaz y flexible que, a partir de lo que hacen los estudiantes, puede mejorar la calidad de su aprendizaje universitario en aspectos muy diversos".

Así, el ABP ayuda al alumno a desarrollar y a trabajar diversas competencias: la identificación de problemas relevantes del contexto profesional, la conciencia del propio aprendizaje, la planificación de las estrategias que se van a utilizar para aprender, el pensamiento crítico, el aprendizaje auto dirigido, las habilidades de evaluación y autoevaluación y el aprendizaje permanente, entre otras.

Además de enfatizar el aprendizaje a través de tareas, el ABP necesita que los alumnos mantengan un nivel meta cognitivo de consciencia 
(Gijselaers, 1996). Esto quiere decir que los alumnos deben aprender a tomar consciencia de:

a. La información que tienen acerca del problema.

b. La información que necesitan adquirir para resolverlo.

c. Las estrategias que han de emplear para ello.

Al ser capaces de articular tales ideas, los alumnos se vuelven más efectivos como solucionadores de problemas y aprendices auto dirigidos. Sin embargo, al principio muchos de estos alumnos no son capaces de practicar este proceso de razonamiento por su propia cuenta. Es por esta razón que el profesor se convierte en un tutor o "entrenador cognitivo" que modela las estrategias de investigación, guía las exploraciones, y ayuda a los alumnos a clarificar y profundizar en las preguntas de investigación (Arambula-Greenfield, 1996).

Flavell fue el primero en acuñar el término meta cognición a finales de 1970. Definió la meta cognición como "el conocimiento que tiene uno mismo acerca de su propio conocimiento o su propia forma de conocer, así como de controlar y monitorizar su propia cognición. El aprendiz que autorregula su proceso de aprendizaje, está desarrollando sus habilidades meta cognitivas y será consciente de cuándo ha adquirido un conocimiento o una habilidad y cuándo no" (Escribano y del Valle, 2008, pág. 60). Como se comentó en primer capítulo, la 
autorregulación es crucial en todas las fases del aprendizaje, incrementa el aprendizaje significativo y, las habilidades meta cognitivas deben trabajarse en y desde la acción; deberían ser desarrolladas de manera autónoma por los estudiantes.

El trabajo grupal es también un aspecto esencial del ABP por diversas razones. Primero, el trabajo grupal ayuda a desarrollar equipos de aprendizaje en los cuales los alumnos se sienten cómodos desarrollando nuevas ideas y planteando preguntas sobre las materias. Además, el trabajo grupal permite mejorar las habilidades comunicativas y la capacidad de manejo de la dinámica de grupos. Por último, resulta interesante y motivador para los alumnos pues ellos se involucran más activamente en la tarea y asumen una responsabilidad ante sus compañeros de grupo. Aprender a vivir juntos expresa una actitud que debe transmitirse también en las aulas, aunque no esté en los textos. Se trata de desarrollar la comprensión del otro y la percepción de las formas de interdependencia. Hay que aprender a desarrollar proyectos comunes, a abordar con rigor y respeto las discrepancias, y a fomentar los valores del pluralismo y la comprensión mutua, sin renunciar a las propias ideas (Michavilla \& Calvo, 1998).

De acuerdo con a Kneser \& Ploetzner (2001), se trata de una resolución de problemas colaborativa que implica un compromiso 
mutuo entre los participantes para resolver el problema de forma conjunta, no de una resolución cooperativa que se suele llevar a cabo dividiendo la tarea entre los componentes del grupo. El Aprendizaje Colaborativo en la resolución de problemas permite a los estudiantes ser consistentes con la teoría del constructivismo social. Esta teoría establece el aprendizaje mediado a través del lenguaje, el conocimiento como construcción social y la resolución de problemas como un proceso basado en la práctica social. La interacción colaborativa y la comunicación entre iguales se logran mejor en grupos pequeños en el que pueden darse el intercambio entre pares y la investigación colaborativa (Escribano y del Valle, 2008).

Los problemas bien diseñados y de final abierto que tienen soluciones múltiples y requieren de los alumnos que consideren varios métodos antes de decidirse por una solución específica (Shelton y Smith, 1998). Los problemas de estructura incompleta ayudan a aprender un conjunto de importantes conceptos, ideas y técnicas, pues provocan discusiones grupales y proveen a los alumnos de la experiencia de resolver problemas que también enfrentan los expertos en la materia. Los alumnos reconocen dichos problemas como relevantes desde el aspecto profesional, por ello se sienten motivados para trabajar en ello, no solo porque comprenden que los conocimientos que obtienen al pensar en estos problemas les serán útiles en un futuro, sino 
también porque reciben oportunidades significativas para desplegar su creatividad, así como flexibilidad en la resolución de problemas ABP.

El ABP no es una simple aplicación metodológica que pueda utilizarse en las aulas sin realizar cambios estructurales, como son los cambios organizativos y culturales (Bouhuijs, 2011). La metodología ABP requiere un cambio de actitud en el profesorado, demanda al profesor una serie de documentos que debe preparar con antelación antes del comienzo del curso. Es necesario elaborar la programación didáctica de la materia o asignatura donde se especifiquen los objetivos generales y específicos, temas, actividades, metodología, instrumentos de evaluación, bibliografía... La documentación básica que se debe elaborar es la guía tutorial y el escenario (texto, video, caso clínico, artículo...). El factor clave para llevar a cabo esta reforma con éxito es el profesorado universitario. La formación de los docentes universitarios y su actitud ante la reforma son fundamentales a la hora de afrontar este cambio. Es importante trabajar las actitudes de profesores ante las innovaciones y la resistencia al cambio. Se deberían estudiar los incentivos que se pretenden aplicar en la carrera docente para conseguir la máxima implicación del profesorado. Se ha constatado que las actitudes del profesorado cambian a medida que se implican en dichos proyectos y esto tiene una repercusión positiva sobre su práctica docente y por tanto, sobre el aprendizaje de sus alumnos (Ruiz \& Martin, 2005). 
Los procesos de enseñanza-aprendizaje son intencionales, expresamente creados y planificados; no son espontáneos, naturales, sino pretendidos y provocados (Contreras, 1990). La innovación docente empleando ABP requiere diversos compromisos que implican a los profesores y los órganos responsables de un centro universitario, aunque existen experiencias de inferior nivel que también han funcionado. Si pensar significa operar, el problema didáctico consiste en concebir una situación que va a poner en acción mental al alumno (Berbaum, 2000).

La implantación institucional del ABP puede crear fuertes resistencias, especialmente cuando es utilizado como único método de aprendizaje o de forma predominante por lo que se puede utilizar como método docente complementario con las clases magistrales, lo que también permite alcanzar muchos de los objetivos propuestos con un número de resistencias menor (Baños, 2001).

\subsubsection{Fases del proceso}

La secuencia metodológica que sigue el proceso de aprendizaje convencional se invierte al trabajar en el ABP. Mientras tradicionalmente primero se expone la información y posteriormente se busca su aplicación en la resolución de un problema, en el caso del ABP primero se presenta el problema, se identifican las necesidades 
de aprendizaje, se busca la información necesaria y finalmente se regresa al problema (Bernabeu \& Cónsul, 2004).

En el ABP durante el recorrido que viven los alumnos desde el planteamiento original del problema hasta su solución se trabaja de manera colaborativa en pequeños grupos, compartiendo en esa experiencia de aprendizaje la posibilidad de practicar y desarrollar habilidades, y de observar y reflexionar sobre actitudes y valores que en el método convencional expositivo difícilmente podrían ponerse en acción. En estas actividades grupales los alumnos adquieren responsabilidades y realizan acciones que son básicas en su proceso formativo. Dentro del proceso de trabajo del ABP los alumnos tienen la responsabilidad de participar activamente en las discusiones del grupo, deben estar dispuestos a dar y aceptar crítica constructiva, admitir las deficiencias de conocimiento en donde se presenten y estudiar de manera independiente para poder contribuir al esfuerzo grupal. El alumno también tiene la responsabilidad de ser honesto al evaluar las actividades de todos los miembros del equipo, incluyendo las del tutor y las propias.

El cambio de un currículo tradicional a un enfoque de ABP puede parecer inicialmente arriesgado e incierto, de modo que si para los estudiantes el trabajo con esta metodología es una novedad es 
esencial una buena planificación de todas las tareas del proceso, siendo muy recomendable: buscar asuntos de interés para los alumnos, propiciar un escenario común donde se discutan sus hipótesis, dar tiempo y motivación para investigar y para mostrar sus puntos de vista, evitar dar mucha información o realizar una simplificación extrema del problema y apoyar al grupo en la determinación de los diferentes roles.

El esquema básico de la metodología ABP consiste en el planteamiento de un problema o situación (normalmente definido por el docente y en ocasiones definido por los estudiantes) a través del cual se solicita de los estudiantes que, en grupos de trabajo, aborden de forma ordenada y desde un trabajo coordinado las diferentes fases que implica la resolución o desarrollo del trabajo en torno al problema o situación.

Una parte de la técnica didáctica es el tránsito que el alumno debe hacer por una serie de etapas.ABP es definido por numerosos autores como un método pedagógico estructurado por etapas en las que se incluye trabajo autónomo y trabajo grupal a partir de problemas significativos, interdisciplinarios inspirados en los contextos de la realidad profesional (Barrows \& Tamblyn, 1980; Cossette, Mc Clish, \& Ostiguy, 2004; Des Marchais, 1996; Evensen, 2000 ; Dochy, Segers, Van den Bossche, \& Gijbels, 2003 ;Savin-Baden, 2000). 
Aunque existe gran variedad y modalidades de aplicación de ABP con diferentes secuencias, en esta investigación se seguirán los llamados "siete pasos" de ABP de la figura 6.

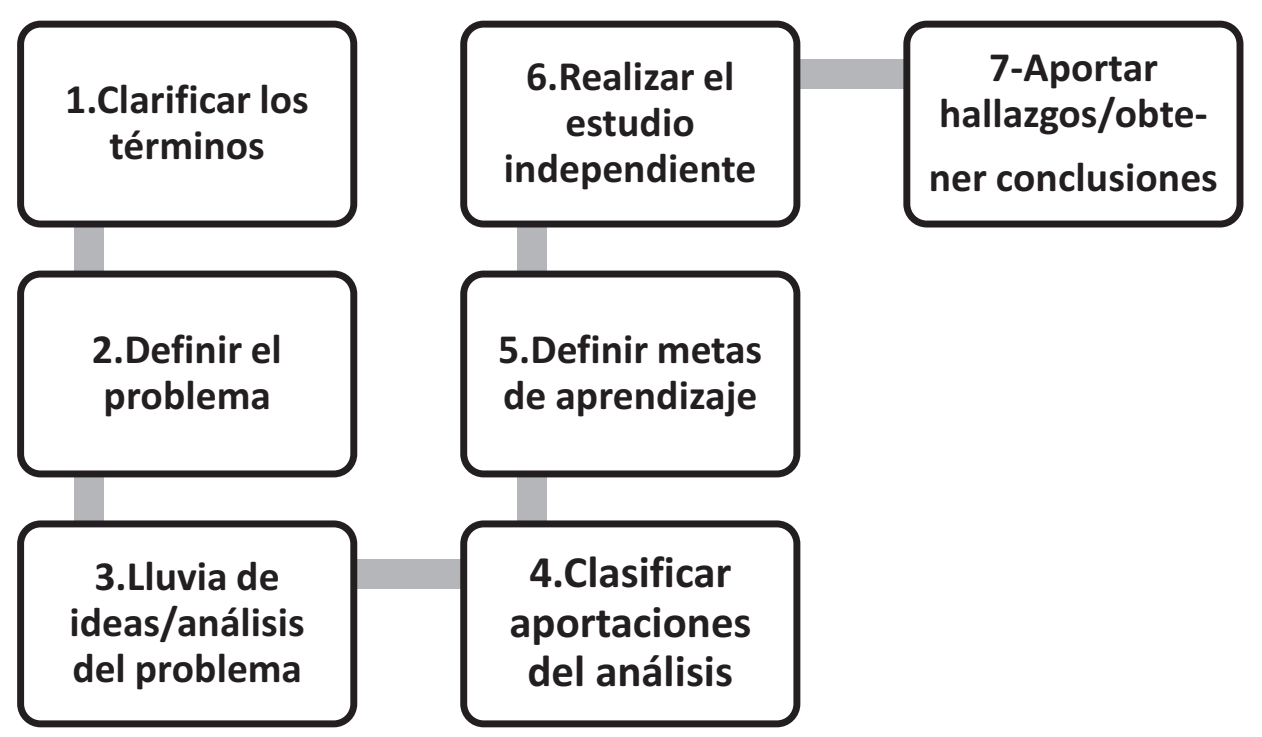

Figura 6. Fases del proceso ABP (Schmidt ,1989)

1. Presentación y lectura comprensiva: Si se trata de un caso clínico, un artículo o un video didáctico, el grupo de alumnos debe hacer una lectura comprensiva o visualización del video, para hacer una puesta en común y comprobar que todos los componentes del grupo entienden lo mismo. Se seleccionarán las ideas principales y conceptos clave.

2. Definición del problema: Dependiendo de lo complejo que sea el escenario-problema, los alumnos deben de definir y redefinir el 
problema principal. Puede que a lo largo del proceso el problema detectado al inicio cambie, por lo que será un proceso dinámico y circular.

3. Lluvia de ideas: Identificado el problema, los alumnos deben pensar en qué conocen sobre ello y qué hay que conocer sobre el problema partiendo de lo que se sabe y no se sabe. Se utiliza la técnica de lluvia de ideas (de Prado, 1982). Surgirán hipótesis que después habrá que confirmar mediante investigación

4. Clasificación de las ideas: Hay que poner orden al registro de las ideas del paso anterior. Se puede hacer una jerarquía según la importancia y las relaciones entre las ideas, el resultado de este proceso refleja normalmente la estructura formal de la investigación.

5. Formulación de objetivos de aprendizaje: Es uno de los momentos más importantes del ABP ya que su actividad debe ser guiada por unos objetivos. Se han de redactar en infinitivo y guiarán la acción- investigación.

6. Investigación: Los grupos de alumnos ya pueden empezar a buscar información, deben indagar, hacer lectura comprensiva, buscar en bibliotecas o internet y finalmente hacer una interpretación correcta del material acopiado. Por esto deben diseñar un plan de acción con un cronograma de trabajo.

7. Presentación y discusión de los resultados: Deben presentar el trabajo realizado según el formato que solicite el tutor, o bien por decisión propia el que hayan elegido. Hay que tener en cuenta que 
deben cuidar el continente y el contenido. Si se trata de un trabajo escrito se tendrá en cuenta la presentación formal como la elaboración de un índice, expresión, paginación del documento, bibliografía y que no tenga faltas de ortografía. La presentación oral también debería ser cuidadosa utilizando estrategias para que resulte eficaz y comprensivo el trabajo que presenten los alumnos.

Se trata de una metodología donde, dependiendo del nivel y preparación del estudiante, del carácter del problema o trabajo planteado, del tiempo y recursos disponibles, la autonomía y tutorización de los grupos de trabajo será mayor o menor. Por otra parte, dicha forma de trabajo no sólo trata de abordar objetivos relativos al conocimiento o dominio de una asignatura o determinada área de conocimientos sino también, el desarrollo de habilidades y competencias relativas a la capacidad de trabajar en equipo, de búsqueda y validación de información, de habilidades comunicativas, entre otras.

Un paso adicional, es que los estudiantes puedan identificar y relacionar los conocimientos adquiridos, consiguiendo un aprendizaje integrador que se puede aplicar a otras situaciones o problemas (Branda, 2009). 
El ABP incide en tres dimensiones: facilita la motivación al presentar situaciones-problema que los estudiantes exploran a través de un conflicto cognitivo; activa el aprendizaje a través de las interacciones entre estudiantes y alumnos-tutor; y se crea un mecanismo de retroalimentación contínuo por parte del docente en tutorías o sesiones evaluativas (Rué, Font, \& Cebrián, 2011).

\subsubsection{Roles}

\subsubsection{Rol del docente}

En primer lugar, siguiendo la propuesta de Cano (2008), si la atención se focaliza en el aprendizaje más que en la enseñanza con un rol activo por parte del alumno, los profesores deben:

- Revisar el modo en que entienden su función docente.

- Pasar de transmisores de contenidos a facilitadores de oportunidades de crecimiento.

- Pensar tanto en el "qué" quieren que aprendan los alumnos como en el "cómo" creen que pueden aprenderlo (y, por supuesto, en el "para qué").

- Reducir sesiones presenciales dedicadas al conocimiento conceptual sobre el que tradicionalmente pivotaban muchas asignaturas para buscar vías de apropiación del mismo a partir de trabajo autónomo (permitiendo así que las sesiones 
presenciales se dediquen al aprendizaje cooperativo, al debate, a la construcción de conocimiento).

- El hecho de aprender por competencias lleva implícito un cambio en el proceso de enseñanza-aprendizaje, tratando de impulsar un aprendizaje activo por parte del alumno, orientado a desarrollar habilidades, destrezas, actitudes y conocimientos que le permita desenvolverse en cualquier situación. Al propiciar un cambio en el papel activo del alumno, cambia el rol del docente que pasa de transmisor de contenidos a mediador aprendizajes.

El papel del profesor en ABP es el de mediador o facilitador de aprendizajes. Debe posibilitar la realización de aprendizajes significativos en los alumnos, teniendo en cuenta su nivel de desarrollo evolutivo y los conocimientos previos que éstos poseen, presentando los nuevos contenidos a aprender de manera adecuada, es decir, comprensibles, claramente estructurados y posean coherencia interna (Exley \& Dennick, 2007). El tutor ayudará a los alumnos a reflexionar, identificar necesidades de información y les motivará a continuar con el trabajo, es decir, los guiará hasta alcanzar las metas de aprendizaje propuestas siempre que sea necesario.

El profesor no es por lo tanto un observador pasivo, sino que debe estar activo y orientar continuamente el proceso de aprendizaje 
asegurándose de que el grupo no se desvíe del objetivo trazado e identifique correctamente los temas más importantes para cumplir con la resolución del problema (véase tabla 3).

Aunque esta metodología supone que el alumno va a realizar una gran parte de su trabajo de forma autónoma, la coordinación del grupo, la corrección de desviaciones, detección de problemas de aprendizaje y finalmente, la necesidad de realizar una evaluación de los trabajos exigen una considerable labor de seguimiento por parte del profesortutor.

\section{Guía tutorial:}

Es un documento elaborado por el profesor, que contiene toda la información importante relativa a la aplicación del escenario problema (tabla 4). Debe contener datos precisos como nombre, la unidad temática a la que pertenece el escenario, conocimientos previos de los alumnos... Orienta rápidamente al docente que aplica la actividad sobre los objetivos que se pretenden lograr, fuentes documentales que se pueden sugerir, control del tiempo de la ejecución y cómo ayudar a los alumnos a conseguir los objetivos. El tutor debe mantener un equilibrio entre la participación y distancia prudente. Para que los alumnos estén activos, es necesario que la participación del tutor sea sutil ya que de ello depende que se mantengan interesados por el 
proceso, destaquen y se manejen con independencia (Instituto Tecnológico de Monterrey, 2006).

Tabla 3. Evolución de los roles ABP. Center for problem-based learning (1996)

\begin{tabular}{|c|c|c|}
\hline & Rol del docente & \multirow{8}{*}{ 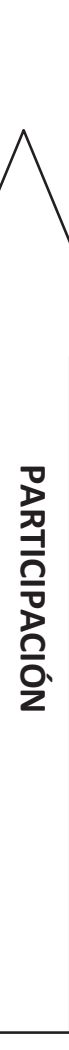 } \\
\hline \multirow{7}{*}{ 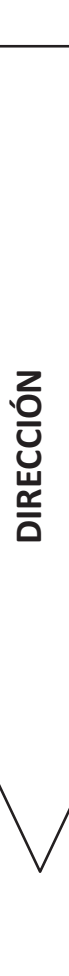 } & $\begin{array}{l}\text { El docente diseña una indagación basada en un problema e implica en ella a } \\
\text { sus alumnos mostrándoles una estrategia para resolver problemas }\end{array}$ & \\
\hline & $\begin{array}{l}\text { El docente habilita a sus alumnos como investigadores del problema, afirma } \\
\text { abiertamente que ellos son quienes controlan la investigación y, al mismo } \\
\text { tiempo, actúa como guía meta cognitivo o preparador en el proceso }\end{array}$ & \\
\hline & $\begin{array}{l}\text { El docente prepara desde un segundo plano a los estudiantes mientras estos } \\
\text { generan las soluciones posibles y llegan a la resolución del problema. }\end{array}$ & \\
\hline & Rol del alumno & \\
\hline & $\begin{array}{l}\text { Los estudiantes se sienten atraídos por la situación problemática que les } \\
\text { intriga } y \text {, participan del proceso. }\end{array}$ & \\
\hline & $\begin{array}{l}\text { Los estudiantes son autorizados para buscar la información requerida, seguir } \\
\text { las líneas lógicas de la indagación y a aprender activamente. A medida que } \\
\text { van autorregulando su aprendizaje, reciben preparación y apoyo del docente. }\end{array}$ & \\
\hline & $\begin{array}{l}\text { Motivados por el problema alrededor del cual gira el ABP, los estudiantes } \\
\text { aplican sus conocimientos, sus habilidades y sus hábitos mentales a una } \\
\text { actividad significativa genuina. Evolucionan como alumnos auto regulados } \\
\text { capaces de resolver problemas. }\end{array}$ & \\
\hline
\end{tabular}


Tabla 4. Estructura formal de una guía tutorial.

Autores :Porres, Sola, Gentil, Epstein, Lapuente, y Illescas(2006)

\begin{tabular}{|l|l|}
\hline \multicolumn{1}{|c|}{ Parte I } & \multicolumn{1}{c|}{ Parte II } \\
\hline $\begin{array}{l}\text { Breve información de la materia y } \\
\text { su relación con otras del } \\
\text { programa }\end{array}$ & $\begin{array}{l}\text { Objetivo general de la actividad } \\
\text { Conocimientos previos que necesita el alumno } \\
\text { Definición del problema que va a ser planteado } \\
\text { Objetivos de aprendizaje } \\
\text { Ubicación del escenario dentro } \\
\text { del programa temático }\end{array}$ \\
$\begin{array}{l}\text { Temas relacionados } \\
\text { Fuentes documentales } \\
\text { Preblemas que pueden encontrar los alumnos }\end{array}$ \\
\hline
\end{tabular}

\section{Escenario problema.}

Se debe replantear la asignatura o materia de estudio, como problemas. Se trata de identificar una situación problemática relativa a los objetivos curriculares, que debe insertarse en un escenario que permite la transmisión. Definir una situación como problema resulta interesante porque el acto mismo de su definición plantea la necesidad de solución (Noone, 2000). El problema debe motivar a los alumnos a la acción y propiciar un pensamiento crítico. El alumno genera mecanismos de meta cognición porque reflexiona sobre su propio conocimiento y la autorregulación.

Es importante tener en cuenta dos aspectos básicos:

a) El docente en todo momento es un tutor/facilitador que ha de promover el trabajo colaborativo. 
b) El objetivo no es resolver el problema sino que el problema es la causa para que los estudiantes consigan adquirir los objetivos de aprendizaje planteados en ese problema.

El tutor resulta fundamental para el desarrollo de la metodología puesto que la dinámica del proceso del grupo depende del buen desempeño del tutor (Instituto Tecnológico de Monterrey, 2006).

Se requiere un cambio en el rol de profesor que pasa de una situación protagónica a la de un facilitador; el docente se convierte en estratega que deberá desarrollar una serie de procesos y actividades necesarias para conseguir que sus alumnos construyan su conocimiento y que, una vez adquirido, se mantengan en el tiempo, para después aplicarlos a otras situaciones (Morales y Landa, 2004, pág. 153).

Escribano y del Valle (2008) proponen que el tutor debe:

$\checkmark$ Presentar el problema

$\checkmark$ Colaborar en el proceso de aprendizaje

$\checkmark$ Ayudar al discente en el conocimiento propio de la materia

$\checkmark$ Facilitar la resolución del problema

$\checkmark$ Potenciar las capacidades de análisis y de síntesis en los alumnos 
$\checkmark$ Favorecer la creación de un espacio de encuentro y relaciones humanas del grupo

$\checkmark$ Favorecer la creatividad que propicia la independencia de los alumnos al abordar nuevos conocimientos.

Barrows \& Tamblyn (1980) creen que en el ABP los tutores deben estar cualificados y ser expertos en la materia (Morales \& Landa, 2004).Numerosos autores sugieren que las cualidades de un buen tutor son la autenticidad, capacidad para facilitar la comprensión de forma empática y valoración al estudiante. El ABP es más efectivo en el desarrollo de competencias debido al cambio que produce en los procesos cognitivos, pero también requiere un tiempo al profesor para que sea efectivo su manejo y el conocimiento de la técnica alrededor de dos años (Vega \& Balderas, 2005).

\subsubsection{Rol del alumno}

El ABP es un proceso de aprendizaje centrado en el alumno, por lo que se espera de él una serie de conductas y actuaciones distintas a las requeridas en el proceso de aprendizaje tradicional. Entre las características deseables en los alumnos que participan en el ABP podemos señalar: motivación profunda y clara sobre la necesidad de aprendizaje, disposición para trabajar en grupo y habilidades sociales, tolerancia para enfrentarse a situaciones ambiguas, habilidades para la solución de problemas, habilidades de comunicación, capacidad para 
ver el campo de estudio desde una perspectiva amplia, y habilidades de pensamiento crítico, reflexivo e imaginativo.

Para trabajar con ABP se forman grupos de alumnos de 3-6 integrantes, aunque hay propuestas de grupos de 8-10 como Johnson, Johnson, \& Smith (1998), que afirman que el tamaño del equipo depende de la complejidad de la tarea. Se pueden formar los equipos aleatoriamente, o bien siendo lo más heterogéneos posibles, el aprendizaje colaborativo es una forma de trabajo en grupo basado en la construcción colectiva del conocimiento y el desarrollo de habilidades mixtas (aprendizaje y desarrollo personal y social), donde cada miembro del grupo es responsable tanto de su aprendizaje como del de los restantes miembros del grupo. Las dinámicas internas que hacen que el aprendizaje colaborativo y cooperativo funcione se basan en características que posibiliten a los docentes estructurar las actividades de manera tal que los estudiantes se vuelvan positivamente interdependientes, individualmente responsables para hacer su parte del trabajo, trabajen cara a cara para promover el éxito de cada cual, usen apropiadamente habilidades sociales y periódicamente procesan cómo pueden mejorar la efectividad de sus esfuerzos. La cooperación, comparada con esfuerzos competitivos e individualistas tiende a resultar en altos niveles de logro, una mayor retención a largo plazo de lo que se ha aprendido, un uso más frecuente de niveles altos de razonamiento, una mayor voluntad para desarrollar tareas difíciles y 
para persistir a pesar de las dificultades, en trabajar hacia el cumplimiento de los objetivos, una mayor motivación intrínseca, una mayor facilidad para transferir el aprendizaje de una situación a otra y una mayor dedicación de tiempo a una tarea (Gil, Alias, \& Montoya, 2006).

Finalmente, los esfuerzos cooperativos ejercen una influencia positiva para evitar el abandono de la Universidad antes de finalizar los estudios que en el caso de España ronda el 30\% de media (Ministerio de Educación, 2003). Estos resultados tienen unas implicaciones importantes ya que la interacción estudiante-estudiante y docenteestudiante son las dos mayores influencias para la efectividad a nivel universitario.

Haciendo una síntesis de proceso ABP:

1. El estudiante lee y analiza el contexto de la situación planteada.

2. Se forman pequeños grupos.

3. Trabajo cooperativo en pequeños grupos.

4. Identificación de los/las objetivos/necesidades de aprendizaje.

5. Conocer la información con la que se cuenta e identificar qué información es necesario buscar.

6. Realizar un breve esquema del problema que hay que resolver.

7. Realizar un diagnóstico de la situación, escribir una serie de preguntas que se necesitan contestar para resolver el problema. 
8. Planificar el trabajo.

9. Plantear un esquema de trabajo, posibles acciones para lograr los objetivos.

10. Búsqueda de la información necesaria.

11. Análisis de esa información.

12. Plantear posibles resultados.

13. Hay un trabajo colaborativo en pequeños grupos y constante retroalimentación durante todo el proceso dejando al finalizar cada sesión unos minutos para una reflexión grupal de lo trabajado y de la evolución como grupo.

14. Observación y reflexión por parte de los implicados de las actitudes y valores que se van desarrollando.

15. Regreso al problema.

Resumiendo, ABP es una metodología activa, cuyo punto de partida es un problema complejo, contextualizado y significativo para los discentes, para ello se diseña en un contexto real. Dicha situación problemática permite que se elaboren hipótesis explicativas y se identifiquen las necesidades de aprendizaje. ABP se ha ido configurando como una forma de entender la educación centrada en los estudiantes. La resolución del problema no es el objetivo prioritario del $\mathrm{ABP}$, lo más importante, es la movilización de los recursos necesarios y que los alumnos adquieran la competencia de “aprender a aprender" desde los retos planteados por el problema, con 
la guía y apoyo del tutor/a que actúa como un facilitador/a. Los estudiantes desarrollan habilidades cognitivas, interpersonales e instrumentales orientadas hacia un problema clínico similar al que encontrarán en su labor como profesionales de enfermería. Deberán indagar en múltiples disciplinas, con una visión transdisciplinar sin perder de vista al paciente como un ser biopsicosocial, de ahí, la complejidad del problema y su similitud con los problemas reales significativos para los estudiantes.

La calidad docente es mayor utilizando ABP como afirma Boud (1985), siendo rasgos distintivos del ABP: un reconocimiento de la experiencia por parte de los estudiantes, un énfasis en la responsabilidad de su propio aprendizaje, el carácter transdisciplinar o multidisciplinar de los problemas, la integración entre teoría y práctica, el cambio de rol docente como un facilitador de aprendizajes, la evaluación centrada en autoevaluación y evaluación a pares más que en las notas y que es parte del proceso de aprendizaje, y prestar una especial atención al desarrollo de competencias interpersonales y comunicativas. Las mejores experiencias de aprendizaje son las que desarrollan un aprendizaje en profundidad como el ABP. Ruohoniemi \& Lindblom-Ylänne (2009), establecen una estrecha relación entre el nivel de aprendizaje y el tipo de resultados de aprendizaje como, transferir los conocimientos adquiridos a problemas nuevos, la relación entre el nivel de 
aprendizaje y la posibilidad de autorregularse, considerando la evaluación como un proceso reflexivo que forma parte del proceso.

Para (Barrows \& Tamblyn, 1980), el último objetivo de la educación consiste en producir un profesional que sea capaz de resolver los problemas de los usuarios de forma competente y humana con la habilidad necesaria para utilizar los conocimientos. 


\section{II-MARCO METODOLÓGICO}


CAPÍTULO 4 


\section{Diseño de la Investigación}

\subsection{Planteamiento del problema}

En el proceso de enseñanza-aprendizaje, es habitual que el rol del alumnado sea receptivo y el profesorado exponga los contenidos teóricos con clases magistrales asumiendo el rol de experto.

Han ido surgiendo una serie de preguntas vinculadas a la metodología docente que han ayudado al planteamiento de esta investigación. Para la delimitación del ámbito de estudio se partió de preguntas y problemas complejos. Se plantearon preguntas que pretenden explicar ¿cómo se podría cambiar esta situación para implicar en el aprendizaje al alumnado?, ¿cómo formar en competencias profesionales a nuestros alumnos y alumnas? Otras de las cuestiones planteadas ¿cómo aumentar la motivación de los estudiantes en la búsqueda del conocimiento? y, por último ¿cómo mejorar la calidad de la docencia?

Respecto a la aplicación de la metodología Aprendizaje Basado en Problemas en la que se centra esta investigación, se plantearon las siguientes preguntas: ¿En qué forma se modifica el perfil de autodirección del aprendizaje de los estudiantes de enfermería como resultado de un proceso educativo basado en estrategias didácticas ABP? , ¿Es alta la satisfacción de los estudiante si se utilizan ABP?, 
¿Los alumnos se implican siendo protagonistas en el proceso de su propio aprendizaje con ABP?, ¿Los estudiantes desarrollan competencias transversales y específicas?

Se propone la implementación del Aprendizaje Basado en Problemas (ABP) como un método de enseñanza para que los estudiantes de Grado en Enfermería puedan “aprender a aprender” en colaboración con un grupo de compañeros para la búsqueda de solución de problemas clínicos reales. Según Dewey (1967) un verdadero aprendizaje se basa en el descubrimiento guiado por tutores, en lugar de transmisión del conocimiento.

El pilar de esta metodología es el alumno, quien aprende tanto del trabajo colectivo como del trabajo individual. El Aprendizaje Basado en Problemas (ABP) es afín al Sistema de Crédito Europeo que, al enfatizar el papel del alumno en el proceso de enseñanza y aprendizaje, toma como referencia para la asignación de créditos el tiempo que el educando invierte en aprender dentro y fuera del aula. Por primera vez, el proceso de aprendizaje se deja de medir en horas de docencia para pasar a hacerlo en horas de esfuerzo (Font, 2004).

Se trata de hacer una propuesta didáctica contemporánea funcional, basada en la psicología cognitiva, en la que el alumnado construye su aprendizaje desarrollando competencias del modelo de profesional 
que la sociedad moderna aspira lograr. Cabe destacar que se pretende un alejamiento de la escuela tradicional. Hay que tener en cuenta que el estudiante es un ser pensante activo y no solo receptivo. Con esta metodología se busca lograr la autonomía del alumno y el cambio de los roles del profesorado y el alumnado para lograr un aprendizaje activo.

\subsection{Finalidad y Objetivos}

Se pretende dar cuenta de las potencialidades, el valor y la finalidad de la metodología ABP en la adquisición de las competencias del alumnado de Enfermería a través de una intervención educativa.

\subsubsection{Objetivos específicos}

1. Aplicar ABP en la formación de los estudiantes de $2^{\circ}$ de Grado en Enfermería durante las prácticas de aula.

2. Medir el efecto de la estrategia didáctica $\mathrm{ABP}$ en la autodirección del aprendizaje, utilizando un instrumento estandarizado para la medición de esta habilidad.

3. Comprobar si se desarrollan competencias en los estudiantes con inmersión en la metodología ABP.

4. Analizar la evaluación por competencias ABP a través de la autoevaluación de los alumnos, evaluación a los compañeros de grupo, evaluación a la tutora, observación de las tutorías, trabajos escritos y trabajos de presentación oral. 
5. Determinar el grado de satisfacción de los estudiantes después utilizar ABP.

6. Reflexionar sobre la propia práctica y la pertinencia de la implementación $\mathrm{ABP}$ en la Escuela Universitaria de Enfermería de Valladolid.

\subsection{Hipótesis}

Se exponen las preguntas y las hipótesis generadas:

¿En qué forma se modifica el perfil de autodirección del aprendizaje de los estudiantes como resultado de un proceso educativo basado en estrategias didácticas (ABP)?

H1: Los alumnos que cursan materias con estrategias didácticas $\mathrm{ABP}$ registran cambios en su autodirección de aprendizaje.

$\mathrm{H} 2$ : Existe una diferencia significativa en la puntuación global de autodirección entre los alumnos antes y después de utilizar metodología ABP.

H3: Existe una diferencia significativa en los cinco componentes del AAR: planificación y selección de estrategias, autorregulación y motivación (potencial interno), independencia y autonomía (potencial interno), uso de experiencias y conciencia crítica e interdependencia social, después de aplicar ABP. 
¿El uso de metodologías activas como ABP influye en la motivación y satisfacción de los estudiantes?

H4: Si se aplica la metodología ABP la motivación y el grado de satisfacción serán elevados.

¿El cambio de rol del profesor y los estudiantes se acepta y se manifiesta en un compromiso del proceso enseñanzaaprendizaje entre alumnos y profesores?

H5: Los estudiantes perciben favorablemente un cambio de rol del profesor como guía o facilitador del aprendizaje.

H6: Los estudiantes perciben favorablemente un cambio de rol del alumno como responsable de su aprendizaje.

¿El aprendizaje utilizando ABP es un aprendizaje de calidad?

H7: El aprendizaje es más profundo y mejora la calidad del proceso enseñanza-aprendizaje al aplicar ABP.

¿Permite ABP el desarrollo de competencias necesarias para profesionales de enfermería? ¿Es posible institucionalizar esta innovación docente en la Escuela de Enfermería de Valladolid?

H8: La metodología ABP permite el desarrollo de competencias transversales entre ellas, trabajo en grupo, 
mejora en habilidades de razonamiento y aprendizaje autónomo, pensamiento reflexivo, pensamiento crítico, búsqueda de información, competencias comunicativas y creatividad en los alumnos de enfermería.

H9: Una metodología ABP requiere evaluar las competencias de los estudiantes con distintos instrumentos que complementen al examen de conocimientos de la metodología tradicional.

H10: ABP es una metodología idónea para lograr competencias necesarias para formar a los futuros profesionales de enfermería y permite una innovación educativa afín al EEES.

\subsection{Material y Método}

En este estudio se utilizó una metodología mixta. Para la investigación cuantitativa se recogieron los datos a través de cinco cuestionarios. Para el análisis de los datos y la obtención de los resultados se empleó SPSS para Windows.

Para la medición del aprendizaje autorregulado a través del cuestionario se ejecutó un diseño cuasi experimental pre-test y postest de un solo grupo. El esquema del diseño es $\mathrm{O}_{1} \mathrm{X} \mathrm{O}_{2}$, siendo $\mathrm{O}_{1}$ la observación inicial, $\mathrm{X}$ el tratamiento (la intervención ABP) y O2 la segunda medida (León \& Montero, 1997). 
Se comprobó la fiabilidad del instrumento (cuestionario CIPA+) en la muestra, a través del coeficiente alfa de Cronbach en el pre-test $=$ $0,886(\mathrm{~N}=127)$ y en pos-test $=0,919(\mathrm{~N}=129)$. Se puede afirmar que el cuestionario tiene un buen nivel de fiabilidad puesto que niveles alfa de Cronbach entre 0,7 y 0,9 indican una buena consistencia interna (Oviedo \& Campo, 2005).

Para el análisis de los datos se utilizó primero la prueba paramétrica de Kolmogorov-Smirnov para comprobar el ajuste a la curva normal. Después se usó la T-Test para muestras apareadas. Se hallaron la correlación y las diferencias de forma global (Total CIPA) en el pretest y pos-test. También se hallaron las correlaciones y las diferencias de medias en el pre-test y pos-test entre los cinco componentes de la autorregulación del aprendizaje: planificación y selección de estrategias, autorregulación y motivación, independencia y autonomía, uso de la experiencia y la conciencia crítica e interdependencia y valor social. Los resultados entre los componentes no son comparables entre sí puesto que algunos se miden con más ítems que otros.

Para medir el Grado de satisfacción de los estudiantes que utilizaron ABP al finalizar el semestre, se analizaron las respuestas del cuestionario de la Universidad de la Colima (México) de Márquez, Uribe, Montes, Monroy, \& Ruiz (2011), este cuestionario se aplicó a los estudiantes de enfermería del estudio. 
La consistencia interna de la escala se presenta en la tabla 5.

Se consideró que la escala era apropiada para efectuar los análisis correspondientes, según los intereses del estudio.

Tabla 5. Estadísticos de fiabilidad del cuestionario de satisfacción

\begin{tabular}{|r|r|}
\hline $\begin{array}{c}\text { Alfa de } \\
\text { Cronbach }\end{array}$ & $\begin{array}{c}\text { N de } \\
\text { elementos }\end{array}$ \\
\hline 0,833 & 10 \\
\hline
\end{tabular}

Para la obtención de los resultados, se hallaron las proporciones de las respuestas a través del programa SPSS. También se hizo un análisis de contenido de las justificaciones escritas de forma breve sobre cada pregunta. De esta forma, se obtuvo una integración entre los dos análisis efectuados.

El proceso de evaluación por competencias se realizó a través de tres escalas: evaluación a la tutora, autoevaluaciones de los estudiantes y las evaluaciones a compañeros del grupo. Las observaciones de las tutorías y las respuestas escritas sobre las ventajas e inconvenientes del ABP, permitió la evaluación continua y la evaluación por competencias.

En el paradigma de la investigación cualitativa por tanto, se efectuó la observación de las tutorías de las prácticas de aula y de las presentaciones orales de los alumnos, el análisis de las respuestas 
abiertas del cuestionario de satisfacción, y el análisis de los trabajos escritos en los que reflejaron las ventajas e inconvenientes percibidas por los estudiantes sobre empleo de ABP. Se realizó una categorización y un análisis de contenido de las observaciones y documentos escritos. La triangulación de métodos múltiples permitió la obtención de los resultados verificando los hallazgos (Cohen \& Manion, 1994).

\subsection{Muestra}

El total de estudiantes de $2^{\circ}$ de Grado en Enfermería de la Universidad de Valladolid matriculados en la asignatura Salud Sexual y Reproductiva en el curso 2011-2012 fue de 135.

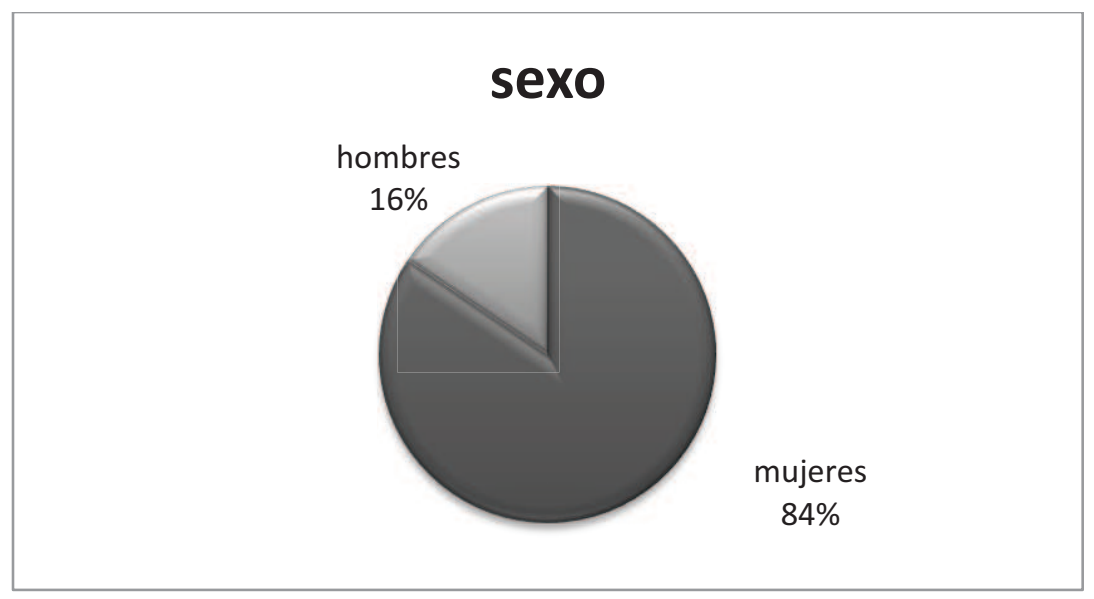

Figura 7. Muestra: Variable sexo en porcentaje. $\mathrm{N}=129$. 
Formaron parte del estudio todos los estudiantes del curso excepto los comprendidos en los criterios de exclusión. Se excluyó a los estudiantes sin posibilidad de asistencia a todas las tutorías $\mathrm{ABP}$ en el aula y a todas las reuniones del grupo fuera del aula. La muestra correspondió a 129 alumnos de $2^{\circ}$ curso de Grado en Enfermería, 109 mujeres y 20 hombres, tratándose de una muestra no probabilística, por conveniencia. La edad media fue de 23 años, el rango de edades entre 19 y 51 años y la desviación típica de 5.4.

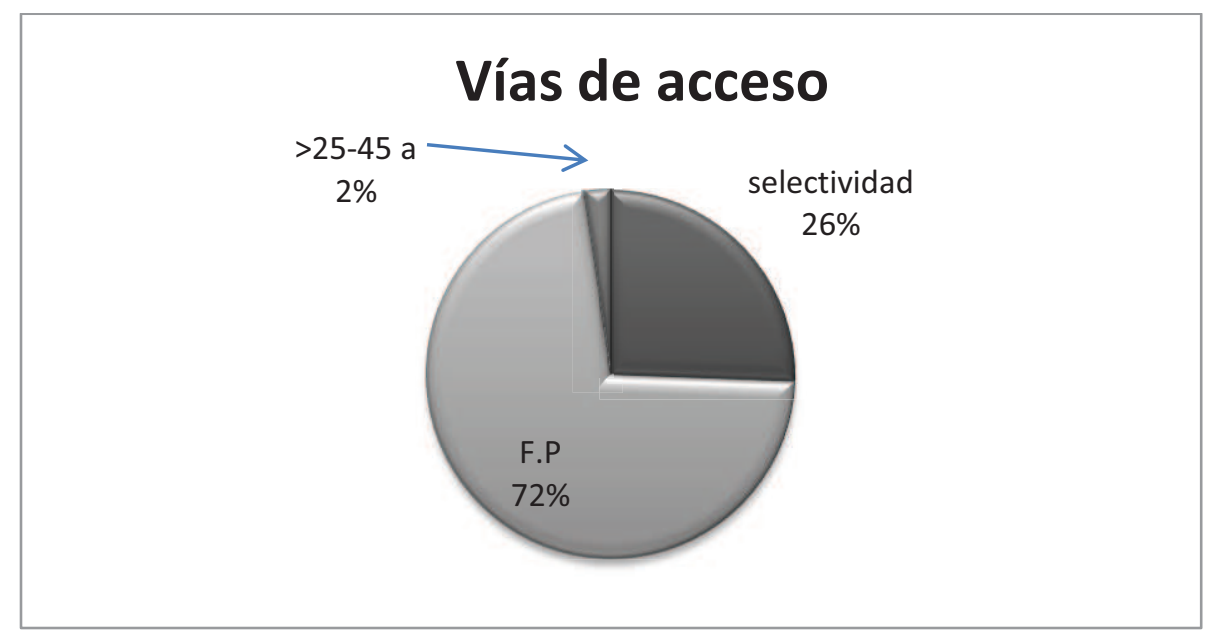

Figura 8. Muestra: vías de acceso al Grado en Enfermería. N=129.

Según el Real Decreto 1892/2008, existen varias vías de acceso a la universidad. La muestra estuvo compuesta por estudiantes que accedieron a Enfermería por la vía de Bachillerato, por la vía de 
Formación Profesional (FP) y por la vía de acceso a mayores de 25 o 45 años (véase la figura 8 )

\subsection{Instrumentos}

\subsubsection{Cuestionario de indagación de Perfil auto dirigido CIPA}

La Dra. Guglielmino desarrolló el Self-Directed Learning Escala Readiness (SDLRS) en 1978 para medir el conjunto de actitudes, habilidades y características que componen la disposición a participar en el aprendizaje auto dirigido. Es el instrumento más utilizado de su tipo en el mundo y ha sido traducido a más de 22 idiomas (Guglielmino \& Associates, 2012). La escala SDLRS dirigida a adultos de Estados Unidos y Canadá, fue adaptada en el año 2002 por Cázares, para la población mejicana de habla hispana. El Cuestionario de Indagación del Perfil Auto dirigido, mejor conocido como CIPA, tras una serie de ajustes, sufrió modificaciones y la segunda edición recibió el nombre de CIPA+ (Cázares,2005; Guerra, 2008; Cázares \& Ponce, 2009; Olivares, 2011).

Para la presente investigación se seleccionó el CIPA+ de Cázares \& Aceves (2007). Este cuestionario realiza la evaluación del perfil de autodirección en estudiantes que pertenecen a la sociedad del conocimiento. El cuestionario se encuentra en el Anexo 1. 
Este instrumento presenta 41 reactivos que incorporan los cinco componentes que conforman la autodirección:

1) Planificación y selección de estrategias

2) Autorregulación y motivación(potencial interno)

3) Independencia y autonomía(potencial interno)

4) Uso de la experiencia y la conciencia crítica

5) Interdependencia y valor social.

De acuerdo con la descripción de Cázares \& Aceves (2007), la escala se puntúa entre 1 y 5 y los resultados se obtienen de la suma de las puntuaciones. La escala por componentes se divide en cinco componentes, incluye ítems diferentes por lo que los componentes no son comparables entre sí. La validez y fiabilidad del instrumento fueron probadas, tanto en la prueba piloto que llevaron a cabo las autoras del instrumento, como en la aplicación del estudio definitivo durante el período que va del 2005 al 2007. La escala de calificación del cuestionario (Total CIPA) va de 41, el valor mínimo, a 205, el valor máximo. Las puntuaciones bajas indican mayor autodirección que las altas como se ve en la tabla 6 . 
Tabla 6.Distribución de las puntuaciones globales del cuestionario CIPA + (Total CIPA)

\begin{tabular}{l|l} 
Óptimo & $41-73$ \\
\hline Muy bueno & $74-106$ \\
\hline Moderado & $107-139$ \\
\hline Insuficiente & $140-172$ \\
\hline Bajo & $173-205$
\end{tabular}

En la tabla 7 se pueden ver las puntuaciones por componentes. Las puntuaciones de los componentes se basan en la suma de los ítems de cada uno. Los resultados entre los componentes no son comparables pues algunos se miden con más ítems que otros 


\section{Tabla 7. Componentes e ítems del cuestionario CIPA+}

\begin{tabular}{l|l} 
& \\
$\begin{array}{l}\text { 1-Planificación y selección de estrategias para } \\
\text { alcanzar el futuro que has definido para ti, al } \\
\text { definir fines, metas, objetivos y acciones }\end{array}$ & $1,2,3,8,10,12$, \\
\hline & $19,35,37,39$ \\
$\begin{array}{l}\text { 2-Autorregulación y motivación para sobresalir y } \\
\text { conseguir lo que has planeado al administrar tu } \\
\text { tiempo, esfuerzo e información }\end{array}$ & $4,6,9,23,26,27$, \\
\hline & $30,33,41$ \\
3-Independencia y autonomía para conseguir lo \\
que te interesa, así como para asumir la \\
responsabilidad de tus actos & $11,16,17,18,20,22$, \\
\hline & $28,31,32,36,38,40$ \\
$\begin{array}{l}\text { 4-Uso de experiencia y conciencia crítica para } \\
\text { resolver tus problemas diarios y corregir tus } \\
\text { acciones a tiempo }\end{array}$ & \\
\hline
\end{tabular}




\subsubsection{Cuestionario sobre el grado de satisfacción del estudiante con respecto al $\mathrm{ABP}$}

El objetivo fundamental fue conocer la satisfacción respecto a esta metodología y la postura de los estudiantes en cuanto a la implementación de $\mathrm{ABP}$ en la Escuela de Enfermería de Valladolid.

Para esta investigación se seleccionó la escala de satisfacción diseñada en la Universidad de la Colima (México), con más de 10 años de experiencia en la aplicación de ABP en Ciencias de la Salud de Márquez, Uribe, Montes, Monroy, \& Ruiz, (2011).Se trata de una escala tipo Likert con ocho ítems y seis opciones de respuesta que van de 1 (nada satisfecho) a 6 (completamente satisfecho). La escala se encuentra en Anexo 2.

Evalúa el grado de satisfacción de los alumnos en cuanto a:

1. Contenidos revisados en las tutorías

2. El rol del tutor

3. El rol del estudiante

4. El proceso de tutoría

5. El proceso de evaluación

6. Los recursos educacionales

7. El diseño de casos 
8. El tiempo asignado a la hizo un análisis de contenido que se incluye en los resultados revisión de los casos

9. Características de las aulas

10. Grado de satisfacción con ABP considerando todo lo que este implica

Para cada ítem, se solicita que los encuestados justifiquen de forma breve la respuesta seleccionada en la escala, se analizaron los contenidos de las respuestas.

\subsubsection{Observación de tutorías y de presentaciones orales}

Para la observación de tutorías se utilizó el modelo de "facilitador flotante" propuesto por Escribano \& del Valle (2008), en el que el instructor se moviliza de grupo en grupo haciendo preguntas, dirigiendo la discusión y verificando la comprensión. Se controló la asistencia a las prácticas de aula, siendo obligatoria. El tamaño de los grupos fue de entre 4-6 estudiantes, coincidiendo en cada tutoría 5 o 6 grupos ABP. La duración de cada tutoría o práctica de aula fue de 2 horas. La tutora realizó anotaciones sobre la distribución de los grupos, anécdotas, interacciones y la percepción personal de cada tutoría. Además, se realizó una observación estructurada a través de código o rúbricas para evaluar las presentaciones orales de los grupos de alumnos (León \& Montero, 1997). Se recurrió a tres observadores conformados por la tutora y otros dos (estudiantes diferentes para cada observación) con el fin de aumentar la fiabilidad de la observación. 
Para mejorar la validez de las observaciones se utilizaron códigos o criterios, que los alumnos conocían de antemano, puntuables entre 110. Los criterios, elegidos siguiendo la propuesta de Escribano \& del Valle (2008) fueron:

a. Comunicación: mirada, gestos con manos, voz adecuada (acento, tono y volumen), duración y fluidez del habla...

b. Creatividad: Calidad y originalidad de las aportaciones, recursos y medios empleados...

c. Cohesión: coordinación y sincronización de los miembros del grupo

d. Organización: secuencia, estructura y desarrollo coherente de los contenidos.

e. Claridad: descripción, precisión y síntesis de lo expresado.

f. Contenidos: nivel de adecuación, rigurosidad y riqueza de los datos aportados.

g. Comprensión: grado de reflexión, argumentación y razonamiento.

h. Aplicación: congruencia y pertinencia de las experiencias proporcionadas.

Las Rúbricas para la observación de presentaciones orales se encuentran en el Anexo 3. 
El tiempo máximo estipulado para la presentación fue de 20 minutos, siendo necesario que participasen todos los alumnos. Esta evaluación tuvo un $20 \%$ de valoración sobre la nota global de la asignatura.

\subsubsection{Análisis de contenido}

Se realizaron dos análisis de contenido, uno de las respuestas justificadas de forma breve del cuestionario de satisfacción (Márquez, Uribe, Montes, Monroy, \& Ruiz, 2011). El segundo análisis de contenido se centró en las ventajas e inconvenientes percibidas por los estudiantes al trabajar con la metodología $\mathrm{ABP}$, este punto de reflexión, lo incluyeron en el trabajo escrito cuyo valor en la calificación final fue de un $20 \%$. Se trató de que los alumnos desarrollaran competencias comunicativas, pensamiento crítico y reflexivo con la elaboración del documento escrito.

El análisis de Contenido es una técnica para la descripción objetiva y sistemática del contenido de la comunicación. Krippendorff (1990) afirma que es una técnica destinada a formular, a partir de ciertos datos, inferencias reproducibles y válidas que puedan aplicarse a su contexto. Se siguieron las fases de pre análisis, formación del sistema categorial, codificación, interpretación y verificación de los resultados. El análisis de contenido es un reflejo del enfoque teórico metodológico que sustenta el proceso de investigación. Las fases de pre análisis, transformación del material, integración significativa de 
los contenidos, construcción de los resultados y exploración del material, con sus respectivos procedimientos, le confieren rigor científico a la aplicación del método análisis de contenido en la etapa de evaluación de la información en la investigación educativa, así como una mejor aproximación a la realidad educativa estudiada.

\subsubsection{Evaluación de pares y autoevaluación}

Los estudiantes evaluaron a sus compañeros del grupo ABP y realizaron su propia evaluación a través de una escala numérica tipo Likert propuesta por el Instituto Tecnológico de Monterrey (1.999). La escala puntúa de de 1 a 4 , donde 1 significa totalmente en desacuerdo y 4 totalmente de acuerdo. Esta escala se ha incluido en el Anexo 4.

Los ítems valoran:

1. Asistencia a actividades del grupo.

2. Si terminan los trabajos.

3. La implicación en el trabajo y lectura de bibliografía.

4. Escucha a los otros.

5. Contribuciones a la discusión del grupo.

6. Aportación de nueva y relevante información.

7. Recursos utilizados para investigar.

8. Si realiza preguntas para mejorar la comprensión.

9. Comunicación de ideas.

10. Ayuda para mejorar. 


\subsubsection{Evaluación a la tutora}

Se hizo una evaluación a la tutora por los estudiantes de los grupos ABP utilizando la escala propuesta por Allen en la Universidad de Delaware (ISTEM, 1999). Esta escala se encuentra en el Anexo 5.

Se trata de una escala tipo Likert que puntúa entre 1 (totalmente en desacuerdo), 2 (en desacuerdo), 3 (de acuerdo) y 4 (totalmente de acuerdo).

Los ítems valoran si:

1. La tutora muestra interés por el grupo.

2. Crea un ambiente relajado.

3. Escucha y responde a las preguntas.

4. Admite conocimientos que no sabe.

5. Ayuda al grupo.

6. Guía e interviene cuando es preciso.

7. Provee comentarios constructivos.

8. Plantea preguntas.

Las respuestas de la evaluación a la tutora, autoevaluación y evaluación a pares se analizaron con SPSS, obteniendo las proporciones de las respuestas. 


\subsection{Procedimiento}

Siguiendo a Egido, y otros (2007); Higgs (2005); Solaz-Portolés, Sanjosé, \& Gómez, (2011), se utilizó la metodología ABP combinada con otros métodos tradicionales para el aprendizaje de la asignatura Salud Sexual y Reproductiva. Esta asignatura de 6 créditos ECTS, se programó para seguir una metodología tradicional en el 50\% (3 ECTS) y el otro $50 \%$, para el desarrollo de las prácticas de aula siguiendo metodología ABP. Respondiendo a las preguntas ¿qué?, ¿cuándo?, ¿cómo?, ¿dónde? y ¿quién? Se aplicó la metodología ABP durante el $2^{\circ}$ semestre del curso académico 2011-2012 siguiendo "los siete pasos ABP" propuestos por Schmidt( 1989), durante las tutorías o prácticas de aula de los estudiantes de enfermería de la asignatura.

El procedimiento para recolectar los datos primarios de la investigación cuantitativa se hizo a través de la administración de cuestionarios, y de la investigación cualitativa a través de la observación y documentos escritos (notas de campo de la tutora durante la observación, opiniones de estudiantes en foros virtuales y trabajos de los alumnos).

\subsubsection{Grupos ABP:}

Los 129 sujetos participantes, se distribuyeron en dos aulas (A y B) en las que se organizaron las prácticas de aula en cuatro subgrupos: 


\begin{abstract}
Aula A:
Subgrupo del 1 al 6

Subgrupo del 7-12
\end{abstract}

Aula B:

Subgrupo del 13 al 18

Subgrupo del 19 al 24.

Los estudiantes se agruparon en 23 subgrupos ABP de forma aleatoria y cada uno estuvo formado por 4 - 6 estudiantes. Se anuló uno de los veinticuatro grupos previstos al inicio, debido a los criterios de exclusión. Los grupos fueron heterogéneos con alumnos que trabajaban o tenían formación práctica como técnicos de laboratorio, técnicos de anatomía patológica, técnicos de rayos o auxiliares de enfermería. Además, algunos estudiantes conciliaban su vida familiar y laboral o tenían hijos a su cargo. La variabilidad de los grupos es un factor importante, puesto que permite diferentes puntos de vista y es una oportunidad para desarrollar competencias transversales. No participaron en la investigación cuatro estudiantes que compatibilizan su trabajo con los estudios universitarios y no podían acudir a tutorías y reuniones de grupo. Hubo un abandono de un alumno del grupo $\mathrm{ABP}$ después de la primera tutoría y otro estudiante abandonó el grupo en la tercera tutoría. Estos seis estudiantes excluidos de la 
investigación, acordaron con la profesora realizar un estudio de caso de forma individual en sustitución del trabajo con metodología ABP.

\subsubsection{Planificación:}

Antes de empezar a aplicar ABP hubo que hacer una planificación de los recursos necesarios (aula, mobiliario, documentos...) y de la organización de los grupos y el cronograma prácticas de aula.

Para facilitar la adaptación al Proceso de Bolonia, se hicieron reformas y adaptaciones de espacios en la Escuela de Enfermería de Valladolid. Durante la planificación ABP para el curso académico 2011-2012, las prácticas de aula se programaron en un aula con sillas y mesas móviles que facilitaron el trabajo de los grupos.

La profesora elaboró una serie de documentos entre ellos, una guía tutorial, el diseño de casos, la guía del estudiante, las rúbricas de evaluación, la selección de instrumentos para evaluación (test evaluativo a tutora, autoevaluación y evaluación a compañeros), la actualización de una página web con enlaces y documentos útiles para los estudiantes, y el diseño de un foro virtual para opinar sobre ABP.

\subsubsection{Guía tutorial:}

En primer lugar, se planificó una "guía tutorial" con el objetivo de realizar la innovación educativa y no dejar nada a la improvisación. La profesora se formó en metodología $\mathrm{ABP}$ a nivel teórico, y en la 
práctica utilizó esta metodología en la enseñanza de estudiantes de matrona en el curso 2009-2010 siendo útil como una "prueba piloto". La diferencia con la actual investigación, fue el número de estudiantes, que en el caso de las alumnas de matrona, se trató de grupos reducidos, en concreto, dos grupos de cinco estudiantes. En esta investigación sin embargo, el número de alumnos es de 129 estudiantes divididos en veintitrés grupos de entre 4-6.

\subsubsection{Diseño de casos o problemas:}

Se diseñaron diferentes supuestos o casos clínicos en forma de problemas complejos, poco estructurados y de solución abierta. El contenido de los problemas incluyó diferentes temáticas específicas de la asignatura, entre ellas: planificación familiar, sexualidad y discapacidad, lactancia materna, prematuridad, sexualidad y enfermedad, sexualidad y ciclo vital, menopausia, embarazo adolescente, infecciones de transmisión sexual, crecimiento intrauterino retardado, consulta joven, cáncer de mama, atrofia urogenital, candidiasis vaginal, violencia de género...Los casos presentados para trabajar con ABP se encuentran en el Anexo 6.

El diseño de los casos clínicos se realizó en los seis meses anteriores a la aplicación ABP. Se seleccionaron casos reales de la "consulta de matrona" en la que trabaja la autora. Se siguieron las recomendaciones éticas de la Declaración de Helsinki (2009) protegiendo la 
confidencialidad de las pacientes, cambiando sus nombres y evitando datos confidenciales. La elección de los casos se hizo seleccionando los de mayor interés para el aprendizaje en Enfermería, y los más complejos, incluyendo múltiples problemas con la necesidad de un abordaje de las pacientes desde el punto de vista integral (biopsicosocial) y multidisciplinar. Cada caso clínico asignado a cada grupo de 4-6 estudiantes, fue diferente para profundizar en los distintos contenidos de la asignatura. Uno de los objetivos era que al finalizar el trabajo y la resolución del problema, los estudiantes compartiesen las presentaciones y los trabajos con el resto de los compañeros de la clase, para aprender unos de otros. En estas formas de actividad social, práctica y participativa se inicia un andamiaje del proceso de construcción compartida de conocimientos (Bruner, 1997; Coll, Colomina, Onrubia \& Rochera, 1992) y se integran aspectos emocionales, relacionales y cognitivos.

En conclusión, se intentó que los estudiantes se identificaran con su futuro perfil profesional y con los "verdaderos casos" que atendemos en las consultas. Por lo tanto, se trató de contextualizar y hacer significativo el aprendizaje (Del Río \& Alvarez, 2002;Esteban 2011).

\subsubsection{Guía del estudiante:}

Se elaboró un documento que se presenta en el Anexo 8 "Guía del estudiante" como material de apoyo en la implementación de ABP. La 
guía del estudiante se les entregó a los estudiantes durante la primera tutoría y además se insertó en la plataforma digital para disponer de la guía en todo momento.

\subsubsection{Tutorías $\mathrm{ABP}$ en las prácticas de aula}

Se desarrollaron cuatro tutorías presenciales por estudiante durante las prácticas de aula, de dos horas de duración. Se siguieron los siete pasos ABP propuestos por Schmidt (1989):

1. Clarificar los términos

2. Definir el problema

3. Lluvia de ideas/análisis del problema

4. Clasificar las aportaciones del análisis

5. Definir metas de aprendizaje

6. Realizar un estudio independiente

7. Reportar hallazgos/obtener conclusiones

Dado que la inmensa mayoría de los alumnos universitarios españoles desconocen lo que es el ABP, se empezó explicándoles la utilidad principal de la metodología (desarrollo de competencias profesionales), especificando los procedimientos y habilidades a ejercitar durante la resolución del problema.

En la primera tutoría se expuso y consensuó con los estudiantes el cambio de metodología docente que se iba a utilizar en el segundo semestre del curso, siguiendo la propuesta de (Carbonero, Román, Martín-Antón, \& Reoyo, 2009, pág 229): “las habilidades docentes 
motivadoras se convierten en una cuestión imprescindible a la hora de abordar la implicación del alumnado". Se intentó por tanto, utilizar una comunicación persuasiva con los discentes, hacerles partícipes de la necesidad de un cambio para lograr el desarrollo de competencias transversales y específicas fundamentales para su futuro ejercicio profesional como enfermeras y enfermeros. Es muy importante que los estudiantes estén de acuerdo con el cambio de metodología, puesto que así no lo sienten como una imposición del profesor y aumenta su compromiso hacia su propio aprendizaje (Moesby, 2008).

Se administró el cuestionario de perfil auto dirigido CIPA (pre-test) durante esta primera tutoría. Debido a la ausencia de dos estudiantes, en la recogida de datos se perdieron dos casos del pre-test recogiéndose para el estudio 127 cuestionarios pre-test.

El alumnado distribuido en los diferentes grupos, inició el aprendizaje con ABP. Se explicaron las instrucciones y se les entregó "La guía del estudiante" .Se repartió un caso clínico impreso diferente para cada uno de los subgrupos y entre ellos, se repartieron los roles de los distintos componentes del grupo según el Anexo 7. La tutora hizo la observación y se movilizó de grupo en grupo haciendo preguntas, dirigiendo la discusión y verificando la comprensión del caso problema. Al finalizar la sesión la autora hizo las anotaciones y percepciones sobre el trabajo realizado. 
En las tutorías o prácticas de aula sucesivas, se fue avanzando de forma progresiva en el caso ABP con la misma dinámica, observación de los grupos y "tutora flotante" para supervisar los trabajos grupales. Aparte de las tutorías presenciales, se intercaló el trabajo autónomo de los alumnos y varias reuniones de grupo sin tutor fuera del aula. Se fijó una fecha para el envío online de los avances del trabajo y el estudiante con el rol de "secretaria/o" contactó semanalmente con la tutora para comentar los avances o dificultades de su trabajo grupal. Por lo tanto, la comunicación y retroalimentación fue continua entre estudiantes y tutora.

Se siguió el siguiente cronograma:

Primera práctica de aula: Administración del cuestionario CIPA (pretest), reparto de equipos de trabajo, lectura de las instrucciones y casos clínicos, reparto de roles y "lluvia de ideas".

Segunda práctica de aula: Los estudiantes aportaron el material necesario (ordenador portátil, artículos, resúmenes...) y los avances del trabajo, las dificultades...se continuó con el trabajo grupal en el aula.

Tercera práctica de aula: Se siguió con el trabajo de grupo y al finalizar la sesión se realizaron las evaluaciones de estudiantes a la tutora, autoevaluación y evaluación a pares a través de cuestionario.

Cuarta práctica de aula: Administración del cuestionario CIPA (postest). Presentación oral del trabajo con apoyo del formato PowerPoint, 
observación de las presentaciones y registro siguiendo las rúbricas del Anexo 3.

El cuestionario para conocer la satisfacción de los estudiantes al trabajar con ABP, se administró al final del semestre, en los 15 minutos previos al examen de conocimientos teóricos de la asignatura Salud Sexual y Reproductiva 


\section{CAPÍTULO 5}




\section{Resultados}

A continuación se presentan los resultados que se han agrupado en cuatro categorías partiendo de los objetivos de la investigación:

5.1. Efecto de la estrategia didáctica $\mathrm{ABP}$ en la autodirección del aprendizaje

5.2. Evaluación por competencias con ABP

5.2.1Autoevaluación y evaluación a pares

5.2.2 Evaluación a la tutora

5.2.3 Observación de las prácticas de aula

5.2.4 Observación de las presentaciones orales de los estudiantes.

5.3. Satisfacción de los estudiantes de Grado en Enfermería que han aprendido con ABP

5.4. Ventajas e inconvenientes percibidos por los estudiantes al utilizar ABP.

\subsection{Efecto de la estrategia didáctica $\mathrm{ABP}$ en la autodirección del} aprendizaje

A través de los resultados que se presentan se pretende responder al objetivo de medir la autodirección en el aprendizaje de los estudiantes de Enfermería. Se administró antes y después de aplicar ABP, el cuestionario de perfil auto dirigido CIPA+ y se realizó el procesamiento de los casos para demostrar el 
incremento de la autodirección del aprendizaje como se muestra en la tabla.

Tabla 8. Procesamiento de los casos

\begin{tabular}{rlrr} 
& & $\mathrm{N}$ & \multicolumn{1}{c}{$\%$} \\
\hline Casos & Válidos & 127 & 98,4 \\
\hline & Excluidos(a) & 2 & 1,6 \\
\hline & Total & 129 & 100,0
\end{tabular}

a. Eliminación por lista basada en todas las variables del procedimiento

El test CIPA+ muestra una alta fiabilidad el alfa de Cronbach en el pre-test es 0,886 y en el pos-test 0,919 (valores mayores de 0,7 indican que es muy fiable).

Para el análisis de los datos primero se utilizó la prueba de Kolmogorov-Smirnov que es una prueba no paramétrica para determinar la bondad de ajuste de dos distribuciones de probabilidad entre sí y se comprobó que las variables se ajustan a la curva normal. La prueba se realizó para la distribución de las diferencias pre-test y post-test en cada componente y el CIPA global. Se demuestra que la práctica totalidad de los valores se adapta a la curva normal puesto que el valor es mayor de 0,05 , excepto el componente 5 pre-test y pos-test en el que existe diferencia significativa entre la muestra y la curva de Gauss (véase el Anexo 11). 
Se seleccionó la T-Test para muestras apareadas y se hallaron las diferencias de medias entre la puntuación global del cuestionario y también entre los cinco componentes. El procedimiento Prueba T para muestras relacionadas compara las medias de dos variables de un solo grupo. El procedimiento calcula las diferencias entre los valores de las dos variables de cada caso y contrasta si la media difiere de 0 .

Estadísticos. Para cada variable: media, tamaño de la muestra, desviación típica y error típico de la media. Para cada pareja de variables: correlación, diferencia promedio entre las medias, prueba t de intervalo de confianza para la diferencia entre las medias (puede especificarse el nivel de confianza). Desviación típica y error típico de la diferencia entre las medias

Supuestos. Las observaciones de cada par deben hacerse en las mismas condiciones. Las diferencias entre las medias deben estar normalmente distribuidas. Las varianzas de cada variable pueden ser iguales o desiguales.

En primer lugar, se presentan los resultados de las puntuaciones globales: 
Tabla 9.Puntuaciones globales del perfil auto dirigido en pre-test y pos-test.

\begin{tabular}{|c|c|c|c|}
\hline CIPA + & Media & $\begin{array}{l}\text { Desviación } \\
\text { típica }\end{array}$ & $\begin{array}{l}\text { Error } \\
\text { típico de } \\
\text { la media }\end{array}$ \\
\hline Total pre-test & 82,566 & 14,457 & 1,282 \\
\hline Total pos-test & 74,157 & 15,499 & 1,375 \\
\hline
\end{tabular}

Tabla 10. Correlaciones entre CIPA total pre-test y pos-test

\begin{tabular}{ccc}
\hline $\mathrm{N}$ & Correlación & Sig. \\
\hline 127 &, 588 &, 000 \\
\hline
\end{tabular}

Tabla 11. Diferencias relacionadas entre puntuaciones globales del cuestionario CIPA pre-test y pos-test

\begin{tabular}{|c|c|c|c|c|c|c|}
\hline \multicolumn{4}{|c|}{ Diferencias relacionadas } & \multirow{3}{*}{$\mathrm{t}$} & \multirow{3}{*}{ gl } & \multirow{3}{*}{$\begin{array}{c}\text { Sig. } \\
\text { bilateral }\end{array}$} \\
\hline Media & $\begin{array}{l}\text { Desviación } \\
\text { típica }\end{array}$ & \multicolumn{2}{|c|}{$\begin{array}{l}95 \% \text { de intervalo de confianza para la } \\
\text { diferencia }\end{array}$} & & & \\
\hline & & Superior & inferior & & & \\
\hline 8,409 & 13,627 & 6,016 & 10,802 & 6,954 & 126 & ,000 \\
\hline
\end{tabular}


Resultados:

- Los estudiantes de $2^{\circ}$ de Grado en Enfermería tienen un nivel que se clasifica en la categoría "muy bueno" en su perfil de autodirección de aprendizaje antes de la aplicación de ABP como se observa en la tabla 9.

- Existe correlación lineal entre pre-test y pos-test, siendo coeficiente de correlación Pearson $=0,588(\mathrm{p}<0,05)$.

- Con una confianza del 95\% se puede afirmar que después de aplicar ABP a los alumnos de enfermería, la puntuación global del perfil auto dirigido mejora, en promedio, 8,41 puntos.

En segundo lugar se presentan los resultados de los cinco componentes AAR: Planificación y selección de estrategias; autorregulación y motivación para sobresalir y conseguir lo que has planificado al administrar tiempo, esfuerzo e información; independencia y autonomía para conseguir objetivos y asumir la responsabilidad de tus actos; uso de experiencia y conciencia crítica para resolver los problemas diarios y corregir tus acciones a tiempo; interdependencia social al valorar y considerar la diversidad de las personas y su aportación al bien social 
Tabla 12. Componente 1: Planificación y selección de estrategias al definir fines, metas, objetivos y acciones.

\begin{tabular}{|c|c|c|c|}
\hline CIPA + & Media & $\begin{array}{l}\text { Desviación } \\
\text { típica }\end{array}$ & $\begin{array}{l}\text { Error } \\
\text { típico de } \\
\text { la media }\end{array}$ \\
\hline Pre-test & 20,503 & 4,307 & ,382 \\
\hline Pos-test & 18,007 & 4,254 & ,377 \\
\hline
\end{tabular}

Tabla 13. Correlaciones entre pre-test y pos-test en el componente 1

\begin{tabular}{ccc}
\hline $\mathrm{N}$ & Correlación & Sig. \\
\hline 127 &, 577 &, 000 \\
\hline
\end{tabular}

Tabla 14. Diferencias relacionadas en puntuaciones del componente 1 entre pre-test y pos-test

\begin{tabular}{|c|c|c|c|c|c|c|}
\hline \multicolumn{3}{|c|}{ Diferencias relacionadas } & & & \\
\cline { 1 - 5 } Media & Desviación típica & $\begin{array}{c}\text { 95\% de intervalo de } \\
\text { confianza para la } \\
\text { diferencia }\end{array}$ & $\mathrm{t}$ & gl & $\begin{array}{c}\text { Sig. } \\
\text { bilateral }\end{array}$ \\
\hline & & Superior & inferior & & & \\
\hline 2,496 & 3,937 & 1,804 & 3,187 & 7,143 & 126 &, 000 \\
\hline
\end{tabular}


Tabla 15 .Componente 2: Autorregulación y motivación para sobresalir y conseguir los objetivos al administrar el tiempo, el esfuerzo e información

\begin{tabular}{|c|c|c|c|}
\hline CIPA + & Media & $\begin{array}{l}\text { Desviación } \\
\text { típica }\end{array}$ & $\begin{array}{l}\text { Error } \\
\text { típico de } \\
\text { la media }\end{array}$ \\
\hline Pre-test & 19,566 & 3,652 & ,324 \\
\hline Pos-test & 17,685 & 3,953 & ,350 \\
\hline
\end{tabular}

Tabla 16.Correlaciones entre pre-test y pos-test en el componente 2

\begin{tabular}{ccc}
\hline $\mathrm{N}$ & Correlación & Sig. \\
\hline 127 &, 460 &, 000 \\
\hline
\end{tabular}

Tabla 17. Diferencias relacionadas en el componente 2 entre el pre-test y pos-test

\begin{tabular}{|c|c|c|c|c|c|c|}
\hline \multicolumn{4}{|c|}{ Diferencias relacionadas } & \multirow{3}{*}{$\mathrm{t}$} & \multirow{3}{*}{ gl } & \multirow{3}{*}{$\begin{array}{c}\text { Sig. } \\
\text { bilateral }\end{array}$} \\
\hline \multirow[t]{2}{*}{ Media } & \multirow[t]{2}{*}{ Desviación típica } & \multicolumn{2}{|c|}{$\begin{array}{c}95 \% \text { de intervalo de } \\
\text { confianza para la } \\
\text { diferencia }\end{array}$} & & & \\
\hline & & Superior & inferior & & & \\
\hline 1,881 & 3,961 & 1,186 & 2,577 & 5,354 & 126 &, 000 \\
\hline
\end{tabular}


Tabla 18.Componente 3: Independencia y autonomía para conseguir los objetivos así como para asumir la responsabilidad de tus actos.

CIPA + Media Desviación Error típica típico de la media

\begin{tabular}{|c|c|c|c|}
\hline Pre-test & 23,063 & 5,012 & ,444 \\
\hline Pos-test & 21,007 & 5,057 & ,448 \\
\hline
\end{tabular}

Tabla 19.Correlaciones entre pre-test y pos-test en el componente 3

\begin{tabular}{ccc}
\hline $\mathrm{N}$ & Correlación & Sig. \\
\hline 127 &, 554 &, 000 \\
\hline
\end{tabular}

Tabla 20.Diferencias relacionadas en el componente 3 entre el pretest y pos-test

\begin{tabular}{|c|c|c|c|c|c|c|}
\hline \multicolumn{4}{|c|}{ Diferencias relacionadas } & \multirow{3}{*}{$\mathrm{t}$} & \multirow{3}{*}{ gl } & \multirow{3}{*}{$\begin{array}{c}\text { Sig. } \\
\text { bilateral }\end{array}$} \\
\hline \multirow[t]{2}{*}{ Media } & \multirow[t]{2}{*}{ Desviación típica } & \multicolumn{2}{|c|}{$\begin{array}{c}95 \% \text { de intervalo de } \\
\text { confianza para la } \\
\text { diferencia }\end{array}$} & & & \\
\hline & & Superior & inferior & & & \\
\hline 2,055 & 4,754 & 1,220 & 2,890 & 4,871 & 126 &, 000 \\
\hline
\end{tabular}


Tabla 21. Componente 4: Uso de experiencia y conciencia crítica para resolver problemas diarios y corregir tus acciones a tiempo.

\begin{tabular}{|c|c|c|c|}
\hline CIPA + & Media & $\begin{array}{l}\text { Desviación } \\
\text { típica }\end{array}$ & $\begin{array}{l}\text { Error } \\
\text { típico de } \\
\text { la media }\end{array}$ \\
\hline Pre-test & 15,929 & 3,462 & ,307 \\
\hline Pos-test & 14,244 & 3,571 & ,316 \\
\hline
\end{tabular}

Tabla 22. Correlaciones entre pre-test y pos-test en el componente

\begin{tabular}{ccc}
\hline $\mathrm{N}$ & Correlación & Sig. \\
\hline 127 &, 533 &, 000 \\
\hline
\end{tabular}

Tabla 23.Diferencias relacionadas en el componente 4 entre el pretest y pos-test

\begin{tabular}{|c|c|c|c|c|c|c|}
\hline \multicolumn{4}{|c|}{ Diferencias relacionadas } & \multirow{3}{*}{$\mathrm{t}$} & \multirow{3}{*}{$\mathrm{gl}$} & \multirow{3}{*}{$\begin{array}{c}\text { Sig. } \\
\text { bilateral } \\
\end{array}$} \\
\hline \multirow[t]{2}{*}{ Media } & \multirow[t]{2}{*}{ Desviación típica } & \multicolumn{2}{|c|}{$\begin{array}{c}95 \% \text { de intervalo de } \\
\text { confianza para la } \\
\text { diferencia }\end{array}$} & & & \\
\hline & & Superior & inferior & & & \\
\hline 1,685 & 3,325 & 1,101 & 2,269 & 5,710 & 126 &, 000 \\
\hline
\end{tabular}


Tabla 24. Componente 4 y tipo de acceso

\begin{tabular}{|ll|l|r|r|r|}
\hline $\begin{array}{l}\text { tipo de } \\
\text { acceso }\end{array}$ & & $\mathrm{N}$ & Media & Desv. típica & $\begin{array}{c}\text { Error. Típ } \\
\text { media }\end{array}$ \\
\hline selectividad & Pretest & 33 & 16,300 & 3,254 &, 566 \\
& Pos-test & 33 & 14,393 & 3,570 &, 621 \\
FP & & & & &, 370 \\
& Pretest & 91 & 15,846 & 3,536 &, 377 \\
& Postest & 91 & 14,263 & 3,598 & \\
\hline
\end{tabular}

Tabla 25. Correlaciones del componente 4 entre pre-test y pos- test según el tipo acceso a Enfermería

\begin{tabular}{|ll|r|r|r|}
\hline tipo de acceso & N & Correlación & Sig. \\
\hline selectividad & $\begin{array}{l}\text { Componente } 4 \\
\text { Pre-test y } \\
\text { Pos-test } \\
\text { FP }\end{array}$ & 33 &, 487 &, 004 \\
$\begin{array}{l}\text { Componente } 4 \\
\text { Pre-test y } \\
\text { Pos-test }\end{array}$ & 91 &, 602 &, 000 \\
\hline
\end{tabular}

Tabla 26.Diferencias relacionadas en el componente 4 entre el pretest y pos-test según el tipo de acceso

\begin{tabular}{|c|c|c|c|c|c|c|c|}
\hline & \multicolumn{4}{|c|}{ Diferencias relacionadas } & \multirow{3}{*}{$\mathrm{t}$} & \multirow{3}{*}{ gl } & \multirow{3}{*}{$\begin{array}{c}\text { Sig. } \\
\text { bilateral }\end{array}$} \\
\hline & \multirow[t]{2}{*}{ Media } & \multirow[t]{2}{*}{ Desviación típica } & \multicolumn{2}{|c|}{$\begin{array}{c}95 \% \text { de intervalo de } \\
\text { confianza para la } \\
\text { diferencia }\end{array}$} & & & \\
\hline & & & Superior & inferior & & & \\
\hline selectividad & 1,909 & 3,467 & ,679 & 3,138 & 3,163 & 32 & ,003 \\
\hline FP & 1,582 & 3,183 & ,919 & 2,245 & 4,742 & 90 & ,000 \\
\hline
\end{tabular}


Tabla 27.Componente 5: Interdependencia social al valorar y considerar la diversidad de las personas y su aportación al bien de la sociedad.

\begin{tabular}{lccc}
\hline CIPA + & Media & $\begin{array}{l}\text { Desviación } \\
\text { típica }\end{array}$ & $\begin{array}{l}\text { Error } \\
\text { típico de } \\
\text { la media }\end{array}$ \\
\hline Pre-test & 3,503 & 1,390 &, 123 \\
\hline Pos-test & 3,212 & 1,343 &, 119 \\
\hline
\end{tabular}

*A menor puntuación mejor nivel (puntuaciones entre 2-10). N=127

Tabla 28.Correlaciones entre pre-test y pos-test en el componente 5

\begin{tabular}{ccc}
\hline $\mathrm{N}$ & Correlación & Sig. \\
\hline 127 &, 524 &, 000 \\
\hline
\end{tabular}

Tabla 29.Diferencias relacionadas en el componente 5 entre el pretest y pos-test

\begin{tabular}{|c|c|c|c|c|c|c|}
\hline \multicolumn{3}{|c|}{ Diferencias relacionadas } & & & \\
\cline { 2 - 5 } Media & Desviación típica & $\begin{array}{c}\text { 95\% de intervalo de } \\
\text { confianza para la } \\
\text { diferencia }\end{array}$ & $\mathrm{t}$ & gl & $\begin{array}{c}\text { Sig. } \\
\text { bilateral }\end{array}$ \\
\hline & & Superior & inferior & & & \\
\hline, 291 & 1,333 &, 057 &, 525 & 2,461 & 126 &, 015 \\
\hline
\end{tabular}

Se puede afirmar que existen diferencias significativas en los cinco componentes del AAR entre el pre-test y pos-test demostrando que la puntuación mejora en cada componente. 
5.2. Evaluación por competencias con ABP

5.2.1Autoevaluación y evaluación a los compañeros

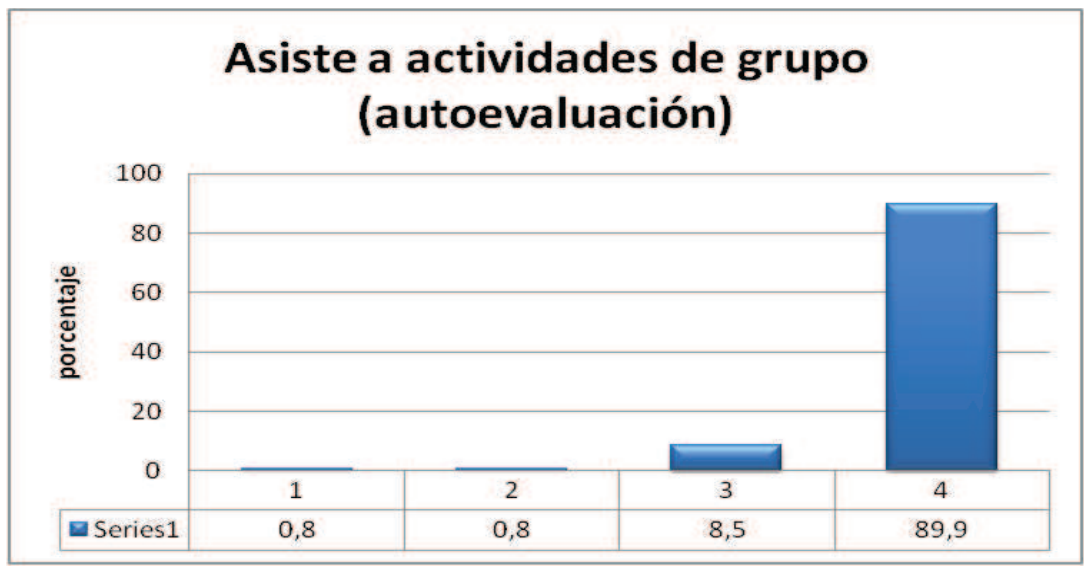

Figura 9. Respuestas a la pregunta $1 . \mathrm{N}=129$. La puntuación va de 1 "totalmente en desacuerdo" a 4 "totalmente de acuerdo". Fuente: Cuestionario para autoevaluación y evaluación a compañeros (ISTEM, 1999).

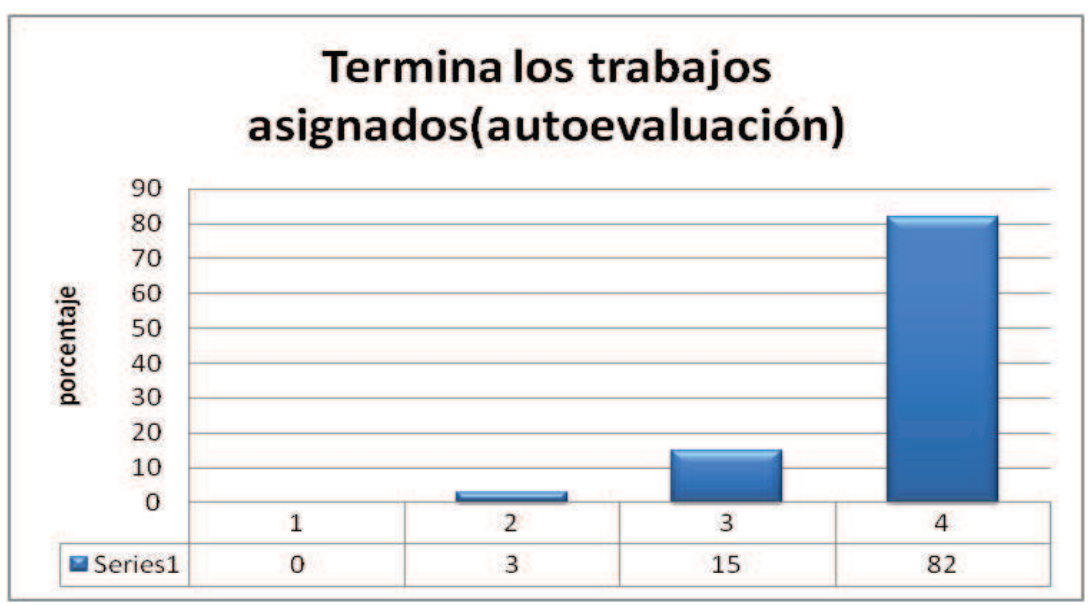

Figura 10. Respuestas a la pregunta $2 . \mathrm{N}=129$ 


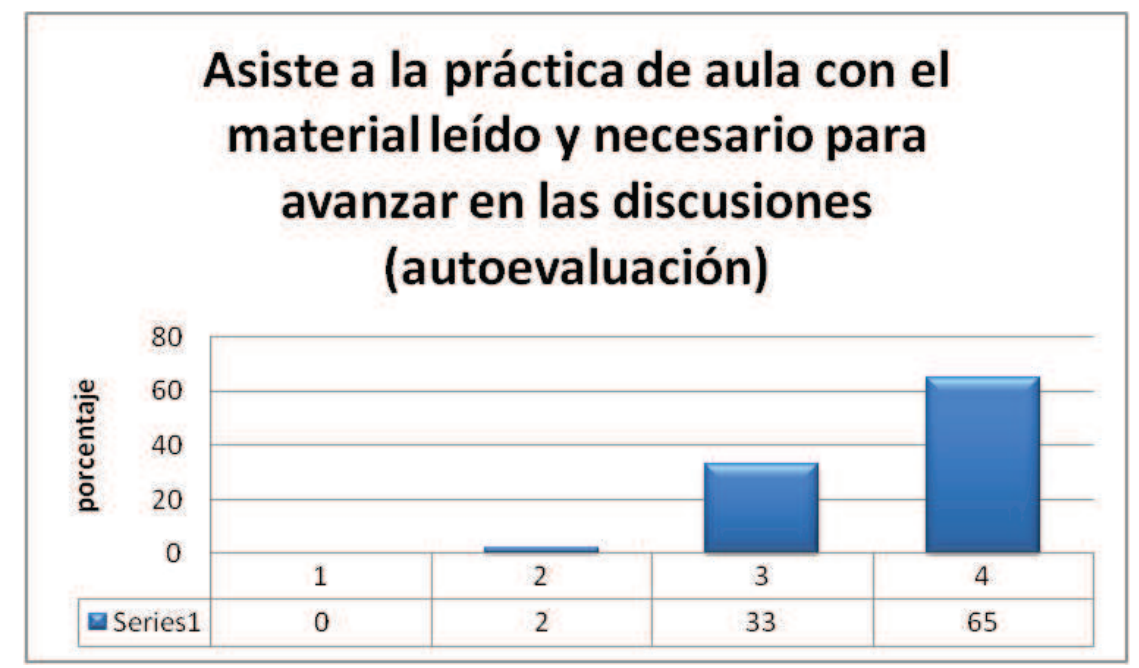

Figura 11.Respuestas a la pregunta 3. $\mathrm{N}=129$

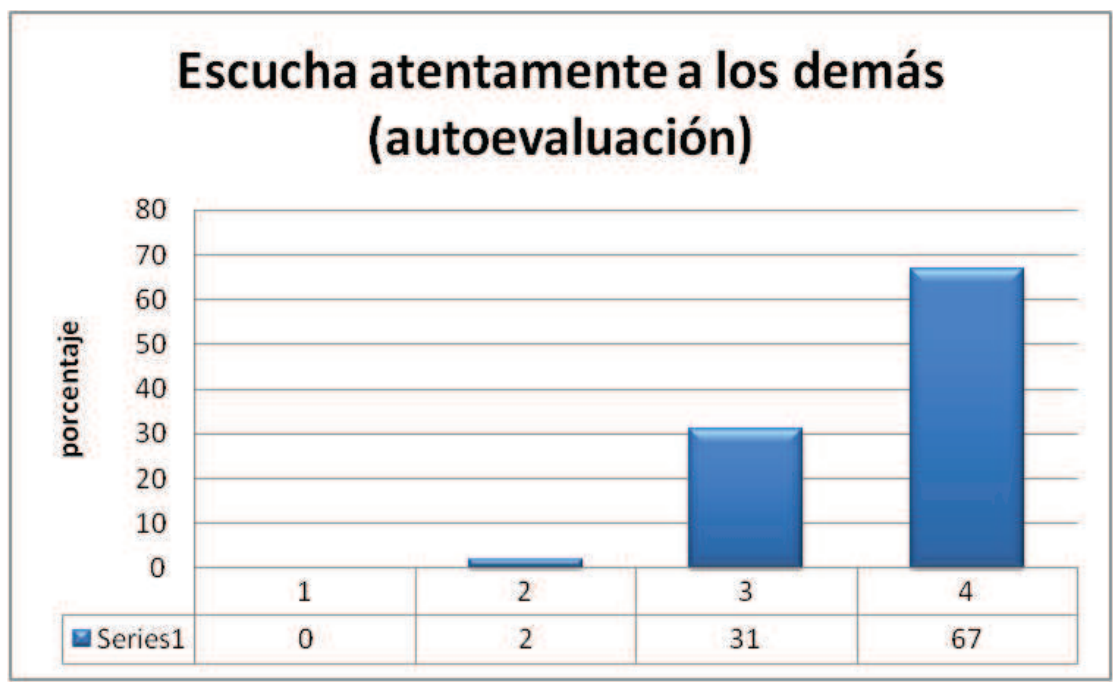

Figura12. Respuestas a la pregunta 4. $\mathrm{N}=129$ 


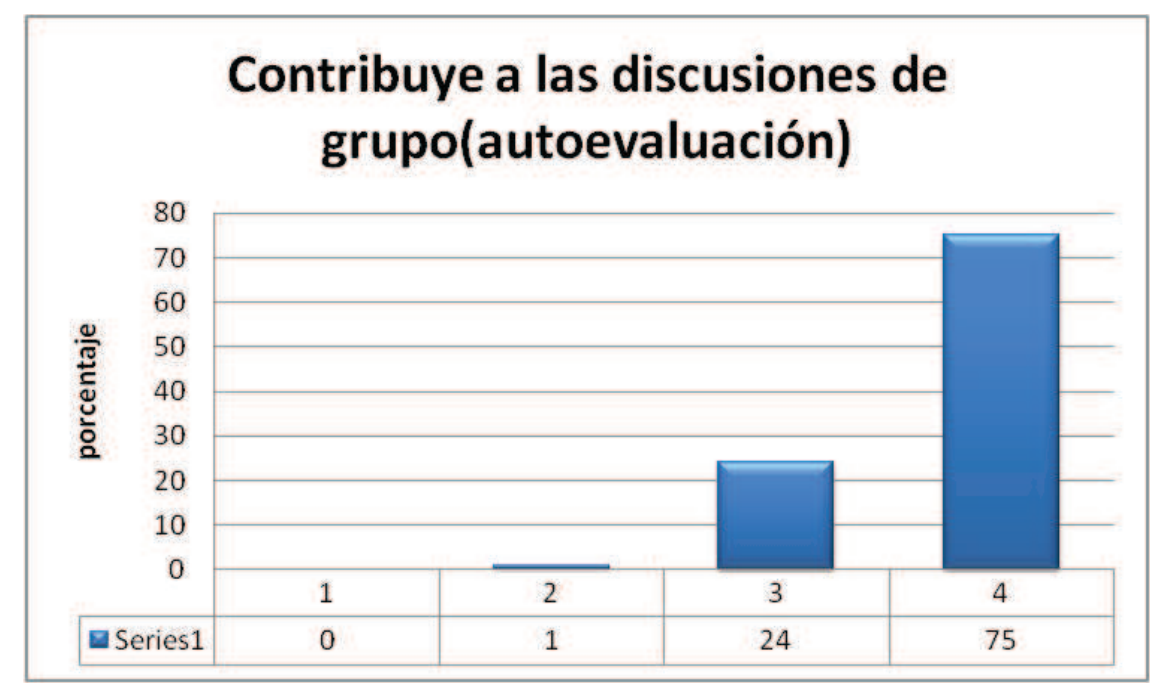

Figura13. Respuestas a la pregunta 5. $\mathrm{N}=129$.

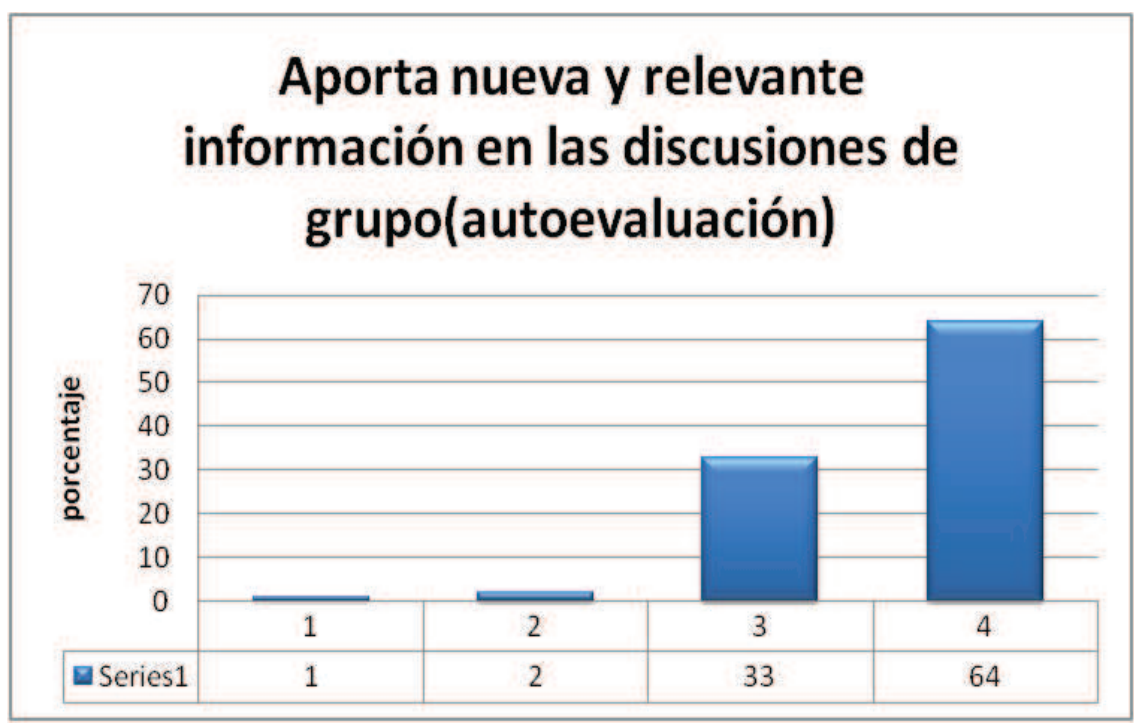

Figura 14. Respuestas a la pregunta $6 . \mathrm{N}=129$ 


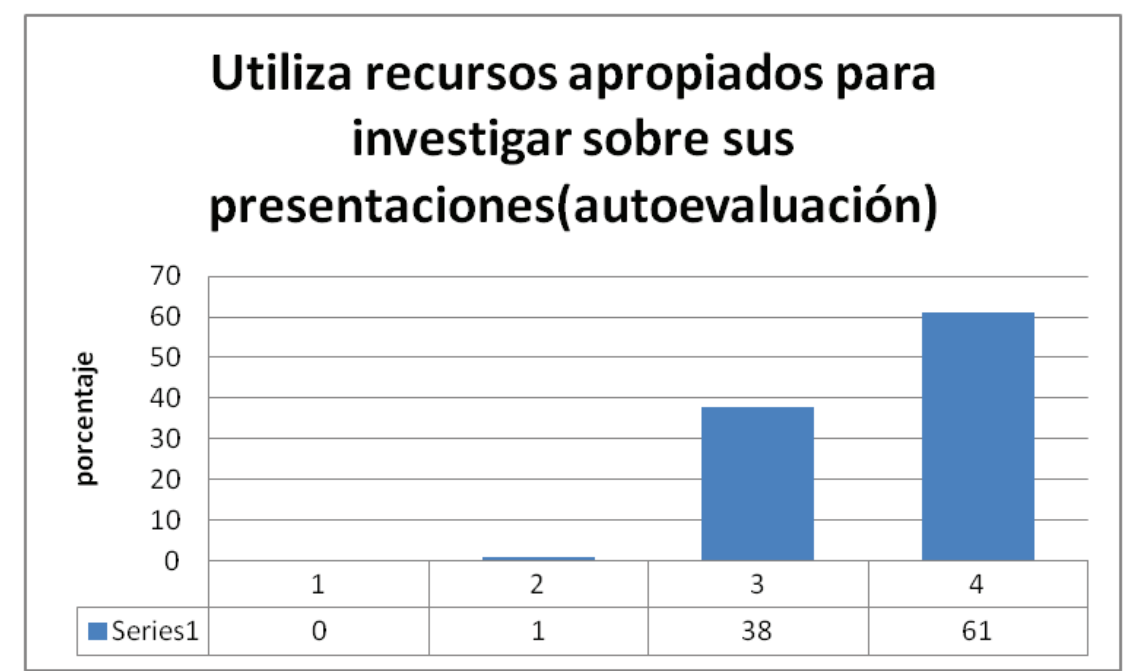

Figura 15. Respuestas a la pregunta 7. $\mathrm{N}=128$

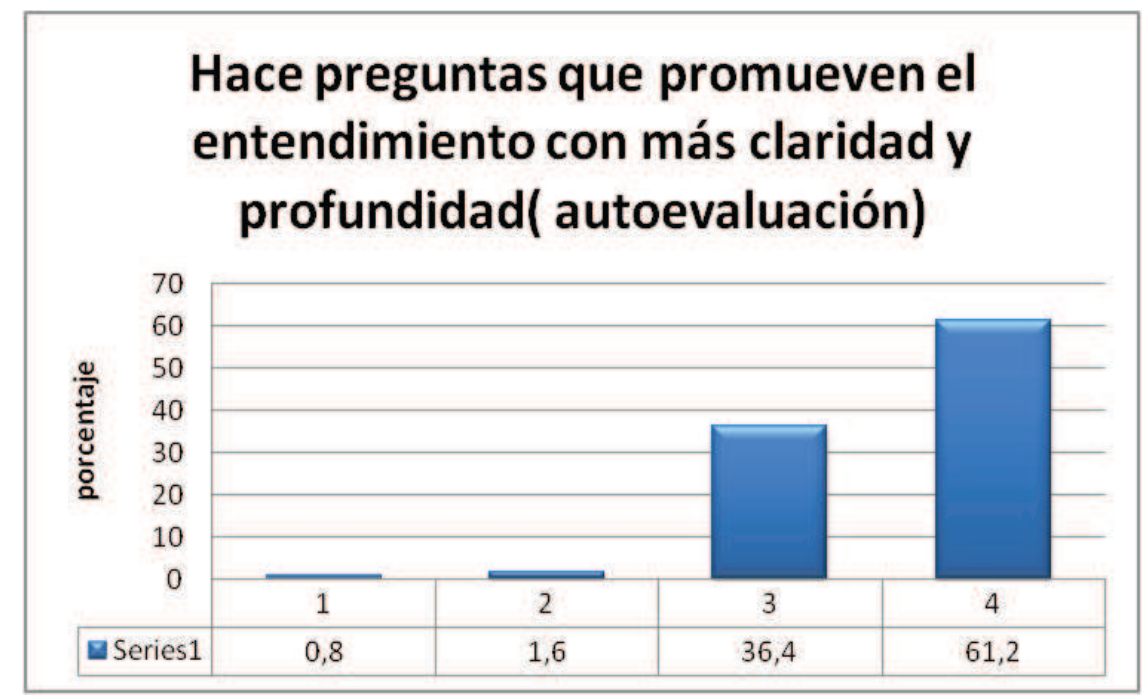

Figura 16. Respuestas a la pregunta 8. $\mathrm{N}=129$ 


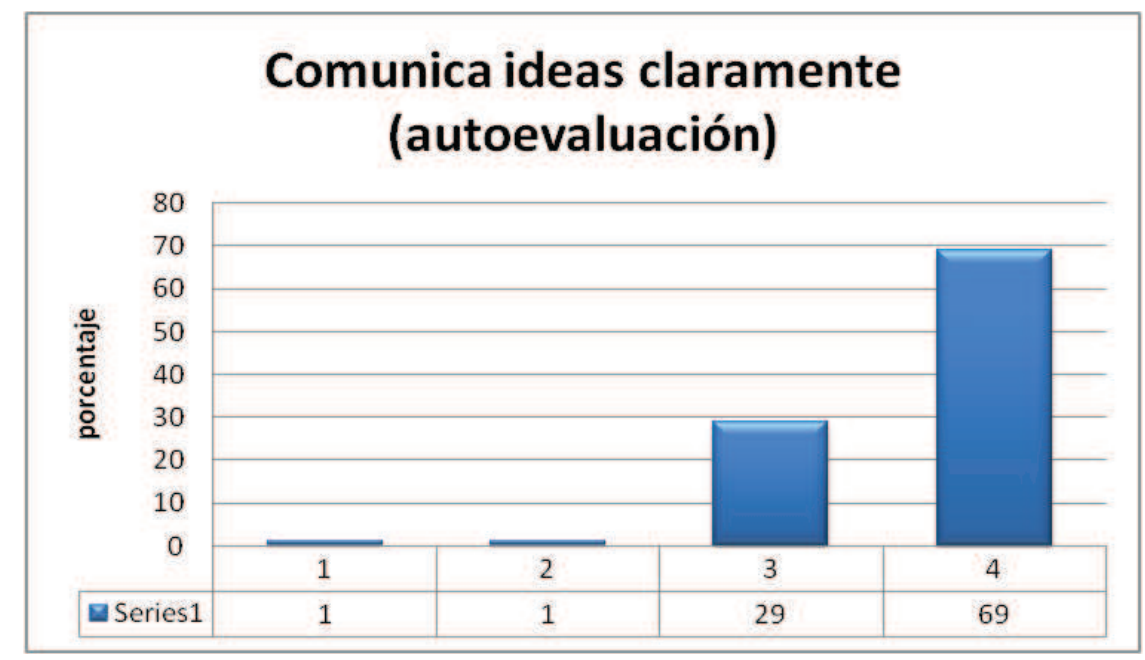

Figura 17. Respuestas a la pregunta $9 . \mathrm{N}=129$

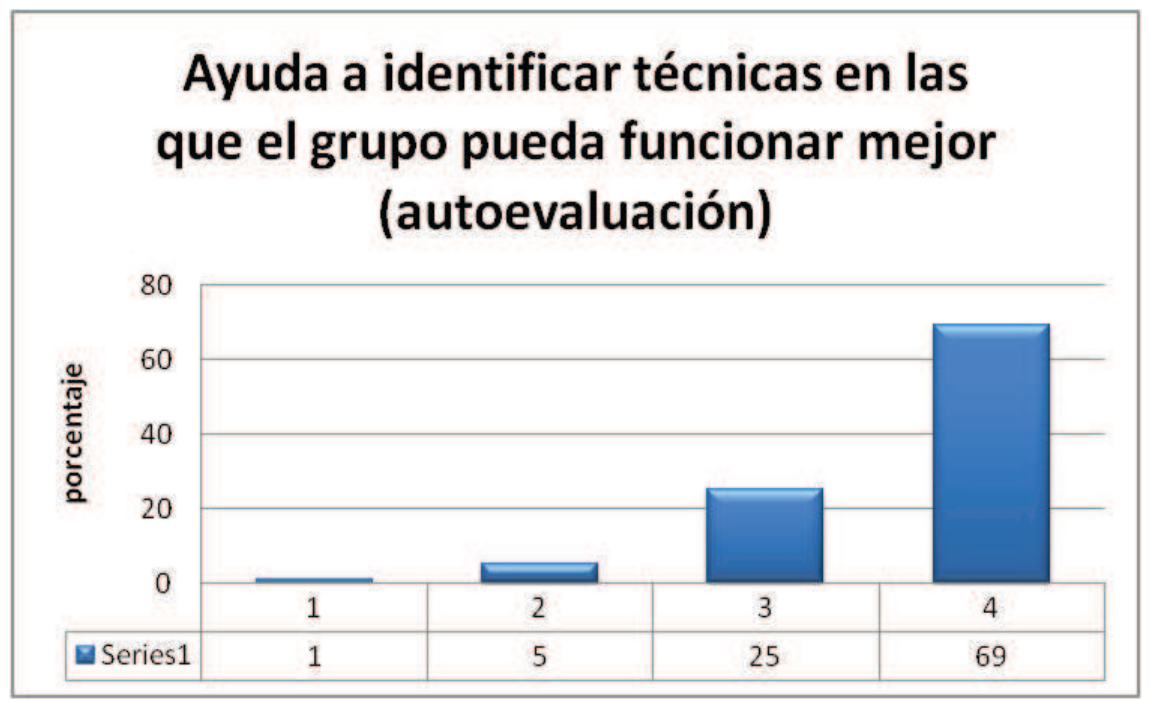

Figura 18. Respuestas a la pregunta 10. $\mathrm{N}=129$ 


\section{Puntuación media en las preguntas de evaluación por pares}

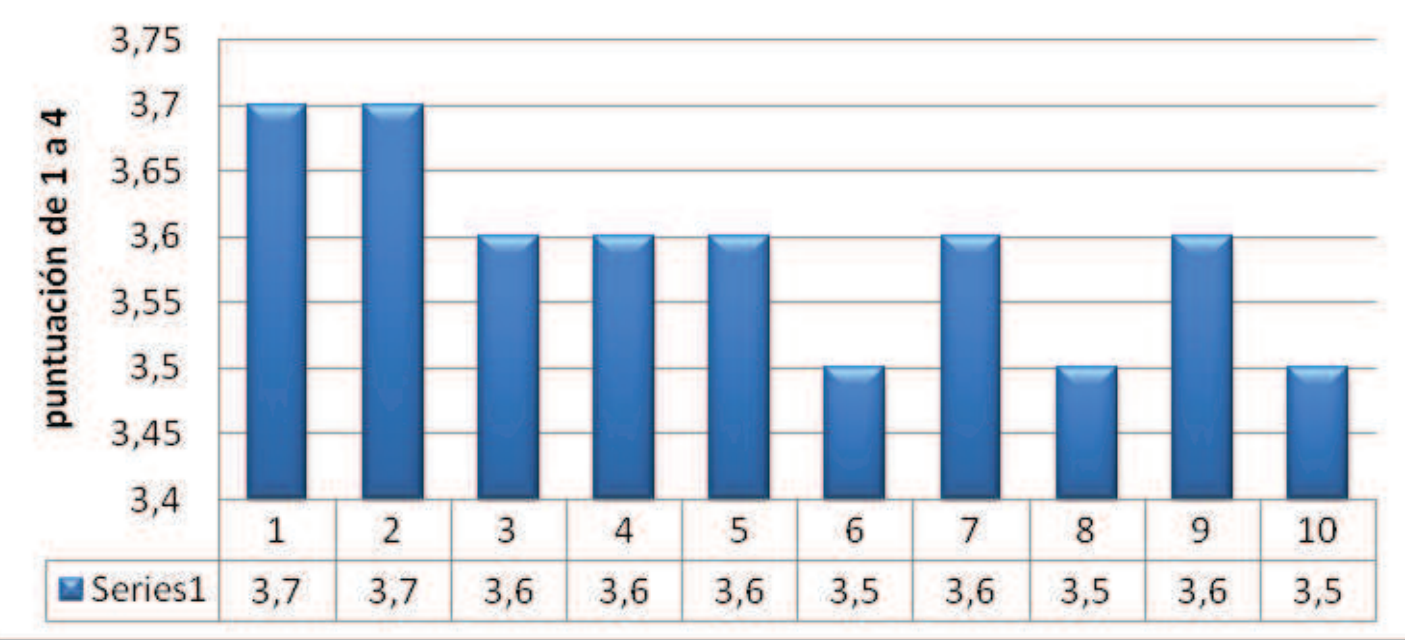

Figura 19. Puntuación media de las preguntas del cuestionario de evaluación por pares. $\mathrm{N}=129$. Fuente: ISTEM, 1999.

En la evaluación por los compañeros de su grupo ABP, los estudiantes tuvieron que contestar al mismo cuestionario que en la autoevaluación. La puntuación 1"totalmente en desacuerdo", 2 "en desacuerdo", 3"de acuerdo" y 4" totalmente de acuerdo". Como se comprueba en la figura 19 las puntuaciones a todas las preguntas estuvieron en un rango entre 3,5 y 3,7 . 


\subsubsection{Evaluación a la tutora}

Los resultados obtenidos del cuestionario evaluación a tutora:

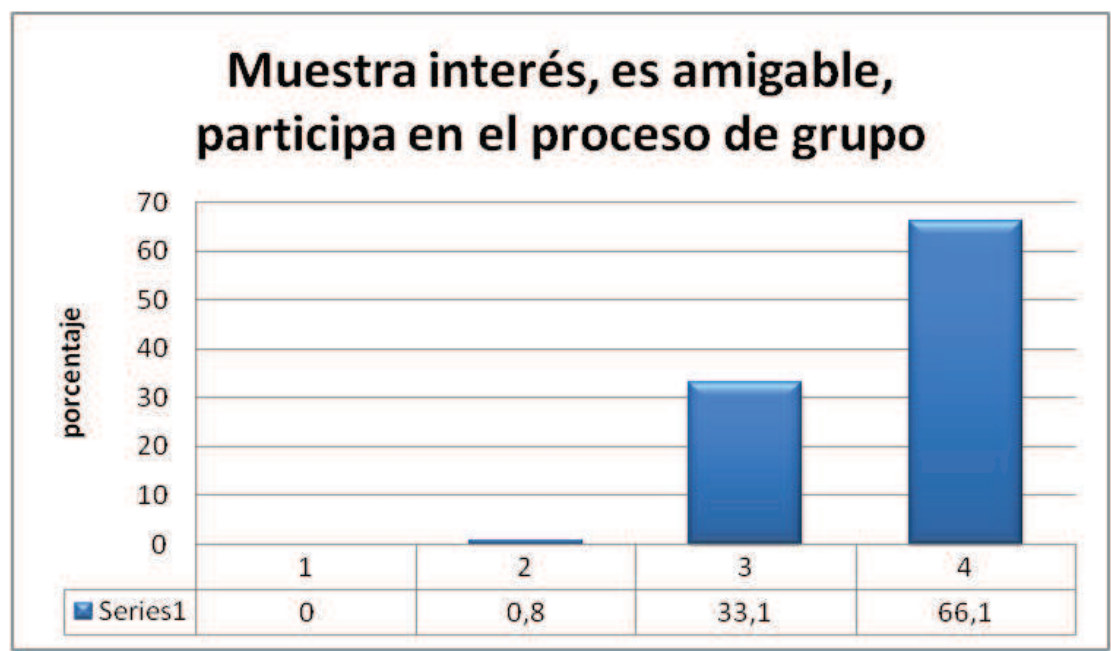

Figura 20. Respuestas de la pregunta 1 del cuestionario de

evaluación a la tutora. $\mathrm{N}=129$. El rango de puntuación de 1 "totalmente en desacuerdo" a 4 "totalmente de acuerdo

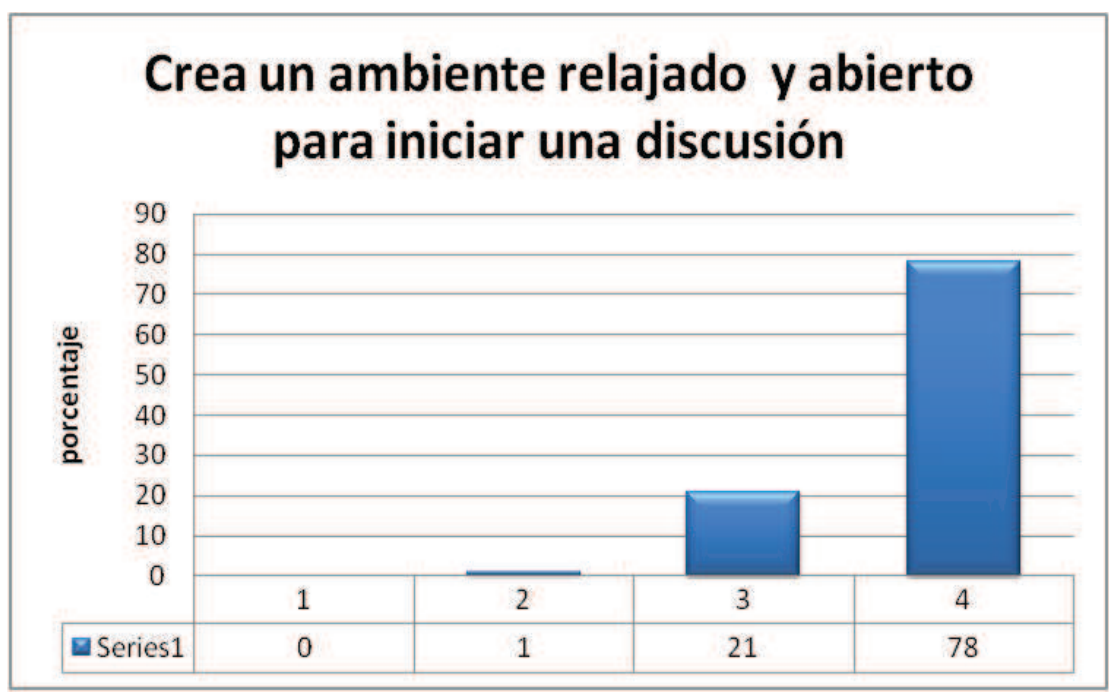

Figura 21. Respuestas de la pregunta 2. $\mathrm{N}=129$. 


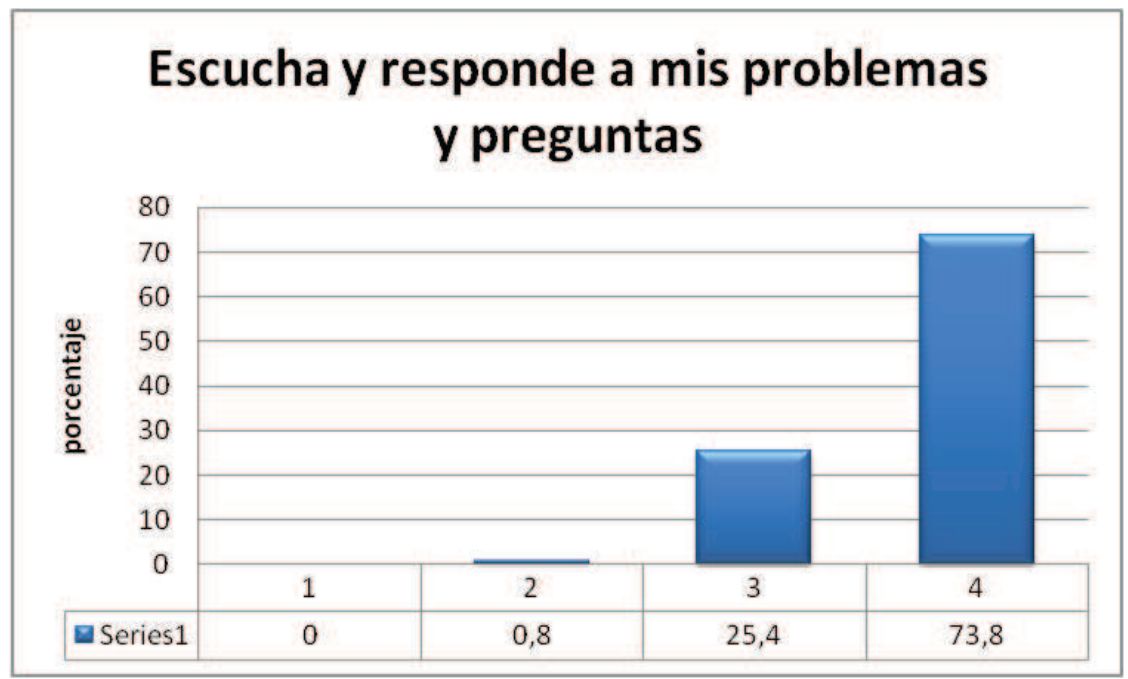

Figura 22.Respuestas de la pregunta $3 . \mathrm{N}=129$. El rango de puntuación de 1 "totalmente en desacuerdo" a 4 "totalmente de acuerdo

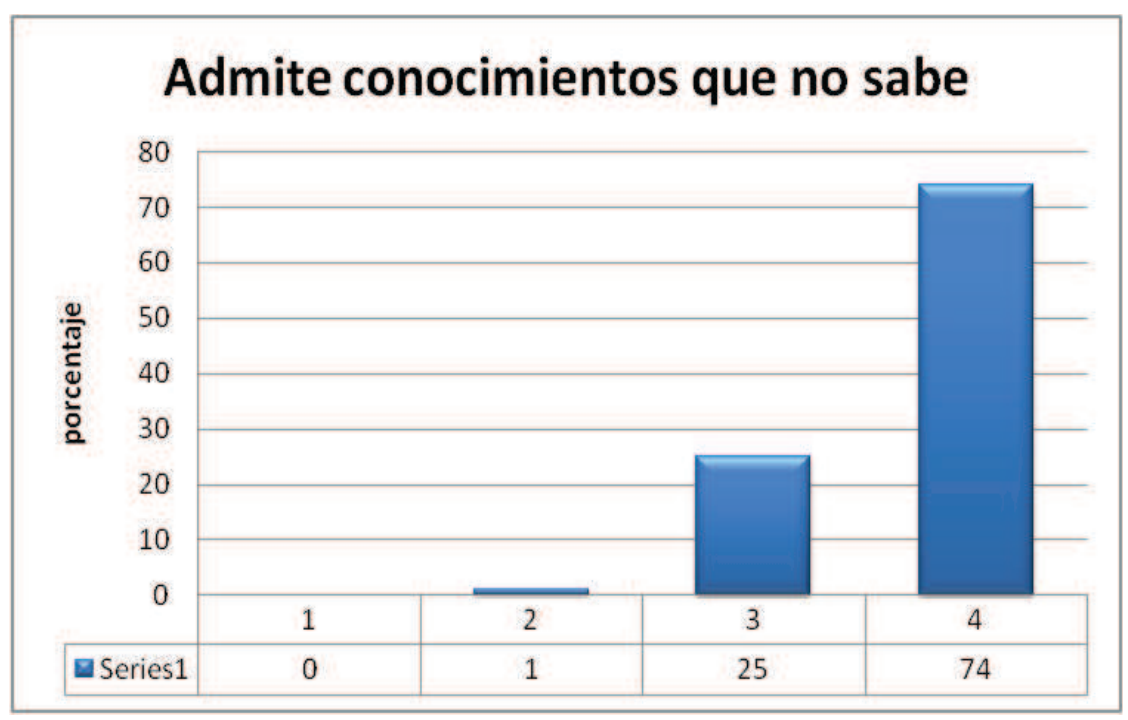

Figura 23. Respuestas de la pregunta 4 . $\mathrm{N}=129$ 


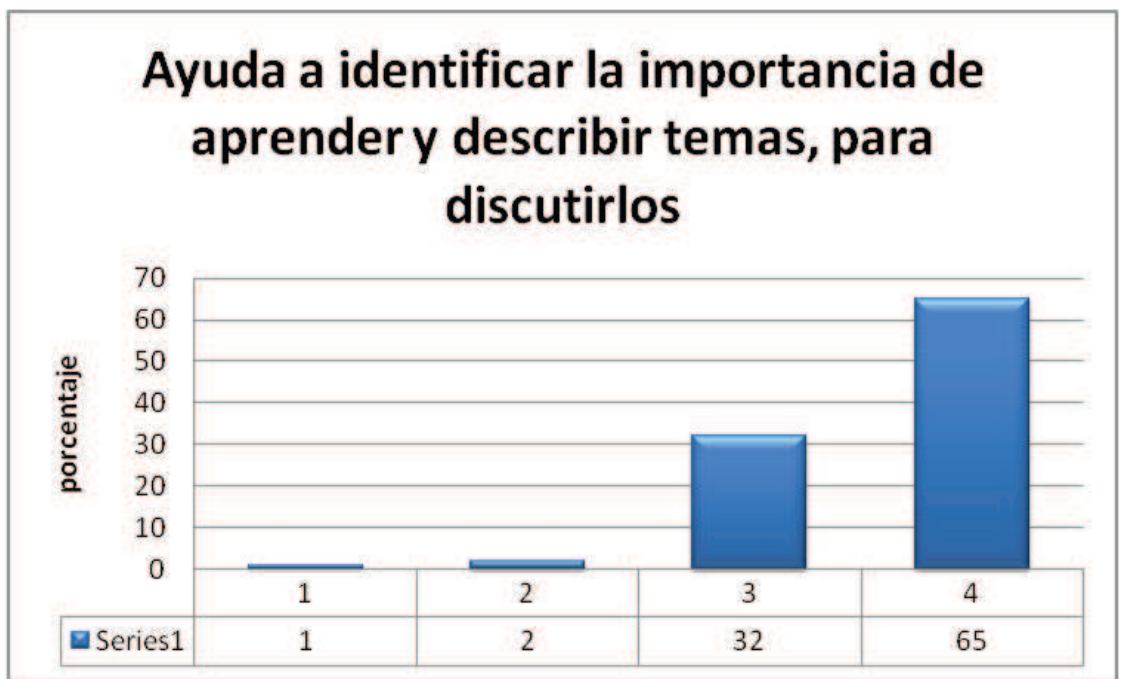

Figura 24. Respuestas de la pregunta $5 \cdot \mathrm{N}=129$. El rango de puntuación de 1 "totalmente en desacuerdo" a 4 "totalmente de acuerdo.

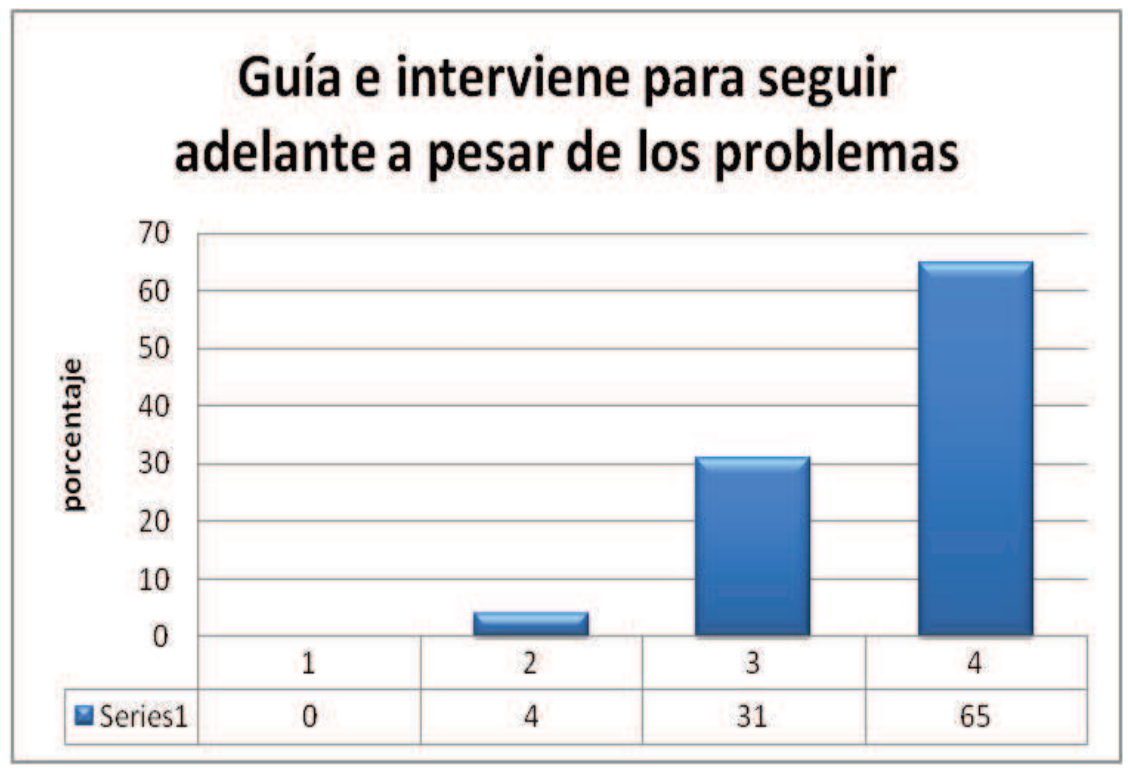

Figura 25. Respuestas de la pregunta $6 . \mathrm{N}=129$. 


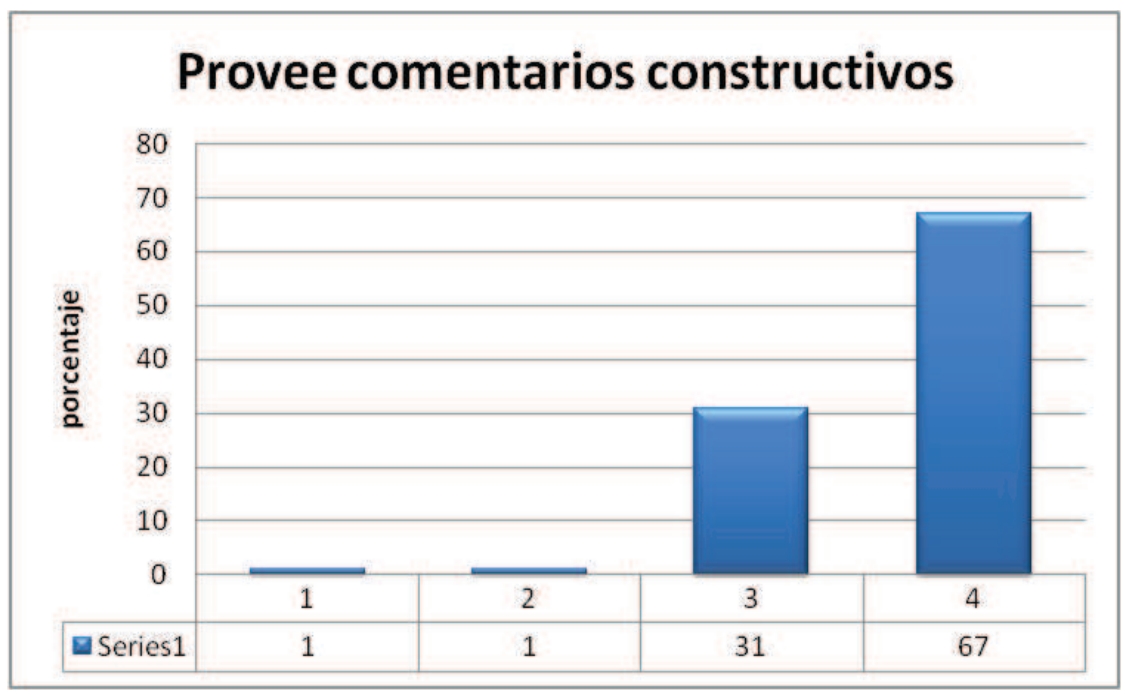

Figura 26.Respuestas de la pregunta $7 . \mathrm{N}=129$. El rango de puntuación de 1 totalmente en desacuerdo" a 4 "totalmente de acuerdo.

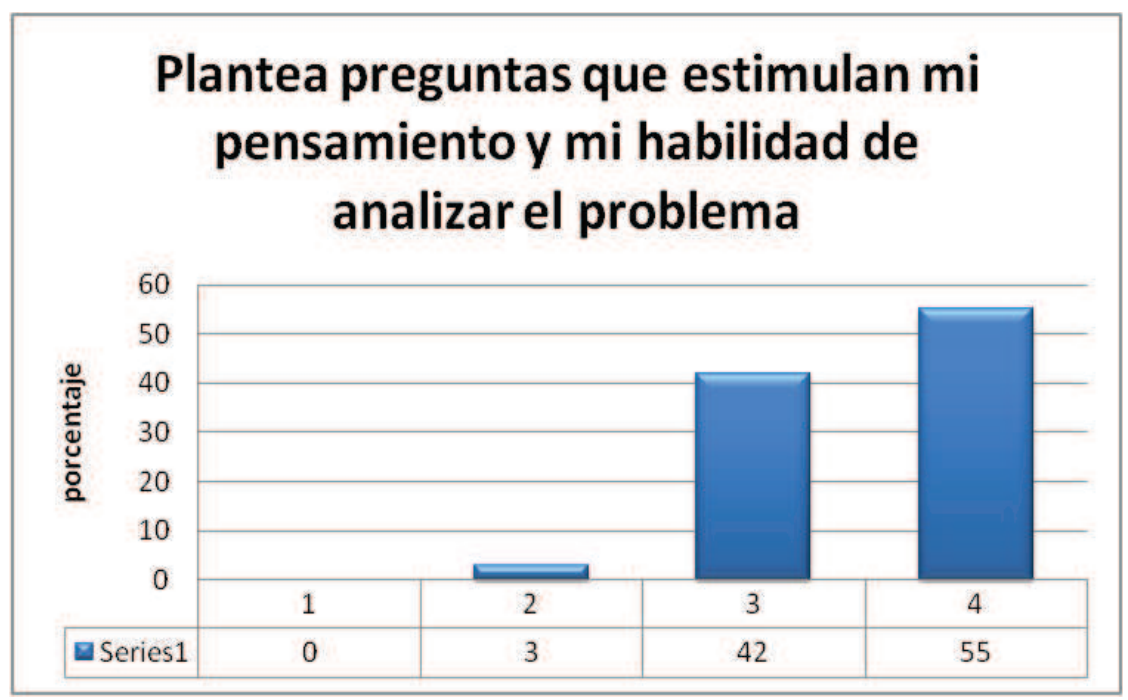

Figura 27. Respuestas de la pregunta $8 \cdot \mathrm{N}=129$ 


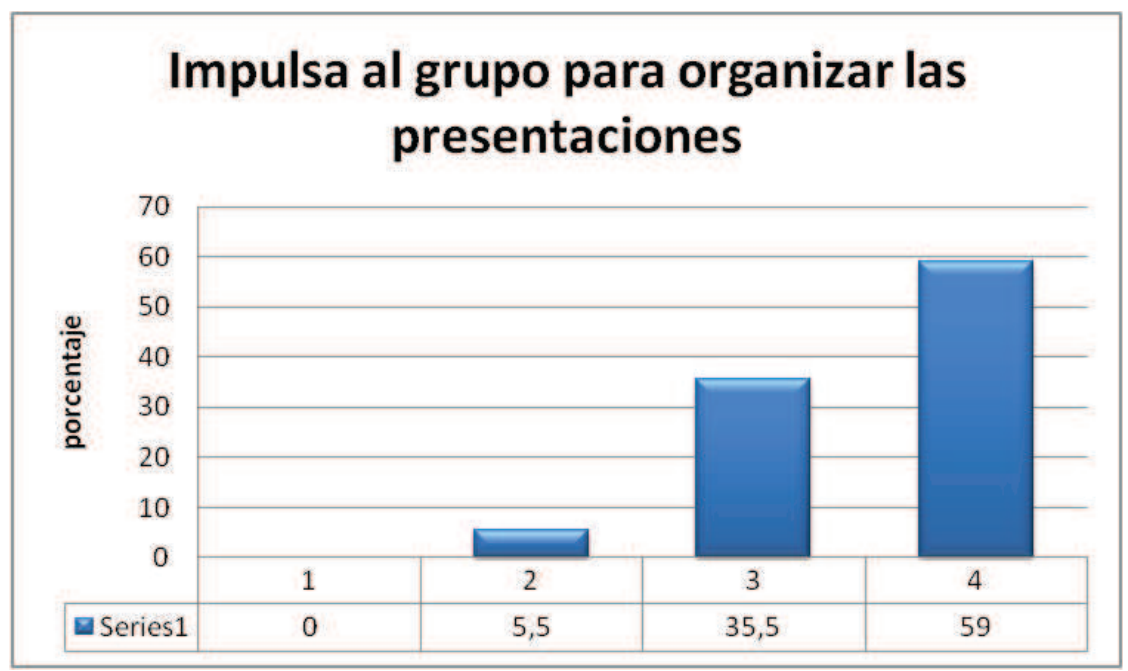

Figura 28.Respuestas de la pregunta $9 . \mathrm{N}=129$, el rango de puntuación de 1 "totalmente en desacuerdo" a 4 "totalmente de acuerdo.

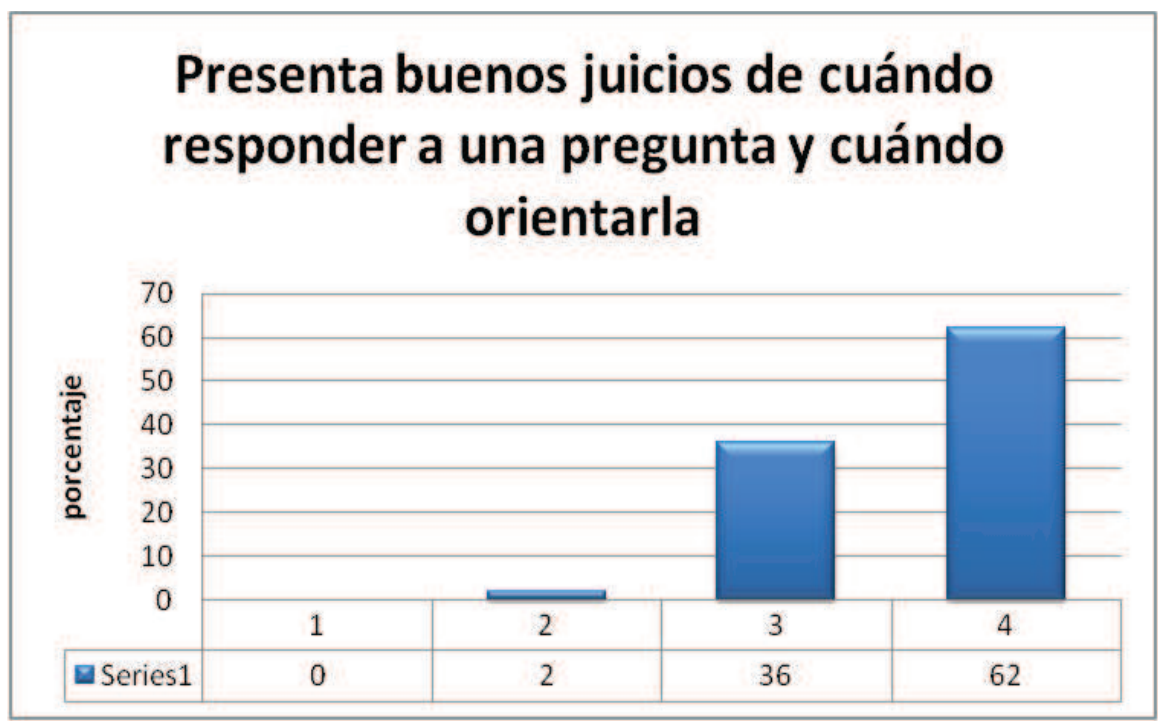

Figura 29.Respuestas de la pregunta 10. $\mathrm{N}=129$. 


\subsubsection{Observación de las prácticas de aula o tutorías}

Se obtuvieron los siguientes resultados de la observación y las anotaciones hechas por la tutora durante las prácticas de aula. Tal como se observa en la figura 30 :

-Dificultad ante un cambio de metodología. En esta experiencia tres estudiantes manifestaron su desacuerdo, aunque finalmente aceptaron trabajar con ABP.

-El seguimiento continuo de los grupos supuso una carga de trabajo importante para la tutora. ABP conlleva supervisar los trabajos y el funcionamiento de los grupos, revisiones parciales, correcciones, diálogo y retroalimentación.

-Conflictos grupales difíciles de manejar. Esto repercutió en el grupo de trabajo creando tensiones entre los compañeros. Los estudiantes que no colaboran, no aportan o no muestran interés, no obtienen las ventajas de trabajo grupal en ABP. En esta investigación, este perfil se presentó en cuatro estudiantes. 


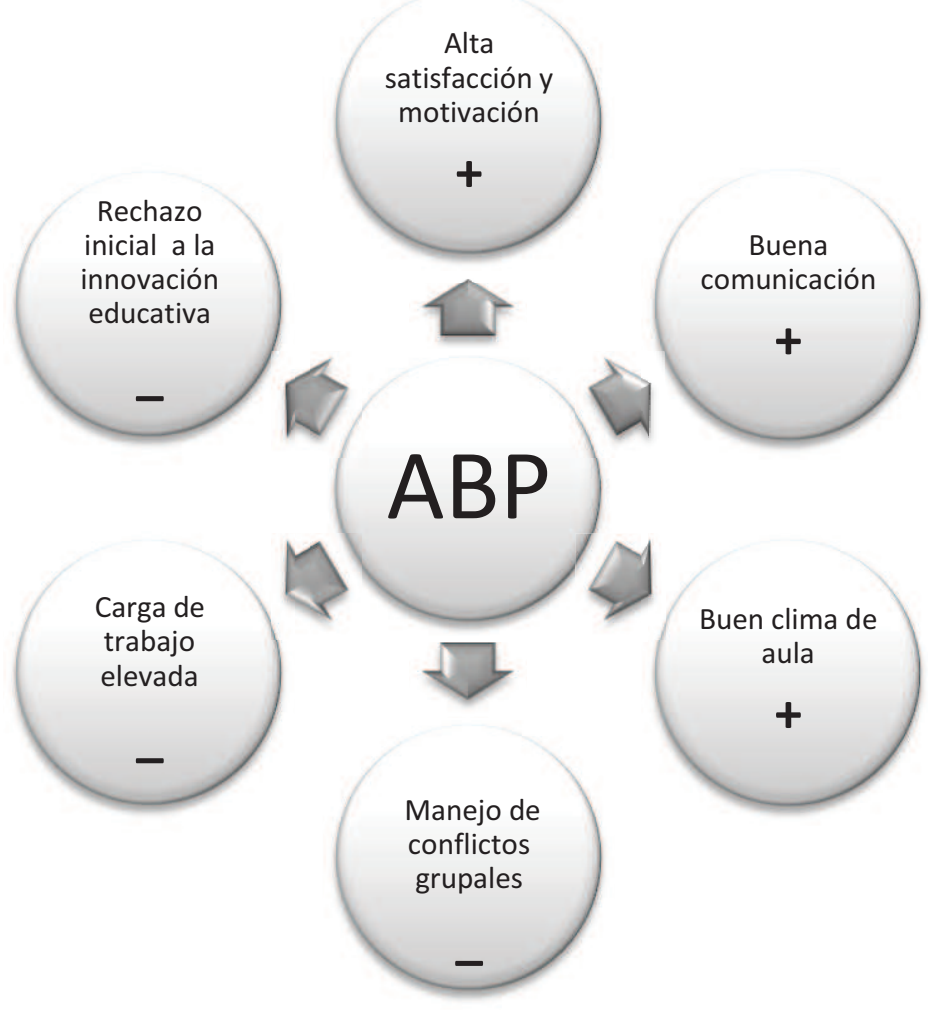

Figura 30. Observación de prácticas de aula o tutorías ABP. Fuente: elaboración propia basada en el análisis de la observación y las percepciones de la tutora.

-Elevado grado de motivación de la tutora al trabajar con ABP porque desde el principio se van viendo avances y resultados en los estudiantes. 
-Óptimas interacciones con los alumnos estableciéndose un buen clima en el aula que facilitó la comunicación entre los estudiantes y tutora.

-Resultó satisfactorio para la profesora utilizar metodología ABP y comprobar un aprendizaje activo de los estudiantes que aportaron trabajos bien elaborados, videos creativos, presentaciones imaginativas, mensajes espontáneos sobre sus experiencias, demostraron empatía con los pacientes del caso clínico, respeto a las opiniones de otros, deseo por el aprender más haciendo pequeñas investigaciones de campo, valores éticos...

\subsubsection{Observación de las presentaciones orales}

La totalidad de los grupos utilizaron la herramienta PowerPoint en la exposición oral y siguieron las normas, tiempo máximo 20 minutos por grupo, y la obligatoriedad participar todos los estudiantes. Cinco grupos crearon un video complementario a su presentación en el que ellos mismos eran los actores, cuatro grupos presentaron un "juego de roles" sobre su caso clínico, dos grupos diseñaron la presentación con preguntas-respuestas, un grupo realizó una demostración práctica sobre el método madre canguro con un pañuelo y un muñeco, y otro realizó la presentación con música y una narración de su experiencia e impacto al acudir a una asociación de discapacitados. Este último grupo, animó al resto de los alumnos a realizar actividades de voluntariado con discapacitados e informó que estas actividades son 
convalidadas por la universidad con créditos ECTS. La evaluación de cada presentación se realizó por tres observadores cuyo fin fue mejorar la fiabilidad y validez de las observaciones. La profesora pidió la ayuda de dos voluntarios diferentes en cada presentación que registraron la observación de sus compañeros en un formulario, al igual que la profesora. Al finalizar las presentaciones, los estudiantes las compartieron con el resto de sus compañeros insertándolas en la plataforma virtual como se observa en la figura 31. 


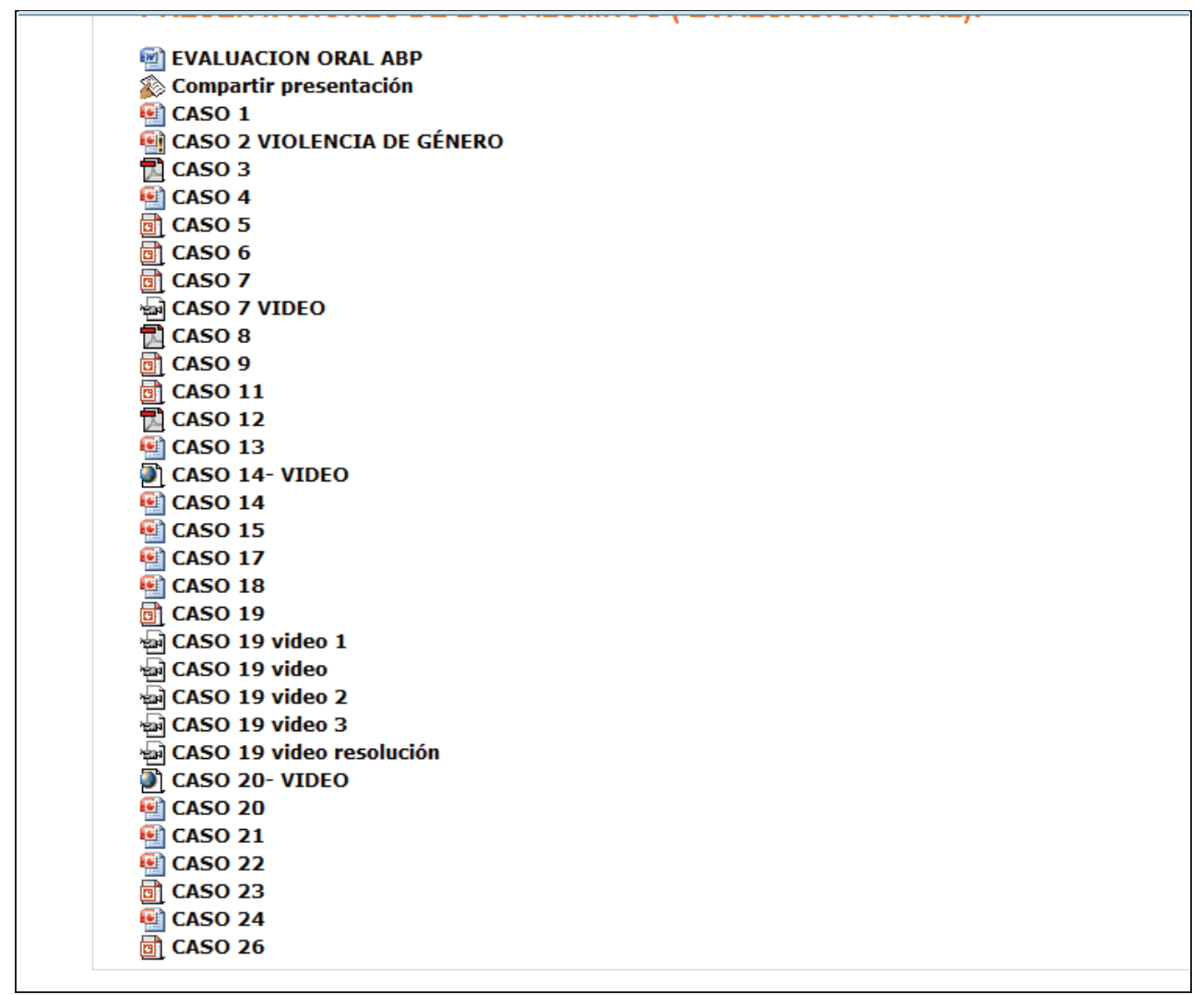

Figura 31.Presentaciones en PowerPoint y videos que se insertaron en la plataforma Moodle. *Los estudiantes enviaron su presentación y videos para compartirlos con el resto de los alumnos de $2^{\circ}$ de Grado en Enfermería. Todos los casos clínicos fueron diferentes.

\subsection{Grado de satisfacción de los estudiantes de Enfermería que}

\section{han aprendido con ABP}

Otro objetivo fue conocer el grado de satisfacción de los estudiantes en relación con el ABP a través del cuestionario que se incluye en el Anexo 2. Los datos cuantitativos se analizaron a través del programa SPSS y los cualitativos mediante el análisis de contenido de las 
justificaciones a las respuestas del cuestionario de satisfacción de Márquez, Uribe, Montes, Monroy, \& Ruiz, (2011).

Los resultados obtenidos son:

Tabla 30. Procesamiento de los casos

\begin{tabular}{|ll|r|r|}
\hline & & \multicolumn{1}{|c|}{$\mathrm{N}$} & \multicolumn{1}{c|}{$\%$} \\
\hline Casos & Válidos & 122 & 91,0 \\
& Excluidos(a) & 12 & 9,0 \\
& Total & 134 & 100,0 \\
\hline
\end{tabular}

a Eliminación por lista basada en todas las variables del procedimiento.

Tabla 31. Variable sexo (resultados cuestionario grado satisfacción)

\begin{tabular}{|ll|r|r|r|}
\hline & & & \multicolumn{2}{c|}{$\begin{array}{c}\text { Porcentaje } \\
\text { válido }\end{array}$} \\
\hline Válidos & mujer & 114 & 85,1 & 85,1 \\
& hombre & 20 & 14,9 & 14,9 \\
& Total & 134 & 100,0 & 100,0 \\
\hline
\end{tabular}

Tabla 32. Nota media actual

\begin{tabular}{|ll|r|r|r|r|}
\hline & & & \multicolumn{2}{c|}{$\begin{array}{c}\text { Porcentaje } \\
\text { válido }\end{array}$} & $\begin{array}{r}\text { Porcentaje } \\
\text { acumulado }\end{array}$ \\
\hline Válidos & $5-6,9$ & 45 & 33,6 & 34,4 & 34,4 \\
& $7-7,9$ & 61 & 45,5 & 46,6 & 80,9 \\
& $8-8,9$ & 23 & 17,2 & 17,6 & 98,5 \\
& $9-10$ & 2 & 1,5 & 1,5 & 100,0 \\
& Total & 131 & 97,8 & 100,0 & \\
Perdidos & Sistema & 3 & 2,2 & & \\
Total & 134 & 100,0 & & \\
\hline
\end{tabular}


Tabla 33. Metodología preferida

\begin{tabular}{|ll|r|r|r|}
\hline & & & \multicolumn{1}{|c|}{$\begin{array}{c}\text { Porcentaje } \\
\text { válido }\end{array}$} \\
\hline Válidos & ABP & 59 & 44,0 & 45,4 \\
& Método tradicional & 71 & 53,0 & 54,6 \\
& Total & 130 & 97,0 & 100,0 \\
Perdidos & Sistema & 4 & 3,0 & \\
Total & & 134 & 100,0 & \\
\hline
\end{tabular}

Tabla 34. ¿Te gusta ABP?

\begin{tabular}{|ll|r|r|r|}
\hline & & & \multicolumn{2}{c|}{$\begin{array}{c}\text { Porcentaje } \\
\text { válido }\end{array}$} \\
\hline Válidos & si & 105 & 78,4 & 78,4 \\
& no & 29 & 21,6 & 21,6 \\
& Total & 134 & 100,0 & 100,0 \\
\hline
\end{tabular}

Tabla 35.¿Cómo te consideras como estudiante?

\begin{tabular}{|ll|r|r|r|}
\hline & & & \multicolumn{2}{c|}{$\begin{array}{c}\text { Porcentaje } \\
\text { válido }\end{array}$} \\
\hline Válidos & malo & Frecuencia & Porcentaje & 0,7 \\
& regular & 0,7 & 24,6 \\
& bueno & 1 & 24,6 & 74,6 \\
& Total & 100 & 74,6 & 100,0 \\
\hline
\end{tabular}

Se presentan primero los resultados de las respuestas de satisfacción en porcentajes y después las justificaciones escritas de cada ítem. 


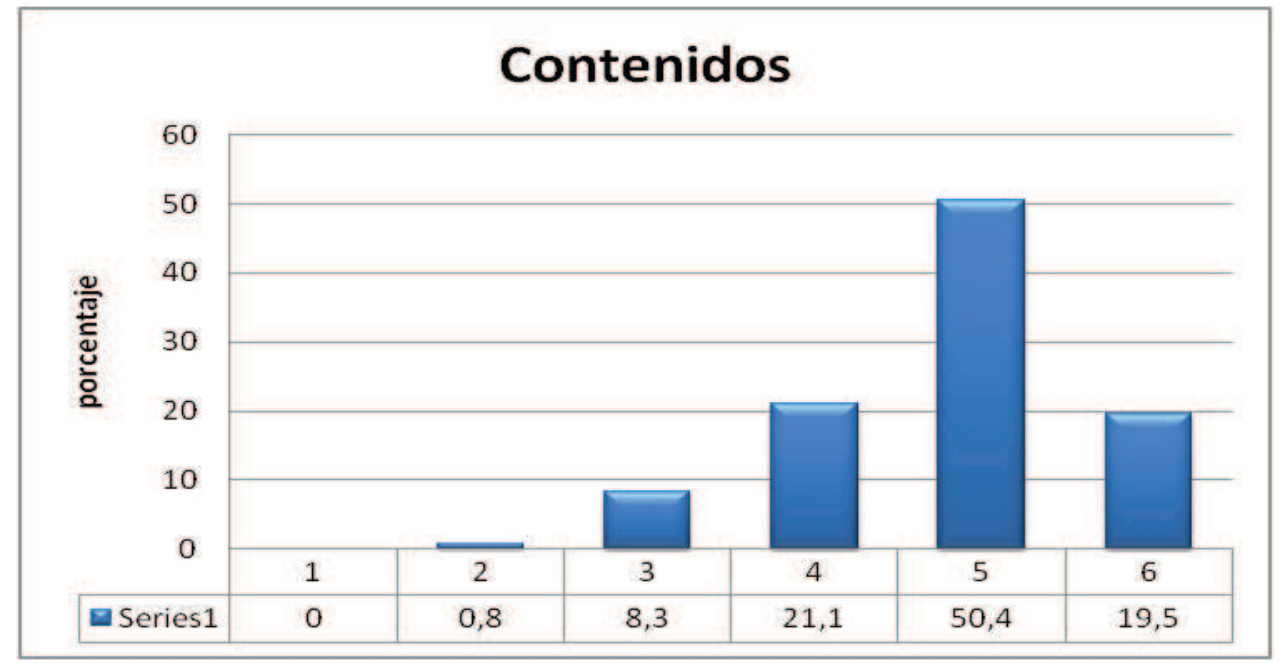

Figura 32. Grado de satisfacción respecto a los contenidos revisados en tutorías ABP. La puntuación se valora desde 1(nada satisfecho) a 6(totalmente satisfecho.
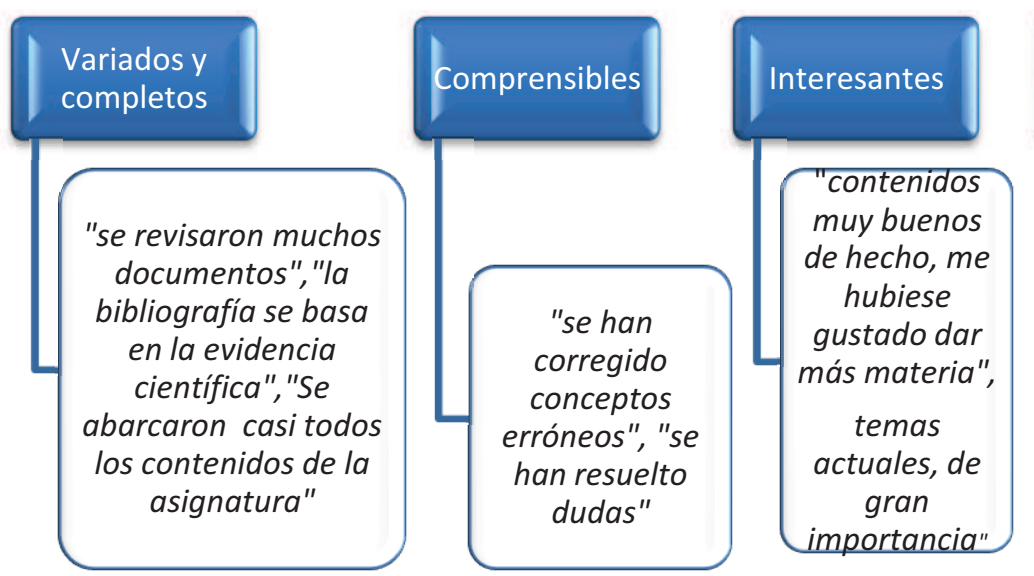
Prácticos y útiles

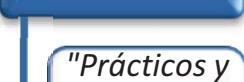 cercanos al hospital"," Me han servido para contestar dudas de salud de mis amigas"

Figura 33. Satisfacción de los estudiantes con los contenidos de las

tutorías ABP Fuente: respuestas del cuestionario de satisfacción. *Cuatro estudiantes justificaron los contenidos como: "insuficientes, no me han gustado, son demasiados y no valen para mucho. 


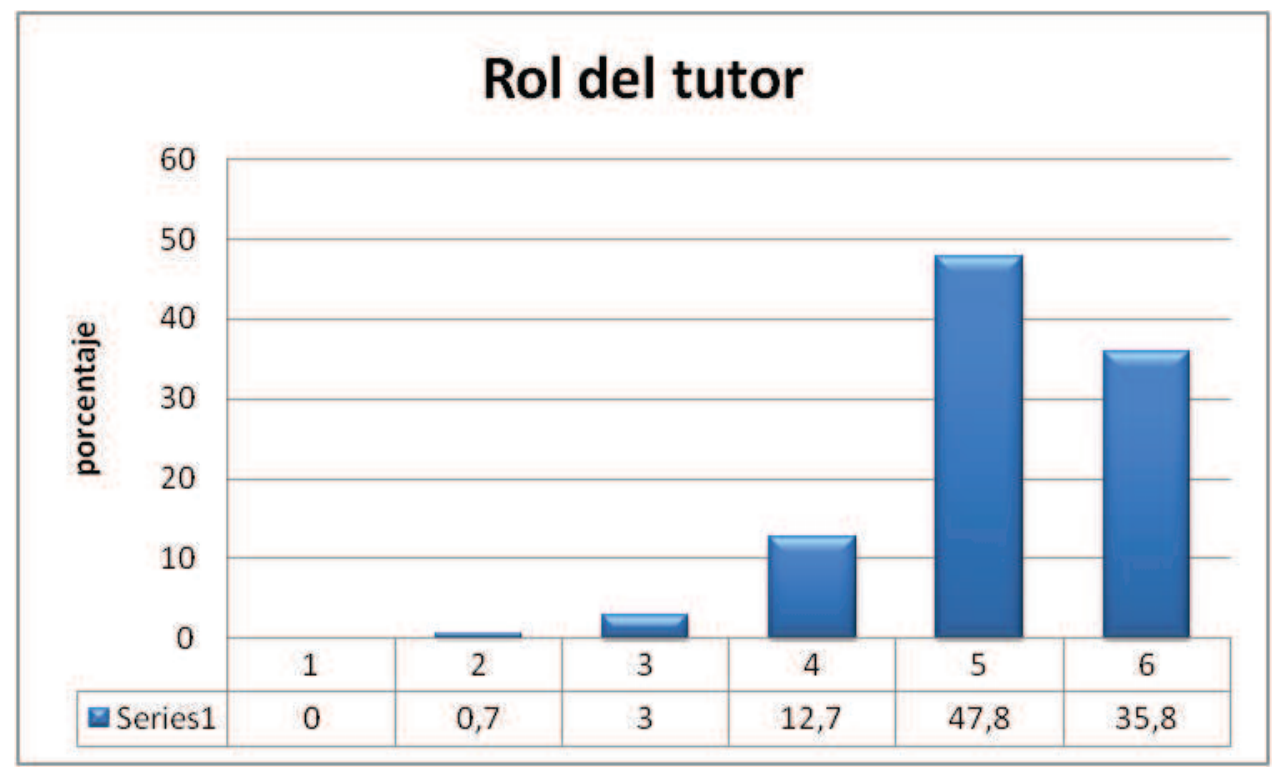

Figura 34.Satisfacción respecto al rol de la tutora en ABP. La puntuación se valora desde 1(nada satisfecho) a 6(totalmente satisfecho).

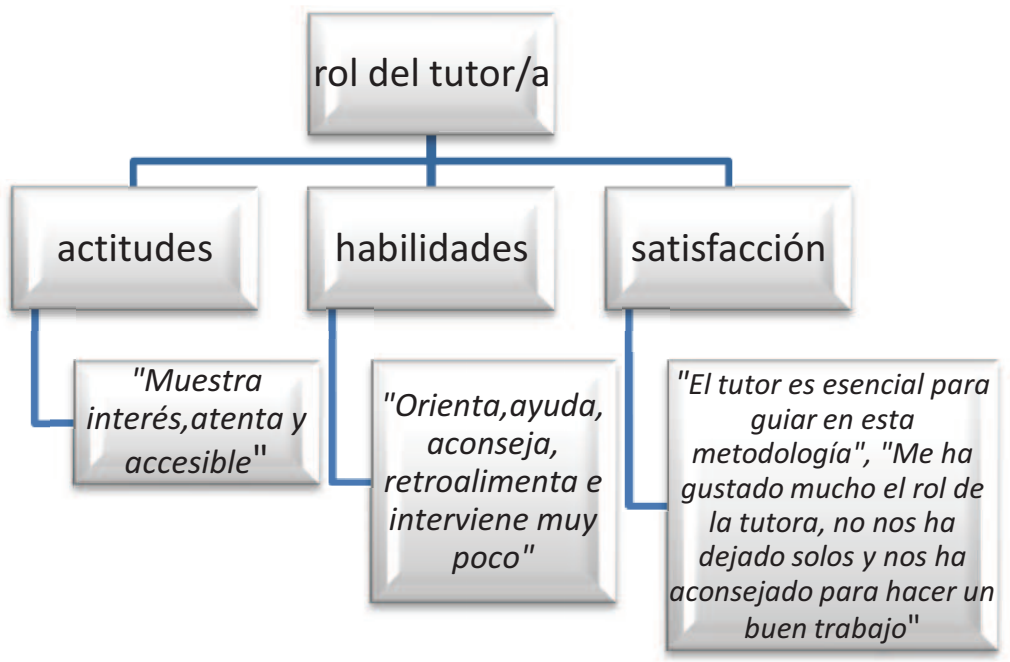

Figura 35. Respuestas justificadas respecto a la satisfacción de los estudiantes con el rol del tutor 


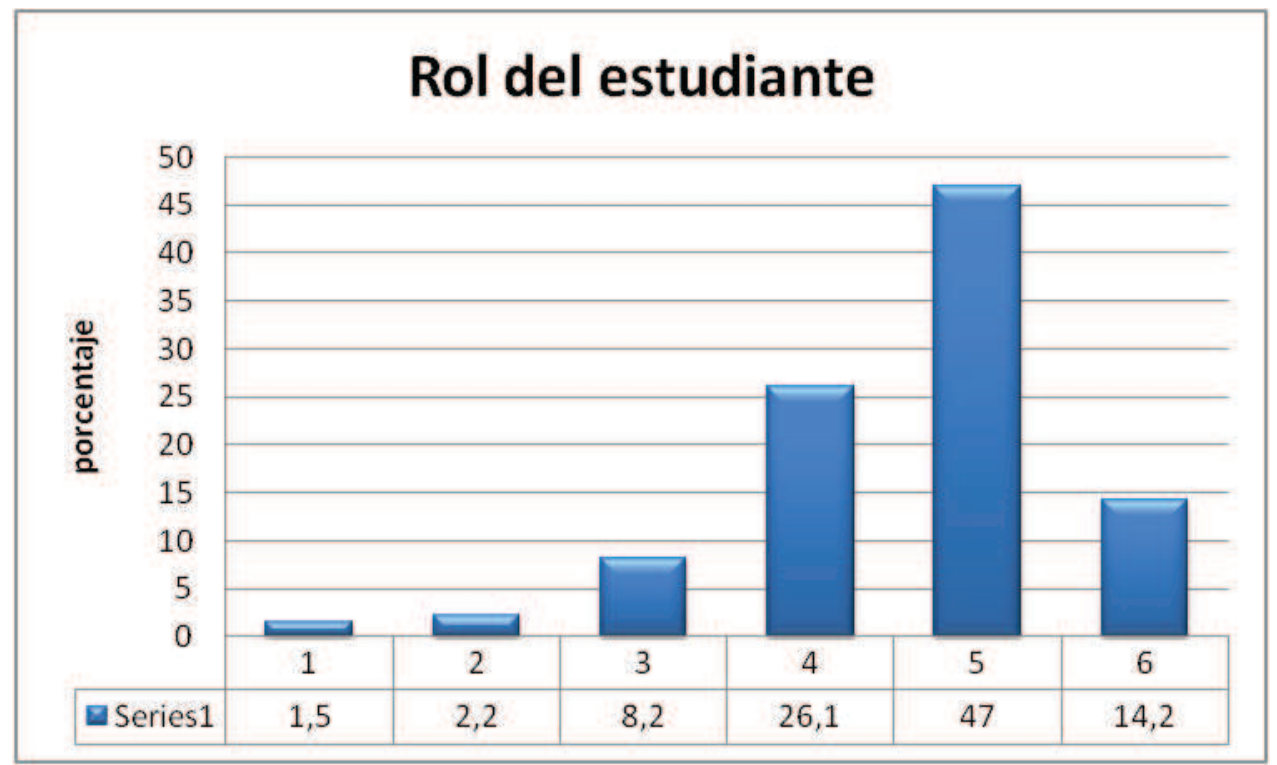

Figura 36. Satisfacción con el rol del estudiante en ABP. La puntuación se valora desde 1(nada satisfecho) a 6(totalmente satisfecho).

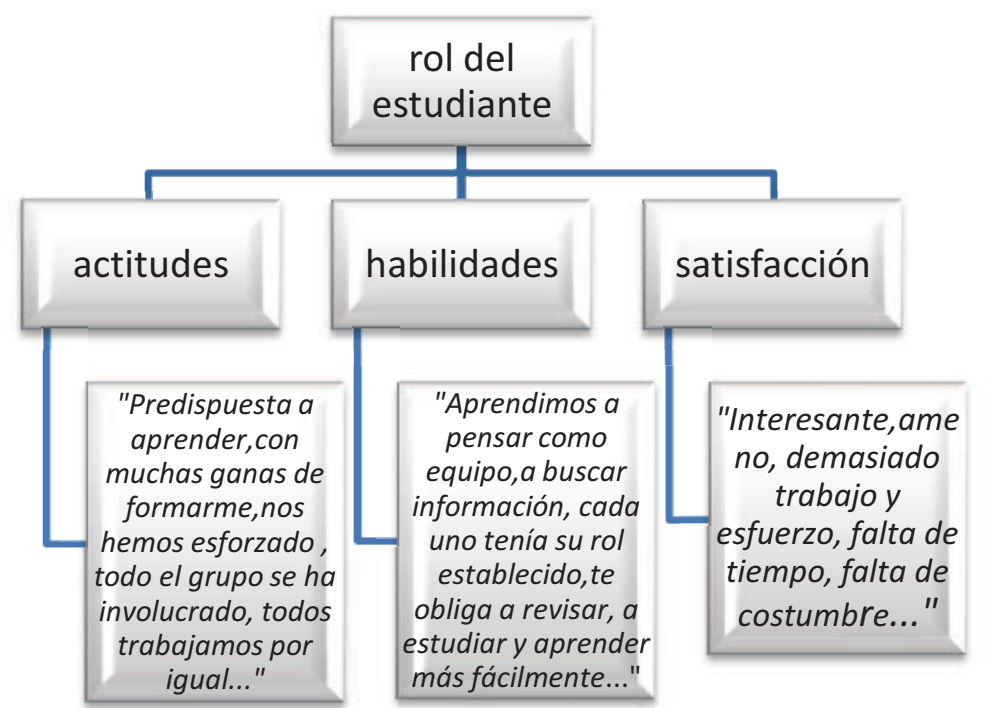

Figura 37. Respuestas justificadas respecto a la satisfacción de los alumnos con el rol del estudiante 


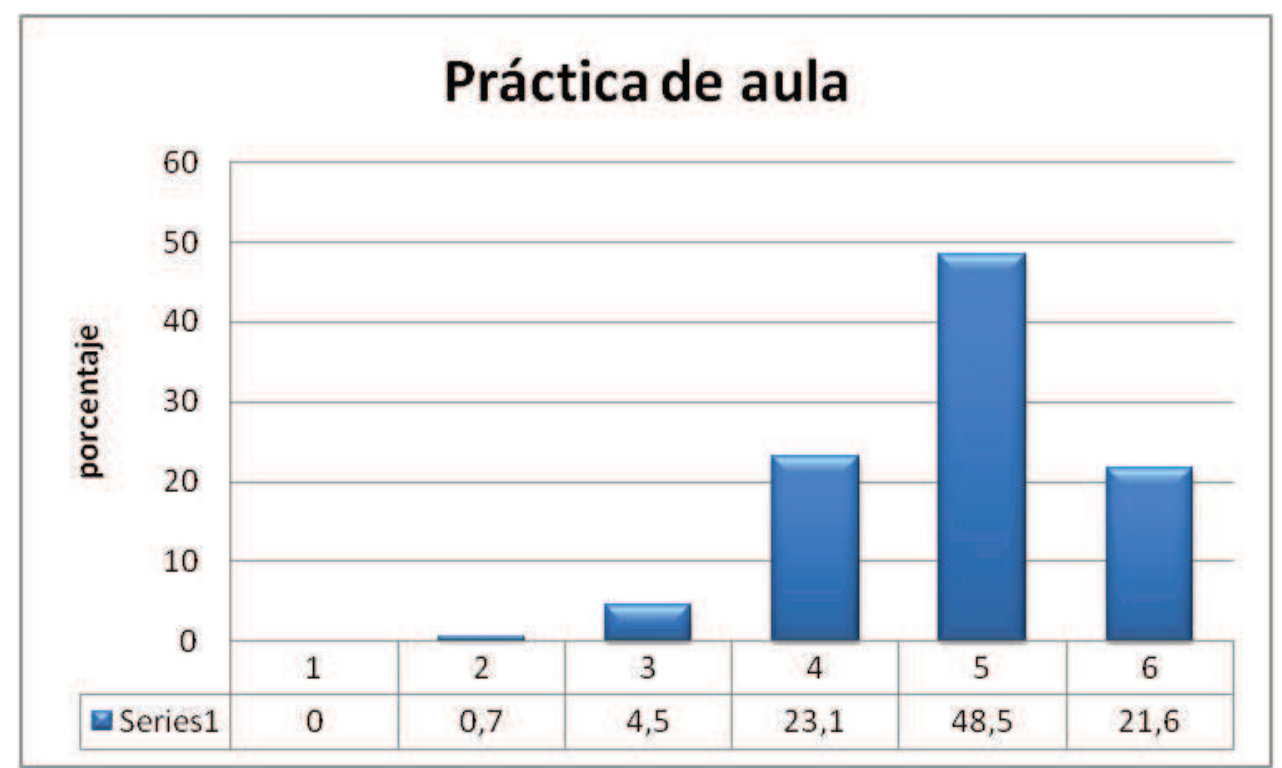

Figura 38. Satisfacción con el proceso tutorial ABP. La puntuación se valora desde 1(nada satisfecho) a 6(totalmente satisfecho).

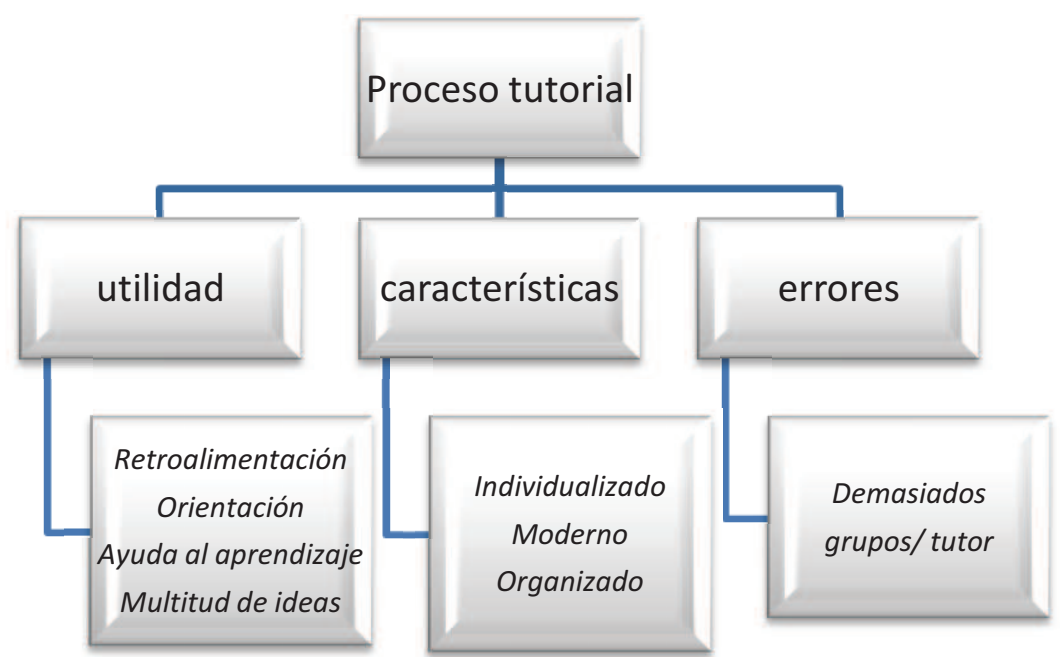

Figura 39.Respuestas justificadas sobre la satisfacción de estudiantes con el proceso tutorial o práctica de aula. 


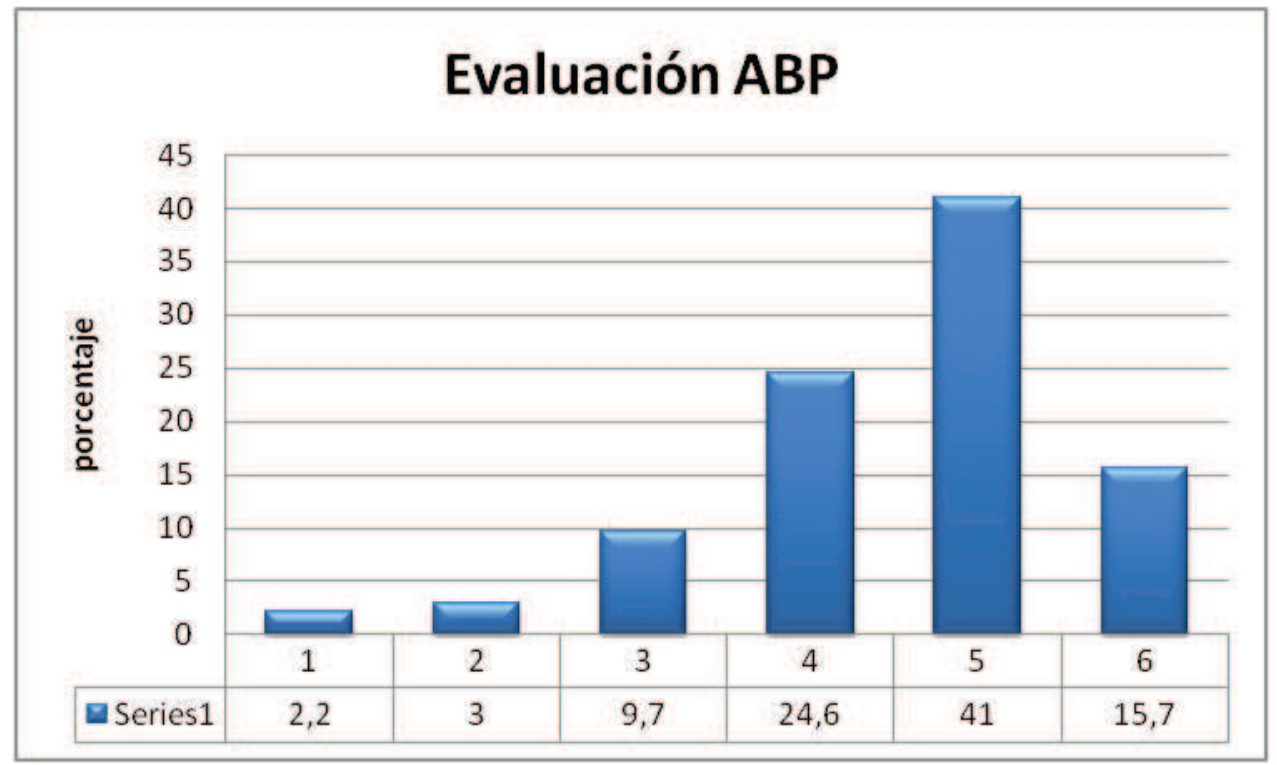

Figura 40. Satisfacción de los estudiantes con la evaluación ABP. $L a$ puntuación se valora desde 1(nada satisfecho) a 6(totalmente satisfecho).

Respecto al proceso de evaluación entre las justificaciones que añadieron: "no se aprecia el trabajo individual, se valoran aspectos nuevos e interesantes, nos ha permitido evaluarnos y evaluar a nuestros compañeros, es importante incentivar el trabajo con la evaluación”

En las respuestas sobre los recursos educacionales piensan en general, que han sido suficientes, los casos preparados les pareció interesantes por ser reales, y las aulas que se utilizaron consideran que fueron adecuadas. 


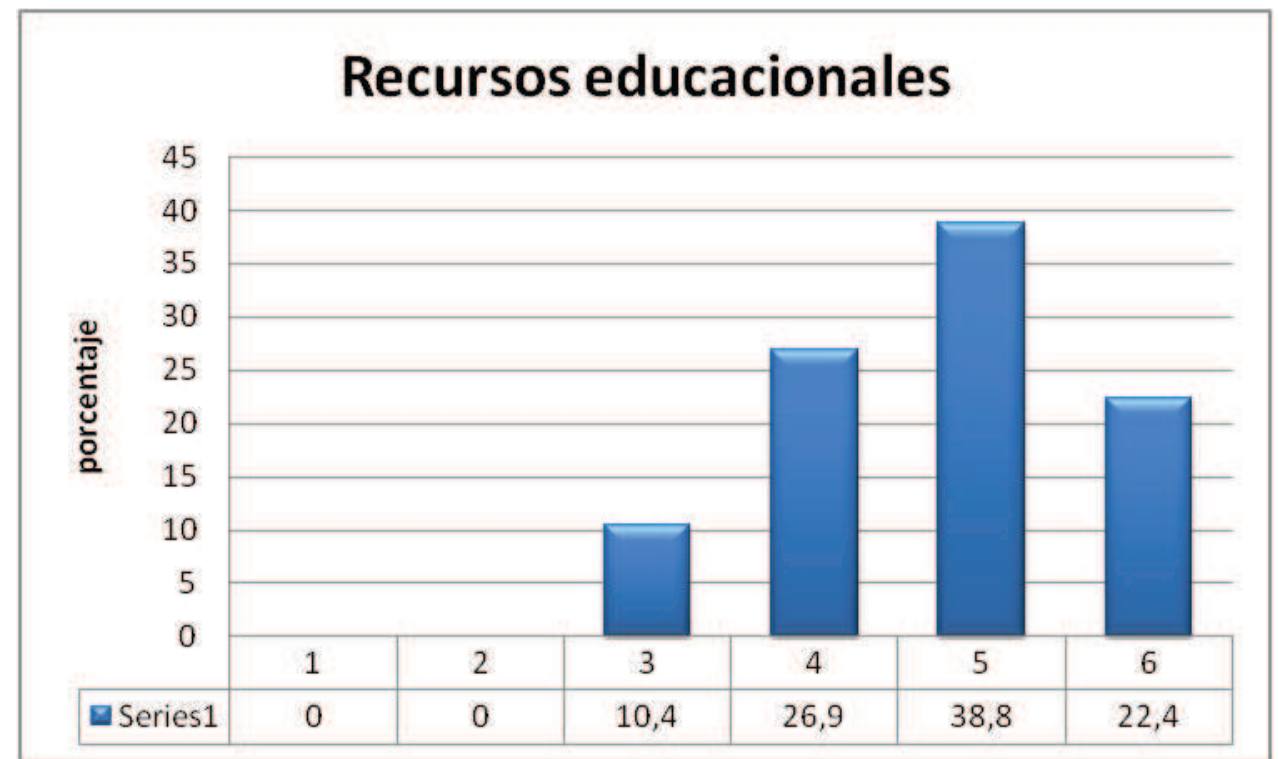

Figura 41. Satisfacción respecto a los recursos utilizados (libros, artículos, páginas web...)

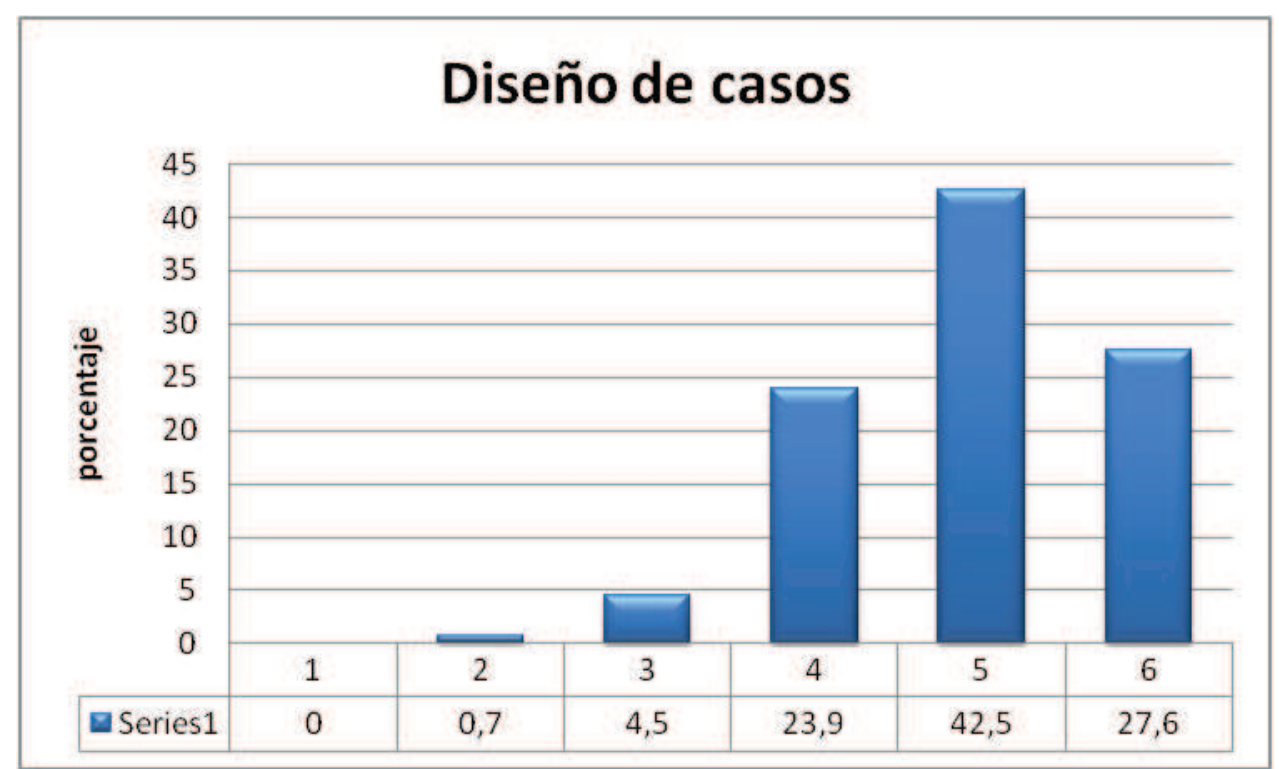

Figura 42. Grado de satisfacción respecto a los casos clínicos para ABP. La puntuación se valora desde 1 (nada satisfecho) a 6(totalmente satisfecho. 


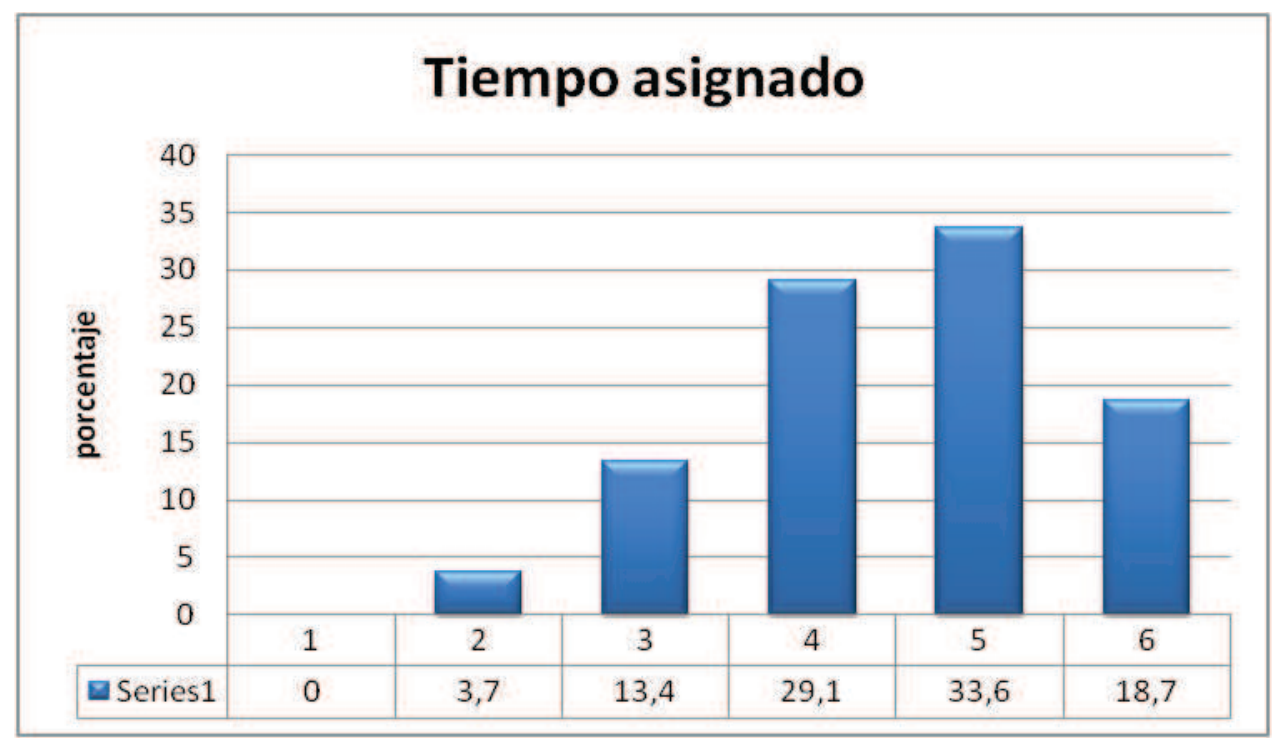

Figura 43.Satisfacción del tiempo asignado a la revisión del caso.

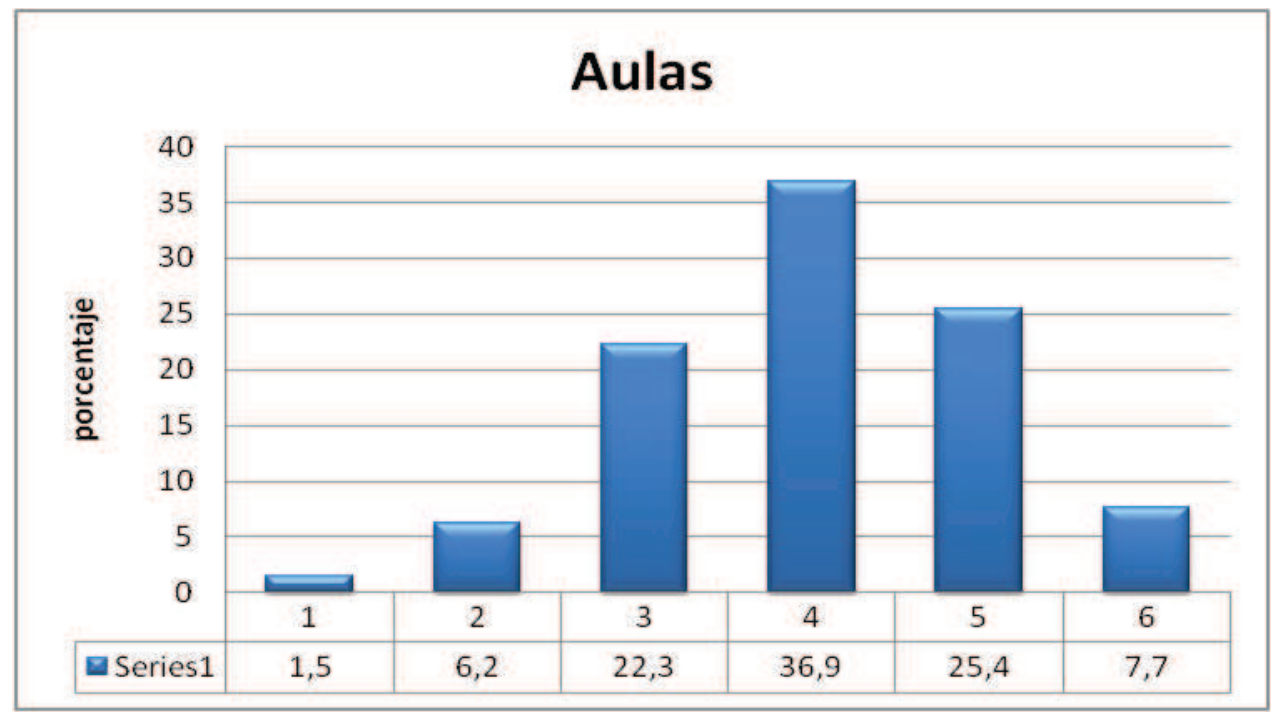

Figura 44. Satisfacción con las características de las aulas. La puntuación se valora desde 1(nada satisfecho) a 6(totalmente satisfecho). 


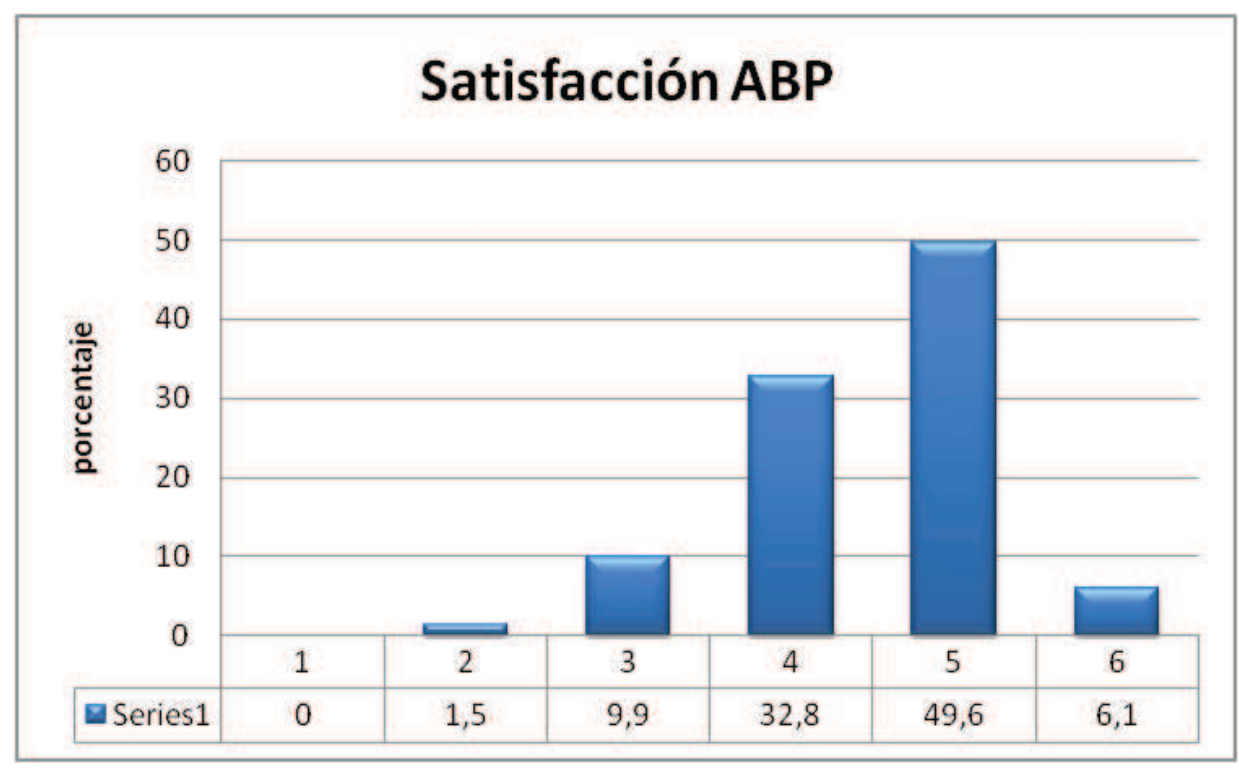

Figura 45.Grado de Satisfacción general con ABP

5.4. Ventajas e inconvenientes percibidos por los estudiantes al utilizar ABP

En la figura 46 se presenta de una forma sintética los resultados del análisis de contenido sobre las ventajas expresadas por los grupos de estudiantes que emplearon la metodología ABP. En el Anexo 9 se puede ver de forma global el análisis que incluye categorías, subcategorías y el sistema de registro. 


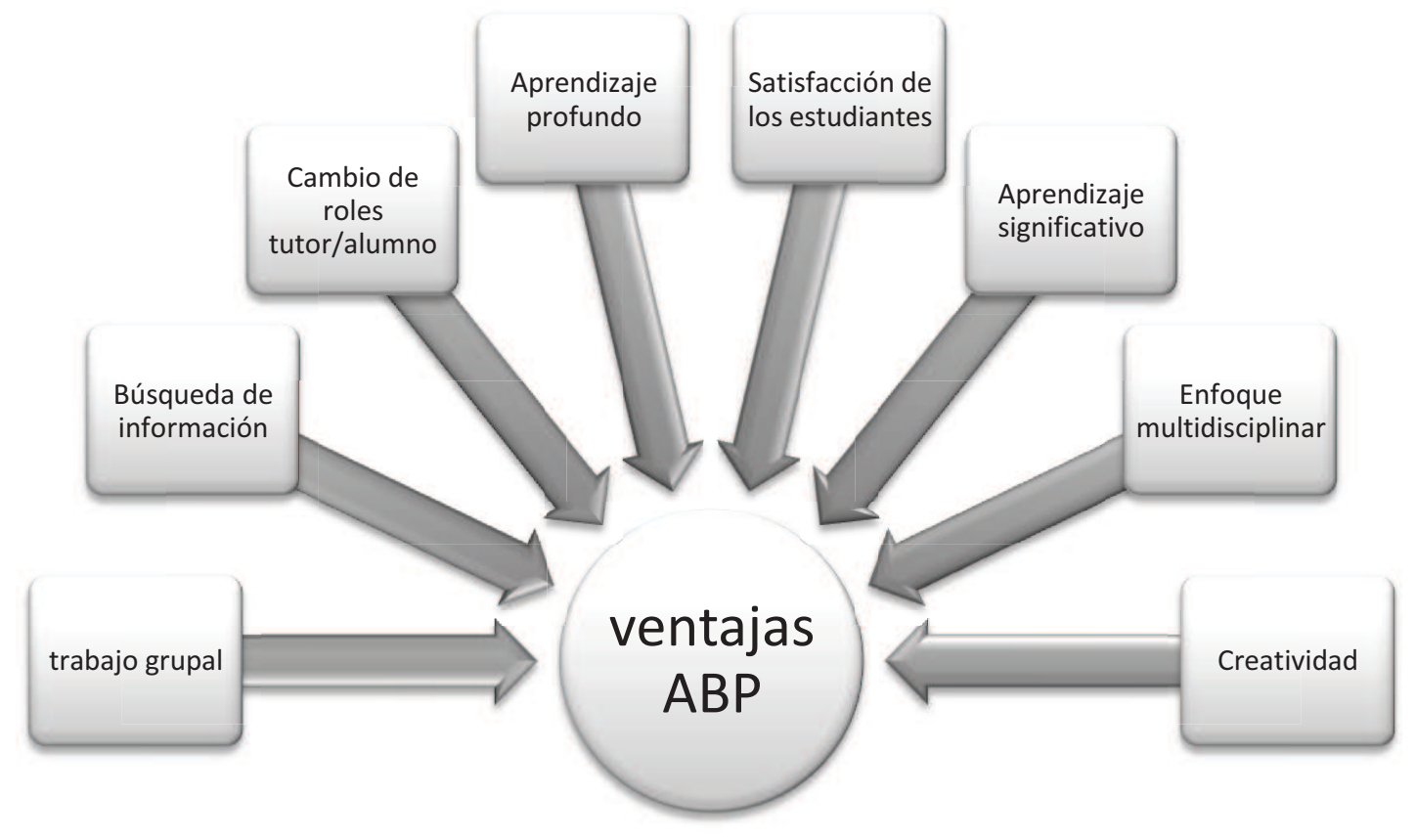

Figura 46. Ventajas de ABP percibidas por estudiantes.

Fuente: elaboración propia sobre el análisis del contenido de los trabajos escritos y las opiniones en los foros virtuales.

Al igual que con las ventajas, en la figura 47 se presenta de una forma sintética los resultados del análisis de contenido sobre los inconvenientes expresadas por los grupos de estudiantes que emplearon la metodología ABP. En el Anexo 10 se presenta de forma general el análisis que incluye categorías, sub-categorías y el sistema de registro. 


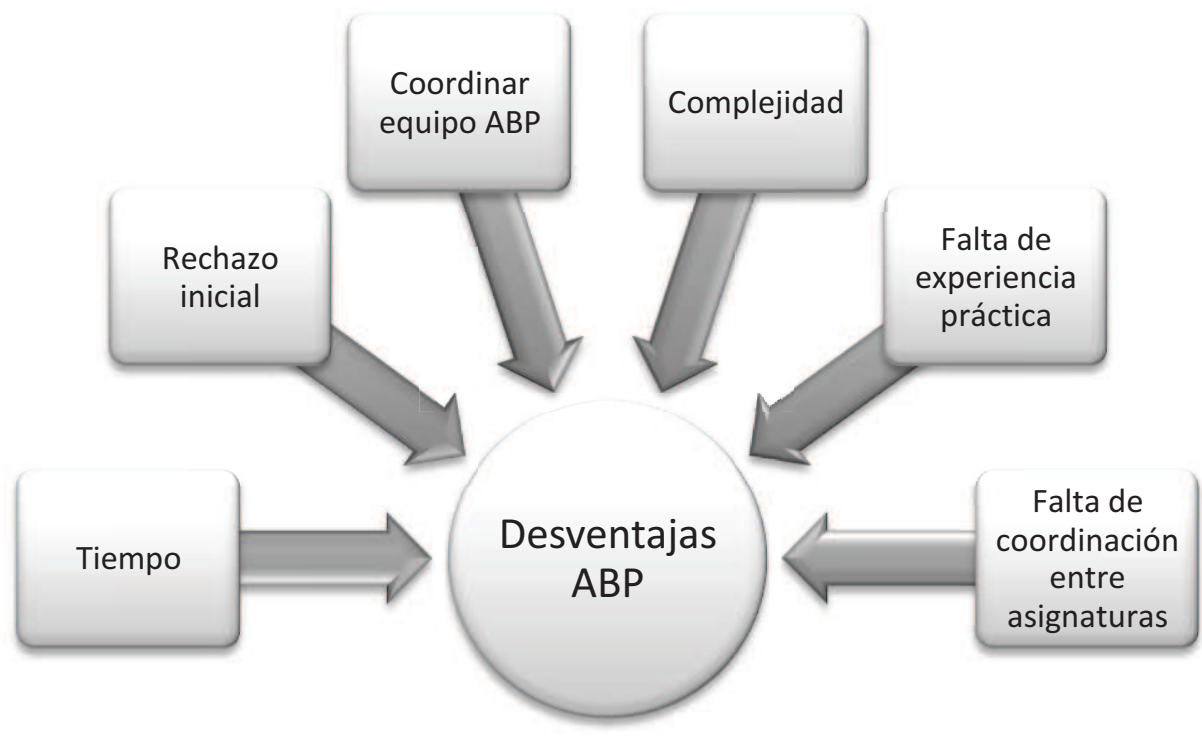

Figura 47. Desventajas de ABP percibidas por estudiantes.

Fuente: elaboración propia sobre el análisis del contenido de los trabajos escritos y las opiniones en los foros virtuales.

Para incrementar la fiabilidad de la información, se hizo la triangulación de los resultados de las prácticas de aula mediante observación, y de las ventajas e inconvenientes expresados por los estudiantes en sus trabajos escritos.

Se puede afirmar que:

- ABP supuso una alta motivación por el aprendizaje y una elevada satisfacción percibida por alumnos/as y tutora. 
- Se creó un buen clima de aula que permitió una fluida interacción entre todos, surgiendo propuestas creativas en los trabajos y presentaciones de los estudiantes

- Se produjo el cambio de rol del estudiante que fue activo en busca de los conocimientos y el rol de la tutora como guía.

- Aunque hubo un rechazo inicial en algunos estudiantes, se superó y se comprometieron a seguir esta metodología.

- Fue costosa la coordinación de algunos equipos, la carga de trabajo y el tiempo que conlleva aprender con ABP. 
CAPÍTULO 6 


\section{Discusión y conclusiones}

Aprovechando un momento favorable en el que se exigen cambios importantes en la cultura pedagógica en las universidades españolas, se utilizó la metodología ABP en la formación de los alumnos de la Escuela de Enfermería de Valladolid, para comprobar las ventajas empíricamente. En este estudio, hay múltiples resultados, y diferentes perspectivas que se integran.

\subsection{Competencia "aprender a aprender"}

En primer lugar, para confirmar el desarrollo de la competencia "aprender a aprender" y conocer el perfil auto dirigido en los estudiantes de enfermería, se utilizó el instrumento CIPA+ de Cázares y Aceves (2007) por ser un instrumento válido y fiable que le confiere validez interna al presente estudio (Aceves, 2008).Se eligió este instrumento por estar adaptado a la lengua castellana. Se trata de una adaptación de la escala SDLRS de Guglielmino, siendo el instrumento más utilizado de su tipo en el mundo. La muestra de estudio incluyó a 129 estudiantes tratándose de una muestra no probabilística, con el inconveniente de la generalización de los resultados, por lo tanto, los resultados obtenidos se restringen a la muestra y al contexto del estudio. Lo que sí se puede generalizar es la metodología, ya que el instrumento permite medir el perfil auto dirigido de los estudiantes universitarios. Aunque se seleccionó el cuestionario CIPA, existen otros instrumentos como la escala de Fisher, King, \& Tague (2001) 
que ha sido validada en enfermeras, traducida al castellano y utilizada en estudiantes de medicina por Fasce, Ortiz, Parra, \& Matus (2011) no obstante, aun se desconoce si es un instrumento válido en otras poblaciones. En futuras investigaciones, se podrían hacer estudios comparativos con ambas escalas para comprobar la idoneidad de una $\mathrm{u}$ otra.

En los resultados obtenidos, los estudiantes de enfermería tienen un nivel que se clasifica en la categoría "muy bueno" en su perfil de autodirección, categoría casi "óptima" en el pos-test. La puntuación media en el pre-test fue de 83 y en el pos-test de 74 . Puntuaciones entre 74 y 106 se consideran como categoría "muy buena" en autodirección, y puntuaciones entre 41 y 73 se considera categoría “óptima” en autodirección.

Es importante señalar que de forma general, existe una diferencia significativa en la que mejora la autodirección de los estudiantes entre el pre-test y pos-test, siendo resultados similares a los de otras investigaciones. Sin embargo, la mayoría de los estudios revisados utilizaron instrumentos diferentes al CIPA como el Self-Directed Learning Readiness Scale (SDLRS), Learning Skills Profile, cuestionarios diseñados para el estudio... En las investigaciones de Aceves, Leal, \& Pérez (2009); Kocaman, Dicle, \& Ugur, (2009) y Litzinger, Wise, \& Lee (2005) en las que utilizaron el CIPA en la 
primera, y el SDLRS en las otras dos, estas investigaciones se realizaron en contextos de formación universitaria en Ingeniería y en Enfermería, y los resultados coinciden con el presente estudio porque mejoran el aprendizaje auto dirigido de forma global existiendo diferencias significativas entre el pre-test y el pos-test después de la aplicación de Aprendizaje Basado en Problemas. En contraste, Olivares (2011) utilizó el cuestionario CIPA y realizó una investigación en una universidad de México en tres carreras de salud, y solo obtuvo una mejoría mínima en autodirección en la carrera de Nutrición, una diferencia desfavorable en Medicina y no hay diferencias en Ingeniero Biomédico después de utilizar ABP.

Respecto a los cinco componentes del aprendizaje autorregulado (AAR) que se midieron en la escala CIPA, en los resultados en el primer componente: planificación y selección de estrategias didácticas, se demostró que existen diferencias significativas entre el pre-test y pos-test tras utilizar ABP como estrategia didáctica. Los estudiantes de enfermería acudieron a las prácticas de aula con el material necesario, en los resultados obtenidos de la autoevaluación el 98\% de los estudiantes confirmaron asistir a las prácticas de aula con el material leído y resumida la información encontrada, debían programar su tiempo de estudio individual y organizar sus reuniones de grupo. 
Muchos de los alumnos, realizaron esquemas y mapas conceptuales para mejorar la comprensión de los contenidos. Además, planificaron la elaboración de material propio (videos, folletos...), planificaron actividades (trabajo de campo, rol playing...), ensayaron sus presentaciones...

En una investigación de Sleight \& Mavis (2006) se confirmó que los alumnos con mejor nota en el examen tienen mayor motivación, disciplina, concentración y atención. Estos estudiantes utilizaban esquemas, tablas y mapas conceptuales propios. ABP promueve el aprendizaje auto dirigido porque obliga a los estudiantes a prepararse para las tutorías, en $\mathrm{ABP}$ el $60 \%$ de tiempo requiere aprendizaje autónomo y el $40 \%$ tutorías o trabajo de grupo (Van Der Hurk, 2006).Este autor, realizó una investigación en la Universidad de Maastrich (Holanda) llegando a la conclusión de que la mayor dedicación con ABP se refleja en los resultados académicos. Downing,K , Kwong, Lam, \& Downing,W (2009) hallaron que ABP es adecuado para desarrollar la meta cognición (uso de estrategias para controlar los propios conocimientos) como la planificación, autocontrol y estrategias de autorregulación. Lycke, Grøttum, \& Strømsø (2006) en sus resultados, mostraron una diferencia significativa entre alumnos que recibieron enseñanza tradicional comparados con $\mathrm{ABP}$ en autorregulación y motivación hacia el aprendizaje. Sungur \& Tekkaya (2005) obtuvieron una diferencia 
significativa al utilizar ABP en elaboración, aprendizaje en equipo, pensamiento crítico y autorregulación meta cognitiva. Los estudios anteriores coinciden con la presente investigación en el componente de planificación y selección de estrategias didácticas, en el que se encontraron diferencias significativas entre el pre-test y pos-test tras utilizar ABP como estrategia didáctica.

El segundo y tercer componente medido en el estudio, incluye el potencial interno del estudiante (componentes autorregulación y motivación; independencia y autonomía) siendo el más importante para el AAR. Siguiendo a Cázares (2009), una persona con potencial interno muestra interés por obtener conocimiento, habilidad y comprensión de lo que le rodea, así como interés por sobresalir. Varios autores han evaluado el cambio en el potencial interno usando ABP entre ellos, Dunlap (2005); Hesterberg (2005); Martin, West, \& Bill (2008); Sungur \& Tekkaya (2005). Los resultados de estas investigaciones indican que los estudiantes estudian por razones como reto, curiosidad y dominio, siendo el valor de la tarea una variable importante, es decir, que el aprendizaje les resulte interesante, importante o útil, aumenta la motivación intrínseca y mejoran su auto percepción para enfrentar problemas. Estos resultados son análogos a los resultados obtenidos a través del cuestionario, las observaciones de las prácticas de aula y el análisis de los documentos escritos, en los que los alumnos afirmaron que "aprender era un reto, los contenidos 
les resultaron interesantes y útiles para su futuro profesional" y sobresalieron como protagonistas en los videos elaborados por ellos mismos. Algunos estudiantes diseñaron videos que presentaron en el aula $\mathrm{y}$ los insertaron en Youtube, otros, presentaron trabajos creativos(elaboración de folletos,demostraciones prácticas...), rol playing, preguntas-respuestas... En general, se encontraron diferencias significativas mejorando en los componentes de potencial interno (autorregulación y motivación; independencia y autonomía) entre el pre-test y el pos-test después de utilizar ABP, coincidiendo con las investigaciones de Hesterberg (2005); Martin, West, \& Bill (2008); Sleight \& Mavis(2006); Sungur \& Tekkaya, (2005).

En el cuarto componente uso de experiencia y conciencia crítica, que se refiere al aprendizaje por la experiencia acumulada en resolver problemas, corregir acciones y la empatía, en los resultados obtenidos existen diferencias significativas entre el pre-test y pos-test. Este cuarto componente tiene mejor resultado en el pre-test en los estudiantes que accedieron a Enfermería por la vía de de Formación Profesional. Puede ser debido a que algunos estudiantes ya trabajan en el ámbito clínico como auxiliares o técnicos, conocen casos similares a los asignados, y al acceder a Enfermería desde FP, tienen más experiencia práctica. Sin embargo, después de la inmersión en el ABP, los estudiantes que provienen de FP y los que provienen de Selectividad, aunque ambos mejoran en el componente, se igualan. 


\begin{abstract}
Algunos estudiantes manifestaron comprender muy bien el caso clínico, por ejemplo la adolescencia, recordando sus propias vivencias; la menopausia porque sus madres estaban atravesando esta etapa y en algunos casos, las propias alumnas habían padecido síntomas similares a los planteados demostrando empatía hacia las pacientes. En una investigación de Baker, McDaniel, Pesut, \& Fisher( 2007) en la que utilizaron tres pruebas estandarizadas para medir el impacto de ABP en la formación de Enfermería, se llegó a la conclusión de que los estudiantes mejoran el razonamiento inductivo orientado a la lógica y a conceptos abstractos. Ozturk, Muslu, \& Dicle (2008) encontraron que los estudiantes de enfermería con metodología $\mathrm{ABP}$ respecto a la enseñanza tradicional, mejoran en pensamiento crítico, siendo una diferencia significativa en la búsqueda de la verdad y libertad, y no hubo diferencias significativas en el análisis, autoconfianza, indagación y madurez de juicio.
\end{abstract}

Respecto al quinto componente interdependencia y valor social en el estudio de Crawford \& Machemer (2008) se demuestra que las habilidades sociales e interpersonales son importantes y se desarrollan con ABP como son el trabajo en equipo, la comunicación, entendimiento y las habilidades para resolver problemas.

Broussard, La Lopa, \& Roos-Davis (2007), evalúan el trabajo en equipos multidisciplinares con $\mathrm{ABP}$ y confirman que se mejora esta competencia cuando se tiene una actitud favorable a trabajar en 
equipo. En la investigación de Esteban (2011) se llega a la conclusión que con $\mathrm{ABP}$ el aprendizaje se genera a través de la participación guiada en la actividad social con compañeros que apoyan y estimulan la comprensión, y es necesaria la implicación en una actividad. Villa \& Poblete (2007) afirman que con ABP se desarrollan competencias como el trabajo en equipo y la comunicación. Del mismo modo, en los resultados obtenidos en esta investigación, durante las observaciones de las prácticas de aula se comprobó una buena comunicación y clima de aula, y en los trabajos escritos los estudiantes declaran: "aprendimos a pensar como equipo, han surgido diversidad de opiniones e ideas, y fue necesario el respeto a los puntos de vista de los otros" demostrando el desarrollo de la competencia comunicativa, el trabajo en equipo y las habilidades sociales al utilizar metodología ABP. No obstante, se presentaron algunos conflictos grupales que finalmente se resolvieron bien. De acuerdo con las investigaciones de Biley \& Smith (1999) y Faidley, Evensen, Salisbury-Glennon, Glenn, \& Hmelo (2000), las competencias como el trabajo en equipo y las habilidades sociales se desarrollan dependiendo de la dinámica del grupo, por ejemplo, la competición, los conflictos o la pasividad dificultan la cooperación.

ABP favorece la autodirección en cada uno de los componentes (Litzinger, Wise, \& Lee, 2005) y al igual que en la presente 
investigación, hay diferencias significativas mejorando en todos los componentes.

El desarrollo de la competencia de aprendizaje autorregulado es importante en el ambiente profesional de enfermería porque existe una necesidad de una actualización y resolución de problemas clínicos complejos. Es preciso que los estudiantes adquieran competencias para que sepan seleccionar información pertinente, analizarla y aplicarla en un mundo donde se genera información constantemente. Un profesional de la salud capacitado necesita autonomía y desarrollo de la competencia "aprender a aprender". El aprendizaje autorregulado es un constructo complejo en el que hay que actuar a nivel del alumnado, el profesorado y las interacciones entre todos. Aunque las metodologías docentes no determinan de forma directa el AAR, si pueden promover su desarrollo, puesto que se puede “aprender a aprender". Se enfatiza la importancia del aprendizaje autorregulado de nuestros alumnos y alumnas, y en la literatura científica, se hace referencia a los procesos de autorregulación como una de las principales contribuciones para aumentar la motivación y el aprendizaje académico (Rosário, Mourao, Trigo, Núñez, \& GonzálezPineda, 2005 ; Suárez, Fernández , \& Anaya , 2005;Torrano \& González Torres, 2004 ;Zimmerman \& Martínez-Pons, 1990; Zimmerman, 2000). 
De acuerdo con Gallardo (2012) y García (2012), el aprendizaje autorregulado se aprende y se desarrolla, por esto se habla de la competencia "aprender a aprender" y se puede enseñar por medio de la instrucción y la práctica repetida de experiencias diversas en diferentes contextos.

En el anterior análisis sobre el AAR al aplicar ABP, se han aportado resultados interesantes porque existen diferencias significativas favorables en el perfil auto dirigido de los estudiantes de enfermería, tanto en las puntuaciones globales como en los cinco componentes entre el pre-test y el pos-test por lo que se aceptan las hipótesis:

H1: Los alumnos que cursan materias con estrategias didácticas ABP registran cambios favorables en la autodirección de aprendizaje.

H2: Existe una diferencia significativa en el puntaje de autodirección entre los alumnos antes y después de utilizar metodología ABP.

H3: Existe una diferencia significativa entre el pre-test y el pos-test en los cinco componentes del AAR.

Se ha generado una nueva hipótesis: existe una progresión hacia un mejor nivel de AAR al utilizar ABP en la formación de los estudiantes a través del tiempo, por lo que se proponen futuros estudios de forma longitudinal en los que se pueda hacer un seguimiento de los estudiantes durante su etapa formativa y/o profesional porque se han hecho pocas investigacionesen este campo. 
En una investigación de Iputo (1999) se realizó un estudio comparativo entre ABP y enseñanza tradicional investigando la evolución de los estilos de aprendizaje de 106 estudiantes de medicina durante 4 años, en los resultados los estudiantes que utilizaron ABP mejoraron de forma significativa los estilos de aprendizaje y estos eran más versátiles, por lo tanto más eficaces.

\subsection{Grado de satisfacción}

Para determinar el grado de satisfacción del ABP de los estudiantes de enfermería al finalizar el semestre, se seleccionó el cuestionario de satisfacción de Márquez, Uribe, Montes, Monroy, \& Ruiz (2011) por la facilidad de aplicación y porque sus autores tienen una experiencia en ABP de más de 10 años. Al ser un cuestionario de opiniones, no es generalizable restringiéndose a la experiencia y contexto en el que se aplicó ABP.

En los resultados obtenidos, los alumnos declaran que los contenidos les resultaron interesantes, prácticos, útiles y variados. Una característica importante consiste en utilizar problemas concretos de situaciones reales, resultando estimulante $\mathrm{y}$ contribuyendo al desarrollo de la responsabilidad social. En las presentaciones orales de los trabajos grupales destaca la creatividad de los estudiantes, la participación en su aprendizaje y la implicación de la emoción en la motivación para aprender. 
Resulta curioso que los estudiantes prefieran la metodología de enseñanza tradicional en un $55 \%$ frente al $45 \%$ que prefieren $\mathrm{ABP}$. Puede ser debido a que el aprendizaje activo con metodología ABP requiere mayor esfuerzo y mayor tiempo de dedicación de los alumnos para profundizar en los conocimientos. Además los estilos de aprendizaje son diferentes en los estudiantes, es imposible que a todos les guste una metodología activa, y por último no están acostumbrados al uso de ABP en su formación. Sin embargo, cuando se les preguntó si les gusta la metodología $\mathrm{ABP}$, un $72 \%$ respondió de forma afirmativa frente al $22 \%$ que no les gustó. En la escala de satisfacción general donde 1 significa "nada satisfecho" y 6 "totalmente satisfecho", el 50\% de los estudiantes le asignó la puntuación de 5, un 33\% una puntuación de 4 y un $6 \%$ una puntuación de 6, por lo que se puede afirmar que la satisfacción general percibida por los estudiantes de enfermería al usar ABP fue alta.

Del mismo modo, desde el punto de vista del tutor/a, hacer un seguimiento de los grupos en las prácticas de aula, revisar los envíos parciales de los trabajos, crear una retroalimentación guiando a los estudiantes, preparar el material con antelación (casos clínicos, guías, artículos de interés, contenido de los debates...), hacer preguntas para que reflexionen sobre los problemas, mediar en los conflictos 
grupales...conlleva mayor dedicación y esfuerzo docente, sin embargo, aporta mayor satisfacción y mayor calidad al proceso de enseñanza- aprendizaje. De acuerdo con Legault ( 2012) no todos los profesores están en disposición de ser tutores en $\mathrm{ABP}$, entre otros factores, por la resistencia al cambio, por la falta de motivación para innovar en la docencia, por el desconocimiento de método, falta de tiempo, pérdida de protagonismo en el aula y no delegar protagonismo del aprendizaje a los propios estudiantes. Se propone una línea de investigación futura sobre el perfil y capacitación docente del tutor en ABP ya que es una línea muy interesante y que ha sido poco investigada.

Los resultados obtenidos coinciden con dos meta-análisis que incluyeron investigaciones durante 20 años sobre la metodología ABP en Ciencias de la Salud, realizados por Albanese \& Mitchell (1993) y Vernon \& Blake( 1993), que son la principal referencia debido al rigor metodológico. Los autores llegan a la conclusion que ABP presenta tasas de satisfacción significativamente más elevadas en los estudiantes que el aprendizaje tradicional. Vernon y Blake afirman que los estudiantes expuestos a ABP declaran tener menos estrés (ansiedad, depresión, hostilidad y somatización) que los sometidos a enseñanza tradicional. Esteban (2009) confirma que se perciben más ventajas que inconvenientes, el aspecto positivo más mencionado es 
que $\mathrm{ABP}$ permite discutir con los compañeros $\mathrm{y}$ trabajar colaborativamente, y la desventaja es que requiere más tiempo.

Integrando los resultados obtenidos a través de las observaciones de las tutorías, el análisis del contenido y el cuestionario de satisfacción que se pasó a los estudiantes, se revela que $\mathrm{ABP}$ supuso una alta motivación para el aprendizaje y una elevada satisfacción percibida por alumnos/as y la tutora. Además, aceptan satisfactoriamente los cambios de roles de los alumnos siendo los responsables de su aprendizaje y el rol del tutor/a como guía. El rol del estudiante se convierte en un rol activo, en busca del conocimiento para intentar resolver el problema clínico planteado. El tutor es el que orienta y motiva al grupo ABP, debe abandonar la perspectiva vertical y autoritaria para dar paso a un rol más dialogante, capaz de asumir la construcción colectiva del conocimiento. Los problemas clínicos diseñados se basan en la realidad es decir, están contextualizados y son significativos para los alumnos. Los estudiantes reconocen dichos problemas como relevantes desde el aspecto profesional, por ello se sienten motivados para trabajar, no solo porque comprenden que los conocimientos que obtienen al pensar en estos problemas les serán útiles en un futuro, sino también porque tienen la oportunidad de desplegar su creatividad, así como una flexibilidad en la resolución de problemas $\mathrm{ABP}$. 
Lo que menos satisfactorio resultó fue la carga de trabajo, el tiempo empleado y que hubo demasiados grupos/ tutor. La dificultad en el mayor empleo del tiempo es porque como los estudiantes se convierten en elementos activos de su aprendizaje, reconocen que deben emplear más tiempo en la asignatura, incluso se sienten inseguros del conocimiento adquirido. Este resultado coincide con otras experiencias como la de Alvarez, Rius, \& Viladés (2005) y Esteban (2009).

Por lo tanto, se aceptan la hipótesis:

H4: Si se aplica la metodología ABP la motivación y el grado de satisfacción serán elevados.

H5: Los estudiantes perciben favorablemente un cambio de rol del profesor como guía o facilitador del aprendizaje.

H6: Los estudiantes perciben favorablemente un cambio de rol del alumno como responsable de su aprendizaje.

\subsection{Aprendizaje de calidad}

El aprendizaje profundo y la autorregulación implican una motivación intrínseca. Cuando los estudiantes experimentan la satisfacción de aprender, estudian no solo para obtener buenas notas, sino por el gusto de aprender. Lo fundamental de $\mathrm{ABP}$ es la integración: permite integrar la formación teórica y la práctica, integrar diferentes disciplinas, integrar al paciente desde una perspectiva biopsicosocial, 
integrar diferentes puntos de vista y experiencias previas de los estudiantes para construir nuevos conocimientos. Además, con ABP no se pretende un aprendizaje memorístico de forma superficial propio del paradigma de la enseñanza, sino dentro del paradigma del aprendizaje, el objetivo de ABP es una transferencia de conocimientos a través de la comprensión, la empatía, el razonamiento clínico y el desarrollo de competencias relacionadas con el rol profesional enfermero. Es por esto que se utilizaron casos clínicos reales de la consulta, para hacer una inmersión en lo que serán los "verdaderos casos" con los que nos encontramos en las consultas, permitiendo ensayar la resolución de los problemas y los cuidados de enfermería que realizarán en el futuro profesional.

Los estudiantes manifestaron:

"Hemos aprendido nuevos conocimientos en los que profundizamos". "El trabajo tiene mayor riqueza por la cantidad de ideas aportadas". "Los conocimientos se adquieren de una forma más razonada y autocrítica". "Nos ha aportado una visión más global del problema, por lo que lo comprendimos mejor". "Estudiamos el tema en profundidad". "Aprendimos a vertebrar el manejo de información". "Hemos actualizado los conocimientos"...

Según las investigaciones de Aspegren, Blomqvist, \& Borgstrom, (1998); Branda (2004); Cossette, Mc Clish, \& Ostiguy (2004); Dochy, Segers, Van den Bossche, \& Gijbels (2003); Duek (2000); Hmelo 
(1998); Myers \& Horst (2000); Morales-Mann \& Kaitell (2001); Savin-Baden (2000) y White, Amos, \& Kouzekanani (1999) los estudiantes que aprenden a través de $\mathrm{ABP}$ tienen un mejor razonamiento clínico, son más hábiles para utilizar los conocimientos en tiempo real (integran), mantienen la motivación, utilizan estrategias para un aprendizaje en profundidad y estrategias meta cognitivas, en mayor proporción que los estudiantes que reciben enseñanza expositiva de forma tradicional. Se acepta la hipótesis H7: El aprendizaje es más profundo y mejora la calidad del proceso enseñanza-aprendizaje al aplicar ABP.

\subsection{Desarrollo de competencias}

Respecto al desarrollo de competencias de los estudiantes, ya en el informe UNESCO(1996) se apuntaba en esta dirección señalando los cuatro pilares de la educación del futuro: aprender a conocer, aprender a hacer, aprender a vivir y aprender a ser. De acuerdo con el proyecto de Definición y Selección de Competencias DeSeCo de la Organización para la Cooperación y Desarrollo Económico (OCDE, 2002), se constata la necesidad de otra orientación de los currículos y el reenfoque del profesorado, para que los alumnos adquieran competencias. En esta línea, en los resultados obtenidos al aplicar $\mathrm{ABP}$, se practicaron $\mathrm{y}$ desarrollaron competencias transversales $\mathrm{y}$ específicas, entre ellas, la búsqueda de información, la creatividad, el trabajo en grupos colaborativos, la comunicación oral y escrita, el 
pensamiento reflexivo, el pensamiento crítico, el razonamiento clínico, la gestión del tiempo, el trabajo autónomo, la síntesis de información, la utilización de herramientas tecnológicas, las habilidades sociales y valores éticos, y la realización de pequeñas investigaciones de campo. Al igual que en la investigación de López, González, \& Agudo (2007), se concluye que ABP es una herramienta que permite aprender además de los conocimientos teóricos, el desarrollo de competencias transversales.

En las presentaciones orales de los grupos se detectó la cohesión grupal necesaria para una buena coordinación y que pudiesen participar todos los estudiantes; la revisión y profundización en los contenidos; la comprensión de la materia y la integración de la teoría con la práctica. ABP permitió practicar habilidades comunicativas y el uso de herramientas tecnológicas. Algunos estudiantes que leen o se ponen nerviosos ante una presentación oral, toman conciencia de que deben superar estos puntos débiles. Los estudiantes demostraron con sus presentaciones que el aprendizaje activo motiva, les hace protagonistas, desarrollan su creatividad y se implican emocionalmente en aprender para un fin profesional.

Para elaborar los trabajos escritos, los grupos de estudiantes demostraron un rol activo, tuvieron que buscar información a través de internet y en varias bibliotecas; pasaron cuestionarios en salas de 
espera de centros sanitarios; realizaron investigaciones de campo acudiendo a un centro de discapacitados; fueron a una reunión de " un grupo de lactancia"; otros se desplazaron hasta una clínica de ginecología; varios grupos realizaron entrevistas, entre ellas, entrevistaron a una trabajadora social de un Centro de Salud, a una enfermera pediátrica del hospital y a dos matronas. Debido a la abundancia de material recogido, la síntesis de los artículos y de otras informaciones fue necesaria para realizar su trabajo de evaluación. Los estudiantes demostraron habilidades de razonamiento clínico en los trabajos escritos y en las presentaciones orales, incluyeron un apartado sobre las ventajas e inconvenientes al utilizar ABP y opinaron en un foro de debate virtual. Aprender es una experiencia social y cuando se trabaja colaborativamente se potencia el sentido de la pertenencia y ayuda mutua (Monereo, 2007). Además, en el aprendizaje colaborativo, al apoyarse los estudiantes entre sí, ayuda a crear una ambiente favorable para el aprendizaje.

En los estudios de De Ketele (1996); Gimeno (2008); Le Boterf (2001); Roegiers (2007); Tardif (2006), y Zabala (2008) se llega a la conclusión de la relación entre el desarrollo de las competencias de los alumnos y la movilización de los conocimientos previos, de las habilidades para integrar el conocimiento y su utilización, el análisis y la síntesis; todos ellos con el fin de resolver problemas reales y cercanos al alumnado, como son los casos ABP presentados en esta 
investigación. Como se ha comprobado en este estudio y coincidiendo con López (2011), las competencias se manifiestan y demuestran el la acción y permiten una formación integral del estudiante. Un aprendizaje de calidad requiere que los discentes adopten un rol activo, que sean capaces de adquirir un comportamiento estratégico y táctico frente a las tareas académicas(Hernández, Rosário, \& Cuesta, 2010). Exige a los estudiantes universitarios una reflexión sobre su propia actividad de aprendizaje. La adquisición de esta competencia es importante en sí misma para investigadores que defienden que el fin de la educación es preparar a los estudiantes a aprender por ellos mismos (Pintrich, 2004; Ramsdem, Prosser, Trigwell, \& Martin, 2007).

Al contrastar los resultados obtenidos con los objetivos planteados, se acepta la hipótesis H8: La metodología ABP permite el desarrollo de competencias transversales entre ellas, trabajo en grupo, mejora en habilidades de razonamiento y aprendizaje autónomo, pensamiento reflexivo, pensamiento crítico, búsqueda de información, competencias comunicativas y creatividad en los alumnos de enfermería.

\subsection{Evaluación de competencias}

Para evaluar las competencias que se desarrollan con ABP se utilizaron distintos instrumentos, entre ellos: la observación de las prácticas de aula, la revisión de trabajos parciales, la observación de presentaciones orales, la evaluación de los trabajos finales, la 
evaluación a la tutora, la autoevaluación de estudiantes y la evaluación a los compañeros de equipo. La valoración del ABP sobre la nota final de la asignatura fue del $50 \%$, contabilizando un $20 \%$ el trabajo escrito, otro $20 \%$ la presentación oral de trabajo de grupo y un $10 \%$ la autoevaluación y evaluación a pares. El otro 50\% de la nota se valoró a través de un examen de conocimientos tipo test. Después de revisar la literatura científica, se siguieron las propuestas de Milligan (1999) y Baños (2001), estos autores afirman que utilizar una metodología ABP exclusivamente es arriesgado por los distintos estilos de aprendizaje de los alumnos. Es por ello que la autora optó por una metodología híbrida para el aprendizaje de la asignatura.

En la observación de las tutorías se comprobó el avance en la competencia de trabajo en equipo, el buen clima de aula favoreció las interacciones y comunicación.

Para la observación de las presentaciones orales se utilizaron rúbricas que facilitaron la evaluación. En la misma, colaboraron dos estudiantes con la tutora para disponer de tres observadores y así aumentar la fiabilidad de la puntuación, además permitió a los estudiantes participar en el proceso. Las competencias como comunicación oral, creatividad, trabajo grupal, comprensión de los conocimientos, aplicación de los cuidados al caso asignado, 
pensamiento reflexivo...se desarrollaron en el trabajo de las presentaciones orales de los grupos ABP.

Respecto a la autoevaluación y evaluación a pares, se utilizó el mismo cuestionario para las dos evaluaciones, se eligió la escala tipo Likert propuesta por el Instituto Tecnológico de Monterrey (1999) que puntúa de 1 "totalmente en desacuerdo" a 4 "totalmente de acuerdo". En los resultados obtenidos en la autoevaluación, las mejores puntuaciones se refieren a la asistencia a las reuniones de grupo y al cumplimiento de los trabajos asignados, y puntuaron más bajo en la utilización de los recursos apropiados para investigar, y en la formulación de preguntas para una mejor comprensión y profundidad en su aprendizaje. Sin embargo, todas las respuestas en un 97\%, corresponden a puntuaciones entre 3 y 4 . Se obtuvo una puntuación muy alta en las respuestas y se demuestra que la mayoría de los estudiantes contribuyen activamente al trabajo de grupo. Los resultados de la autoevaluación coinciden con los de la evaluación a los compañeros de grupo, en los que la media de las puntuaciones a las mismas preguntas se encuentra entre 3.5 y 3.7 .

De acuerdo Rué (2009) la influencia de la evaluación en el aprendizaje es fundamental, puesto que los estudiantes aprenden en función de cómo se les enseña y cómo se les evalúa. Cuando la evaluación es responsabilidad de los profesores exclusivamente, los 
estudiantes crean conductas adaptativas como pedir apuntes o memorizarlos, en vez conductas autónomas como buscar información, profundizar en la materia o comparar información con otros compañeros. Cuando se da un alto valor a la nota final, se devalúa el papel formativo de los trabajos intermedios y los estudiantes pueden pensar que pierden su tiempo al profundizar en un tema. En ABP, la evaluación se incluye en el proceso de formación y el proceso de retroalimentación debe ser constante a lo largo del desarrollo de trabajo en grupo, de tal manera que sirva de estímulo para la mejora y desarrollo del aprendizaje.

La autocrítica en la vida profesional es importante para un aprendizaje para toda la vida y para mejorar en el plano humano y profesional. Es una de las competencias que deben adquirir los estudiantes durante su formación universitaria. Siguiendo a Álvarez (2009); Boud (1985);Brew (1999); Chapel \& Hager, (1995); Hanrahan \& Isaacs (2001); Patterson, Crooks, \& Lunyk-Child (2002); es necesaria la autoevaluación individual en el proceso de aprendizaje. Watts \& García-Carbonel (2006) abogan por una evaluación compartida.

La participación de los alumnos en el proceso de evaluación es un elemento esencial para el desarrollo de su autonomía. Además les permite darse cuenta de los "puntos débiles" y "puntos fuertes" en su proceso de aprendizaje, y poder aplicar medidas correctoras si fuera 
preciso. Cuando se reflexiona durante el proceso de autoevaluación, evaluación a los compañeros y a la tutora, se activa la capacidad de autocrítica y crítica, y se fortalecen las actitudes relacionadas con su dimensión afectiva (saber ser) como son la honestidad, la responsabilidad y la autonomía las cuales, tienen relación directa con su formación personal. La evaluación compartida contribuye de forma positiva al rendimiento de los alumnos y les proporciona experiencia de aprendizaje en juzgar el trabajo realizado por compañeros de forma objetiva, tarea que será útil en su futuro profesional. En este trabajo ABP los estudiantes se autoevaluaron, evaluaron a sus compañeros de equipo y a la tutora del ABP.

Para evaluar a la tutora se utilizó la escala utilizada en la Universidad de Delaware propuesta por el ISTEM (1999). En los resultados obtenidos con mejor puntuación según los estudiantes, se observa que la tutora crea un ambiente relajado para iniciar la discusión, admite conocimientos que no sabe, escucha y responde a las preguntas; y con una peor puntuación, plantea preguntas que estimulen el pensamiento o impulsa al grupo para afinar y organizar las presentaciones. Sin embargo, un 95\% de las respuestas puntuaron entre 3 y 4 demostrando un resultado satisfactorio. La evaluación por los estudiantes permite obtener resultados y hacer una reflexión de la práctica docente para detectar la necesidad de correcciones y cambios en sucesivos cursos en los que se aplique esta metodología. La principal ventaja derivada 
recae en el desarrollo y mejora continua de las competencias del docente para ejercer el acompañamiento del estudiante. Siguiendo a Porres., y otros (2006) dirigir es promover, entusiasmar, comprometer y lograr resultados.

Ríos (2007) afirma que la principal utilidad de la participación de los alumnos en la evaluación es que toman conciencia de su proceso formativo, pueden valorar la contribución de los demás y elaboran juicios propios para la toma de decisiones. Para alcanzar una nueva cultura de evaluación en ABP, los profesores deben modificar su mentalidad y ser capaces de asumir el desafío de evaluar aprendizajes de orden superior como el análisis, la interpretación, la síntesis, la inferencia, la resolución de problemas; actitudes como la responsabilidad, el compañerismo, el trabajo en equipo, la tolerancia y el respeto, la empatía, la iniciativa y la creatividad.

Los alumnos participan en la autoevaluación, evaluación al tutor y evaluación a los compañeros con el fin de aprender a valorar los logros y las debilidades, potenciar la autorregulación del aprendizaje y conseguir una mayor autonomía que será necesaria para su ejercicio profesional. Se acepta la hipótesis planteada H9: Una metodología $A B P$ requiere evaluar las competencias de los estudiantes con distintos instrumentos que complementan al examen de conocimientos de la metodología tradicional. 


\subsection{Innovación educativa}

ABP se perfila como uno de los enfoques más innovadores en la formación profesional y académica actual, conquistando cada vez más espacio en las principales universidades del mundo (Morales \& Landa, 2004). Las transformaciones de la ciencia y la tecnología ejercen una presión dentro del ámbito académico. Los cambios son fundamentales para mantener y consolidar el papel de la universidad en la sociedad contemporánea como se ratifica en diversos estudios, investigaciones y propuestas en la literatura científica que han abierto muchas posibilidades de innovación educativa. El cambio del enfoque en la enseñanza superior deja de centrarse en la enseñanza, para hacerlo en los procesos de aprendizaje. Después de los análisis aportados, ABP demuestra ser una de las metodologías que permite la adquisición y desarrollo de un mayor número de competencias profesionales enfermeras. Además, existe una amplia experiencia (de más de 40 años) de aplicación con éxito en Universidades de prestigio de todo el mundo, y sobre todo, se ha utilizado en la formación Universitaria en Ciencias de la Salud. En síntesis, es necesario un cambio en la enseñanza universitaria centrado en el aprendizaje y en los estudiantes (UNESCO, 1998; Declaración de Bolonia, 1999; Yániz, 2006).

Por tanto, se acepta la H10: ABP es una metodología idónea para lograr competencias necesarias para formar a los futuros profesionales de enfermería y permite una innovación educativa afín al EEES. 


\section{Conclusiones:}

1- $\quad$ ABP no es una simple aplicación metodológica que pueda utilizarse en las aulas sin realizar cambios estructurales, son necesarios cambios organizativos, culturales y requiere un cambio de actitud en el profesorado y en la institución educativa.

2- De acuerdo con los resultados de la investigación, el perfil auto dirigido de los estudiantes mejora después de utilizar ABP y es de suma importancia para el desarrollo de la autonomía y autorregulación en su aprendizaje. El desarrollo de la competencia "aprender a aprender" servirá para un aprendizaje para toda la vida necesario en los profesionales de enfermería del siglo XXI.

3- Utilizar una metodología ABP permite una elevada satisfacción en los estudiantes y en los profesores que la emplean. Los roles cambian siendo los alumnos los protagonistas de su propio aprendizaje y los docentes los que les guían; existe una retroalimentación constante en el proceso, tanto en sesiones de evaluación, como en el trato personal y se mejora la comunicación entre todos.

4- $\quad$ El aprendizaje al utilizar ABP es de mayor calidad, se trata de un aprendizaje profundo con la intención de resolver problemas complejos del mundo real. Debido a la 
complejidad de las situaciones a resolver, se activan actividades intelectuales de nivel superior como la reflexión, el pensamiento crítico, la empatía, la creatividad, la síntesis, el razonamiento clínico...

5- $\quad$ ABP permite ensayar en las prácticas de aula o tutorías, las competencias necesarias para el futuro ejercicio profesional como el trabajo en equipo, la búsqueda de información, la mejora en habilidades sociales, la comunicación escrita y oral, el uso de tecnologías y la transferencia y construcción de conocimientos para aplicarlos en otras situaciones clínicas.

\section{Limitaciones:}

Este estudio tiene limitaciones porque no es posible la generalización de los resultados debido a que la muestra fue no probabilística. Se realizó en el contexto de la Educación Superior en Enfermería, por lo que esta investigación se restringe a la muestra y al contexto.

Una de las limitaciones para el establecimiento de Aprendizaje Basado en Problemas es el tiempo. Con este método se requiere más tiempo para lograr el aprendizaje. La dificultad parte de que los alumnos, al convertirse en elementos activos de su aprendizaje, se quejan de que deben utilizar más tiempo de dedicación para la 
asignatura, y además el profesor o profesora también necesita dedicar más tiempo para la planificación de la misma. Por esto, es importante una correcta planificación, explicarles a los estudiantes de forma clara en qué consiste esta nueva forma de aprender, y dar un alto valor en la evaluación y en la nota final al trabajo realizado con metodología $\mathrm{ABP}$.

Al tratarse de un estudio con metodología mixta, se mezclan aproximaciones cuantitativas y cualitativas que han permitido obtener resultados más comprensivos que los que se podrían conseguir en una investigación cuantitativa o cualitativa por separado, pero supuso mayor complejidad y fue necesaria la triangulación de métodos múltiples.

\section{Recomendaciones:}

1. Es necesario diversificar las actividades académicas a través de metodologías activas si se pretende que los estudiantes adquieran y desarrollen competencias para su futuro ejercicio profesional.

2. Hay que ser coherentes con la evaluación, utilizando indicadores que evalúen las competencias, accediendo a fuentes múltiples y variadas (protocolos de observación, el razonamiento clínico a través de la resolución de problemas 
clínicos, autoevaluaciones que permitan la autorregulación del aprendizaje, entrevistas, exámenes sorpresa, evaluaciones a pares, evaluaciones al tutor, portafolios, diarios reflexivos...) porque la competencia es "un saber actuar complejo", y estas fuentes permiten complementar, sin que el nuevo modelo de evaluación implique el olvido de las pruebas más tradicionales.

3. Es recomendable el uso de las TIC como apoyo al ABP. Se dispone de la plataforma Moodle en la Universidad de Valladolid y puede ser una herramienta útil que favorezca el aprendizaje reflexivo no presencial, permita profundizar y aumentar la transferencia del conocimiento sobre la materia, y desarrollar el pensamiento crítico en el alumnado. A través de las TIC, los estudiantes pueden articular sus ideas y opiniones, promoviendo el aprendizaje en interacción en distintos momentos y lugares fuera del aula.

4. Hay que optimizar la eficiencia con un cambio de mentalidad del proceso de enseñanza-aprendizaje, contar con los profesores más sensibles a la innovación educativa y con docentes comprometidos, para mejorar la calidad formativa. Se debe favorecer el control del aprendizaje por el propio estudiante, el profesor debe ser el que le guíe. Se recomienda ampliar y profundizar la capacitación docente para fortalecer la función del tutor, y aumentar el número de tutores/ grupo en la 
metodología ABP. Se podría contar con el apoyo de los profesores de prácticas clínicas para conseguir estos fines.

5. Se proponen líneas nuevas e interesantes de investigación como estudios longitudinales para comprobar el incremento del aprendizaje autorregulado de los estudiantes en cursos posteriores o durante su etapa profesional; estudios sobre la evaluación por competencias con la metodología ABP; sería interesante realizar estudios comparativos con diferentes instrumentos como los ya mencionados, para medir la autodirección en el aprendizaje de los estudiantes universitarios y; finalmente se proponen investigaciones sobre el perfil y capacitación docente en ABP.

6. Se espera que los resultados derivados de este análisis aporten información valiosa a los docentes y directivos, con el propósito de tomar las acciones correspondientes en respuesta a las opiniones y demandas de los estudiantes; asimismo, que sea de utilidad para otras universidades que en la actualidad implementan o desean implementar el Aprendizaje Basado en Problemas.

La educación para toda la vida se presenta como una de las llaves de acceso al siglo XXI y responde al reto de un mundo que cambia rápidamente y por tanto, la Educación Superior en Enfermería tiene que adaptarse a las nuevas demandas y cambios sociales. 


\section{Referencias bibliográficas}

Aceves, N. (2008). Adaptación, confiabilidad y validez del Cuestionario de Indagación del Perfil Autodirigido(CIPA) y su evaluación en adultos jóvenes que pertenecen a la Sociedad del Conocimiento. Disertación doctoral asesorada por Cázares, Y.

Aceves, N., Leal, M., \& Pérez, G. (2009). Efectos de las estrategias didácticas sobre el nivel de autodirección del aprendizaje de alumnos de Ingeniería. X Congreso Nacional de Investigación educativa. Veracruz. Recuperado de http://www.comie.org.mx/congreso/memoriaelectronica/ v10/pdf/area_tematica_01/ponencias/1716-F.pdf

Albanese, M., \& Mitchell, S. (1993). Problem-based Learning: A review of literature on its outcomes and implementation issues. Academic Medicine, 68(1), 5281.

Alberdi, R., \& Cuxart, A. (2005). Cuidados, enfermeras y desarrollo profesional: Una reflexión sobre las bases del ejercicio profesional. Presencia. Revista de Enfermería en Salud Mental,1(2). Recuperado de http://www.indexf.com/presencia/n2/23articulo.php

Alles, M. (2002). Gestión por competencias: El diccionario. México: Granica.

Alonso, P., Ezquerro, O., Fargues, I., García, J., Marco, M., Navarra, M.,Pardo, J.,Subirana,M., \& Urrutia,G. (2004). Enfermería Basada en la Evidencia. Hacia la excelencia de cuidados. Madrid: DAE. Recuperado de http://www.enfermeria21.com/pfw_files/cma/2_varios/li bros_on_line/evidencia.PDF

Álvarez, I. (2009). Evaluar para contribuir a la autorregulación del aprendizaje. Electronic Journal of Research in Educational Psychology, 7(3), 1007-1030.Recuperado de 
http://www.investigacion-

psicopedagogica.org/revista/articulos/19/espannol/Art_1

9 368.pdf

Álvarez, I., \& Ayuste, A. (2003). Construir conocimiento con soporte tecnológico para un aprendizaje colaborativo. Revista Iberoamericana de Educación, 1(4), 1-15.

Alvarez, I., Rius, P., \& Viladés, M. (2005). Proyecto educativo de centro con aprendizaje basado en problemas: relato de una experiencia. Revista Iberoamericana de Educación, $35(3)$.

Andrade, J., \& Campo-Redondo, M. (2008). Tecnologías de información. Revista Mexicana de Investigación Educativa, 13(36), 223-248.

ANECA. (2005). Libro Blanco titulación Enfermería. Recuperado de http://www.aneca.es/var/media/150360/libroblanco_jun0 5 enfermeria.pdf

Arambula-Greenfield, T. (1996). Implementing problem based learning in college science class: Testing problemsolving methodology as a viable alternative to traditional science teaching techniques. Journal of College Science Teaching, 26(1), 26-30.

Aráujo, U., \& Sastre, G. (2008). El Aprendizaje Basado en Problemas. Una nueva perspectiva de la enseñanza en la universidad. Barcelona: Gedisa.

Argudín, Y. (2009). La educación basada en competencias. México: Universidad Iberoamericana.

Aspegren, K., Blomqvist, P., \& Borgstrom, A. (1998). Live patients and problem-based learning. Medical Teacher, 20(5), 417-420.

Aznar, P. (1992). Constructivismo y educación. Valencia: Tirant lo Blanch.

Baker, C. (2000). Problem-based learning for nursing : Integrating lessons from other disciplines with nursing experiences. Journal of Professional Nursing(16), 258266. 
Baker, C., McDaniel, A., Pesut, D., \& Fisher, M. (2007). Learning skills profiles of mater's students in nursing administration: Assessing the impact of problem-based learning. Nursing Education Perspectives, 28(4), 190195.

Baños, J. (2001). El aprendizaje basado en problemas en los planes de estudio tradicionales ¿una alternativa posible? Educación Médica, 4, 4-12.

Baños, J., \& Pérez, J. (2005). Cómo fomentar las competencias transversales en los estudios de Ciencias de la Salud: una propuesta de actividades. Educación Médica, 8(4), 221225.

Barbeau, D., Montini, A., \& Roy, C. (1997). Tracer les chemins de la connaissance. Montréal: AQPC. Recuperado de http://www.cdc.qc.ca/Pages/Tracerleschemconn.htm

Barnet, R. (2001). Los límites de la competencia. Barcelona: Gedisa.

Barrón, T. (2000). La educación basada en competencias en el marco de los procesos de globalización. México: CESUNAM.

Barrows, H. (1996). Problem-based learning in medicine and beyond: A brief overview. En L. y. Wilkerson, Bringing problem-based learning to higher education: Theory and practice (págs. 3-12). San Francisco: Jossey-Bass.

Barrows, H., \& Tamblyn, R. (1980). Problem based learning: an approach to Medical Education. Nueva York: Springer.

Benedito,V.(1995). La formación universitaria a debate: análisis de problemas y planteamiento de propuestas para la docencia y la formación del profesorado universitario. Universidad de Barcelona, 59-60.

Berbaum. (2000). Aprendizaje y formación. Una pedagogía por objetivos. México: Fondo Cultura Económica.

Bereiter, C., \& Scardamalia, M. (1989). Intentional learning as a goal of instruction. En L. Resnick, knowing, learning, and 
instruction:Essays in honor of Robert Glaser (págs. 361392). Hillsdale, NJ: Lawrence Erbaum Associates.

Bernabeu, M., \& Cónsul, M. (2004). Una experiencia global.La Escuela de Enfermería de Vall d'Hebrón. En El Aprendizaje basado en problemas:Una herramienta para toda la vida (págs. 40-52). Madrid: Agencia Laín Entralgo.

Bernando, J. (1991). Técnicas y recursos para el desarrollo de las clases. Madrid: Rialp.

Biley, F., \& Smith, K. (1999). Making sense of problem-based learning: The perceptions and experiences of undergraduate nursing students. Journal of Advanced Nursing, 30(5), 1205-1212.

Bishop, W., \& Goldie, S. (1962). A Bio-bibliography of Florence Nightingale . London: Dawson's of Pall Mall.

Blumberg, P. (2000). Evaluating the evidence that problembased learners are self-directed learners : A review of the literature. En D H. Evensen \& C.E. Hmelo(Ed), Problem-based learning. A research perspective on learning interactions (págs. 199-226). Mahwah, NJ, US: Lawrence Erlbaum Associates Publishers

Boekaerts, M. (1996). Self-regulated Learning at the Junction of Cognition and Motivation.European Psychologist, 1(2), 100-112.

Boud, D. (1985). Problem-based learning in Perspective. En D.Boud (Ed), Problem-Based learningin Education for the Professions. Sydney: Higher Education Research and Development Society of Australia.

Bouhuijs, P. (2011). Implementing Problem Based Learning :Why is it so hard? Revista de Docencia Universitaria,9(1), 15-16.

Boutin, J., \& Julien, L. (2010). Los límites del enfoque por competencias. Revista en Educación, 15(178), 20-24.

Bowles, K. (2000). The relationship of critical-thinking skills and the clinical-judgment skills of baccalaureate nursing students. Journal of Nursing Education, 39(8), 373-376. 
Branda, L. (2001). El aprendizaje basado en problemas, centrado en el estudiante orientado a la comunidad. Aportes para un cambio curricular.Universidad McMaster(Canadá). Recuperado de: http://www.psico.uniovi.es/Fac_Psicologia/paginas_EEE s/Adaptacion_de_profesorado/metodos_docentes/aprendi zaje_basado_en_problemas_aulafutura.pdf

Branda, L. (2004). El Aprendizaje Basado en Problemas en la formación de Ciencias de la Salud. Madrid: Agencia Laín Entralgo.

Branda, L. (2009). "L'aprenentatge basat en problemes". Cendanyola del Vallès: IDES-UAB.

Brew, A. (1999). Towards autonomous assessment: using selfassessment and peer assessment. En S. Brown, \& A. Glasner (eds), Assessment Matters in Higher Education. Buckingham: Society for Research into Higher Education.

Broussard, S., La Lopa, J., \& Roos-Davis, A. (2007). Synergistic Knowledge Development in Interdisciplinary Teams. Journal of Natural Resources and Life Sciences Education, 36, 129-133.

Bruner, J. (1997). La educación, puerta de la cultura. Madrid: Visor.

Bunk, G. (1994). Teaching competence in initial and continuing vocational training in the Federal Republic of Germany. Vocational Training European Journal, 1, 8-14.

Cabero, J. (1994). Nuevas tecnologías, comunicación y educación. Revista Comunicar, colectivo andaluz para la educación en medios de comunicación, 1(3), 14-25.

Caja, L. (2011). Atención Primaria en España y en Cataluña. Rev ESC Enferm USP,45(2), 1722-1730. Recuperado de http://www.scielo.br/pdf/reeusp/v45nspe2/15.pdf

Cajide, J., \& Abeal, C. (2002). Competencias adquiridas en la universidad y habilidades requeridas por los empresarios. Revista de Investigación Educativa, 20(2), 449-467. 
Cano, E. (2008). La evaluacion por competencias en la educación superior. Revista de currículum y formación del profesorado, 12(3), 220-235.

Carbonero, M., Román, J., Martín-Antón, J., \& Reoyo, N. (2009). Efecto del Programa de Habilidades Docentes Motivadoras en el profesorado de Secundaria. Revista de Psicodidáctica, 14(2), 229-249.

Carrera, C., \& Marín, R. (2011). Modelo pedagógico para el desarrollo de competencias en Educación Superior. Revista Electrónica Actualidades Investigativas en Educación, 11(1), 1-32.

Carretero, M. (1993). Constructivismo y educación. Zaragoza: Luis Vives.

Cázares, M. (2005). Hacia un modelo de componentes que explican el aprendizaje autodirigido en estudiantes adultos mexicanos en cursos en línea en la Universidad TecMilenio. México: Universidad Virtual Tecnológico de Monterrey.

Cázares,M (2009). La autodirección, la persona autodirigida y sus componentes: definiciones conceptuales. El Tintero, 38(9), 137-139.

Cázares, M., \& Ponce, M. ( 2009). Medición de la autodirección; comparación de tres instrumentos OCLI, SDLRS y CIPA, para obtener el perfil de estudiantes en entornos virtuales $\mathrm{X}$ Congreso Nacional de Investigación Educativa (21-25 de septiembre de 2009). Recuperado de http://www.comie.org.mx/congreso/memoriaelectronica/ v10/contenido/contenido0107T.htm

Chapel, C., \& Hager, P. (1995). Problem-Based Learning and Competency Development. Australian Journal of Teacher Education, 20(1), 1-7.

Claxton, G. (2001). El reto del aprendizaje continuo. (W. Up, Trad.) Barcelona: Paidós.

Cohen, L., \& Manion, L. (1994). Research Methods in Education. London: Routledge. 
Coll, C., Colomina, R., Onrubia, J., \& Rochera, M. (1992). Actividad conjunta y habla:una aproximación al estudio de los mecanismos de influencia educativa. Infancia $y$ Aprendizaje(59-60), 189-232.

Comisión Europea. (2012). Comunicación a los Ministros del Proceso de Bolonia: la reforma de la educación superior es clave para el empleo y el crecimiento. Recuperado de http://europa.eu/rapid/pressReleasesAction.do?reference $=\mathrm{IP} / 12 / 394 \&$ format $=\mathrm{HTML} \&$ aged $=0$ \&language $=\mathrm{ES} \& \mathrm{gu}$ iLanguage $=\mathrm{en}$

Contreras, J. (1990). Enseñanza, currículum y profesorado. Madrid: Akal.

Cooke, M., \& Moyle, K. (2002). Students'evaluation of problem-based learning. Nurse Education Today(22), 330-339.

Cooke, M., Irby, D., \& y O'Brien, B. (2010). Educating physicians:a call for reform of medical schools and residency. The Carnegie Foundation for the Advancement of Teaching. San Francisco: Jossey-Bass.

Cossette, R., Mc Clish, S., \& Ostiguy, K. (2004). L'apprentissage par problèmes en soin infirmiers:adaptation en clinique el évaluation des effets. Québec: Cégep du Vieux Montréal.

Crawford, P., \& Machemer, P. (2008). Measuring incidental learning in a PBL environment. The Journal of Faculty Development, 22(1), 104-112.

Crispin, M., Esquivel, M., Loyola, M., \& Fregoso, A. (2011). ¿Qué es el aprendizaje y cómo aprendemos?.En M.Crispín,M.C.Doria,A.B.Rivera,T.De la Garza,S.Carrillo,L.Guerrero, et al. Aprendizaje Autónomo.Orientaciones para la docencia.(pág 1022).México:Universidad Iberoamericana.(ed electrónica ISBN:978-607-417-137-2) Recuperado de http://www.uia.mx/web/files/publicaciones/aprendizajeautonomo.pdf. 
De Ketele, J. M. (1996). Enseñanza en la Universidad. Bruselas: D Boeck y Lacier.

De la Torre, S. (1994). Innovación curricular:Proceso, estrategias y evaluación. Madrid : Dickynson.

De Miguel, M. (2006). Modalidades de la enseñanza centradas en el desarrollo de competencias.Orientaciones para promover el cambio metodológico en el Espacio Europeo de Educación Superior. Oviedo: Ediciones Universidad de Oviedo.

De Prado, D. (1982). El torbellino de ideas. Hacia una enseñanza más participativa. . Madrid: Cincel Kapelusz.

Declaración Alma-Ata. (2002). Salud Publica Educ Salud 2002; 2 (1), 22-24.

Declaración de Bolonia. (1999). Espacio Europeo de Educación Superior.Declaración conjunta de los Ministros europeos de Educación. Recuperado de http://www.eees.es/pdf/Bolonia_ES.pdf

Declaración de Helsinki. (2009). Declaración de Helsinki de la AMM. Principios éticos para las investigaciones médicas en seres humanos. Recuperado de http://www.wma.net/es/30publications/10policies/b3/

Del Río, P., \& Alvarez, A. (2002). From Activity to Directivity: The Question of Involvement in Education. En G. Wells, \& G. Claxton, Learning for life in the 21: Sociocultural Perspectives on the Future of Education (págs. 59-72). Oxford: Blackwell Publishers.

Delors, J. (1996). La educación encierra un tesoro. México: UNESCO.

Dembo, M.H, Junge, L., \& Lynch, R. (2004). Becoming a self regulated learnening: implications for web based education. Annual Conference of the American Educational Research Association. San Diego.

Des Marchais, J. E. (1996). Apprendre à devenir médecin : bilan d'un changement pédagogique centré sur l'étudiant. Sherbrooke : Presses de l'Université de Sherbrooke. 
Dewey, J. (1967). Democracia y Educación. Buenos Aires: Losada.

Díaz Barriga, A. (2006). El enfoque de competencias en la educación: ¿una alternativa o un disfraz de cambio? Perfiles educativos, 28(11), 7-36.

Dochy, F., Segers, M., Van den Bossche, P., \& Gijbels, D. (2003). Effects of problem-based learning: a metaanalysis. Learning and Instruction, 13(5), 533-568.

Domínguez, C. (1986). Los cuidados y la profesión enfermera en España. Madrid : Pirámide.

Dominguez, C., Rodríguez, J., \& de Miguel, J. (1983). Sociología y Enfermería. Madrid: Pirámide.

Downing, K., Kwong, T., Lam, T.-F., \& Downing, W. (2009). Problem Based Learning and development of metacognition. Higher Education, 57(5), 609-621.

Duek, J. (2000). Whose group is it anyway? Equity of student discourse in problem based-learning ? En D. Evensen, \& C. Hmelo, Problem-based learning : A research perspective on learning interactions (págs. 75-107). Mahwah, NJ: Lawrence Erlbaum Associates.

Dunlap, J. (2005). Educational Technology, Research and Development. Problem-based learning and self-efficacy :How a capstone course prepareds students for a profession, 53(1), 65-85.

Egido, I., Aranda, R., Cerrillo, R., De la Herrán, A., De Miguel, S., Gómez, M., . . Rodríguez, R. (2007). El aprendizaje basado en problemas como innovación docente en la universidad:Posibilidades y limitaciones. Educación y Futuro, 16, 85-100.

Escribano, A., \& del Valle, A. (2008). El Aprendizaje Basado en Problemas.Una propuesta metodológica en Educación Superior. Madrid: Narcea.

Esteban, M. (2008). Uso problemáticas éticas para el uso de la enseñanza del código deontológico de la psicología.Una sesión ilustrativa. Revista de Enseñanza de la Psicología:Teoría y Experiencia(4), 14-20. 
Esteban, M. (2009). La dimensión ética de la práctica profesional:Evaluación de un programa formativo. Diálogo Educacional(9), 91-101.

Esteban, M. (2011). Del "Aprendizaje Basado en Problemas"(ABP) al "Aprendizaje Basado en la Acción" (ABA). Claves para su complementariedad e implementación. Revista de Docencia Universitaria, 91107.

Esteban, M., \& Branda, L. (2011). El aprendizaje Basado en Problemas aplicado a la enseñanza de la Etica Profesional en los estudios de Psicología.La experiencia de la Universidad de Girona. Actas del $V$ Congreso Iberoamericano de Docencia Universitaria. Valencia: Universidad de Valencia.

Europa.press. (19 de octubre de 2012)."Alto nivel de la enfermería española".(en prensa). Recuperado de : http://www.europapress.es/castilla-lamancha/noticiadona-letizia-resalta-altisimo-nivel-enfermeria-espanolaimportancia-innovacion-campo-20121019141310.html

Evensen, D. (2000). Observing self directed learners in a problem-based learning context : two case studies. En D. Evensen, \& C. Hmelo, Problem-based learning. A research perspective on learning interactions (págs. 263297). New Jersey : Lawrence Erlbaum Associates.

Evensen, D., \& Hmelo, C. (2000). Problem-based learning.A research perspective on learning interaction. New Jersey: Lawrence Erlbaum Associates.

Exley, K., \& Dennick, R. (2007). Enseñanza en pequeños grupos en Educación Superior. Tutorías, seminarios y otros agrupamientos. (P. Manzano, Trad.) Madrid: Narcea.

Faidley, J., Evensen, D., Salisbury-Glennon, J., Glenn, J., \& Hmelo, C. (2000). How are we doing? Methods of assessing group processing in a problem-based learning context. En D. Evensen, \& C. Hmelo, Problem-based learning. A research perspective on learning interactions 
(págs. 109-135). New Jersey: Lawrence Erlbaum Associates.

Fasce, A. P., Ortiz, L., Parra, P., \& Matus, O. (2011). Estructura factorial y confiabilidad de la escala de aprendizaje autodirigido de Fisher, King \& Tague en alumnos de medicina chilenos.Rev Med Chile(139), 1428-1434. doi: 10.4067/S0034-98872011001100006

Fernández Enguita, M. (2009). La profesión docente: realidades y retóricas. Conferencia impartida en la XXV Semana Monográfica.Enseñar y aprender: ideas y prácticas del profesorado. Madrid. Recuperado de http://www.fundacionsantillana.com/upload/ficheros/noti cias/200911/ponencia_mariano_fernandez_enguita.pdf

Fernández, C., Garrido, M., Tomás, M., \& Serrano, M. (2000). Enfermería Fundamental. Barcelona: Masson.

Fisher, M., King, J., \& Tague, G. (2001). Development of a selfdirected learning readiness scale for nursing education. Nurse Educ Today, 21(7), 516-525.

Flavell, J. (1979). Metacogniton and cognitive monitoring. American Psychologist, 34(10), 906-911.

Font, A. (2004). Líneas maestras del Aprendizaje Basado en Problemas. Revista interuniversitaria de Formación del Profesorado, 18(1), 79-95.

Gairin, J. (2006). La cultura Institucional y la Universidad. En M. Tomás, Reconstruir la universidad a través del cambio cultural. (págs. 9-45). Universitat Autónoma de Barcelona: Server de Publicacions.

Gallardo, B. (2012). El aprendiz estratégico para una nueva sociedad. Teoría de la Educación, Educación y Cultura en la Sociedad de la Información, 13(2), 246-272.

García, M. (2012). La autorregulación académica como variable explicativa de los procesos de aprendizaje universitario. Profesorado, 16(1), 203-221.

Garcia, S., \& Calvo, E. (1992). Historia de la enfermería, textos mínimos. Málaga: Universidad de Málaga. 
Gijbels, D., van de Watering, G., \& Dochy, F. (2005). Integrating assessment tasks in a problem-based learning environment.Assessment \& Evaluation in Higher Education 30(1), 73-86.

Gijselaers, W. H. (1996). Connecting problem-based learning whit educational theory. En L. Wilkerson, \& W. H. Gijserlaers(Eds), Bringing problem-based learning to higher education .Theory and Practice (págs. 13-21). San Francisco: Josey-Bass.

Gijón, J., \& Crisol, E. (2012). La iternacionalización de la Educación Superior.El caso del Espacio Europeo de Educación Superior. Revista de Docencia Universitaria, 389-414.

Gil, C., Alias, A., \& Montoya, M. (2006). Cómo mezclar diferentes metodologías docentes para motivar e implicar a un mayor número de alumnos. VI Jornadas de Aprendizaje Cooperativo. Barcelona.

Gil, C., Baños, R., Alias, A., \& Gil, D. (2007).Aprendizaje cooperativo y desarrollo de competencias. $7^{a}$ Jornada sobre aprendizaje cooperativo organizada por los grupos GIAC de la UPC y GREIDI. Recuperado de http://www.greidi.uva.es/JAC/GIAC_JAC/07/30.pdf

Gimeno, J. (. (2008). Educar por competencias, ¿Qué hay de nuevo? Madrid: Paidós básica.

Girao, J. (2004). La medida del cuidado. $V$ Congreso de la Asociación AAEC.(28-29 y 30 Oct). Murcia.

Gómez, C., Hernández, J., \& Moral de Calatrava, P. (1999). Análisis de la enseñanza de la enfermería en España contemporánea.Desde los planes de estudio. Rev Enfermería de la Infancia y Humanidades(6), 61-65.

González Fernández, A. (2001). Autorregulación del aprendizaje: una difícil tarea. Iberpsicología, 6(1), 30-67.

González, C., Carbonero, M., \& Sánchez-Crespo, J. (2011). Aprendizaje basado en problemas (ABP) como innovación educativa en la formación en enfermería 
obstétrico-ginecológica. Rev Paraninfo Digital, 14. Recuperado de http://www.index-f.com/para/n14/147d.php

González, J., \& y Wagenaar, R. (2003). Tuning Educational Structures in Europe.Informe Final. Bilbao: Universidad de Deusto.

González, S. (2010). Competencias en la reforma educativa. Revista en Educación, 15(178), 7-11.

Guerra, A. (2008). Estudio comparativo en cuanto al perfil autodirigido de estudiantes de preparatoria versus estudiantes de secundaria, medidos a través del CIPA+. México: Instituto Tecnológico de Monterrey.

Guglielmino \& Associates, L. ( 2012). He Self-Directed Learning Readiness Scale (SDLRS) Also Known as the Learning Preference Assessment (LPA). Recuperado de $\mathrm{http}: / / \mathrm{www}$.guglielmino734.com/

Guillanet, A., González, P., Heierle, C., \& Celma, M. (2008). El aprendizaje basado en problemas como cambio de cultura para las escuelas de enfermería. Nursing, 26(3), 64-66.

Hanrahan, S., \& Isaacs, G. (2001). Assessing self- and peerassessment: the students' views. Higher Education Research and Development, 20(1), 53-70.

Harland, T. (2003). Vygotsky's Zone of Proximal Development and Problem-based. Teaching in Higher Education, 8(2), 263-272.

Hernández, F. (1996). Historia de la enfermería en España.Desde la antigüedad hasta nuestros dias. Madrid: Síntesis.

Hernández, F., Rosário, P. J., \& Cuesta, D. J. (2010). Impacto de un programa d eautorregulación del aprendizaje de estudiantes de Grado. Revista de Educación, 571-588.

Hesterberg, L. (2005). Evaluation of a problem- based learning practice course : Do self-efficacy, critical thinking, and assessment skills improve? Proquest Dissertations and Thesse No 3162941. 
Higgs, B. (2005). The evolution from problem-based learning $(P B L):$ a case study in Earth Sciences ay University College Cork. Obtenido de http://www.nuigalway.ie/celt/pblbook/

Hmelo, C. (1998). Problem-based learning : Effects on the early acquisition of cognitive skill in medicine. The journal of the learning sciences, 7(2), 173-208.

Hmelo, C., \& Evensen, D. (2000). Problem-based learning: Gaining insights on learning interactions through multiple methods of inquiry. En D. Evensen, \& C. Hmelo, Problem-based learning. A research perspective on learning interactions (págs. 1-16). New Jersey: Lawrence Erlbaum Associates.

INE. (2012). Recuperado de http://www.ine.es/jaxi/menu.do?type=pcaxis\&path=/t20/ e245/p04/provi\&file=pcaxis

Iputo, J. (1999). Impact of the problem-based learning curriculum on the learning styles and strategies of medical students of University of Transkei. South African Medical, 89(5), 550-554.

Instituto Tecnológico de Monterrey. (2006). Estrategias y técnicas didácticas en el rediseño.Recuperado de http://www.sistema.itesm.mx/va/dide/inf-doc/estrategias.

Johnson, D., JohnsonR., \& Smith, K. (1998). Active learning:cooperation in the College Classroom. Minnesota: Interaction Book Company.

Kirk, A., Bélise, M., \& McAlphine, L. (2003). Successful strategies for learning in Engineering, results of student survey. Recuperado de www.education.mcguill.ca/learning_engineering

Klipperndorff, P. (1990). Metodología de análisis de contenido. Teoría y práctica. Barcelona: Paidós.

Kneser, C. \& Ploetzner, R. (2001).Collaboration on the basis of complementary domain knowledge: observed dialogue structures and their relation to learning succes. Learning and Instruction, 11, pág 53-83. 
Kocaman, G., Dicle, A., \& Ugur, A. (2009). A longitudinal Analysis of the Self-Directed Learning Readiness Level of Nursing Students Enrolled in a Problem-Based Curriculum. Journal of Nursing Education, 48(5), 286290.

Ladios Martín, M. (2005). El legado de Nightingale. Recuperado de

http://www.enfermeria21.com/pfw_files/cma/revistas/Ed ucare 21/2005/22/aprendiendo2.pdf

Langevin, L., \& Bruneau, M. (2000). Enseignement supérieur: vers nouveau scénario. Paris: ESF.

Larue, C., \& Hrimech, M. (2009). Analyse des stratégies d'apprentissage dans une méthode d'apprentissage par problèmes: le cas d'étudiantes en soins infirmiers. Revue Internacional de pédagogie de l'enseignement supérieur 25(2), 1-12. Recuperado

de http://ripes.revues.org/pdf/221

Lasnier, F. (2000). Réussir la formation par compétences. Montréal: Guérin.

Le Boterf, G. (2001). Ingeniería de las competencias. Barcelona: Gestión 2000.

Legault, A. (2012). ¿Una enseñanza universitaria basada en competencias? ¿Por qué? ¿Cómo? Revista Electrónica de Desarrollo de Competencias, 5(1).

León, O., \& Montero, I. (1997). Diseño de investigaciones. Introducción a la lógica de la investigación en Psicología y Educación (2a ed.). Madrid: McGraw-Hill.

Ley Orgánica 6/2001, de 21 de diciembre, de Universidades . Recuperado de http://www.boe.es/boe/dias/2001/12/24/pdfs/A4940049425.pdf

Ley Orgánica 4/2007, del 12 de abril, por la que se modifica la Ley Orgánica 6/2001, de 21 de diciembre, de Universidades. Recuperado

de 
http://www.boe.es/boe/dias/2007/04/13/pdfs/A1624116260.pdf

Lieberman, S., Stroup-Benham, C., Peel, J., \& Camp, M. (1997). Medical student perception of the académic environment: A prospective comparison of traditional and problembased curricula. Academic Medicine, 72(10), 13-15.

Litzinger, T. A., Wise, J. C., \& Lee, S. H. (2005). Self-directed Learnin Readinessamong engineering undergraduate students. Journal of Engineering Education, 94(2), 215221.

Lizzio, A., Wilson, K., \& Simons, R. (2002). University students' perceptions of the learning environment and academic outcomes: implications for theory and practice. Studies in Higher Education, 27(1), 27-52.

López, I., González, J., \& Agudo, E. (2007). Desarrollo de Competencias Transversales a través del método ABP en la asignatura Enfermería Comunitaria II. Madrid: Universidad Europea de Madrid.

López, J. I. (2011). Un giro copernicano en la enseñanza universitaria:formación por competencias. Revista de Educación(356), 279-301.

Lycke, K., Grøttum, P., \& Strømsø, H. (2006). Student learning strategies, mental models and learning outcomes in problem-based and traditional curricula in medicine. Medical Teacher, 28(8), 717-722.

MacKinnon. (1999). CORE elements of student motivation in problem-based learning. New Directions for teaching and learning(78), 49-74.

Marcelo, C. (2011). La profesión docente en momentos de cambios. ¿Qué nos dicen los estudios internacionales? CEE Participación educativa, 49-68.

Márquez, C., Uribe, J., Montes, R., Monroy, C., \& Ruiz, E. (2011). Satisfacción académica con el ABP en estudiantes de licenciatura de la Universidad de Colima,México. Revista Intercontinental de Psicología y Educación, 13(1), 29-44. 
Martin, L., West, J., \& Bill, K. Incorporating problem-based learning strategies to develop. Learning autonomy and employability skills in sports science undergraduates. Journal of Hospitality, Leisure, Sport and Tourism Education, 7(1), 18-30.

Martínez Fernández, J. (2002). Aprender: necesaria unión entre el querer, el saber y el poder. Revista de Pedagogía, 23(68).

Martínez, M. (2007). 30 años de evolución de la formación enfermera en España. Educación Médica, 10(2), 93-96.

Martínez, P. (2008). Estilos de aprendizaje: pautas metodológicas para trabajar en el aula. Revista Complutense de Educación, 19(1), 73-94.

Martínez, P., \& Echeverría, B. (2009). Formación basada en competencias. Revista de Investigación Educativa, 27(1), 125-147.

Marton, F., \& Säljö, R. (1976(a)). On qualitative differences in learning: I. Outcome and process. British Journal of Educational Psychology, 46, 4-11.

Marton, F., \& Säljö, M. (1976(b)). On qualitative differences in learning: II. Outcome as a function of the learner's conception of the task. British Journal of Educational Psychology, 46, 115-127.

Matesanz, M. (2009). Pasado, presente y futuro de la Enfermería:una aptitud constante. Revista Administración Sanitaria, 7(2), 243-260.

McGrath, D. (2002). Teaching on the Front Lines: Using the Internet and Problem-Based Learning To Enhance Classroom Teaching. Holist Nurs Pract, 16(2), 5-13.

McKinnon, M. (1999).CORE elements of student motivation in problem-based learning. New Directions for Teaching and Learning, 78, 49-58.

Medina, J. (1999). La pedagogía del cuidado: saberes y prácticas en la formación universitaria de enfermería.Barcelona: Alertes Psicopedadogía. 
Mennin, S., Gordan, P., Majoor, G., \& Osman, H. (2003). Position Paper on Problem-Based Learning. Education for Health, 16(1), 98-113.

Michavilla, F., \& Calvo, B. (1998). La universidad española de hoy. Madrid: Síntesis.

Milligan, F. (1999). Beyond the rhetoric of problem-based learning: emancipatory limits and links with andragogy. Nurse Education Today, 19, 548-555.

Ministerio de Educación y Ciencia. (2003). La integración del sistema universitario español en el Espacio Europeo de Educación Superior. Documento-Marco Madrid: Ministerio de Educación.

Ministerio de Educación y Ciencia. (2009). Panorama de la educación, indicadores de la OCDE 2009, informe español. Madrid: Ministerio de Educación. Recuperado de

http://www.educacion.gob.es/dctm/ministerio/horizontal es/prensa/documentos/2009/informe-espanol-panoramaeducacion-ocde.pdf?documentId=0901e72b8007cd90

Ministerio de Educación y Ciencia.(2010). Estrategia Universidad 2015. El camino para la modernización de la Universidad. Recuperado de http://www.educacion.gob.es/dctm/eu2015/2010-pdfeu2015.pdf?documentId $=0901 \mathrm{e} 72 \mathrm{~b} 801$ ee $2 \mathrm{a} 4$

Ministerio de Educación y Ciencia. (2012). ¿Qué es Bolonia? Recuperado de http://www.queesbolonia.gob.es/queesbolonia/procesoen-marcha/grupo-seguimiento-bolonia/que-es-el-grupode-seguimiento-del-proceso-de-bolonia.html

Moesby, E. (2008). Perspectiva general de la introducción e implementaciónde un nuevo modelo educativo basado en el aprendizaje orientado a proyectos y basado en problemas. En U. Araújo, \& G. Sastre, Aprendizaje Basado en Problemas. Una nueva perspectiva de la enseñanza en la universidad (págs. 93-128). Barcelona: Gedisa. 
Molina, J., García, A., Pedraz, A., \& Antón, M. (2003). Aprendizaje Basado en Problemas.Una alternativa al método tradicional. Revista de la Red estatal de Docencia Universitaria (3)2, 79-85. Recuperado de http://revistas.um.es/redu/article/view/10191

Monereo, C. (2007). Hacia un nuevo paradigma del aprendizaje estratégico:el papel de la mediación social, del self y de las emociones. Revista electrónica de investigación Psicoeducativa, 497-534.

Mora, J. (2004). Necesidad del cambio educativo para la sociedad del conocimeinto. Revista iberoamericana de Educación, 13-37.

Morales, P., \& Landa, L. (2004). Aprendizaje Basado en problemas. Theoria(13), 145-157.

Morales-Mann, E., \& Kaitell, C. (2001). Problem-based learning in a new Canadian curriculum. Journal of Advanced Nursing(33), 13-19.

Moreno, A. (1989). Metaconocimiento y aprendizaje escolar. Cuadernos de pedagogía(173), 53-58.

Moreno, O. (2009). Competencias en Educación Superior: un alto en el camino para revisar la ruta de viaje. Perfiles educativos, 31(124), 7-36.

Morin, E. (1999). Los siete saberes necesarios para la educación del futuro.Paris:UNESCO. Recuperado de http://www.unmsm.edu.pe/occaa/articulos/saberes 7.pdf

Museo Florence Nightingale . (18 de agosto de 2012). Notes on Nursing: What it is and what it is not. Londres.

Myers, I., \& Horst, S. (2000). Groups in problem-based learning (PBL) : Essential elements in theory and practice. En H. Evensen, \& C. (. Hmelo, Problem-based learning : a research perspective on learning interactions (págs. 263297). Mahwah, NJ: Lawrence Erlbaum Associates, Inc.

Nightingale, F. (1990). Notas sobre la Enfermería.Qué es y que no es. Barcelona: Salvat.

Nijhuis, J., Segers, M., \& Gijselaers, W. (2008). The extent of variability in learning strategies and students' perceptions 
of the learning environment. Learning and Instruction, $18,121-134$.

Noone, D. (2000). Soluciona problemas creativamente. Barcelona: Gestión.

Norman, G., \& Schmidt, H. (1992). The psychological basis of problem-based learning : A review of the evidence. Academic Medecine(67), 557-565.

OCDE. (2000). Schooling for Tomorrow. Learning to bridge the digital divide. Centre for Educational Research and Innovation. Paris: OCDE

Olivares, S. (2011). Formación del Pensamiento crítico y la Autodirección. Impacto del Aprendizaje Basado en problemas en programas de salud. Alemania: Editorial Académica Española.

OMS. (1978). Declaración de Alma-Ata. Conferencia Internacional sobre Atención Primaria de Salud. Recuperado de http://www.paho.org/spanish/dd/pin/almaata_declaracion.htm

OMS (2003). Conferencia Internacional sobre Atención Primaria: 25 aniversario. 56 ${ }^{\mathrm{a}}$ ASAMBLEA MUNDIAL DE LA SALUD.

Orlan, R. (1993). Constructivismo y escuela. Sevilla: Diada.

Oviedo, H., \& Campo, A. (2005). Aproximación al uso del coeficiente alfa de Cronbach. Revista colombiana de psiquiatría, 34(4), 572-580.

Ozturk, C., Muslu, G., \& Dicle, A. (2008). A comparison of problem-based and traditional education on nursing students' critical thinking dispositions. Nurse Education Today, 28(5), 627-632.

Palés, J., \& Gual, A. (2004). Recursos educativos en Ciencias de la Salud. Revista Educación Médica, 7(1), 4-9.

Parra, C. (2002). Investigación -Acción y desarrollo profesional. Educador y educadores, 5, 113-125.

Parra, C. (2009). Apuntes sobre investigación formativa. Educación y Educadores, 7, 57-77. 
Patterson, C., Crooks, D., \& Lunyk-Child, O. (2002). A new perspective on competencies for self-directed learning. Journal of Nursing Education, 41(1), 25-31.

Peñalosa, E., Landa, P., \& Vega, C. (2006). Aprendizaje Autorregulado: Una revisión conceptual. Revista Electrónica de Psicología Iztacala, 9(2), 1-21.

Pérez, G. (2007). La naturaleza de las competencias básicas y sus aplicaciones pedagógicas. Cuadernos de Educación de Cantabria, 4-34.

Perrenoud, P. (1998). Construir competencias desde la escuela. París: $2^{\mathrm{a}}$ ed.ESF.

Perrenoud, P. (2004). Diez nuevas competencias para enseñar. Barcelona: Graó.

Perrenoud, P. (2008). Construir las competencias ¿Es darle la espalda a los saberes? Revista Docencia Universitaria, 2(6), 12-16.

Pintrich, P. (2000). The role of goal orientation in self-regulated learning. En H. o. self-regulation, Boakerts, $P$;Pintrich,P;Zeidner, $M$ (págs. 451-502). San Diego: Academic Press.

Pintrich, P. (2003). A motivational science perspetive on the role of student motivation in learning and theaching contexts. Journal of Educational Psychology, 16(4), 667-686.

Pintrich, P. (2004). A conceptual framenwork for assessing motivation and self-regulated learning in college students. Educational Psychology Review, 16(4), 385407.

Pintrich, P., \& De Groot, E. (1990). Journal of Educational Psychology(82), 33-40.

Pintrich, P., \& Schunk, D. (2006). Motivación en contextos educativos. Madrid: Pirámide.

Planella, J., Escoda, L., \& Suñol, J. (2009). Análisis de una experiencia de aprendizaje basado en problemas en la asignatura de Fundamentos de Física. Recuperado de http://revistas.um.es/redu/article/view/69971/67441 
Porres, M., Sola, C., Gentil, R., Epstein, L., Lapuente, G., Limon, S., . . Illescas, F. (2006). Aprendizaje Basado en Problemas. De la teoría a la práctica. México: Trillas.

Pozo, J. (1999). Aprendices y maestros. Madrid: Alianza.

Pozo, J., Monereo, C., \& Castelló, M. (2005). El uso estratégico del conocimiento. En C. Coll, J. Palacios, \& A. Marchesi, Desarrollo psicológico $y$ educación.2.Psicología de la educación escolar. Madrid: Alianza.

Prat, J., Palés, J., Nolla, M., Oriol, A., \& Gual, A. (2010). El Proceso de Bolonia II: educación centrada en el que aprende. Educación Médica, 13(4), 197-203.

Prieto, L. (2006). Revista de Ciencias Humanas y Sociales. Aprendizaje activo en el aula universitaria: el caso del aprendizaje basado en problemas, 64(124), 173-196.

Quintanilla, M., \& Carulla, T. (2010). Cómo trabajar más contenidos en Enfermería Geriátrica siguiendo las indicaciones de Bolonia y transformando la metodología docente. Gerokomos (online), 21(4), 167-170.

Quintanilla, M., Bernaus, E., Guillamet, A., \& Fernández, A. (2004). learning to solve problems in clinical practice. Educación Médica, 3, 104.

RAE. (2012). Recuperado de http://lema.rae.es/drae/?val=competencia

Ramnarayan, K., \& Hande, S. (2005). Thoughts On SelfDirected Learning In Medical Schools: Making Students More Responsible. Recuperado de http://www.newhorizons.org/lifelong/higher_ed/ramnara yan $\% 20$ hande.htm

Ramsdem, P., Prosser, M., Trigwell, K., \& Martin, E. (2007). Unoversity teachers' experiences of academic leadership and their approaches to teaching. Learnig and Instruction(14), 140-155.

Real Decreto 1027/2011, de 15 de julio, por el que se establece el Marco Español de Cualificaciones para la Educación Superior. Recuperado de 
http://www.boe.es/boe/dias/2011/08/03/pdfs/BOE-A2011-13317.pdf

Real Decreto 139372007, de 29 de octubre, por el que se establece la ordenación de las enseñanzas universitarias oficiales. Recuperado de http://www.boe.es/boe/dias/2007/10/30/pdfs/A4403744048.pdf

Real Decreto 1466/1990, de 26 de octubre, B.O.E no 278 de 20 de noviembre de 1990, por el que se establece el título universitario oficial de Diplomado Universitario en Enfermería y las directrices generales propias de los planes de estudio conducentes a la obtención de aquél.

Real Decreto 1892/2008, de 14 de noviembre, por el que se regulan las condiciones para el acceso a las enseñanzas universitarias oficiales de grado y los procedimientos de admisión a las universidades públicas españolas. Recuperado de http://www.boe.es/boe/dias/2008/11/24/pdfs/A4693246946.pdf

Real Decreto 2128/1977, B.O.E n ${ }^{\circ} 283$ de 26 de noviembre de 1977, 28232 Orden de 31 de octubre de 1977 por la que se dictan directrices para la elaboración de planes de estudios de las Escuelas Universitarias de Enfermería. Recuperado de http://www.boe.es/boe/dias/1977/11/26/pdfs/A2598725989.pdf

Real Decreto 450/2005, de 22 de abril, sobre especialidades de Enfermería. Recuperado de http://www.boe.es/boe/dias/2005/05/06/pdfs/A1548015486.pdf

Restrepo, B. (2005). Aprendizaje Basado en Problemas ABP:una innovación didáctica para la enseñanza universitaria. Educación y educadores, 8, 9-19.

Ríos, D. (2007). Sentido, criterios y utilidades de la evaluación del aprendizaje basado en problemas. Educación Médica Superior,21(3).Recuperado

de: 
http://scielo.sld.cu/scielo.php?script=sci_arttext\&pid=S0 864-21412007000300004

Roegiers, X. (2000). Una pedagogía de la integración. Bruselas: De Boeck.

Rosário, P., Mourao, R., Trigo, J., Núñez, J., \& GonzálezPineda, J. (2005). Academic Exchange Quarterly. Winter, 9(4), 73-77.

Rué, J. (2008). Aprender en autonomia en Educación superior. En U. Araújo, \& G. sastre, El Aprendizaje Basado en Problemas. Una nueva perspectiva de la enseñanza en la Universidad (págs. 47-66). España: Gedisa.

Rué, J. (2009). El aprendizaje autónomo en Educación Superior. Madrid: Narcea.

Rué, J., Font, A., \& Cebrián, G.(2011). El ABP, un enfoque estratégico para la formación en Educación Superior. Aportaciones de un análisis de la formación en Derecho. Revista de Docencia Universitaria, 9(1), 25-43.

Ruiz, C., \& Martin, C. (2005). Innovación docente en la Universidad en el marco de la EEES. Educatio(23), 171189.

Ruohoniemi, M., \& Lindblom-Ylänne, S. (2009). "Students" experiences concernig course workload and factors enhancing and impeding their learning a useful resource for quality enhancement in thing and curriculum planning. International Journal for Academic Development, 14(1), 69-81.

Sahuquillo, M., \& Sevillano, E.(en prensa). (2012). El éxodo de medicos y enfermeras se duplica por los recortes sanitarios. Recuperado http://politica.elpais.com/politica/2012/08/06/actualidad/ 1344284347_177524.html

Salaburu, P., Haug, G., \& Mora, J.-G. (2011). España y el proceso de Bolonia, un encuentro imprescindible. Madrid: Academia Europea de las ciencias y las artes. 
Sancho, C., \& Prieto, L. (julio de 2012). Teorías y modelos en la práctica enfermera.¿Un binomio imposible? Enfermería Global(27), 292-297.

Savin-Baden, M. (2000). Problem-based learning in higher education : Untold stories. Buckingham : The Society for Research into Higher Education \& Open University Press.

Schmidt, G. (1989). New Directions for Medical Education.Problem Based Learning and Community Oriented Medical Education. En G. Schmidt, M. Lipkin, M. Vries, \& J. Greep, The rationale behind problembased learning. Nueva York: Springer-Verlag.

Schmidt, H., \& van der Molen, H. (2001). Self-reported competency ratings of graduates of a problem-based medical curriculum. Academic Medecine, 76(5), 466468.

Sefton, A., Gordon, J., \& Field, M. (2000). Teaching clinical reasoning to medical students. En J. Higgs, \& M. Jones, Clinical reasoning in the health professions $2^{a}$ ed. (págs. 184-190). Boston: Butterworth-Heinemann.

Shelton, J., y Smith, R. (1998). "Problem-based learning in analytical science undergraduate teaching". Research in Science and Technological Education, 16 (1), 19-29.

Siles, J. (1999). La enfermería preprofesional:la larga transición hacia la profesionalización(de finales del siglo XVIII al XX. En 1. edición (Ed.), Historia de la Enfermería (pág. 230). Alicante: Aguaclara editores.

Silva, M. (2008). ¿Contribuye la universidad tecnológica a formar las competencias necesarias para el desempeño profesional? Revista Mexicana en Investigación Educativa, 13(38), 773-800.

Sleight, D., \& Mavis, B. (2006). Study skills and academic performance among second-year medical studentes in Problem-Based Learning. Medical Education Online, 11(23), 1-6. 
Sola, C. (2006). Ventajas y desventajas del ABP:a modo final. En M.Porres,. y. otros, Aprendizaje Basado en Problemas. De la teoría a la práctica (págs. 188-201). Sevilla: Trillas.

Solaz-Portolés, J., Sanjosé, V., \& Gómez, A. (2011). Aprendizaje basado en problemas en la formación del profesorado. Recuperado de http://roderic.uv.es/bitstream/handle/10550/21337/177186.pdf? sequence $=1$ :

Steenkamps, F., De Looper, H., \& Bliekendaal, M. (2006). Keuzegids Hoger Onderwijs. Leiden: Hoger Onderwijs Persbureau.

Suárez Riveiro, J., Fernández Suárez, P., \& Anaya Nieto, D. (2005). Un modelo sobre la determinación motivacional del aprendizaje autorregulado. Reciónvista de Educ(338), 295-306.

Sungur, S., \& Tekkaya, C. (2005). Effects of problem-based learning and traditional instruction on self-regulated learning. The Journal of Educational Research, 99(5), 307-317.

Tardif, J. (1998). Intégrer les nouvelles technologies de l'information. Quel cadre pédagogique? Paris: ESF.

Tardif, J. (2006). L'évaluation des compétences. Documenter le parcous de développement. Montréal: Chenelière Éducation.

Tejada, A. (2003). Alma-Ata 25 años después. Perspectivas en Salud, revista de la OPS, 8(1).

Tejada, J. (1998). Los agentes de la innovación en los Centros Educativos. Granada: Aljibe.

Tejada, J., \& Navío, A. (2005). El desarrollo y la gestión de competencias profesionales:una mirada desde la formación. Revista Iberoamericana de Educación, 14-28.

Tesouro, M. (2005). La metacognición en la escuela:la importancia de enseñar apensar. Educar(35), 135-144.

Torrano, F., \& González Torres, M. (2004). El aprendizaje autorregulado:presente y futuro de la investigación. 
Revista electrónica de Investigación Psicoeducativa, 2(1), 1-34.

Trice, H., \& Beyer, J. (1993). En H. Trice, \& J. Beyer, Classics of Organitational Theory (págs. 414-424). Nueva York: Wadsworth, Thomson Learning.

UNESCO. (1998( a)). La Educación Superior en el siglo XXI. Visión y Acción. París: UNESCO

UNESCO. (1998(b)). Florence Nightingale(18201910).Perspectivas: revista trimestral de educación comparada, 28(1),173-189.Recuperado de http://www.ibe.unesco.org/fileadmin/user_upload/archiv e/publications/ThinkersPdf/nightins.PDF

UVA. (2012). Estudios de Grado en Enfermería en la Universidad de Valladolid. Recuperado de http:/grado.uva.es/grado-en-enfermeria-valladolid

Valle, A., \& Barca, A. (1993). Aprendizaje significativo y enfoques del aprendizaje: el papel del alumno el proceso de construcción de conocimientos. Revista Ciencias de la Educación, 156, 481-502.

Van Der Hurk, M. (2006). The relation between self regulated strategiesand individual study time, prepared participation and archievement in a problem based curriculum. Learning in higher education, 7(2), 155-169.

van Grieken, R. (2012). Diez años de ANECA:el futuro de la evaluación de la universidad en España. Encuentro , Universidad Internacional Menéndez Pelayo, Santander.

Vega, E., \& Balderas, J. (2005). El Aprendizaje Basado en Problemas y la adquisición de competencias en el curso de la Probabilidad y estadística. II Congreso Nacional y $V$ Encuentro de Estudiantes y Académicos de Posgrado. México: Tecnológico de Monterrey.

Vernon, D., \& Blake, R L. (1993). Does problem-based learning work? A meta-analysis of Evaluative research.Academic Medicine 68(7), 550-563.

Vidal, M., \& Rivera, N. (2007). Investigación-acción.Educación Médica Superior, 21(4). Recuperado de 
http://bvs.sld.cu/revistas/ems/vol21_4_07/ems12407.htm 1

Villa, A., \& Poblete, M. (2007). Aprendizaje basado en Competencias ( $2^{\mathrm{a}}$ ed.). Bilbao: Mensajero.

Villa, A., \& Poblete, M. (2011). Evaluación de competencias genéricas:principios, oportunidades y limitaciones. Bordón, 63, 147-170.

Walton, H., \& Matthews, M. (1989). Essentials of problem based learning. 23, 542-558.

Watts, F., \& García-Carbonel, A. (2006). La evaluación compartida: investigación multidisciplinar. Valencia: UPV.

Westera, W. (2001). Competences in education: A confusion of tongues. Journal of Curriculum Studies, 33(1), 75-88.

White, M. J., Amos, E., \& Kouzekanani, K. (1999). Problem based-learning : An outcomes study. Nurse Educator, 24(2), 33-36.

Williams, B. (2001). Developing critical reflection for professional practice through problem based learning. Journal of Advanced Nursing, 34(1), 27-34.

Yániz, C. (2006). Planificar la enseñanza universitaria para el desarrollo de competencias. Educatio siglo XXI(24), 1734.

Young, P., Hortis, V., Chambi, M., \& Finn, B. (2011). Florence Nightingale (1820-1910),101 años de su fallecimiento. Revista Médica de Chile, 139, 807-813. Recuperado de http://www.scielo.cl/pdf/rmc/v139n6/art17.pdf

Zabala, A. (1995). La práctica educativa. Cómo enseñar. Barcelona: Grao.

Zabala, A. (2008). 11 ideas clave . Cómo aprender y enseñar competencias. México: Grao.

Zabala, M. (2011). La aventura de aprender y el desafío de enseñar. REDU Revista de docencia Universitaria(9)1, 9-10.

Zimerman, B., \& Schunk, D. (2008). Motivation: An essential dimension of self-regulated learning. En B. Zimerman, \& 
D. Schunk, Motivation and self-regulated learning: Theory, research, and applications (págs. 1-30). Mahwah,NJ: Erlbaum.

Zimmerman. (2000). Attainment of self-regulation:A social cognitive perspective. En M. Boekaerts, P. Pintrich, \& M. Zeidner, Handbook pf self-regulation (págs. 13-39). San Diego: Academic Press.

Zimmerman, B. (2001). Theories of self-regulated learningand academic achivement: an overview and analysis. Mahwah,NJ: Erlbaum.

Zimmerman, B. (2002). Becoming al self-regulated leaner:an overview. Theory Into Practice.41(2), 64-70.

Zimmerman, B., \& Martínez-Pons, M. (1986). Developing a estructured interview for assesing student use of selfregulated Learning Strategies. American Educational Research Journal(23), 614-628.

Zimmerman, B., \& Martínez-Pons, M. (1990). Student differences in self-regulated learning:Relating grade, sex and giftedness to self efficacy and strategy use. Journal of Educational Psychology. (82), 51-59.

Zimmerman, B., Bonner, S., \& Kovach, R. (1996). Developing self regulated learnes.Beyond achievement to selfefficacy. Whashington: American Psychological Association. 
Anexos 
Anexo 1 .Cuestionario de perfil Autodirigido CIPA+ Me siento así: 1 siempre 2 ocasionalmente 3 a veces 4 casi nunca 5 nunca

\begin{tabular}{|c|c|c|c|c|}
\hline N & feactivo & $1|2|$ & 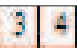 & 5 \\
\hline 1 & Se itentifier alternatives de solubion a las problemas & & & \\
\hline 2 & Administro bier el tiempa, me gusta hacer las cosas antes de b fecta limite & & & \\
\hline 3 & Ante una tarea essolar, utlize dise ras fuertes y recurses para realizarla & & & \\
\hline 4 & Cres en el autoestroly lo prastics & & & \\
\hline 5 & Distinge tarte enductas acteuasas eomo in abecuatas & & & \\
\hline 6 & E) exito no es cuestiso de suerte & & & \\
\hline 7 & Entiente y ase pto las consecuenoias te las eecisiones que tomb & & & \\
\hline 8 & Hago is que tengo que hacer para alzarzar de manera ralista mis metas & & & \\
\hline 9 & Me asapto con facilitad & & & \\
\hline 10 & Me pongo objetives para orientar mi rumbo: & & & \\
\hline 11. & Tergo potendoal para realizar mis metas & & & \\
\hline 12 & Tenge una idea dara de is que quiere en la wisa & & & \\
\hline 13 & Put do tistirguir entre algo importante pers no urgerts & & & \\
\hline 14 & Futdo distirguir entre algo importants yurgents & & & \\
\hline 15 & Puedo ide ntificar afirmaciones in sostenibles & & & \\
\hline 16 & Putdo ide ntifcar cuando "sl grupo" me presiona para decieir sobre algo & & & \\
\hline 17 & Pusto ide ntifear mis se rtimientss. & & & \\
\hline 18 & Reconsaso mis limitabones, de red as y necesitades personales & & & \\
\hline 19 & Reconosco zue tenge muthas alternativas para aicarzar mis metss & & & \\
\hline 20 & Reconsecby pics ayuta cuan do ss nese sarib & & & \\
\hline 21 & Respets los purtes de vist diferentes a les mies & & & \\
\hline 22 & Se cuáles son mis fortalezas y mis tebilitades & & & \\
\hline 23 & Se cuando debo esforzarme mas & & & \\
\hline 24 & Se determinar la cresibile ad te una fuents de informasbn & & & \\
\hline 25 & Se distinguirentre hectes reales y prejuicios & & & \\
\hline 26 & Sin eficis ncia no vale el sfútura & & & \\
\hline 27 & Sobresalgo por mis propies merites & & & \\
\hline 28 & Soy autos isoplinatio/a & & & \\
\hline 29 & Soy critico/a y doy alternativas & & & \\
\hline 30. & Soy perseverante pare alzan zar mis metas, no me venas facilme rte. & & & \\
\hline 31 & Soy realista y segurs de mi tabilitad acatemica & & & \\
\hline 32 & 5oy responsabie de mis actiones & & & \\
\hline 33 & Soy una persona altamente notivasa: & & & \\
\hline 34 & Soy una persora padente y respetuosa de la diversitad & & & \\
\hline 35 & Tergo estrategias te estudib oue me permiten tenter exite acade miso: & & & \\
\hline 36 & Tengo inisiativa & & & \\
\hline 37 & Tengo metas tefinitas a corts plazs & & & \\
\hline 38 & Tenge una actitud positiva res pets a verme coms un ser humano salieso & & & \\
\hline 39 & Terge una idea dara del tiempo aus hay que invertir para hacer alge & & & \\
\hline 40 & Una situacibr novescas, re presenta un rets a ve ncer & & & \\
\hline 41 & Utilize mis recurses y talentos para te ner exouts acasemies. & & & \\
\hline
\end{tabular}




\section{Anexo 2. Cuestionario Sobre el Grado de Satisfacción del Estudiante con Respecto al ABP (Márquez, Uribe, Montes, Monroy, \& Ruiz, 2011).}

El propósito de este cuestionario es conocer tu postura acerca de la implementación del ABP en tu facultad. Para ello, se te solicita responder a cada una de las preguntas que a continuación se presentan. Tus respuestas son personales y confidenciales. En este sentido, se te pide que contestes de la manera más franca posible. No hay respuestas correctas 0 incorrectas.

- Marca solo una respuesta por pregunta

- Marca la opción que mejor represente tu opinión

- Responde a TODAS las preguntas

Datos de Identificación

1. Sexo: Hombre ( ) Mujer ( ) 2. Edad:

4. Nota media actual (aproximada):

$$
\text { 5-6.9( ) 7-7.9( ) 8-8.9( )9-10( ) }
$$

5. Método de enseñanza preferido: $\quad \operatorname{ABP}(\quad)$ Tradicional ( )

6. ¿Te gusta el ABP? Si ( ) No ( )

7. ¿Cómo te consideras como estudiante? Malo ( ) Regular ( ) Bueno ( ) Excelente ( )

\section{Instrucciones:}

Marca con un círculo en las siguientes preguntas, el número que mejor describa tu grado de satisfacción con el ABP implementado este curso, utilizando las opciones que se presentan. Estas opciones van de 1 a 6 , donde 1 significa "Nada Satisfecho" y 6 significa Completamente satisfecho". En este continuo, elige el número que mejor represente tu satisfacción.

En el recuadro anexo a cada pregunta, justifica brevemente la respuesta elegida.

\begin{tabular}{|c|c|c|c|c|c|c|}
\hline \multirow{2}{*}{$\begin{array}{l}\text { Contenidos revisados en } \\
\text { Tutoria ABP }\end{array}$} & \multicolumn{2}{|c|}{$\begin{array}{l}\text { Nada } \\
\text { Satisfecho }\end{array}$} & & & \multicolumn{2}{|c|}{$\begin{array}{l}\text { Completamente } \\
\text { Satisfecho }\end{array}$} \\
\hline & 1 & 2 & 3 & 4 & 5 & 6 \\
\hline El rol del Tutor & 1 & 2 & 3 & 4 & 5 & 6 \\
\hline El rol como Estudiante & 1 & 2 & 3 & 4 & 5 & 6 \\
\hline
\end{tabular}




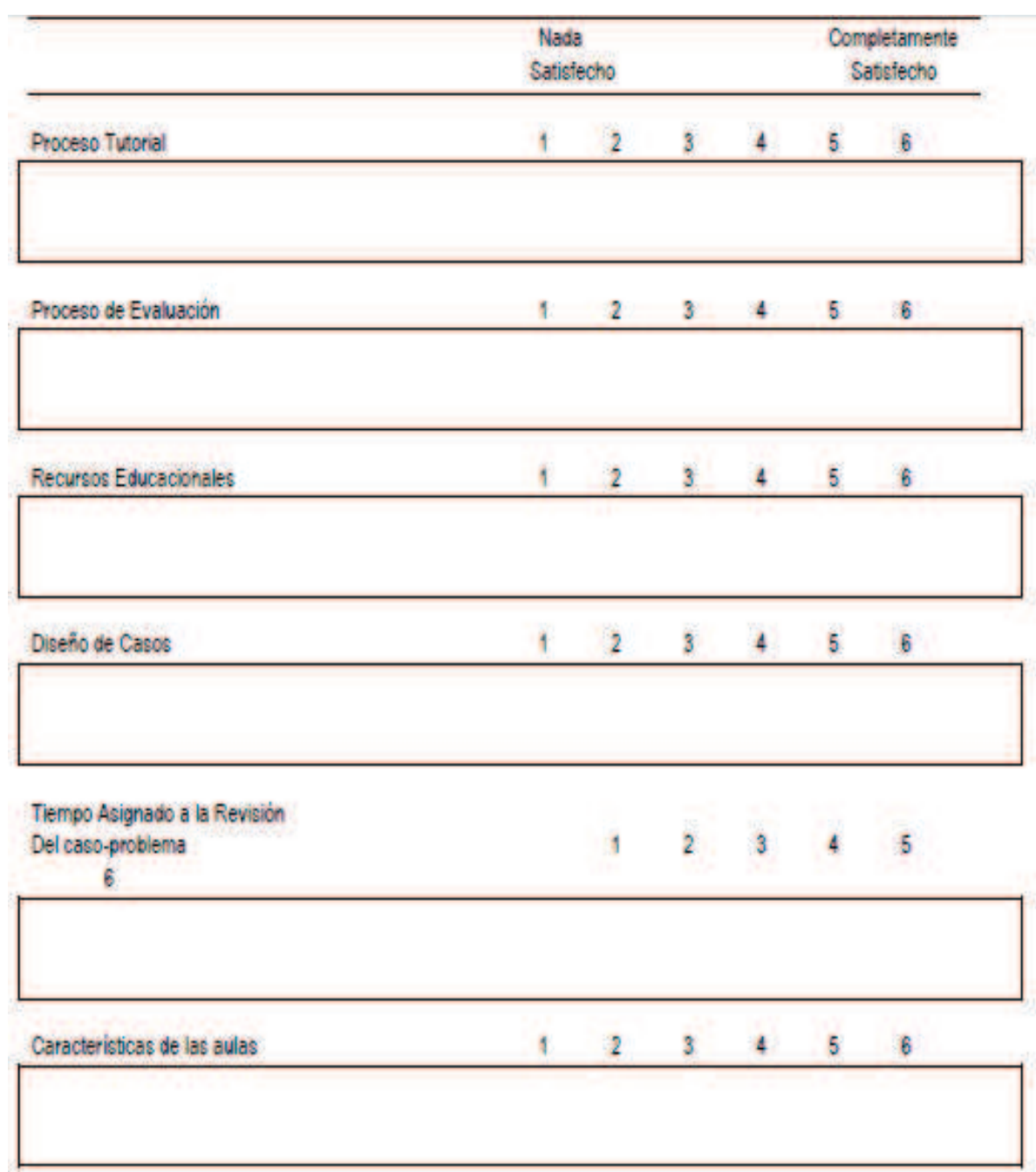

En la siguente escala, marca con un circulo el numero que mejor describa tu grado de sabsfaccion con el ABP considerando todo ib que este implica.

\begin{tabular}{cccccc}
\hline 1 & 2 & 3 & 4 & 5 & 6 \\
$\begin{array}{c}\text { Nada } \\
\text { Satisfecho }\end{array}$ & & & & & $\begin{array}{c}\text { Completamente } \\
\text { Satisiecho }\end{array}$ \\
\hline
\end{tabular}


Anexo 3. Rúbricas para la observación de presentaciones

orales. Fuente: Escribano \&Valle, Universidad Castilla y la Mancha.

\section{EVALUACIÓN DE PRESENTACIÓN ORAL}

- Comunicación: mirada, gestos con manos, voz adecuada (acento, tono y volumen), duración y fluidez del habla...

- Creatividad: calidad y originalidad de las aportaciones, recursos y medios empleados, etc.

- Cohesión: coordinación y sincronización de los miembros del grupo

- Organización: secuencia, estructura y desarrollo coherente de los contenidos.

- Claridad: descripción, precisión y síntesis de lo expresado.

- Contenidos: nivel de adecuación, rigurosidad y riqueza de los datos aportados.

- Comprensión: grado de reflexión, argumentación y razonamiento.

- Aplicación: congruencia y pertinencia de las experiencias proporcionadas.

\section{Cada una se puntúa de 0-10 puntos}


Anexo 4. Cuestionario autoevaluación y evaluación a pares. Fuente: Instituto Tecnológico de Monterrey, 1999.

EVALUACIÓN A COMPAÑEROS AUTOEVALUACIÓN ALUMNA/O

\section{GRUPO:}

\begin{tabular}{|l|l|l|l|l|}
\hline Asiste a las actividades de grupo & & & & \\
\hline $\begin{array}{l}\text { Termina los trabajos asignados al grupo a } \\
\text { tiempo }\end{array}$ & & & & \\
\hline $\begin{array}{l}\text { Asiste a Clase con el material leído y } \\
\text { necesario para avanzar satisfactoriamente en } \\
\text { las discusiones del grupo }\end{array}$ & & & & \\
\hline $\begin{array}{l}\text { Escucha atentamente las presentaciones de } \\
\text { los demás }\end{array}$ & & & & \\
\hline $\begin{array}{l}\text { Contribuye a la discusión de grupo } \\
\text { Aporta nueva y relevante información en las } \\
\text { discusiones que realiza en equipo }\end{array}$ & & & & \\
\hline $\begin{array}{l}\text { Utiliza recursos apropiados para investigar } \\
\text { sobre sus presentaciones }\end{array}$ & & & & \\
\hline $\begin{array}{l}\text { Realiza preguntas que promueven un } \\
\text { entendimiento con mayor claridad y } \\
\text { profundidad en lo que respecta a la } \\
\text { comprensión }\end{array}$ & & & & \\
\hline $\begin{array}{l}\text { Comunica ideas e información claramente } \\
\text { grupo pueda funcionar mejor }\end{array}$ & & & & \\
\hline
\end{tabular}

1-totalmente en desacuerdo, 2-en desacuerdo, 3-de acuerdo y 4 -totalmente de acuerdo 
Anexo 5.Cuestionario para la evaluación a la tutora.

Fuente: Instituto Tecnológico de Monterrey, 1999.

\section{EVALUACIÓN A LA TUTORA}

\begin{tabular}{|c|c|c|c|c|}
\hline & 1 & 2 & 3 & 4 \\
\hline $\begin{array}{l}\text { Muestra interés activo en mi grupo, es amigable y } \\
\text { se interesa por participar en los procesos de grupo }\end{array}$ & & & & \\
\hline Crea un ambiente relajado y abierto para iniciar una discusión & & & & \\
\hline $\begin{array}{l}\text { Escucha y responde adecuadamente a mis problemas y } \\
\text { preguntas }\end{array}$ & & & & \\
\hline Admite conocimientos que no sabe & & & & \\
\hline $\begin{array}{l}\text { Ayuda a mi grupo a identificar la importancia de aprender y } \\
\text { describir temas aprendidos, para poderlos discutir }\end{array}$ & & & & \\
\hline $\begin{array}{l}\text { Guía e interviene para mantener a mi grupo por el camino correcto } \\
\text { para seguir adelante a pesar de los problemas }\end{array}$ & & & & \\
\hline Provee comentarios constructivos acerca de la información presentada & & & & \\
\hline $\begin{array}{l}\text { Plantea preguntas que estimulan mi pensamiento y mi habilidad } \\
\text { analizar el problema }\end{array}$ & & & & \\
\hline $\begin{array}{l}\text { Impulsa a los miembros del grupo para afinar y organizar } \\
\text { sus presentaciones }\end{array}$ & & & & \\
\hline $\begin{array}{l}\text { Presenta buenos juicios acerca de cuándo responder a una pregunta, y } \\
\text { cuándo orientar la pregunta para los miembros del grupo. }\end{array}$ & & & & \\
\hline
\end{tabular}

1-totalmente en desacuerdo, $\mathbf{2}$-en desacuerdo, $\mathbf{3}$-de acuerdo y $\mathbf{4}$-totalmente de acuerdo 


\section{Anexo 6. Casos clínicos para ABP.}

Fuente: Basado en casos clínicos reales, diseño de la autora.

\section{CASO 1- APRENDIZAJE BASADO EN PROBLEMAS}

La promoción de la salud y la prevención de enfermedades a través de consejos de Educación para la Salud, es una de las actividades a realizar por el profesional de Enfermería, tanto a nivel de Atención Primaria, en nivel Hospitalario o bien en el ámbito escolar. Hay que detectar riesgos para la salud y derivar a otros profesionales en el caso que sea preciso. Recuerda que adolescencia según la OMS es la etapa comprendida entre los 10-19 años, y la entrevista clínica que debemos realizar es "la entrevista joven" preguntando sobre: F- familia, A- amistades, C- colegio-trabajo, T-tóxicos, O-objetivos personales, R-riesgos, E-estima, Ssexualidad

Sonia tiene 18 años, piensa que debería acudir a una revisión porque nunca ha ido a un ginecólogo ni a la consulta de la matrona. No hay enfermedades en su familia, y siempre ha ido a las revisiones de pediatría con su madre o su padre (trabajan los dos). La enfermera le administró las vacunas que completan el calendario infantil. Apenas ha hablado de sexualidad con sus padres y si tiene dudas, se lo ha preguntado a sus amigas. Su primera regla le vino a los 10 años, tiene ciclos menstruales irregulares 30-40/7 y eso le preocupa. Además, en varias ocasiones, el sangrado "es más abundante de lo normal" y sus reglas son dolorosas. Últimamente, ha tenido dos infecciones vaginales "por cándida" (le dijeron en urgencias) coincidiendo con épocas de exámenes o cuando el médico le ha recetado un antibiótico. Es fumadora de 5-6 cigarrillos/ día y consume alcohol de forma ocasional los fines de semana. Ahora se está sacando el carnet de conducir, así que de momento no conduce y a veces va con sus amigos en coche, en la bici o coge el autobús. Cuando la enfermera la entrevista afirma "Me llevo bien con mis padres y hermanos, aunque se riña de vez en cuando...". Sonia se considera buena estudiante, cursa $1^{\circ}$ de Magisterio y está muy contenta con la carrera que ha elegido. Tiene amigos y amigas de la pandilla del barrio y otros nuevos, compañeros de clase, se lleva bien con ellos y se comunican a través de la red social. Empezó sus relaciones sexuales a los 17 y actualmente no tiene pareja, rompió con él hace 1 año, ahora tiene relaciones sexuales esporádicas y con diferentes chicos pero procura usar siempre preservativos.

Su exploración: Peso: 57.200, Talla: $1.55 \mathrm{~cm}$, TA: $125 / 75$ y FC: 68

Reflexione sobre el caso clínico y centre el problema principal

¿Qué conozco?, ¿Qué debo aprender? 


\section{CASO 2- APRENDIZAJE BASADO EN PROBLEMAS}

La violencia de género es un problema prioritario de salud, por las dramáticas consecuencias del maltrato para la salud de la mujer que lo sufre y en sus hijos e hijas. El mundo sanitario ha permanecido ajeno a este problema hasta hace escasas décadas, pero el conocimiento actual de la extensión y consecuencias del maltrato, así como su coste sanitario y social, obliga a los profesionales sanitarios a asumir un papel activo ante el mismo.

Carmen acude para hacer una revisión del programa de prevención de cáncer ginecológico. En la historia informatizada no aparece ningún dato.

"Con la cantidad de problemas que he tenido...ahora vengo más tranquila, estoy con mi familia y me siento más segura. Me he puesto muy gorda...”

La paciente tiene 52 años, es obesa e hipertensa. Desde que se casó se ha dedicado a ser ama de casa y a cuidar de su familia. Durante la entrevista clínica se nota bastante tensión y nerviosismo tanto en los gestos con una expresión triste, como al hablar porque le tiembla su voz. Comenta que se ha trasladado desde Gran Canaria porque su marido tiene una orden de alejamiento por violencia, que ha sufrido durante años, pero ahora está segura con sus hermanos y padres.

"La situación era insostenible, le perdonaba y a pesar de eso, otra vez volvía a maltratarla". Hace 3 años se le retiró la regla, después de recibir tratamiento con radioterapia tras haber sufrido un cáncer de mama y siguió los controles periódicos en oncología.

Carmen se casó a los 23 años y tiene 3 hijos. Tuvo 3 partos normales y 3 abortos. Las citologías anteriores han sido normales, aunque siempre nota sequedad que le produce algo de picor. Desde la menopausia ha notado que se le escapa la orina aunque no se lo ha comentado a nadie, a pesar de lo molesto que le resulta. Actualmente no toma medicación.

"Menos mal que usted es una mujer, es que si no me daría vergüenza, ahora me encuentro tranquila, estoy con mi familia pero soy una carga. No crea, esto es un problema para ti y tu familia".

Sus hijos desconocen la situación de tensión que está viviendo, no ha querido contarles nada para que no sufran, Carmen piensa que están muy ocupados y cada uno tiene su vida y sus propios problemas...

Reflexione sobre el caso clínico presentado y centre el problema principal

¿Qué conozco? ¿Qué debo aprender? 


\section{CASO 3- APRENDIZAJE BASADO EN PROBLEMAS}

Las supervivientes de cáncer de mama suelen presentar dificultades sexuales. Muchas pacientes rehúsan hacer preguntas, pero necesitan información sobre las posibles causas de los problemas y cómo superarlos. Esperanza echó de menos mayor información por parte del equipo de salud, a pesar de estar muy agradecida con los médicos y enfermeras que le atendieron.

Esperanza empezó a hacerse las mamografías a los 40 años porque su madre murió de cáncer de mama. No tiene hijos y no ha tomado la píldora anticonceptiva, para evitar los embarazos han usado preservativos. A los 42 años se sometió a una mastectomía, tras el diagnóstico de cáncer de mama.

"Pasé una temporada bastante mal, el tratamiento me quitaba el apetito sexual, y yo me sentía fatal por él. Pensaba: se va cansar de esta situación y no lo va a soportar". Sin embargo, él lo 'soportó', hablaron de lo que uno y otro sentía, de lo que les apetecía y, un día, de repente, notó un cambio, "se te va despertando algo que estaba dormido". Cree que es afortunada, "otras mujeres no reciben tanto cariño de sus parejas como el que tuve yo". En su caso, su marido le dijo, que no era necesario que se sometiese a una reconstrucción mamaria;" pero no lo hago por ti, sino por mí", le respondió ella. Recuerda su cambio de imagen, la peluca, el pañuelo, la mastectomía..."me veo en las fotos y no parezco yo".

De aquello hace ya seis años. Esperanza estudió francés y ha terminado la carrera de Turismo que empezó antes del diagnóstico. Tiene un trabajo que le gusta y ahora ve las cosas de otra manera. Sólo tiene un consejo para las mujeres que estén pasando por la misma situación que ella, "que hablen, que se comuniquen".

Su lema es: "Ios demás no pueden adivinar lo que tú estás pensando".

Reflexione sobre el caso clínico presentado y centre el problema principal.

¿Qué conozco? ¿Qué debo aprender? 


\section{CASO 4- APRENDIZAJE BASADO EN PROBLEMAS}

De las actividades que desarrollamos (asistencial, docente, investigadora y administrativa) es fundamental incluir la Educación para la Salud individual y grupal. Realizar actividades preventivas y de promoción de la salud es el pilar básico de Atención Primaria y responsabilidad de todos los miembros del Equipo de Atención Primaria, pero sobre todo del personal de enfermería.

En el Centro de Salud se están preparando unas actividades comunitarias. Se pretende acudir a los centros educativos a impartir educación sexual a chicos de $3^{\circ}$ de la ESO. Luis, enfermero del centro desde hace 6 años, está convencido de la efectividad de estas actividades. La Trabajadora Social del centro le comentó que habían aumentado las interrupciones voluntarias del embarazo en las jóvenes de nuestra población. La coordinadora del equipo de salud, en una reunión el pasado miércoles, preguntó si hay voluntarios para realizar estas actividades. El problema es que hay profesionales que piensan que hablar de sexualidad a los jóvenes, les puede perjudicar porque aumentarían los embarazos no deseados. Luis no está de acuerdo, cree que la falta de educación sexual da lugar a problemas, tanto los embarazos no deseados como las infecciones de transmisión sexual en jóvenes, a él le habría gustado recibir más formación cuando era estudiante del instituto. Decidió hablarlo con un grupo de compañeros/as y van a organizar actividades de educación para la salud, pero no saben cómo empezar, qué contenidos incluir...

Reflexione sobre el caso clínico presentado y centre el problema principal. ¿Qué conozco? ¿Qué debo aprender? 


\section{CASO 5- APRENDIZAJE BASADO EN PROBLEMAS}

No debemos de olvidar la importancia de la visión integral del paciente, teniendo en cuenta la esfera biopsicosocial en el enfoque de nuestros cuidados. Una entrevista clínica empática y cercana, es una buena herramienta para detectar problemas de salud como en el caso siguiente. Con tu grupo de trabajo lee el caso clínico y sigue los pasos explicados para la resolución del problema.

Rosa tiene 26 años, durante 4 años ha trabajado en Alicante y ahora, vive con sus padres porque está en paro. Su formación es de nivel de $4^{\circ}$ de la ESO e hizo un curso de formación profesional. Acude hoy a la consulta preocupada porque teme haber contraído una infección de transmisión sexual (ITS).Además desde hace 5 años que no se hace una citología. Aunque toma la píldora anticonceptiva y suele usar un doble método (píldora + preservativos), ha tenido una "relación de riesgo". Sus relaciones sexuales son esporádicas, pero únicamente hace un mes no se protegió con el preservativo y el chico con el que estuvo le acaba de avisar que le diagnosticaron una ITS. Él acudió al urólogo por una infección, pero no sabe de qué se trata y ella teme haber contraído una infección de transmisión sexual. Rosa nos dice que tiene todas las vacunas puestas según el calendario de vacunación infantil, aunque no recuerda si se puso la de la hepatitis. Tuvo un embarazo a los 20 años y se sometió a una interrupción (IVE). Desde hace años nota algo de picor en la vulva y mal olor del flujo. Ha empezado a utilizar tampones de algodón desde hace 1 mes, me han dicho que pueden dar problemas...Toma la píldora anticonceptiva de baja dosis y fuma en la actualidad 20 cigarrillos al día. No consume alcohol, excepto los fines de semana de forma ocasional. Es asmática en tratamiento con 2 inhaladores (Symbicort forte $y$ Therbasmin $0.5 \mathrm{mg}$ ) y hace 1 año sufrió una bronquitis. Padece de insomnio, por lo que ha tomado lorazepan de $1 \mathrm{mg}$ en varias ocasiones.

Constantes: TA: 124/73, Peso 61.4 - Talla 1.65.

Reflexione sobre el caso clínico y centre el problema principal

¿Qué conozco?, ¿qué debo aprender? 


\section{CASO 6- APRENDIZAJE BASADO EN PROBLEMAS}

Cuando se padece una enfermedad o hay un cambio corporal tras una intervención, repercute en toda la esfera biopsicosocial y por tanto, también en la vivencia de la sexualidad. El patrón sexual se debe de incluir en los cuidados que presta el profesional de enfermería de forma integral a los pacientes. Se presenta este caso de una mujer durante el climaterio.

Teresa tiene 55 años y ha venido de Andalucía hace 9 meses. No disponemos de resultados de citologías ni mamografías recientes en la historia clínica que enviaron de su anterior centro sanitario, y ella ya no lo recuerda, pero cree que hace 6 años se hizo su última revisión ginecológica. Presenta una esclerosis múltiple leve, sin tratamiento actual y una ileostomía con bolsa de recogida de heces. Su tensión arterial es normal, su índice de masa corporal (IMC) es elevado, no fuma, no bebe alcohol ni consume otras drogas. Actualmente no toma medicamentos. Hace una vida sedentaria porque ve mucho la tele y le gusta coser. Come de todo pero no tolera la lactosa, así que no toma leche.

Historia obstétrica-sexual:

Inició sus relaciones sexuales a los 24 años. Tuvo 2 partos normales y actualmente buena relación familiar con sus hijos y su pareja. La menopausia se presentó a los 46 años y desde entonces no ha vuelto a sangrar, ahora no nota sofocos pero sí sequedad vaginal. Su enfermera le aconsejó que se realizara una citología y la toma del virus del papiloma y también y que se hiciera una mamografía.

Viene muy nerviosa a la consulta, además quiere ir a revisarse al ginecólogo "pero prefiero que sea una mujer", ya que su experiencia anterior no fue buena.

Sus relaciones sexuales han cambiado desde que tiene la ileostomía, "me da apuro que mi marido me vea así", él le dice que no importa, "es un bendito y tiene mucha paciencia. No tenemos relaciones con penetración porque a mi me duele." Llevan 35 años casados y tienen una buena comunicación. Al hacer citología la paciente está muy tensa y presenta una atrofia urogenital intensa.

Reflexione sobre el caso clínico y centre el problema principal

¿Qué conozco?, ¿qué debo aprender? 


\section{CASO 7- APRENDIZAJE BASADO EN PROBLEMAS}

El profesional de enfermería tiene que estar capacitado para realizar una revisión puerperal y orientar respecto a la alimentación del recién nacido. Hay que tener en cuenta la esfera biológica, psicológica y social en nuestra atención a las madres, el siguiente caso clínico requiere que reflexiones sobre ello.

David tiene 11 días, viene con su madre y su abuela a la consulta. Nació por cesárea con un peso de 2.500grms y un Apgar de 9/10. Isabel tiene 23 años, es madre primeriza y aunque acudió al grupo de "Preparación al Parto" a nuestro centro de salud, ahora con el bebé tiene muchas dudas. En el hospital, estuvieron cinco días y parece que todo evolucionó con normalidad. Le dieron un biberón "de refuerzo" cada noche, a pesar de que le dijeron "este niño se agarra muy bien" y la lactancia parece que está muy bien instaurada. Isabel le despierta cada 3 horas y le pone 10 minutos en cada pecho. Ella cree que no tiene suficiente leche puesto que, sus mamas ya no están tensas ni dolorosas como al principio. Ha notado que el bebé moja los pañales y hace deposiciones amarillentas. Lleva un sujetador de aros que es inadecuado, le presiona demasiado el pecho, pero no dispone de mucho dinero para adquirir muchas cosas, así que ha pensado que hay que seleccionar lo importante. Ha notado que la incisión quirúrgica de la cesárea está algo inflamada, quizás sea por las grapas...al quitar las grapas y limpiar la herida notamos pus. Isabel está preocupada porque Miguel, su pareja, aun no ha venido. Se encuentra en Francia trabajando "en la vendimia" y no llegará hasta dentro de 10 días para conocer a su hijo. No tiene tarjeta sanitaria para el bebé que aún no está registrado en el Registro Civil porque están esperando a que venga el padre. A pesar de los problemas económicos, familiares y sociales, la madre es optimista y nos dice que se está adaptando bien a la maternidad.

¿Qué conozco?, ¿qué debo aprender?

Centre el problema principal 


\section{CASO 8- APRENDIZAJE BASADO EN PROBLEMAS}

La salud sexual y reproductiva es un campo de interés en el trabajo de los profesionales de enfermería, otros profesionales sanitarios y trabajadores sociales. Una interrupción voluntaria del embarazo, es un fracaso de la planificación familiar. Ante una amenorrea de más de 10 días, en una mujer fértil y a pesar de negar un embarazo, debemos descartarlo haciendo una rápida prueba en consulta. En este caso, a pesar de la amenorrea la paciente estaba de tres semanas menos de embarazo cuando le hicieron la ecografía. ¿Qué habría pasado si estuviera de las semanas de embarazo que creímos al principio por su amenorrea? Reflexiona sobre el siguiente caso.

Laura tiene 19 años, viene para "hacer una revisión”, no se ha hecho nunca una citología. Ha tomado durante dos años un anticonceptivo hormonal porque sus reglas eran muy dolorosas. Además tuvo una relación con un chico durante 6 meses, pero hace 4 que lo dejaron y ella, decidió dejar de tomar la píldora. Es fumadora de 10c/día y habitualmente consume algo de alcohol, pero más en fin de semana.

La fecha de la última regla (F.U.R) $=24 / 05 / 2011$ y hoy que acude a consulta, es día29 /09/2011.

Laura asegura no estar embarazada, cree que el retraso es por haber dejado de tomar la píldora. En la consulta realizamos un test de gestación ante el retraso menstrual. Para ello, se le pidió a la joven que recogiera su orina. Tras la prueba el resultado es POSITIVO.

El gesto de Laura es de "incredulidad", está segura que no quiere tener un hijo. No notó ningún síntoma, solo que el pecho le dolía...Vive con sus padres, su sueldo no es bueno, no ha sido una buena estudiante y ahora trabaja de camarera en un bar. Hoy está en nuestro Centro de Salud la Trabajadora Social, así que se decide hablar conjuntamente del caso y determinar qué hacer ante este problema.

Centre el problema principal

¿Qué conozco? ¿Qué debo aprender? 


\section{CASO 9- APRENDIZAJE BASADO EN PROBLEMAS}

El fomento de la Salud sexual y reproductiva es parte del trabajo de los profesionales de enfermería. Actualmente acuden a nuestras consultas pacientes inmigrantes, siendo necesaria tener la perspectiva cultural y de género. La orientación y actividades de Educación para la Salud son fundamentales en el desarrollo de nuestra actividad profesional. Con tu grupo y, también de forma individual, vas a profundizar en la materia. Ánimo, aunque tengas algún momento de desaliento o duda debes planteárselo a tus compañeros de equipo y a tu tutora, para intentar encontrar la solución al problema planteado.

Mujer de 30 años que acude a realizar una citología derivada de la consulta de enfermería de Atención Primaria. Es la primera vez que se hace citología y nunca ha acudido al ginecólogo, excepto cuando tuvo a su hijo. Es de Santo Domingo y ha venido a trabajar a España. Ahora se dedica a la hostelería y tiene jornadas a turnos, trasnochando mucho.

-No tiene antecedentes familiares ni personales de enfermedades de interés, tiene las vacunas puestas según el calendario de vacunas de República Dominicana.

-Hábitos tóxicos: no fuma, no consume drogas y el consumo de alcohol es ocasional.

-Antecedentes ginecológicos: menarquía a los 12 años, ciclos menstruales regulares 5/28, dismenorrea por lo que toma un antiinflamatorio para aliviar el dolor menstrual. Tuvo un hijo con 20 años, de su primer novio, y éste se ha quedado con los abuelos para que ella pueda trabajar. Ella llama a menudo a su hijo por teléfono, habla con los abuelos y les envía dinero para que esté bien, es una madre a distancia...

Inició sus relaciones sexuales a los 19, tiene una relación estable desde hace 4 años con un hombre español, no desea embarazos y no utilizan anticonceptivos. "No quiero quedarme embarazada de momento me dedico a la hostelería, ayer trabajé hasta las 5 de la mañana."

Enfermera: "No lo comprendo, no deseas un embarazo y no te planificas, eres joven y cuando menos lo esperes te puedes quedar embarazada, ¿qué harías entonces?"

"En ese caso lo tendría, pero ahora..., ya sabe como son los hombres, no les gusta usar el preservativo y usamos la retirada (C.I), yo no quiero tomar la píldora porque con mi horario, se me olvida, y él no quiere usar el preservativos..."

Reflexione sobre el caso y centre el problema principal

¿Qué conozco? ¿Qué debo aprender? 


\section{CASO 10- APRENDIZAJE BASADO EN PROBLEMAS}

El trabajo del profesional de enfermería abarca un amplio campo de funciones y en algunas de ellas quizás se profundice poco. Con el trabajo que vas a realizar con tu equipo, nos vamos a sumergir y profundizar en algo que puede que no te habías planteado, ya que a veces no nos damos cuenta de la necesidad de informar y dar educación sanitaria sobre sexualidad a personas que han sufrido una enfermedad o discapacidad. Recuerda que la empatía y el saber escuchar, son herramientas básicas en la entrevista clínica. Ánimo, aunque tengas algún momento de desaliento o duda con este trabajo $\mathrm{ABP}$, debes planteárselo a tu equipo y a tu tutora para encontrar la solución del problema

\section{SEXUALIDAD Y DISCAPACIDAD}

Fuente: Nuevo informe Kinsey (Reinisch \& Beasley, 1992)

Mi nieta de 12 años sufre una parálisis cerebral. No puede caminar y habla con dificultad, con la añadidura de que se está volviendo algo espástica. Requiere un cuidado casi total. No obstante, es una niña inteligente y muy consciente del mundo que le rodea. Nos inquieta pensar qué pasará cuando comience con su período. Tememos que no comprenda lo que ocurre y pase una época difícil al tener que vérselas con la menstruación y la incomodidad. Nos preocupa su higiene personal, en especial en el colegio. Además todavía algunas noches se orina en la cama, y eso se sumaría al problema. También pensamos que sería terrible si alguna vez se quedara embarazada. Durante algún tiempo hemos hablado de hacerle una histerectomía, pero no es una solución fácil ni agradable de imaginar.

Centre el problema principal

¿Qué conozco? ¿Qué debo aprender? 


\section{CASO 11- APRENDIZAJE BASADO EN PROBLEMAS}

El trabajo del profesional de enfermería abarca un amplio campo de funciones y en algunas de ellas quizás se profundice poco. Con el trabajo que vas a realizar con tu equipo, nos vamos a sumergir y profundizar en algo que puede que no te habías planteado, pero que debido al envejecimiento de la población española, vas a tener una tarea de educación para la salud y detección de disfunciones sexuales de las mujeres que atiendas en la consulta o en el hospital. Recuerda que la empatía y el saber escuchar, son herramientas básicas en la entrevista clínica. Ánimo, aunque tengas algún momento de desaliento o duda con este trabajo ABP, debes planteárselo a tu equipo y a tu tutora para encontrar la solución del problema.

SEXUALIDAD EN LA VEJEZ

Fuente: Nuevo informe Kinsey (Reinisch \& Beasley, 1992)

En una familia que pertenece a nuestro Centro de Salud, vive una de las abuelas con su hija de 48 años, el yerno de 51 y los dos nietos de 20 y 22 años. Se han enterado de que la abuela ha "ligado", que sale con un hombre que vive solo y también que pasa numerosas tardes en su casa. La hija está enfadada, no acepta que su madre vuelva a tener una nueva relación de pareja, piensa que ya es muy mayor y que en su casa la tratan bien, no entiende ¡cómo ha podido pasar! Últimamente se encuentra muy nerviosa y acude con frecuencia al médico porque se le "están juntando muchas cosas". Aparte de la menopausia, está decaída, ya no tiene ganas de tener relaciones sexuales, aunque nunca fue muy efusiva, y cree que su marido no la entiende. A veces está irritable en casa, discute con sus hijos, pero lo que más le preocupa es la nueva relación de su madre. El médico le recomendó un ansiolítico, y aprovechó para pedirle unas mamografías y una citología por lo que la derivó a la consulta de la matrona

Centre el problema principal

¿Qué conozco?, ¿Qué debo aprender? 


\section{CASO 12- APRENDIZAJE BASADO EN PROBLEMAS}

En la consulta de enfermería a veces se presentan retos como este caso clínico. El profesional de Enfermería trabaja en equipo y una de sus funciones primordiales es la promoción de la salud. Un enfermero/a competente, debe aplicar la evidencia científica en sus actuaciones clínicas. El manejo de la lactancia materna es responsabilidad de todos los profesionales sanitarios que atendemos madres lactantes, a veces la descoordinación puede conllevar al fracaso por falta de apoyo profesional.

"Tengo 39 años y un hijo de 8 meses, la lactancia materna ha funcionado muy bien, mi hijo no se ha enfermado ni ha cogido un resfriado siquiera". La paciente acudió a la consulta de ginecología por presentar un quiste de ovario de $7 \mathrm{~cm}$ y le han programado una cirugía explicándole que le practicarán una ovariectomía derecha. Ella preguntó cuántos días va a estar ingresada en el hospital, generalmente estas cirugías conllevan un ingreso de entre cinco a siete días. Está preocupada, no quiere retirar la lactancia materna y lo planteó en consulta de ginecología. El ginecólogo le indicó que puede tomar una medicación para retirar la leche y, la enfermera le dijo que el niño es muy mayor para seguir con la alimentación al pecho...La mujer piensa que los profesionales "van a lo fácil”, su deseo es continuar con la lactancia y si pudiera hasta los 2 años...Refiere que su madre y su pareja le apoyan para continuar. También consultó al pediatra y no obtuvo ninguna solución. Ha decidido venir a la consulta de enfermería/matrona a plantear este problema. Sabe que hay profesionales que le apoyarán con la continuación de su lactancia, y por eso acudió a nuestra consulta. Nos explica que tener a su hijo fue difícil, se tuvo que someter a tratamiento de infertilidad, y piensa que ya no tendrá más hijos. Ha leído información en internet y, en algunos hospitales llevan a los niños para que las madres sigan lactando. Conoce perfectamente la técnica de extracción de la leche, nos dice que "tiene mucha" y nos pregunta que cuánto tiempo dura la conservación. Su hijo toma papillas de su leche, e incluso está extrayendo y congelando para cuando ingrese, así su madre podrá preparar las papillas al bebé con su leche.

Reflexione sobre el caso clínico y centre el problema principal

-¿Qué conozco?, ¿Qué debo aprender? 


\section{CASO 13- APRENDIZAJE BASADO EN PROBLEMAS}

Aunque es derivada a nuestra consulta para informarle de los métodos anticonceptivos, podemos detectar otros problemas de salud sexual y riesgos en el siguiente caso. La captación activa de la población es una forma de reorientar el trabajo para mejorar los niveles de salud y prevenir factores de riesgo en nuestra población.

Lorena tiene 21 años y quiere empezar a utilizar un anticonceptivo hormonal. Su médico le dijo que viniese a nuestra consulta a informarse sobre los distintos métodos anticonceptivos porque ha solicitado anticoncepción de emergencia varias veces. Dice ser una mujer sana, no es alérgica y, no tiene antecedentes familiares de enfermedades cardiovasculares. Estudió formación profesional y trabaja en un "centro de belleza". Vive con sus padres de momento, pero está pensando independizarse.

Historia sexual:

Tuvo la menarquía a los 12 años, sus ciclos menstruales son regulares de 5/28, no presenta dolor menstrual ni otros problemas. Nunca se ha hecho una citología ni ha ido a un ginecólogo. Eso sí, en los últimos 3 meses solicitó la anticoncepción de urgencia 2 veces en una farmacia. Tiene una pareja desde hace 12 meses y utilizan el preservativo de látex, aunque no siempre (de forma inconsistente).

Hábitos tóxicos: Lorena fumaba 30 cigarrillos al día, pero lo ha dejado hace 1 mes por un problema de disfonía. Lleva varios piercing (uno en nariz, otro en ombligo... se los puso en un sitio de garantía). Su pareja consume cannabis y ella también (4/día). Refiere que no puede dejarlo porque le engordaría y le produciría ansiedad. Consume alcohol de forma ocasional, no practica ejercicio físico de forma regular y descuida bastante su alimentación.

T.A: $112 / 73$ Peso: $51 \mathrm{Kg}$ Talla: 1.70

Reflexione sobre el caso clínico y centre el problema principal

¿Qué conozco? ¿Qué debo aprender? 


\section{CASO 14- APRENDIZAJE BASADO EN PROBLEMAS}

En la entrevista clínica la escucha activa, la comprensión (empatía), y crear un buen clima en la relación enfermera/o-paciente, es fundamental para orientar los cuidados y realizar actividades de Educación para la Salud.

María entra en la consulta, respira hondo, quiere plantear un problema. Ayer estuvo en la consulta médica y solicitó unas pruebas para asegurarse de que no ha contraído una infección de transmisión sexual. Tiene 48 años y se considera responsable respecto a la sexualidad, de hecho, habla con su hija de 23 años y le dice que se proteja, que use siempre los preservativos... ahora dice estar desconocida he hecho locuras que no hice de joven. Tiene una nueva pareja y no usaron los preservativos ni la anticoncepción de emergencia. Ya sabe como son los hombres...qué poco les gusta usar los preservativos. Además su deseo sexual ha aumentado, al contrario que les pasa a sus amigas en esta etapa del climaterio. Su primer marido le fue infiel, ella tenía 25 años y un bebé de 9 meses y su segundo marido era distante, frío y poco cariñoso, pero en los últimos años los insultos, desprecios y la infidelidad se sucedieron. No hubo agresión física, pero si psicológica y se divorció hace 2 años. María está muy preocupada, aunque su citología y test HPV ha sido negativo hace 7 meses, teme haber contraído una infección, y tiene miedo al cáncer de cuello de útero quisiera que le tomemos muestra para citología.

Al revisar su historia: es hipertensa controlada con fármacos, hipotiroidismo, obesidad e hipercolesterolemia, mamografías y citología normales. Hace 3 años le extirparon un ovario y el útero (histerectomía subtotal). Fuma 15 cigarrillos al día, no consume alcohol y no hace ejercicio de forma programada. Su educación fue restrictiva, como la de muchas mujeres de su edad y hablar de sexualidad era un tabú. Tiene amistades y mantiene una buena relación familiar con su hija, ésta le dice que disfrute de la vida, que ya ha sufrido bastante...y María piensa lo mismo

Reflexione sobre el caso clínico y centre el problema principal

¿Qué conozco? ¿Qué debo aprender? 


\section{CASO 15- APRENDIZAJE BASADO EN PROBLEMAS}

A veces las mujeres mayores no se atreven a consultar síntomas ginecológicos. La cercanía y empatía que demuestran muchos profesionales de enfermería y matronas, hace que se detecten síntomas como una incontinencia urinaria, un picor crónico... como en el siguiente caso. En tu trabajo como profesional, no debes olvidar incluir la esfera ginecológica y sexual, como parte de los cuidados de salud.

Mercedes ha venido hoy porque está preocupada. Normalmente acude a la consulta de enfermería a controlarse el Sintrom y la tensión. Hoy nos cuenta que su prima Ana, tenía síntomas parecidos a los que ella nota. Su prima había sangrado después de la menopausia y cuando fue a un ginecólogo se trataba de un cáncer de útero y se lo tuvieron que extirpar. Mercedes enviudó hace 3 años, tiene una hija y recuerda que el parto, aunque algo difícil, fue normal. Le dio lactancia a la niña 6 meses, (eso le han dicho que le protege de padecer cáncer de mama)...A los 48 años se le retiró la regla y desde entonces nota sequedad en la vagina. Ahora tiene 67 años y hace nueve años sufrió una estenosis mitral, tuvo una fibrilación auricular y le tuvieron que poner una válvula. No se ha atrevido a comentarle al médico, pero desde hace cinco años nota picor en la vulva y cuando tose se le escapa un poco la orina. Ella se lava frecuentemente y parece que le alivia, pero su flujo es algo marrón, no sabe si habrá sido por rascarse. A la exploración externa, la región vulvar presenta un aspecto blanquecino, con sequedad (se derivó al médico y se diagnosticó un liquen en dermatología). Su TA: 144/85, FC: 83. Peso: 49Kg. Talla: 1.55 .Su aspecto físico es bueno, pero tiene varices en las extremidades inferiores y algo de cifosis dorsal.

Reflexione sobre el caso clínico y centre el problema principal

¿Qué conozco?, ¿qué debo aprender? 


\section{CASO 16- APRENDIZAJE BASADO EN PROBLEMAS}

Es posible que cuando administres una vacuna del HPV te planteen dudas sobre ello. Hay una gran confusión, ya no solo sobre la vacuna, sino sobre esta infección de transmisión sexual. La salud sexual y reproductiva es parte del trabajo del profesional de enfermería. Con tu grupo de trabajo y de forma individual, vas a profundizar en la materia para intentar resolver el problema. Si hay dificultades o dudas debes plantearlo en tu grupo y a tu tutora, para avanzar en el trabajo. Ánimo.

Isabel acude a ponerse la última dosis de la vacuna HPV. Su citología ha sido normal hace 1 año, sin embargo el virus del papiloma humano 16 era positivo, por eso fue al ginecólogo para completar el estudio. El resultado sin alteraciones, y el ginecólogo le aconsejó realizar revisiones anuales y vacunarse contra el HPV. Ahora tiene 43 años y al revisar la historia: padece de úlcera duodenal, sufre de migrañas y ha presentado infecciones vaginales por cándida en 3 ocasiones. Isabel refiere no fumar, no consume alcohol ni otras drogas. En la historia obstétrica y sexual: Menarquía a los 13 años, ciclos menstruales 5/28. Tuvo 2 hijos y 1 aborto: $3 \mathrm{E} / 2 \mathrm{P} / 1 \mathrm{~A}$, los partos fueron normales, aunque durante los embarazos tuvo amenaza de aborto y los recién nacidos fueron grandes con un peso de 3.800. Inició sus relaciones sexuales a los 18 años y, su única pareja ha sido con su marido Manuel. Ella tomó la píldora durante 10 años y él se hizo la vasectomía hace 4 años, siendo el método anticonceptivo que emplean desde entonces. Después del $2^{\circ}$ parto empezó a notar pequeños escapes de orina, que no ha comentado porque le da vergüenza, pero parece que va a más, sobre todo cuando acude al gimnasio. Manuel acaba de llegar de un viaje, él vive entre Inglaterra y España por motivos laborales. La pareja tiene buena comunicación. Isabel ha hablado con Manuel sobre el resultado del HPV 16 y su preocupación. Le preguntó si se lo transmitió él, pero su marido afirma que no tiene verrugas y no es posible que él se lo transmitiera. Isabel tiene muchas dudas, no sabe si la vacuna puede ser terapéutica, si va a presentar verrugas en la vulva por tener el HPV16, y está preocupada preguntándose cómo lo habrá contraído...Ella ha pensado que su problema puede ser hereditario .Recuerda que su abuela tuvo cáncer de endometrio y su madre cáncer de cuello de útero.

Reflexione sobre el caso clínico y centre el problema principal.

¿Qué conozco, qué debo aprender? 


\title{
CASO 17- APRENDIZAJE BASASO EN PROBLEMAS
}

Un profesional de enfermería que trabaja con eficiencia y calidad, requiere conocimientos actualizados, habilidades y aptitudes en ocasiones difíciles de enseñar en la universidad. En el siguiente caso, en una consulta de ginecología, además de comprobar la correcta esterilización del material, el cuidado del lavado de manos, el cambio de sabanillas para cada paciente, el realizar técnicas de enfermería... se requieren habilidades de comunicación tanto verbal como no verbal, capacidad de empatía y respeto a la intimidad e información de lo que se va a hacer.

\section{SEXUALIDAD EN LA ADOLESCENCIA}

Fuente: Nuevo informe Kinsey (Reinisch \& Beasley, 1992)

\begin{abstract}
Cuando yo era una adolescente, mi madre pidió hora para mí para que me hicieran un examen por problemas menstruales, ya que siempre he tenido las reglas muy dolorosas. Me dijo que el médico me explicaría sobre la exploración ginecológica cuando fuera a verlo. El primer momento incómodo fue, cuando me dijeron que me desvistiera y yo solo me quité las ropas exteriores. ¿Cómo iba a saber lo que querían? El segundo fue que la enfermera me pusiera en una posición sin que yo supiera porqué esa posición era necesaria. Y el tercero fue producido por mis gritos y lucha para salir de la camilla, porque no sabía que ese "tacto" era un examen pelviano. El médico y la enfermera parecieron avergonzados por haber supuesto que, porque yo era una adolescente, ya me habían hecho algún examen o había tenido relaciones sexuales. Yo estaba furiosa con todos: con mamá por su falta de detalles, con la enfermera y el médico por suponer que yo era sexualmente activa. Todavía no he visto que alguien les diga a los padres que avisen a sus hijas qué deben esperar de un examen tan importante en la vida de una mujer. No debería haber motivos para que el primer examen que se le haga a una chica produzca un trauma, vergüenza, ira o incomodidad.
\end{abstract}

Reflexione sobre el caso clínico y centre el problema principal

¿Qué conozco? ¿Qué debo aprender 


\section{CASO 18- APRENDIZAJE BASADO EN PROBLEMAS}

Para la detección de problemas de salud es necesario el autoconocimiento del propio cuerpo. Una de las funciones del profesional de Enfermería es la Educación para la Salud. Reflexione sobre el caso clínico presentado y con tu grupo utilizarás la metodología ABP para buscar la solución al problema planteado.

No hace mucho tiempo, mi hermana y yo escuchamos una conferencia sobre el conocimiento del propio cuerpo. Siguiendo la sugerencia de examinarse con la ayuda de un espejo, mi hermana lo hizo. Me contó que vio unos apéndices muy pequeños de piel rosada con algo en su interior.

Poco después empezó a notar picor intenso y doloroso en sus partes íntimas a pesar de que somos meticulosamente limpias, con una rigurosa higiene. El picor dura desde entonces y las cremas para calmarlo no le hacen ningún efecto.

Mi hermana se volvió a mirar y la zona está roja con flujo blanco y mucho picor. Estamos preocupadas sobre este problema tan molesto

¿Qué debería hacer? ¿Hay que realizar una citología?

Centre el problema principal

¿Qué conozco? ¿Qué debo aprender? 


\section{CASO 19- APRENDIZAJE BASADO EN PROBLEMAS}

En la consulta de enfermería las actividades de promoción de la salud y la educación para la salud son fundamentales. Se presenta el siguiente caso clínico en el que se demanda información .El profesional, además de saber escuchar y tener una visión integral y comprensiva, debe informar, orientar y resolver dudas basándose en la evidencia científica. Con tu grupo y, también de forma individual, vas a profundizar en la materia. Ánimo, aunque tengas algún momento de desaliento o duda con este trabajo $\mathrm{ABP}$, debes planteárselo a tu equipo y a tu tutora para encontrar la solución del problema.

Luisa tiene 35 años y sufrió un episodio de Enfermedad inflamatoria pélvica (EPI) hace 3 años, resuelto con antibióticos. Desde entonces no usa tampones durante la menstruación y, ha sustituido el uso de compresas por "la copa menstrual", con ella está contenta y nos explica que solo tiene que lavarla. Se hizo una citología hace 8 meses, con resultado normal en el que le indican repetir al año. Luisa tiene una relación estable y, como método anticonceptivo usa el "anillo" desde hace 2 años. A ella le pareció un método cómodo y eficaz, aunque ha notado es que ha disminuido el deseo sexual...Acaba de llamar al centro de salud para pedir cita para realizar una citología porque ha notado aumento del flujo vaginal. Ella no sabe si será por el uso del anillo vaginal o por una infección, pero está preocupada. No tiene antecedentes familiares ni factores de riesgo cardiovasculares. No fuma y, consume alcohol de forma ocasional. Practica ejercicio físico: aerobic, spining al menos 3 veces por semana. Luisa y su pareja están pensando en tener un hijo, pero creen que aun no es el momento...de todas formas quiere saber qué precauciones debe tener antes del embarazo. Tiene muchas dudas y en la consulta nos hace varias preguntas, ¿se puede haber alterado mi flora vaginal por la EPI?, ¿la EPI me ha podido afectar a mi fertilidad?, ¿debería hacerme pruebas para saberlo?, ¿tendré más flujo por el anillo?...

Reflexione sobre el caso clínico y centre el problema principal

¿Qué conozco?, ¿qué debo aprender? 


\section{CASO 20- APRENDIZAJE BASADO EN PROBLEMAS}

La expresión no verbal de los pacientes que atendemos nos aporta muchos datos para obtener información y llegar a una comunicación empática. Con tu equipo debes seguir la metodología ABP para solucionar el problema planteado.

Llega a la consulta seria, deja el informe sobre la mesa en el que se lee: IVE (interrupción voluntaria del embarazo), sin complicaciones. Sara no habla nada más.

“¿Cómo te encuentras?”... responde... “jarrepentida!” Hay un silencio y es difícil saber cómo abordar esta entrevista clínica. Tiene 31 años, y hace 7 años tuvo un parto normal, su pareja es estable y usan preservativos como método contraceptivo. Hace años tomó la píldora, y ahora "¡no sé cómo ha podido ocurrir!", se le saltan las lágrimas...se encuentra emocionalmente afectada, nos comenta que mira a la cara de su hijo y llora, su pareja le dice que ya está hecho, no se puede cambiar...Tomaron la decisión de optar por una IVE por los problemas socioeconómicos que tienen, la falta el trabajo... pero Sara afirma que "si me volviera a ocurrir la decisión sería otra y lo tendría"....Es fumadora de 20 cigarrillos al día, no consume alcohol ni otras drogas y no ha tenido enfermedades ni antecedentes familiares de enfermedades de interés. Se hizo la última citología hace 7 años, después de tener a su hijo y no sabe si se debería hacerse una mamografía.

TA: 100/62, talla: 1.52 - peso: 45.200(IMC 19.56).

Reflexione sobre el caso clínico y centre el problema principal

¿Qué conozco?, ¿Qué debo aprender? 


\section{CASO 21- APRENDIZAJE BASADO EN PROBLEMAS}

Sara tiene 36 años. Viene a la consulta a informarse sobre los métodos anticonceptivos. Hace años tomó la píldora anticonceptiva y es el método que prefiere, de todas formas, nos pide información sobre otras opciones. No fuma, su tensión arterial es de 121/79 y la frecuencia cardiaca de 64. Su peso es normal, hace una dieta variada. Su vida es sedentaria, no va al gimnasio y sale de paseo muy poco. Desde la adolescencia tiene acné aunque ahora está mucho mejor. Su familia no ha padecido de enfermedades cardiovasculares, sus padres y hermanos están sanos. En la historia no aparece ninguna citología hecha, únicamente ha acudido a su Médico de Familia por faringitis y procesos banales en varias ocasiones y no ha ingresado nunca en el hospital.

Sara se considera muy nerviosa, toma lorazepan de $5 \mathrm{mg} / 24$ horas ya desde hace mucho tiempo. Su nivel de formación es universitario, estudió Filología Inglesa y Diseño, pero ahora no está trabajando y vive con sus padres. Le gusta consultar los problemas de salud a través de internet. Hace 5 años su enfermera le recomendó seguir el programa de prevención de cáncer ginecológico y la matrona no pudo hacer toma para citología en esa ocasión, al detectar un vaginismo. Sara tuvo la menarquía a los 14 años, sus ciclos son de 5/28 e inició sus primeras relaciones sexuales con coito a los 22 años. Le dolió mucho y piensa que el vaginismo lo tiene desde la adolescencia eso por ser tan nerviosa. Nunca ha podido usar un tampón durante sus menstruaciones, y hace 6 años le ocurrió algo insólito, empezó a sudar, tuvo náuseas, vómitos y se mareaba porque se puso un tampón. Ha leído en internet que eso es un síndrome de shock tóxico, así que no lo ha vuelto a intentar. Ahora ha conocido a un chico y como se gustan, ha vuelto a pensar en su problema de vaginismo. Se está tratando el problema ella sola, porque este tema le cuesta consultarlo con un profesional. Hoy en la consulta está una matrona y una alumna de enfermería y han procurado crear un clima cálido y de confianza para que la paciente se exprese... se intentó hacer una toma para citología con un "espéculo virginal", y aunque se introdujo hasta el final, no fue posible abrirlo para hacer la toma. Sara está contenta por el avance, al menos se ha podido introducir un espéculo vaginal...

Reflexione sobre el caso clínico. ¿Qué conozco? ¿Qué debo aprender? 


\section{CASO 22- APRENDIZAJE BASADO EN PROBLEMAS}

Ángeles tiene 63 años y el resultado de las mamografías ha sido normal excepto en una ocasión que, hubo que repetir por "una calcificación", pero dio todo normal. Viene a consulta porque la enfermera le ha recomendado que se hiciera una citología y el test del virus del papiloma humano, del programa de prevención. Hace 9 años sufrió una fibrilación auricular y toma Simtron Está bien controlada, su enfermera le pregunta siempre por sus cuidados: ejercicio, alimentación, revisiones...

"Soy ama de casa y sé que aunque tengo ajetreo no vale, hay que hacer más ejercicio...Por supuesto no fumo, no bebo y como variado, lo que me sienta mal es la leche..." Se casó a los 25 años y tiene 3 hijos (partos normales).

La regla se le retiró a los 50 años y no ha vuelto a sangrar. "Vengo porque hay que venir, pero no me gusta nada...”Nota sequedad y no tiene ningún deseo de relaciones sexuales (coitales), "para esto mi marido es tranquilo, siempre lo ha sido pero ahora más y me comprende...es que cuando empecé con el Simtron sangré mucho después de una relación y me da miedo..." Ángeles no tiene escapes de orina pero ha tenido cistitis, en el último año tres veces. Al revisar su historia clínica: Fibrilación auricular, depresión hace 9 años, ha presentado problemas gástricos en varias ocasiones, es asmática, y ha consultado por dolor costal, en la espalda y por hombro doloroso...

A la exploración presenta: atrofia urogenital y sequedad, no tiene prolapso genital. Constantes vitales: TA: 128/79 mmHg, F.C:87 latidos/min, Peso: $65 \mathrm{Kg}$, Talla $1.54 \mathrm{~cm}$. La medicación que toma: Sintron $4 \mathrm{mg}$, acetilcisteina 600mg y plusvent accuhaler para el asma, pantoprazol de $40 \mathrm{mg}$ para la gastralgia, y tetrazepam de $50 \mathrm{mg}$.

Reflexione sobre al caso clínico planteado y centre el problema principal ¿Qué conozco? ¿Qué debo aprender? 


\section{CASO 23- APRENDIZAJE BASADO EN PROBLEMAS}

Martina de 34 años ha tenido su primer hijo hace 8 meses, el parto fue con ventosa y no le hicieron episiotomía. "Mi hija era grande y le costaba salir, así que al final la matrona tuvo que avisar y la sacaron con ventosa." Durante el puerperio las cifras de hierro eran bajas, por una anemia ferropénica, le recomendaron suplementos de hierro. Ha notado algún escape de orina cuando tose y le resulta bastante incómodo ya que tiene que usar un protector (salva slip). Como sabe que es lo mejor, le dio lactancia materna a su hijo durante 6 meses. Ha vuelto a fumar 10 cigarrillos al día, lo había dejado en el embarazo y la lactancia pero se encuentra muy nerviosa y lo está pasando muy mal por la muerte de su padre que falleció hace mes y medio. Viene a nuestra consulta porque quiere ponerse un DIU, no desea más hijos y no ha utilizado otro método anticonceptivo desde el parto. "Debido al cansancio aun no he mantenido relaciones sexuales... "y a Luis, su pareja, le preocupa mucho el cambio desde que han sido padres, nota que Martina está decaída, llora y no quiere hacer nada desde entonces. Él está intentando "poner de su parte" para salir de la situación, que resulta bastante difícil. Pidió el permiso por paternidad de 15 días, y como es profesor, las vacaciones escolares las ha aprovechado para cuidar al bebé.

La notamos delgada e inexpresiva, "si he perdido mucho peso..."

Constantes: TA: 126/69mm Hg, FC: 90 , peso: $55 \mathrm{Kg}$, talla: 164.5

Índice de masa corporal: 18.85 .

La última citología (resultado normal) es de hace 4 años.

Centre el problema principal

¿Qué conozco? ¿Qué debo aprender? 


\section{CASO 24- APRENDIZAJE BASADO EN PROBLEMAS}

Los cuidados de Enfermería deben tener una continuidad en el ámbito hospitalario y en Atención Primaria, por eso es necesario elaborar protocolos conjuntos y trabajar en equipo para evitar información contradictoria a los padres, sobre todo si son primerizos. El fomento de la lactancia materna, el vínculo afectivo "urdimbre afectiva" y el fomento de un "apego seguro" es fundamental para el bienestar de los recién nacidos y de los niños.

Alba está embarazada de su primer hijo, ahora cumple las 35 semanas y ha acudido a las revisiones todos los meses. En la ecografía le han detectado un CIR (crecimiento intrauterino retardado), por lo que se realiza revisiones más a menudo. En la última visita, el tocólogo ha decidido que lo mejor será inducirle el parto. Alicia no es fumadora, su edad es de 38 años y es arquitecta, tiene mucho trabajo y está estresada. Ha engordado $7.5 \mathrm{Kg}$ y su tensión es normal. Le gusta estar bien informada, leer sobre su embarazo y ahora más, con el problema que ha surgido. Luis y ella planificaron la gestación y es muy deseada, no han podido ser padres antes por sus ocupaciones...

Hoy han venido al Centro de Salud, están haciendo "el curso de Preparación al Parto" y después de la clase, se han quedado a la consulta para hacernos unas preguntas que les preocupan. Por la consulta de la matrona está rotando Claudia, una estudiante de Enfermería de $4^{\circ}$ que está muy atenta a los consejos, sabe que después los padres le preguntarán a la enfermera de pediatría un montón de dudas y su siguiente rotación es por pediatría.

Alba se queja de que cuando van al tocólogo, la consulta es muy rápida y no tienen tiempo. Antes de que nazca su bebé quieren saber algo más sobre la forma de estimularle a través del tacto, han oído sobre el método "madre canguro" y "piel con piel”. La alimentación que prefiere es la lactancia materna para aportarle defensas a su bebé pero quiere estar preparada para que no fracase, a un prematuro le tiene que costarle más...

Reflexione sobre el caso clínico y centre el problema principal.

¿Qué conozco? ¿Qué debo aprender? 


\section{Anexo 7. Roles de los estudiantes en el grupo ABP.}

Fuente: Universidad de Delaware (Estados Unidos)

GRUPO:

PERÍODO:

COMPONENTES DE EQUIPO

\section{PROBLEMA:}

\section{ROLES:}

Lider:

Su objetivo es lograr un alto rendimiento entre los compañeros de equipo. Es la encargada de la organización y de la comunicación del equipo.

Secretarias/os: Es

la/el responsable de organizar la documentación generada por el equipo y tenerla lista en todo momento con el fin de poder desarrollar las diferentes actividades propias que demanda la solución del problema. Es también la encargada de entregar los documentos parciales y finales a la profesora para su revisión.

\section{Reportera/o}

Es la persona que toma nota de las actividades y aportaciones de cada uno de los miembros del equipo. Sabe lo que cada integrante hace en juntas, las tareas que cada miembro tiene asignadas y como se llegó a un acuerdo o conclusión.

Abogado del diablo

Cuestiona críticamente el trabajo del equipo. Debe tener capacidad crítica y evitar que el equipo utilice datos o ideas de dudosa procedencia.

\section{Vigilante del tiempo}

Hace una distribución eficiente del tiempo durante las sesiones, fomenta la participación activa y evita que se divague. Debe intervenir para que el equipo mantenga su atención concentrada en la solución del problema 


\section{Anexo 8. Guía del estudiante para prácticas de aula con ABP}

Fuente: Asignatura Salud Sexual y Reproductiva $2^{\circ}$ de Grado de Enfermería (Universidad de Valladolid, 2011). Elaboración propia.

\section{INTRODUCCIÓN}

Dentro de los objetivos de este curso se encuentra el aprendizaje de los conceptos básicos en Salud Sexual y Reproductiva (SSR). Para conseguir los mejores resultados se hacen las siguientes indicaciones a los alumnos:

- El proceso de aprendizaje será de modo colaborativo por lo tanto, los alumnos trabajarán en grupos.

- Los conceptos necesarios para resolver los problemas no serán revisados antes de que los problemas sean presentados. A lo largo del curso, los alumnos irán aprendiendo cómo identificar la información que necesitan para atender el problema y dónde buscar esa información.

- El trabajo en clase será en pequeños grupos y las contribuciones individuales se tendrán en cuenta para la evaluación del cuatrimestre.

Las competencias que se van a desarrollar:

Competencias genéricas

1. Capacidad de análisis y síntesis.

2. Razonamiento crítico.

3. Aprendizaje autónomo.

4. Capacidad de gestión de la información.

5. Capacidad de organización y planificación.

6. Trabajo en equipo.

7. Comunicación oral y escrita en lengua castellana.

\section{Competencias específicas}

\section{El alumno será capaz de:}

1. Expresarse correctamente con los términos adecuados sobre los diferentes procesos indicados en el caso clínico.

2. Utilizar las herramientas bibliográficas adecuadas para buscar información complementaria que puede ser necesaria para la mejor comprensión y resolución del problema planteado.

3. Seleccionar críticamente la información.

4. Realizar una exposición breve en lengua castellana a un auditorio no especializado acerca del tema descrito en el caso, con posible impacto actual en la sociedad 


\section{PASOS PARA EMPEZAR A TRABAJAR ABP:}

\section{Comprensión del escenario:}

En tu grupo vas a leer el caso clínico o problema. ¿Qué hacer con él?, ¿por dónde empezar? A través de la lectura conjunta, de los comentarios para aclarar el problema... vamos a comprobar si hemos comprendido todos lo mismo, y así definir el problema. Puede ser útil que alguien lea en voz alta y luego otro con sus palabras repite lo que presenta el escenario. Así conseguimos una sintonía entre los miembros del equipo de trabajo y definimos el problema.

\section{Lluvia de ideas}

Una vez identificado el problema fundamental, hay que intentar buscar soluciones posibles. (Todo cabe, nada queda excluido, hay que hacer preguntas básicas sobre cómo, qué, por qué, para qué...que te ayudan a reflexionar). ¿Qué sabemos sobre este problema?

La "lluvia de ideas" es el momento que más tiempo lleva y de su buena orientación depende el trabajo posterior de investigación. Los resultados con la lluvia de ideas son un poco caóticos por lo que después hay que hacer una crítica y clasificación de lo importante.

3. Crítica y avances, fijamos los objetivos de aprendizaje:

Cuando surjan ideas con las que se pueden explicar las causas del problema y algunas hipótesis sobre el modo de resolverlo, es importante someter este material a crítica. ¿Sabemos realmente lo que creemos saber? Hacemos una crítica (hacer de abogado del diablo) y un orden de prioridades replanteando las preguntas. El trabajo hecho debe ser revisado a fondo y si es preciso se hacen cambios (puede que el problema tomado como principal cambie).

Vamos a revisar ¿qué sabemos?, ¿qué es lo que no sabemos?, así diferenciamos lo que todos debéis de investigar. Una vez identificado el problema dentro del escenario, los alumnos y alumnas deben establecer sus necesidades u objetivos de aprendizaje para darle solución. La investigación posterior y la evaluación se guiarán por los objetivos que se hayan fijado.

4. Reparto de roles del grupo según el formulario que se entregó (véase Anexo 7)

5. Reuniones de grupo: 
Es necesaria una permanente comunicación del equipo. Habrá que fijar reuniones periódicas entre los componentes del grupo, para compartir los avances del estudio y elaborar el trabajo.

6. Reuniones de tutoría o prácticas de aula:

Se entregará el cronograma de las prácticas de aula. La asistencia es obligatoria. El contenido de las prácticas de aula:

- Exposición del ABP, reparto de equipos y lectura de las instrucciones. Caso clínico.

- Se aportarán los avances del trabajo, las dificultades...Trabajo en grupos como práctica de aula.

- Hay que traer el material necesario, artículos, informes, resúmenes, entrevistas...para trabajar en el aula.

\section{Trabajo de investigación:}

Se hará una búsqueda de la información utilizando buscadores, bases de datos, páginas web, revistas científicas, consultando en biblioteca, trabajo de campo (preguntando sobre el problema a las propias mujeres en consulta, en residencias de ancianos, en centros especiales, etc.). Todas los/las alumnos/as aportarán material al grupo. Después hay que hacer una selección del material de interés para vuestro trabajo.

\section{Presentación del trabajo:}

Se presentará el trabajo de forma oral en el aula, según el cronograma previsto. Se entregará el trabajo escrito sobre el caso, un resumen del proceso (cómo se elaboró el trabajo), los roles de cada uno, dificultades encontradas y ventajas de esta nueva forma de aprendizaje.

9. Autoevaluación, evaluación a compañeros y evaluación a la tutora.

Se recuerda a los estudiantes que el proceso de evaluación es continuo, tratando de corregir los puntos débiles que se hayan detectado. En la Guía Docente de la asignatura Salud Sexual y Reproductiva se incluye un apartado sobre la evaluación. 


\section{Anexo 9- Análisis de contenido de las ventajas percibidas por los estudiantes que han usado ABP.}

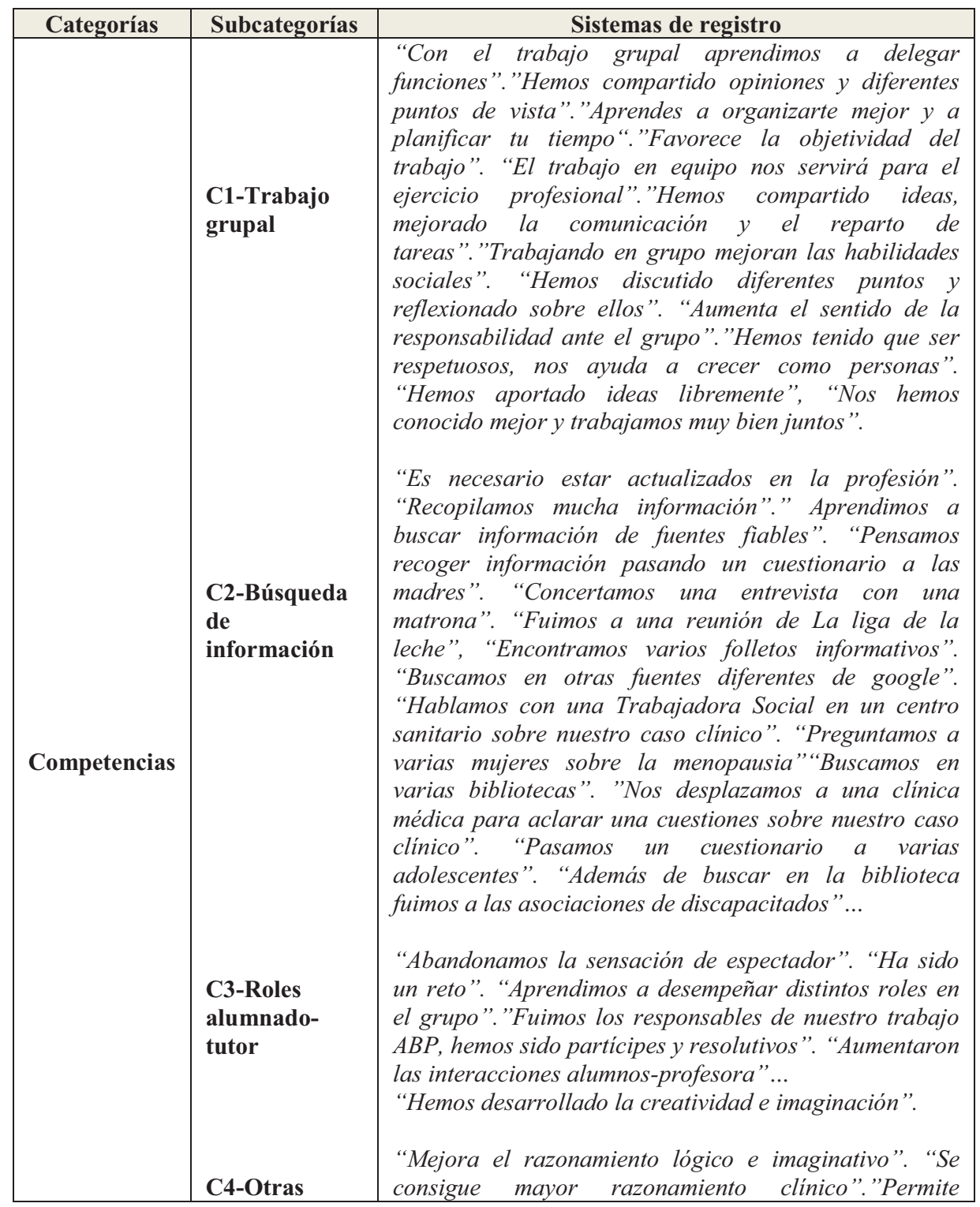




\begin{tabular}{|c|c|c|}
\hline & & $\begin{array}{l}\text { integrar la teoría con la práctica"." Mejora la } \\
\text { capacidad de análisis, síntesis y la visión critica"... }\end{array}$ \\
\hline Aprendizaje & $\begin{array}{l}\text { A1- } \\
\text { Aprendizaje } \\
\quad \text { Profundo }\end{array}$ & $\begin{array}{l}\text { "Hemos aprendido nuevos conocimientos en los que } \\
\text { profundizamos." "El trabajo tiene mayor riqueza por la } \\
\text { cantidad de ideas aportadas"."Los conocimientos los } \\
\text { hemos adquirido de una forma más razonada y } \\
\text { autocrítica". "Nos ha aportado una visión más global } \\
\text { del problema, por lo que lo comprendimos mejor". } \\
\text { "Estudiamos el tema en profundidad". "Aprendimos a } \\
\text { vertebrar el manejo de información"." Hemos } \\
\text { actualizado los conocimientos"... } \\
\text { "Han surgido preguntas, respuestas, hipótesis como si } \\
\text { se tratase de una pequeña investigación".."Pensamos } \\
\text { que es importante individualizar los cuidados, en su } \\
\text { contexto y desde diferentes disciplinas"." El enfoque del } \\
\text { caso ha sido multidimensional. }\end{array}$ \\
\hline Satisfacción & $\begin{array}{l}\text { S1- Mayor } \\
\text { motivación }\end{array}$ & 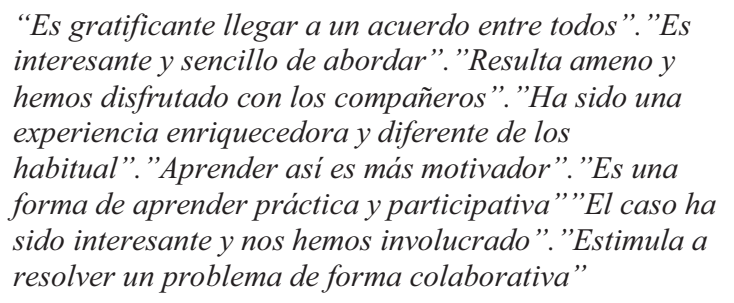 \\
\hline \multirow{2}{*}{ Significación } & $\begin{array}{l}\text { A1-Contexto } \\
\text { real }\end{array}$ & $\begin{array}{l}\text { "Ha sido cercano a nosotros"." Tiene verosimilitud y } \\
\text { permite una intrusión realista en el caso" "La } \\
\text { investigación de campo que hicimos nos acercó a la } \\
\text { realidad y nos ha enriquecido como personas". "Al } \\
\text { tratarse de un caso real nos hemos involucrado más". } \\
\text { "Lo comprendimos mejor porque se asemeja a la } \\
\text { realidad" }\end{array}$ \\
\hline & $\begin{array}{l}\text { A2-Enfoque } \\
\text { profesional }\end{array}$ & $\begin{array}{l}\text { "El desarrollo de empatía y escucha es importante para } \\
\text { el futuro ejercicio profesional". "El caso nos ha } \\
\text { acercado a la práctica profesional". "El enfoque se hizo } \\
\text { como si fuésemos enfermeros en la realidad" }\end{array}$ \\
\hline
\end{tabular}




\section{Anexo 10- Análisis de contenido de las desventajas percibidas por los estudiantes que han usado ABP.}

\begin{tabular}{|c|c|c|}
\hline Categorías & Subcategorías & Sistemas de registro \\
\hline Innovación & 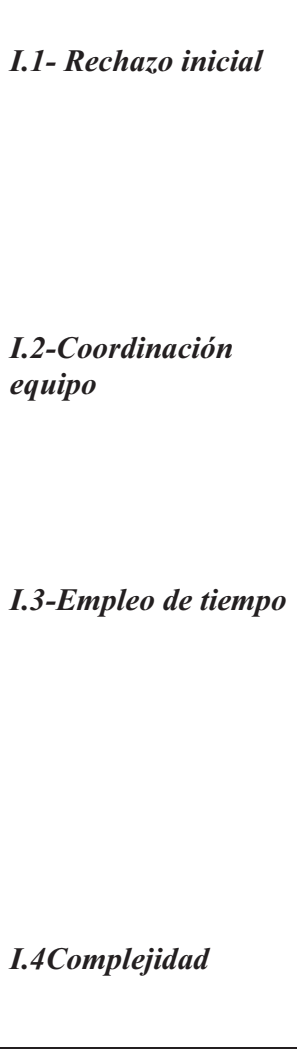 & 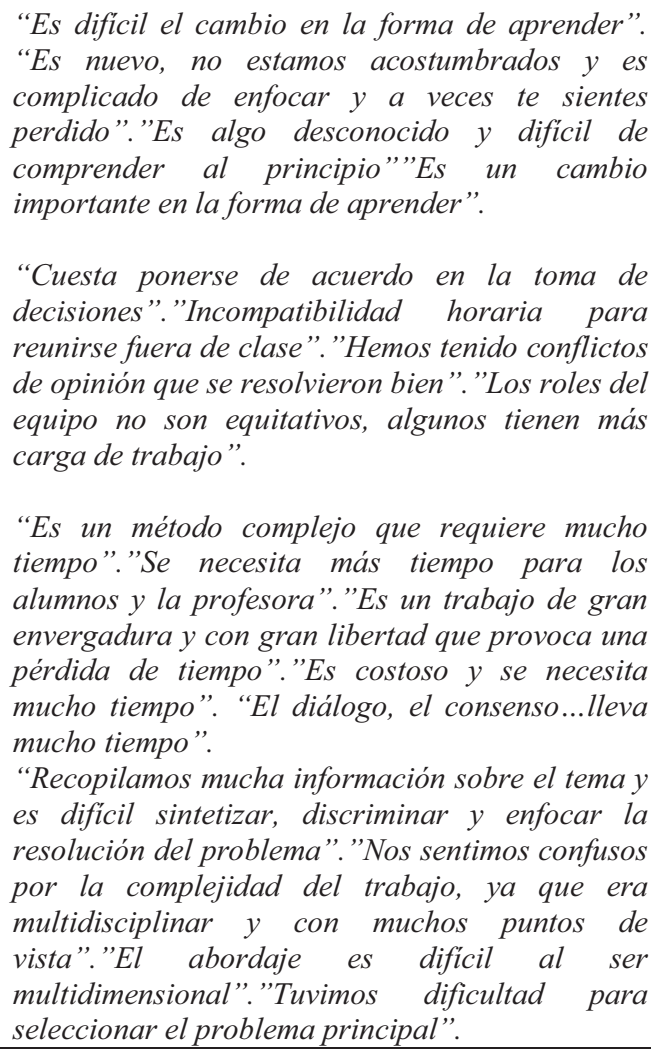 \\
\hline Planificación & $\begin{array}{l}\text { P.1-Experiencia } \\
\text { práctica }\end{array}$ & $\begin{array}{l}\text { "Se presentaron dificultades al pasar la } \\
\text { encuesta"." Aun no hemos tenido contacto con } \\
\text { pacientes"."Creemos que no disponemos de } \\
\text { conocimientos para la resolución del caso ya que } \\
\text { somos de segundo curso"." No tenemos presente } \\
\text { al paciente para preguntarle" } \\
\text { "Es mucha carga de trabajo, en otras asignaturas } \\
\text { pertenecemos a otros grupos y eso nos dificulta el } \\
\text { trabajo ABP". "Dificultad en el tiempo y } \\
\text { compaginarlo con otras asignaturas" }\end{array}$ \\
\hline
\end{tabular}


Anexo 11-Aplicación de la prueba de Kolmogov -Smirnov

Tabla 1.Prueba de Kolmogorov-Smirnov para cada componente del

\begin{tabular}{|c|c|c|c|c|c|c|c|c|}
\hline & $\mathrm{N}$ & Parámetros norm & iales $(a, b)$ & Diferenc & ias más ex & tremas & $Z$ de Kolmpgprox-Smingx & $\begin{array}{c}\text { Sig. } \\
\text { asintót. } \\
\text { (bilateral) }\end{array}$ \\
\hline & Medis & Desviación típica & Absoluta & Positiva & Negativa & Medis & Desviación típica & Absoluta \\
\hline Pre. Comp 1 & 127 & 20,5039 & 4,30738 & .090 & .090 &,- 050 & 1,009 & .260 \\
\hline Pre,cemp 2 & 127 & 19,5669 & 3,65277 & .083 & .083 &,- 062 & .939 & .341 \\
\hline $\mathrm{Pre}_{\mathrm{n}, \mathrm{C}} \mathrm{Comp}^{3}$ & 127 & 23,0630 & 5,01228 & .085 & .085 &,- 051 & .957 & .320 \\
\hline Pre_Comp 4 & 127 & 15,9291 & 3,46222 & .103 & .077 &,- 103 & 1,162 & .135 \\
\hline Pre_Comp5 & 127 & 3,5039 & 1,39087 & . 169 & .169 &,- 140 & 1,905 & .001 \\
\hline Pos.Comp 1 & 129 & 18,0698 & 4,25218 & .098 & .098 &,- 055 & 1,109 & 171 \\
\hline Pos, Comp 2 & 129 & 17,6744 & 3,92341 & .088 & .088 &,- 051 & .995 & .275 \\
\hline Pes, Comp 3 & 129 & 21,0930 & 5,06434 & .087 &, 087 &,- 057 &, 984 & .287 \\
\hline Pos, Come 4 & 129 & 14,2868 & 3,56238 & .103 & .103 &,- 046 & 1,168 & 131 \\
\hline Pes. Comp 5 & 129 & 3,2093 & 1,33858 & .243 & .243 &,- 183 & 2,762 & .000 \\
\hline $\begin{array}{l}\text { CIPA Total Rretest } \\
\text { CIPA Total Rostest }\end{array}$ & $\begin{array}{l}127 \\
129\end{array}$ & $\begin{array}{l}82,5669 \\
74,3333\end{array}$ & $\begin{array}{l}14,45771 \\
15,44361\end{array}$ & $\begin{array}{l}.055 \\
.110\end{array}$ & $\begin{array}{l}.055 \\
.110\end{array}$ & $\begin{array}{l}-, 037 \\
-, 055\end{array}$ & $\begin{array}{r}.622 \\
1,254\end{array}$ & $\begin{array}{l}.833 \\
.086\end{array}$ \\
\hline
\end{tabular}

CIPA en pre-test y pos-test

a La distribución de contraste es la Normal. .

$b$ Se han calculado a partir de los datos.

Pre-test y pos-test de Componentes (comp) y del CIPA Total 
Tabla 2. Prueba de Kolmogorov-Smirnov para las diferencias de cada componente del cuestionario CIPA entre pre-test y pos-test y la diferencia global entre pre-test y pos-test

\begin{tabular}{|c|c|c|c|c|c|c|c|c|}
\hline & $\mathrm{N}$ & \multicolumn{2}{|c|}{$\begin{array}{c}\text { Parámetros } \\
\text { normales }(a, b)\end{array}$} & \multicolumn{3}{|c|}{ Diferencias más extremas } & \multirow{2}{*}{$\begin{array}{c}\text { Z de } \\
\text { Kolmogorou- } \\
\text { Smirnov } \\
\text { Desviación } \\
\text { típica }\end{array}$} & \multirow{2}{*}{$\begin{array}{c}\text { Sig. } \\
\text { asintót. } \\
\text { (bilateral) } \\
\text { Absoluta }\end{array}$} \\
\hline & Media & $\begin{array}{l}\text { Desviación } \\
\text { típica }\end{array}$ & Absoluta & Positiva & Negativa & Media & & \\
\hline $\begin{array}{l}\text { Dif=fact1_post- } \\
\text { fact1_pret }\end{array}$ & 127 & $-2,4961$ & 3,93776 &, 095 &, 063 &,- 095 & 1,068 & 204 \\
\hline $\begin{array}{l}\text { Dif=fact2_post- } \\
\text { fact2_pret }\end{array}$ & 127 & $-1,8819$ & 3,96135 & ,076 &, 069 &,- 076 &, 860 & ,451 \\
\hline $\begin{array}{l}\text { Dif=fact3_post- } \\
\text { fact3_pret }\end{array}$ & 127 & $-2,0551$ & 4,75479 &, 092 &, 063 &,- 092 & 1,041 & 228 \\
\hline $\begin{array}{l}\text { Dif=fact4_post- } \\
\text { fact4_pret }\end{array}$ & 127 & $-1,6850$ & 3,32547 & ,087 & ,087 &,- 080 & 978 & 294 \\
\hline $\begin{array}{l}\text { Dif=fact5_post- } \\
\text { fact5_pret }\end{array}$ & 127 & -2913 & 1,33399 & ,177 & ,177 & -169 & 1,999 &, 001 \\
\hline $\begin{array}{l}\text { Dif=CIPA_Tot_Post } \\
\text { - CIPA Tot_Pret }\end{array}$ & 127 & $-8,4094$ & 13,62733 & ,077 &, 058 &,- 077 &, 865 & ,443 \\
\hline
\end{tabular}

a La distribución de contraste es la Normal.

$b$ Se han calculado a partir de los datos. 
